\title{
INTEGRATED PLANNING FRAMEWORK FOR PUMPED HYDRO ENERGY STORAGE (PHES) SYSTEMS
}

\author{
by \\ Faizul Hasan \\ Bachelor of Science (Engineering), Aligarh Muslim University, Aligarh, India, 1980 \\ Master of Business Administration, University of The Punjab, Lahore, Pakistan, 2001 \\ Master of Philosophy, University of Engineering and Technology, Lahore, Pakistan, 2001 \\ Master of Engineering, Ryerson University, Toronto, Canada, 2011
}

\author{
A dissertation \\ presented to Ryerson University \\ in partial fulfillment of the \\ requirements for the degree of \\ Doctor of Philosophy \\ in the program of \\ Civil Engineering
}

Toronto, Ontario, Canada, 2019

(C) Faizul Hasan, 2019 


\section{Author's Declaration}

I hereby declare that I am the sole author of this dissertation. This is a true copy of the dissertation, including any required final revisions, as accepted by my examiners.

I authorize Ryerson University to lend this dissertation to other institutions or individuals for the purpose of scholarly research.

I further authorize Ryerson University to reproduce this dissertation by photocopying or by other means, in total or in part, at the request of other institutions or individuals for the purpose of scholarly research.

I understand that my dissertation may be made electronically available to the public. 


\begin{tabular}{ll} 
& \multicolumn{2}{c}{ Abstract } \\
Dissertation Title: & $\begin{array}{l}\text { Integrated Planning Framework for Pumped Hydro Energy Storage } \\
\text { (PHES) Systems }\end{array}$ \\
Degree: & Doctor of Philosophy \\
Year: & 2019 \\
Student Name: & Faizul Hasan \\
Program: & Civil Engineering \\
University: & Ryerson University
\end{tabular}

The electric power industry worldwide has been focusing towards increasing utilization of renewable energy resources such as wind and solar to build and maintain clean, reliable and affordable electricity systems. Although these resources are environmentally clean, their uncertain and intermittent nature is a significant issue. Similarly, other energy generators such as nuclear and gas have serious environmental issues. These issues can be resolved with effective management of supply and demand using appropriate energy storage. Although various energy storage options are available, PHES is globally proven technology at grid level. Additionally, gravity power module (GPM) is a newly emerged technology in the power industry. However, its applications at full scale are still awaited.

This research developed methodologies for integrated planning framework for PHES systems at grid level, employing a GIS-based model to identify feasible PHES sites, optimizing the scheduling of feasible PHES potential, and performing the financial analysis of PHES system. The methodologies were applied on grid-connected electricity area of Ontario that identified 285 feasible PHES and GPM sites with storage potential of 56,268 MWh. 
This research proposed the formation of a cooperative association namely 'Pumped Hydro Storage Association (PHSA)' for integration of PHES system in the electricity market system operated by the IESO in Ontario. Using 2016 data, the optimization model resulted that PHSA supplied real-time energy $28,134 \mathrm{MWh} /$ day, provided ancillary services including variable operating reserve 23,914 MWh/ day, fixed operating reserve 4,220 MWh/ day, and purchased energy 65,060 MWh/ day. The optimization results and resultant financial indicators confirmed that proposed PHES system is technically and financially viable in a large electricity market system. As an initial step, partial development of PHES and GPM plants was proposed with an initial capital cost of $\mathrm{C} \$ 1,052$ Million utilizing 7,767 MWh/ day energy potential that resulted in a net profit share of $\mathrm{C} \$ 13.36 / \mathrm{MWh}$ for each participatory plant.

Finally, the developed PHES planning framework for PHES system can certainly be found valuable to the policymakers, system operators, energy developers, research scholars, engineers, financial analysts and scientist community to work on future improvement in the PHES system. 


\section{Acknowledgements}

First and foremost, I would like to express my sincere gratitude to my supervisor, Prof. Dr. Darko Joksimovic for being a mentor, source of inspiration, and for his encouraging valuable advice throughout my research study. Without his invaluable support, guidance and direction, I may not have been able to complete this research.

I am highly thankful to my co-supervisors Prof. Dr. Songnian Li and Prof. Dr. Bala Venkatesh for their expert guidance and invaluable support regarding my research study. I am highly grateful to my external examiner Prof. Dr. Kumaraswamy Ponnambalam from the Department of Systems Design Engineering, University of Waterloo, and my exam committee member Prof. Dr. Arnold Yuan for their valuable comments and ingenious suggestions to finalize the dissertation. I would also like to thank Dr. Chandrabhanu Opathella from Centre of Urban Energy (CUE), Ryerson University for extending his cooperation and sparing his precious time to discuss and share ideas regarding the optimization part of my research.

I am highly thankful to the professionals from power industry for providing the concerned data of this research, especially Christopher J. Grieco, Executive Vice President and James Fiske, CTO, both from Gravity Power, LLC, California, USA, and John Wright, Executive Director,

Northland Power Inc., Toronto, Canada. I am also thankful to the professionals from engineering firms who shared their ideas and provided the data for this research, especially Arshed Mahmood, P.Eng from Wood Environmental and Infrastructure Solutions, Edmonton, Canada and Syed Hasan Riaz, P.Eng from Precisioneering, Toronto, Canada.

My greatest thanks go to my wife and sons for their patience, endless love, encouragement and unwavering support throughout the research study. Especially, I am thankful to my son Ammar Hasan, Software Engineer who helped me in software aspects of my research. 


\section{Table of Contents}

Author's Declaration ...............................................................................................................................ii

Abstract...............................................................................................................................................................ii

Acknowledgements ....................................................................................................................................... v

List of Tables ...............................................................................................................................................

List of Figures................................................................................................................................................

Glossary of Acronyms and Symbols................................................................................................. $\mathrm{xv}$

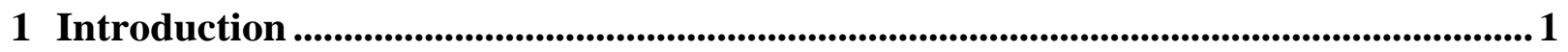

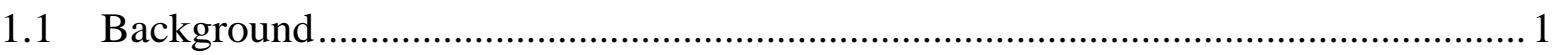

1.2 Choosing Appropriate Energy Storage Technology at Grid Level ........................... 4

1.3 Why is Pumped Hydro Energy Storage (PHES) Needed? .......................................... 7

1.4 Necessity of Developing an Integrated Planning Framework for PHES Systems ... 8

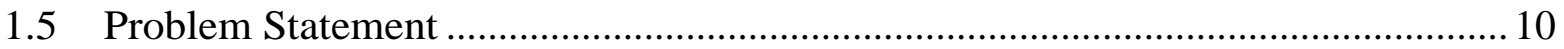

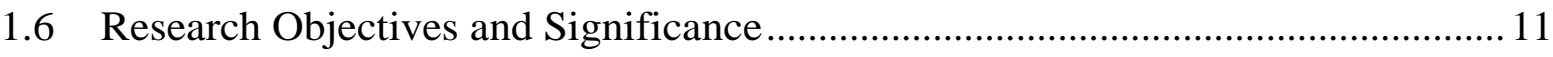

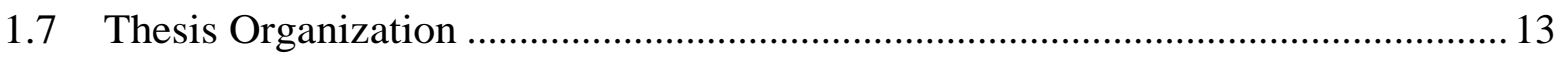

2 Literature Review ....................................................................................................................... 15

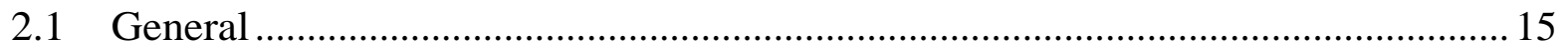

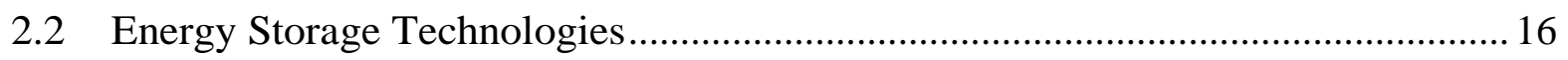

2.3 Pumped Hydro Energy Storage (PHES) Technology ............................................... 16

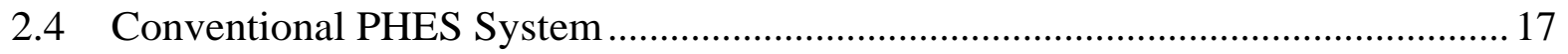

2.5 Technological Advancement in the PHES System.................................................. 20

2.5.1 Conventional PHES with Adjustable-Speed Pump-Turbines.................................. 21

2.5.2 Gravity Power Module (GPM) System..............................................................22 
2.5.3 Selection of Turbines for PHES System .................................................... 26

2.6 Review of Spatial Decision-Support Tools for PHES Siting ..............................2

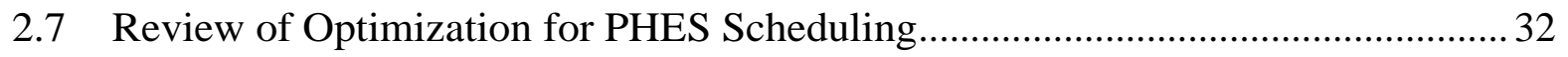

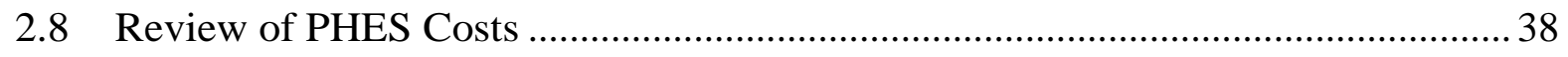

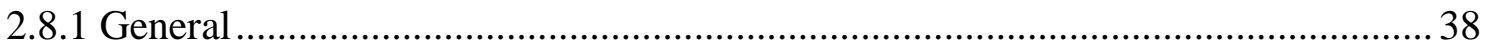

2.8.2 Defining the Unit of Energy Storage Cost.................................................. 40

2.8.3 PHES Cost Needed for This Research Study ................................................ 40

2.8.4 Estimating PHES Costs using Data from Past Studies .................................. 43

2.8.5 Estimating PHES Costs using Site-Specific Empirical Formula ......................... 46

2.8.6 Estimating PHES Cost using Data from Industry Suppliers and Organizations ... 47

2.9 Significance of Study Area Size for Allocating PHES Sites .............................. 48

2.10 Effect of Temperature on PHES Operations .................................................. 49

2.11 Resources Allocation with Combined Spatial Siting and Optimization ................50

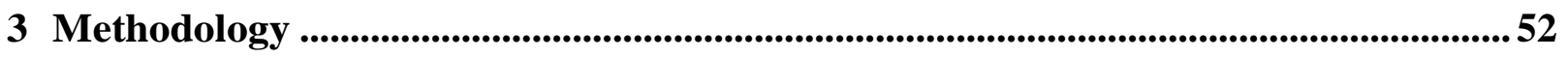

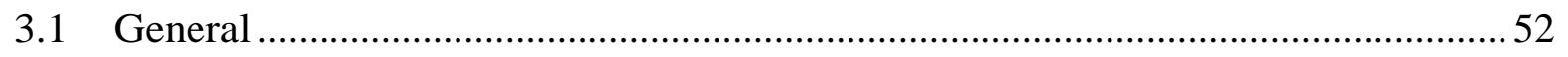

3.2 Defining Technical Terms ......................................................................... 53

3.3 Developing GIS-based Model using Conventional and GPM Methods ................56

3.3.1 Computation of Energy Potential............................................................. 57

3.3.2 Development of GIS Database................................................................ 58

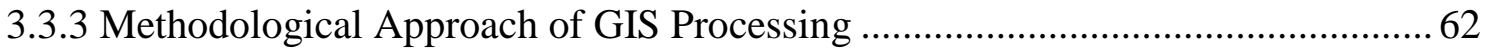

3.3.4 Case I: Identification of Feasible PHES/ GPM Sites with Dams ......................... 64

3.3.5 Case II: Identification of Feasible PHES/ GPM Sites with Lakes ......................... 67

3.3.6 Case III: Identification of Feasible PHES/ GPM Sites with Rivers....................... 67

3.3.7 Case IV: Identification of Feasible PHES/ GPM Sites with Abandoned Mines ... 70 
3.4 Developing Optimization Model for PHES Scheduling …................................ 72

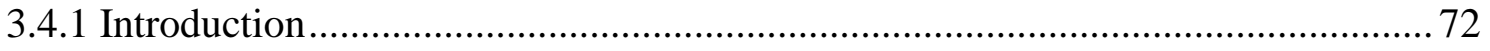

3.4.2 Basic Operating Principles of the Model ..................................................... 74

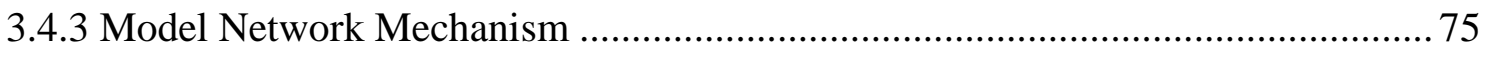

3.4.4 Problem Formulation for Optimization Model .............................................. 77

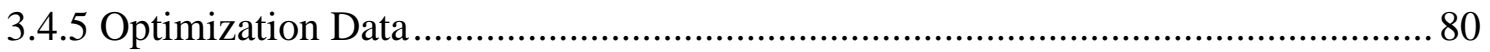

3.5 Sensitivity Analysis for GIS and Optimization Model Parameters...................... 83

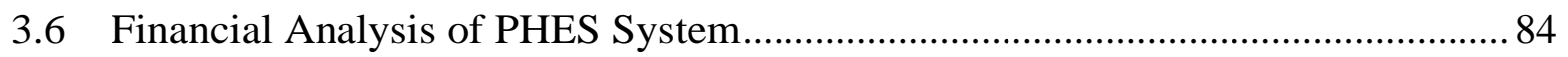

4 Case Study of Ontario ......................................................................................................... 88

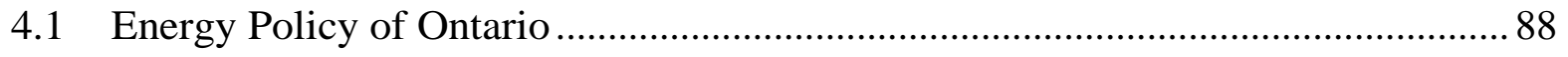

4.1.1 Ontario's Policy on Renewable Energy ................................................... 89

4.1.2 Ontario's Policy on Energy Storage ....................................................... 91

4.1.3 Ontario's Policy on Pumped Hydro Energy Storage (PHES)............................ 93

4.2 Existing and Future Energy Demand in Ontario.............................................. 94

4.3 Existing Energy Output by Fuel Type in Ontario ............................................. 95

4.4 Existing Surplus Baseload Generation (SBG) in Ontario ................................... 96

4.5 Existing System Operating Reserve (OR) in Ontario........................................ 98

4.6 Existing Electricity Rates of IESO Market in Ontario ....................................... 99

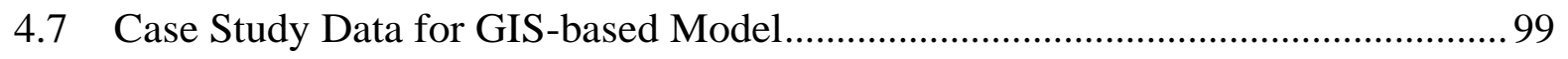

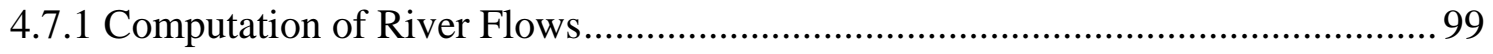

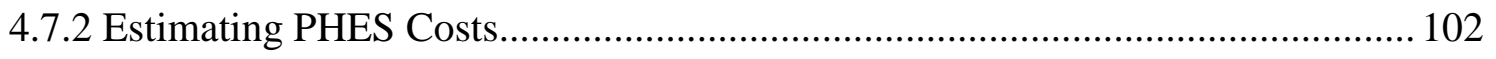

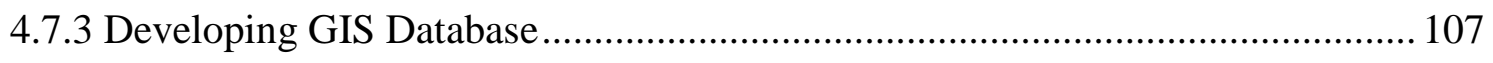

4.7.4 Case Study Data for Conventional and GPM Methods ................................. 111

4.8 Case Study Data for Optimization Model ...................................................... 112 


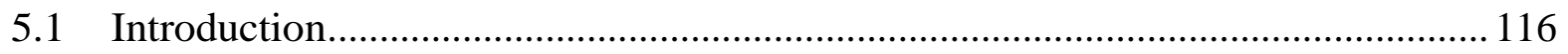

5.2 Applying GIS-based Model using Conventional Method.....................................117

5.2.1 Case I: Identification of Feasible PHES Sites with Dams ................................... 117

5.2.2 Case II: Identification of Feasible PHES Sites with Lakes.................................. 119

5.2.3 Case III: Identification of Feasible PHES Sites with Rivers ................................ 121

5.2.4 Case IV: Identification of Feasible PHES Sites using Abandoned Mines........... 123

5.2.5 Summary of Feasible PHES Sites in Ontario ………………………….......... 125

5.3 Applying GIS-based Model using GPM Method ................................................ 127

5.3.1 Case I: Identification of Feasible GPM Sites with Dams ..................................... 127

5.3.2 Case II: Identification of Feasible GPM Sites with Lakes................................... 128

5.3.3 Case III: Identification of Feasible GPM Sites with Rivers ................................. 128

5.3.4 Case IV: Identification of Feasible GPM Sites using Abandoned Mines............ 129

5.3.5 Summary of Feasible GPM Sites in Ontario.................................................... 130

5.4 Summary of Feasible PHES and GPM Sites in Ontario ........................................ 131

5.5 Validation of GIS-based Model Results .............................................................. 132

5.6 Exploring Valuable Developments Associated with PHES Projects ..................... 134

5.7 Discussion on GIS-based Model Results …………........................................... 135

5.7.1 Water Availability in Primary Reservoirs.......................................................... 136

5.7.2 Site-Specific Parameters ………………………............................................ 136

5.7.3 Screening of Identified Preliminary PHES Sites ................................................. 139

5.7.4 GIS Processing Results .................................................................................. 140

5.8 Sensitivity Analysis for GIS-based Model Parameters ……………..................... 142

5.9 Applying Optimization Model on Case Study of Ontario ...................................... 147 


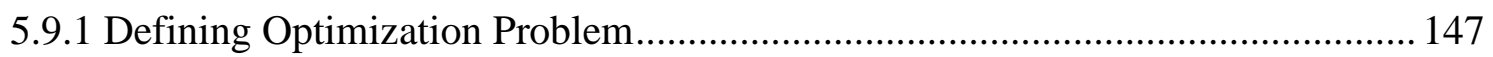

5.9.2 Solution of Optimization Problem .................................................................... 147

5.10 Discussion on Optimization Model Results ……………..................................... 149

5.11 Sensitivity Analysis for Optimization Model Parameters...................................... 153

5.12 Financial Analysis of PHES System for Case Study of Ontario ........................... 159

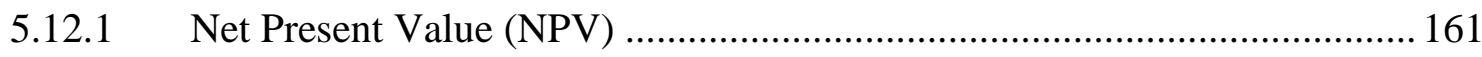

5.12.2 Internal Rate of Return (IRR) ............................................................ 162

5.12.3 External Rate of Return (ERR) .............................................................. 162

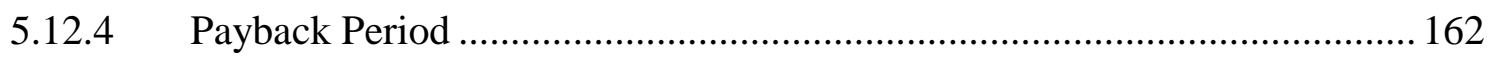

5.12.5 Cost-Benefit Ratio ............................................................................... 162

5.13 Discussion on Financial Analysis Results ............................................................. 163

5.14 Initiating Partial Development of PHES and GPM Plants in Ontario.................... 164

5.15 Distribution of Net Profit in Partially Developed PHES and GPM Plants ........... 167

6 Conclusion ............................................................................................................................................... 168

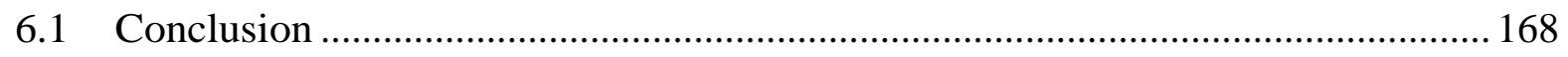

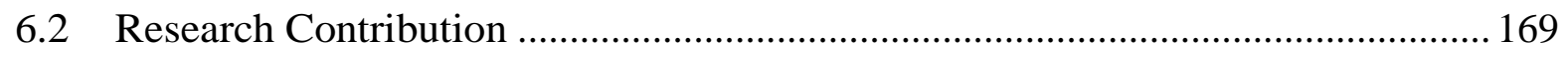

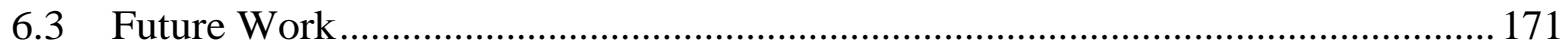

Appendices......................................................................................................................................... 172

Appendix A - Selection of Turbines for PHES Plants ................................................... 173

Appendix B - Rationales of Assumed Model Parameters ……….................................. 175

Appendix C - Estimated River Flows using HYDAT and OFAT III Tool .................. 184

References......................................................................................................................................... 185 


\section{List of Tables}

Table 1.1 Energy storage services required by grid application groups ................................ 3

Table 2.1 Turbines types based on various head ranges ...................................................... 26

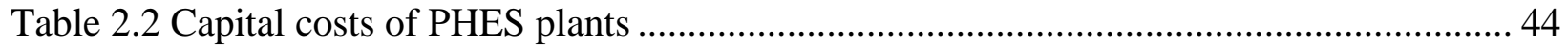

Table 2.3 Cost estimate for Island of Krk pumped hydro project ......................................... 45

Table 2.4 Capital cost and yearly O\&M cost of PHES projects ........................................... 45

Table 2.5 Cost estimate of overhead transmission lines in Ontario......................................... 47

Table 2.6 Cost estimate of BC Hydro pumped storage project ............................................. 48

Table 3.1 Defining cases of waterbodies and abandoned mine to identify PHES/ GPM sites.... 57

Table 3.2 Assumed parameters for the conventional method ................................................ 60

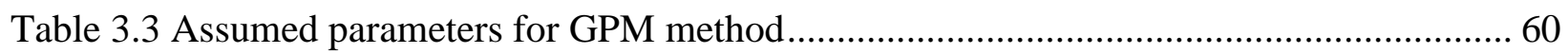

Table 3.4 Assumed criteria for screening constraints ..................................................... 61

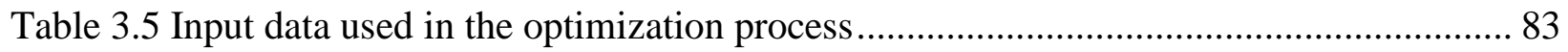

Table 4.1 Existing and planned energy capacity of Ontario (TWh) ...................................... 94

Table 4.2 Effect of projected increase in renewable generation ........................................... 94

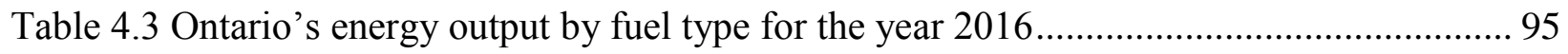

Table 4.4 Proportion of nuclear for daily output as system load of PHSA for 2016 ................. 95

Table 4.5 Proportion of gas for daily output as system load of PHSA for 2016 ...................... 96

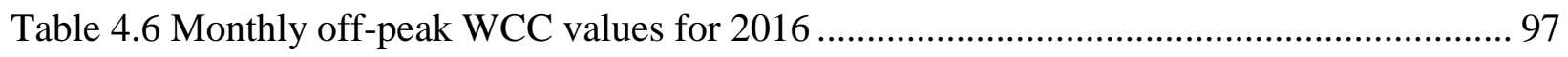

Table 4.7 Unit capital cost of various PHES plants .......................................................... 104

Table 4.8 Yearly O\&M cost of PHES plants .................................................................. 106

Table 4.9 Geospatial Dataset of Ontario ........................................................................ 108

Table 4.10 Assumed criteria for model parameters ........................................................ 109

Table 4.11 Assumed criteria for screening constraint features ............................................ 109

Table 4.12 Average unit cost of individual PHES components........................................... 110

Table 4.13 Season-wise months, days and peak hours of IESO electricity system.................. 113

Table 4.14 Input data used in the optimization process for the year 2016 ............................ 115

Table 5.1 Summary of identified PHES sites with dams .................................................. 118

Table 5.2 Summary of identified PHES sites with lakes .................................................... 119

Table 5.3 Summary of identified PHES sites with rivers ................................................ 122 
Table 5.4 Summary of abandoned mines selected as feasible PHES sites 124

Table 5.5 Summary of feasible PHES sites in Ontario ..................................................... 125

Table 5.6 Summary of identified GPM sites with dams ................................................ 128

Table 5.7 Summary of identified GPM sites with lakes .................................................. 128

Table 5.8 Summary of feasible GPM sites with rivers .................................................. 129

Table 5.9 Summary of feasible abandoned mines selected as GPM sites ............................. 129

Table 5.10 Summary of feasible GPM sites in Ontario ................................................... 130

Table 5.11 Summary of combined feasible PHES and GPM sites in Ontario......................... 131

Table 5.12 Comparison of GIS-based model results with existing Marmora project data......... 132

Table 5.13 Effect on PHES volume and energy potential with change in wall heights ............ 141

Table 5.14 Effect on GPM potential with change in depth and diameter of main shaft............ 141

Table 5.15 Estimating MAPC with change in parameter values .......................................... 142

Table 5.16 Resulted values of decision variables and objective function ............................. 148

Table 5.17 Detail of energy supply and purchase for the year 2016 ................................... 151

Table 5.18 Estimating MAPC with change in model parameters........................................ 153

Table 5.19 Financial indicators in the case study of Ontario............................................... 163

Table 5.20 Profit share of participatory PHES and GPM plants .......................................... 167

Table A-1 Types of turbines used at PHES plants in various countries .............................................173

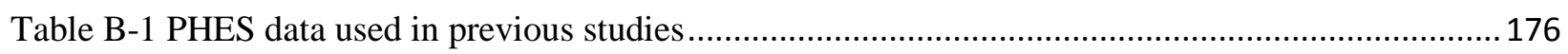

Table B-2 Basic information for water taking from primary waterbodies............................................179

Table B-3 Assumed criteria for model parameters …......................................................................... 183

Table C-1 Estimated river flows using HYDAT database and OFATIII tool .......................................184 


\section{List of Figures}

Figure 1.1 Pumped hydro energy storage share in the global energy storage system ................. 6

Figure 2.1 Schematic diagram of pure and pump-back PHES plants..................................... 18

Figure 2.2 Schematic diagram showing single and double penstock in the PHES system .......... 19

Figure 2.3 Schematic diagram showing GPM storage and generation at grid scale.................. 23

Figure 2.4 Schematic diagram showing construction details of GPM facility ......................... 25

Figure 3.1 Schematic diagram showing primary reservoir, buffer zone and surface regions ...... 56

Figure 3.2 Flowchart of GIS processing for feasible PHES/ GPM sites with dams ................... 66

Figure 3.3 Flowchart of GIS processing for feasible PHES/ GPM sites with rivers .................. 69

Figure 3.4 Flowchart of GIS processing for feasible PHES/ GPM sites with abandoned mines . 71

Figure 3.5 Schematic diagram showing model energy network mechanism of PHES plants ...... 76

Figure 3.6 Schematic diagram showing cash flow system of PHSA model............................ 76

Figure 4.1 Minimum Ontario demand and baseload generation.......................................... 97

Figure 4.2 Average unit capital cost of PHES plants...................................................... 105

Figure 4.3 Average $\mathrm{O} \& \mathrm{M}$ cost as a percentage of capital cost......................................... 106

Figure 5.1 Feasible PHES sites with dams as primary reservoirs....................................... 118

Figure 5.2 Feasible PHES sites with lakes as primary reservoirs ....................................... 120

Figure 5.3 Feasible PHES sites with rivers as primary reservoirs .................................... 122

Figure 5.4 Feasible abandoned mines selected as PHES sites............................................ 124

Figure 5.5 GIS processing results of feasible PHES sites in Ontario ................................... 125

Figure 5.6 GIS results showing the energy potential of feasible PHES sites in Ontario ........... 126

Figure 5.7 GIS processing results of feasible GPM sites in Ontario .................................... 130

Figure 5.8 GIS results showing feasible GPM sites in Ontario ........................................ 131

Figure 5.9 GIS processing results of combined feasible PHES and GPM sites in Ontario ........ 132

Figure 5.10 Histogram showing elevation head distribution of feasible PHES sites ............... 138

Figure 5.11 Effect on preliminary sites with respective change in surface slope..................... 143

Figure 5.12 Effect on preliminary sites with a respective change in surface area ................... 144

Figure 5.13 Effect on preliminary sites with respective change in buffer distance ................. 145

Figure 5.14 Effect on preliminary sites with respective change in elevation head................... 146

Figure 5.15 Preliminary sites with percent changes in default values of model parameters ...... 146 
Figure 5.16 Energy supply by PHSA in one operating cycle of the winter season .................. 150

Figure 5.17 Energy supply by PHSA in one operating cycle of the summer season ................ 151

Figure 5.18 Total NPV with respective change in storage total OR ................................... 154

Figure 5.19 Total NPV with respective change in storage variable OR ............................... 155

Figure 5.20 Total NPV with respective change in energy-price inflation rate ....................... 156

Figure 5.21 Total NPV with respective change in energy-use increase rate ......................... 157

Figure 5.22 Total NPV with respective change in unit capital cost.................................... 158

Figure 5.23 Total NPV with percent changes in default values of model parameters............... 159

Figure 5.24 Total NPV versus discount rates of PHSA for the case study of Ontario .............. 163

Figure 5.25 Location map of partial development for PHES and GPM plants in Ontario ......... 166 


\section{Glossary of Acronyms and Symbols}

\begin{tabular}{ll} 
AAT & All-at-a-time \\
AC & Alternating Current \\
A-CAES & Adiabatic CAES \\
AEMO & Australian Energy Market Operator \\
AFC & Automatic Frequency Control \\
BC & British Columbia, Canada \\
C $\$$ & Canadian Dollar \\
CAES & Compressed Air Energy Storage \\
CAISO & California Independent System Operator \\
CCV & Cycloconverter \\
DC & Direct Current \\
DEM & Digital Elevation Model \\
DFASPSU & Doubly Fed Adjustable-Speed Pumped Storage Unit \\
DFIM & Double-Fed Induction Motor \\
DLC & Double Layer Capacitor \\
DOE & US Department of Energy \\
DSS & Decision Support System \\
DTM & Digital Terrain Model \\
ECEPS & East China Electric Power System \\
ED & Elevation Difference \\
EIA & US Energy Information Administration \\
ELD & Economic Load Dispatching \\
ENS & Energy Not Served \\
EPC & Engineering, Procurement and Construction \\
ERR & External Rate of Return \\
ESA & Electricity Storage Association (USA) \\
ESRI & Environmental System Research Institute Inc., Redlands, California \\
EU & Europe \\
FES & Flywheel Energy Storage \\
\hline
\end{tabular}




\begin{tabular}{|c|c|}
\hline FIT & Feed in Tariff \\
\hline GCT & Gate Commutated Thyristor \\
\hline GEA & Green Energy Act of Ontario, 2009 \\
\hline GHG & Green House Gases \\
\hline GIS & Geographic Information System \\
\hline gm & Gram \\
\hline GPG & Gas/ Oil Power Generator \\
\hline GPM & Gravity Power Module \\
\hline GPP & Gravity Power Plant \\
\hline GTO & Gate Turn Off \\
\hline GW & Gigawatt \\
\hline GWh & Gigawatt Hour \\
\hline HFB & Hybrid Flow Battery \\
\hline HIF & High Flood \\
\hline HPG & Hydro Power Generator \\
\hline HWY & Highway \\
\hline HYDAT & Hydroclimatological Data Retrieval Program (Canada) \\
\hline $\mathrm{I} \& \mathrm{C}$ & Instrumentation and Controls \\
\hline IBM & International Business Machine \\
\hline IEA & International Energy Agency, USA \\
\hline IEC & International Electro-technical Commission, Switzerland \\
\hline IEEE & Institute of Electrical and Electronics Engineers \\
\hline IESO & Independent Electricity System Operator, Ontario \\
\hline IGBT & Insulated Gate Bipolar Transistor \\
\hline IGCT & Integrated Gate Commutated Thyristor \\
\hline IPSP & Integrated Power System Plan \\
\hline IRR & Internal Rate of Return \\
\hline JRC & Joint Research Centre of the European Commission \\
\hline $\mathrm{kg}$ & Kilogram \\
\hline $\mathrm{KKT}$ & Karush-Kuhn-Tucker \\
\hline $\mathrm{km}$ & Kilometer \\
\hline
\end{tabular}




\begin{tabular}{|c|c|}
\hline $\mathrm{kV}$ & Kilo Volt \\
\hline $\mathrm{kW}$ & Kilowatt \\
\hline $\mathrm{kWh}$ & Kilowatt Hour \\
\hline KWO & Kraftwerke Oberhasli AG \\
\hline LAB & Lead Acid Battery \\
\hline LAMH & $\begin{array}{l}\text { Laboratoire de Machines Hydrauliques - Université Laval } \\
\text { (Hydraulic Machinery Laboratory at Laval University) }\end{array}$ \\
\hline Li-ion & Lithium Ion Battery \\
\hline LIO & Land Information Ontario \\
\hline LLC & Limited Liability Company \\
\hline LOF & Low Flow \\
\hline LRP & Large Renewable Procurement \\
\hline LTEP & Long Term Energy Plan \\
\hline MA & Multi-citeria Analysis \\
\hline MAF & Mean Annual Flow \\
\hline MAPC & Mean Absolute Percent Change \\
\hline MARR & Minimum Acceptable Return Rate \\
\hline $\mathrm{MCP}$ & Market Clearing Price \\
\hline MHP & Mini Hydropower Potential \\
\hline MVA & Mega Volt Ampere \\
\hline MW & Megawatt \\
\hline MWh & Megawatt Hour \\
\hline N.m & Newton meter \\
\hline $\mathrm{Na}-\mathrm{NiCl}_{2}$ & Sodium Nickel Chloride Battery \\
\hline $\mathrm{NaS}$ & Sodium Sulfur Battery \\
\hline NERC & North American Electricity Reliability Corporation \\
\hline NGO & Non-Government Organization \\
\hline NHA & National Hydropower Association (USA) \\
\hline $\mathrm{NiCd}$ & Nickel Cadmium Battery \\
\hline $\mathrm{NiMH}$ & Nickel Metal Hybrid \\
\hline NPAs & Nature Protected Areas \\
\hline
\end{tabular}




\begin{tabular}{|c|c|}
\hline NPCC & Northeast Power Coordinating Council \\
\hline NPG & Nuclear Power Generator \\
\hline NPV & Net Present Value \\
\hline NUGs & Non-Utility Generation Contracts \\
\hline NYISO & New York Independent Supply Operator \\
\hline O\&M & Operation and Maintenance \\
\hline OANDA & OANDA Corporation \\
\hline OAT & One-at-a-time \\
\hline OEB & Ontario Energy Board \\
\hline OFAT & Ontario Flow Assessment Tool \\
\hline $\mathrm{OHN}$ & Ontario Hydro Network \\
\hline OPA & Ontario Power Authority \\
\hline OPF & Optimal Power Flow \\
\hline OPG & Ontario Power Generation \\
\hline OR & Operating Reserve \\
\hline ORN & Ontario Road Network \\
\hline OWRA & Ontario Water Resources Act \\
\hline PCS & Power Conversion System \\
\hline PDF & Portable Document Format \\
\hline PHES & Pumped Hydro Energy Storage \\
\hline PHSA & Pumped Hydro Storage Association \\
\hline PSO & Particle Swarm Optimization \\
\hline PV & Photovoltaic \\
\hline $\mathrm{RCC}$ & Reinforced Cement Concrete \\
\hline RFB & Redox Flow Battery \\
\hline ROI & Return on Investment \\
\hline RULA & Ryerson University Library and Archives \\
\hline SBG & Surplus Baseload Generation \\
\hline SMES & Super Magnetic Energy Storage \\
\hline SNG & Synthetic Natural Gas \\
\hline SPG & Solar Power Generator \\
\hline
\end{tabular}




$\begin{array}{ll}\text { SQL } & \text { Structured Query Language } \\ \text { T\&D } & \text { Transmission and Distribution } \\ \text { TWh } & \text { Terawatt hour } \\ \text { UCP } & \text { Unit Commitment Problem } \\ \text { UK } & \text { United Kingdom } \\ \text { UN } & \text { United Nations } \\ \text { UPS } & \text { Uninterruptible Power Supply } \\ \text { USA } & \text { United States of America } \\ \text { WASP } & \text { Wien Automatic System Planning } \\ \text { WCC } & \text { Wind Capacity Contribution } \\ \text { WGC } & \text { Wind Generators Cooperative } \\ \text { Wh } & \text { Watt.hours } \\ \text { WPG } & \text { Wind Power Generator } \\ \text { Zn-Br } & \text { Zinc Bromide Battery } \\ \text { Zn-Cl } & \text { Zinc Chloride Battery }\end{array}$




\section{Introduction}

\subsection{Background}

The electric power industry has been focusing worldwide towards increasing utilization of renewable energy resources in efforts to build and maintain a clean, reliable and affordable electricity system. The restructuring trend of this industry is introducing new challenges to the electricity market systems. The renewable energy resources, specifically wind and solar, are mostly uncertain and intermittent in nature, requiring mitigation strategies in order to maintain consistent power availability at the grid level. Energy storage options can be helpful to manage the equilibrium between demand and supply by adding the needed flexibility to the grid that allows for efficient management of dips in supply and demand. While improvements are needed in terms of bringing down the costs, many experts have predicted that storage systems should be used to greatly increase the uptake of renewable energy (Droege 2008).

In the absence of energy storage, the industry operates within the 'just-in-time' framework which has the uncertainty of both flexible end-use demands and uncontrollable weather conditions. With backup support of an energy storage facility, the industry can develop and maintain a reliable delivery network to meet the peak hour demand. However, Makansi and Abboud (2002) argued that the establishment of an energy storage facility for supplementing the primary energy resources is a significant economic decision to achieve a higher return on investment (ROI).

Currently, different energy storage technologies exist, having their own applications, potentials, limitations, and constraints. The energy storage technologies such as pumped hydro energy storage (PHES), flywheel, super magnetic energy storage (SMES), compressed air energy storage (CAES), lead-acid battery (LAB), sodium sulfur battery (Na-S) and zinc bromide battery $(\mathrm{Zn}-\mathrm{Br})$ are suggested more often as they are the developed technologies.

Although a variety of energy storage solutions are available, the selection of a viable solution is a challenge to satisfy the electricity system requirements such as regulatory and operational framework, sufficient storage capacity for providing services at grid level, etc. Therefore, exploration of the most effective energy storage technology is needed that can be integrated with a diverse supply-mix energy system at the grid level. Currently, the supply-mix energy system is being implemented in many jurisdictions. The Province of Ontario, for example, is using a 
supply-mix of nuclear, hydroelectric, gas/oil, wind, solar, and bio-energy resources. The benefits of energy storage are potentially useful to all stakeholders including power generators, system operators, distribution companies and the end users.

The US Department of Energy identified and defined nineteen potential grid applications for energy storage (Eyer and Corey 2010). Later on, Agrawal et al. (2011) discussed a methodology of choosing the energy storage technologies for particular grid applications which are divided into the following four groups:

\section{- Group 1: Long Discharge with Frequent Use}

○ Electric energy time-shift

○ Electric supply capacity

○ Load following

○ Time-of-use energy cost management

○ Demand charge management

○ Renewable energy time-shift

○ Renewables capacity for firming

$\bigcirc$ Wind generation grid integration (time-shift)

\section{- Group 2: Short Discharge with Frequent Use}

- Area regulation

○ Voltage support

$\bigcirc$ Wind generation grid integration (intermittency)

\section{- Group 3: Long Discharge with Occasional Use}

○ Electric supply reserve capacity

○ Transmission congestion relief

○ Transmission and distribution (T\&D) upgrade deferral $50^{\text {th }}$ percentile

○ T\&D upgrade deferral $90^{\text {th }}$ percentile

○ Substation on-site power (DC backup)

○ Electric service reliability (backup)

\section{- Group 4: Short Discharge with Occasional Use}

○ Transmission support

- Electric service power quality 
The detail of key energy storage service requirements with respect to each group of applications is provided in Table 1.1 as given below.

Table 1.1 Energy storage services required by grid application groups

\begin{tabular}{|l|l|l|l|l|}
\hline \multirow{2}{*}{ Energy Storage Services } & \multicolumn{3}{|c|}{ Services Required Grid Application Groups } \\
\cline { 2 - 5 } & Group 1 & Group 2 & Group 3 & Group 4 \\
\hline Discharge duration & Hours & Minutes & Hours & Seconds \\
\hline Response time (for full power) & Minutes & Seconds & Minutes & Seconds \\
\hline Discharge depth & Deep & Shallow & Deep & Shallow \\
\hline Minimum cycle life (number of cycles) & Few 1000s & Tens of 1000' & Few 100s & Few 100s \\
\hline Energy efficiency & Important & Important & Not important & Not important \\
\hline Feasibility for bulk energy storage & $\begin{array}{l}\text { Main } \\
\text { Applications }\end{array}$ & Not feasible & $\begin{array}{l}\text { Additional value } \\
\text { Applications }\end{array}$ & Not feasible \\
\hline
\end{tabular}

After grouping and highlighting the key energy storage service requirements by grid applications, Agrawal et al. (2011) recommended the following six main applications for bulk energy storage services:

\section{- Electric Energy Time-Shift}

The storage can take advantage of the price difference between on-peak and off-peak timings to utilize the surplus baseload generation (SBG) of conventional primary generators.

\section{- Electric Supply Capacity}

The storage can be used to supply for peak-load demand.

\section{- Load Following}

The storage can provide load following capacity to balance the supply and demand within a specific region or area. The load following function is required when the demand is increasing before reaching its peak or decreasing after it has passed its peak.

\section{- Renewable Energy Time-Shift}

The storage can store the electricity during excess energy production and discharge it in the time period of peak demand when electricity costs are at their highest level.

\section{- Renewable Capacity for Firming (15-60, 60-120 Minutes)}

The objective of this application is to make the renewable generation output constant and, hence, the storage can be used as a spinning reserve to delay the commitment for any additional oil fuel units. 


\section{- Wind Generation Grid Integration (Long Duration)}

This application increases the market penetration of wind-generated electricity which is the most important complementary service of energy storage towards utilization of maximum output of wind generation.

The above applications belong to Group 1 that specifies the storage service requirements such that it should be capable of utilizing the renewable capacity and firming the power; discharge duration should be in hours; etc. Therefore, the energy storage services requirement of a group can lead to appropriate selection of energy storage technology for that group.

\subsection{Choosing Appropriate Energy Storage Technology at Grid Level}

The previous section identifies the level of different energy storage services required by four specified groups of grid application categories. For a particular group, it is important to determine the appropriate energy storage technology that should be the best fit in the concerned electricity market system. For example, bulk energy storage services may be needed to store surplus energy of baseload generators. Similarly, distributed storage may be required at the utility-scale electricity system. The large electricity market operators such as IESO in Ontario, Canada; CAISO in California, USA; NYISO in New York, USA; etc. generally require regulation and power quality services for voltage and frequency control respectively. More importantly, the main focus should be given on fact-based applications of energy storage instead of the perceptions. Considering various technological aspects as mentioned above, the study by Dunn et al. (2011) divided the large electricity grid applications into three broad categories including uninterruptible power supply (UPS), transmission and distribution (T\&D) grid support, and bulk power supply; as well as their possible match with commonly available energy storage technologies. Accordingly, this study highlighted that the pumped hydro energy storage (PHES) and compressed air energy storage (CAES) have their generation capacity range of around $10 \mathrm{MW}$ and above with discharge time in hours at rated power and both technologies are related to bulk power management category to provide the energy storage services at grid level.

Regarding the historical development of CAES, this technology has been used since 1978 for different industrial applications (Konrad et al. 2012). The key advantages of CAES are that it has a large capacity and the air is used as a storage medium which is freely available at all the times 
at any place. The disadvantages are due to its low round-trip efficiency and limited underground geographic locations (IEC 2011). Some studies have considered it to be the most likely successor of PHES, a premier bulk storage technology. However, CAES has not yet gained its maturity of taking over this role. Slocum et al. (2013) stated that CAES has developed only two major successful plants in the world. One plant was built in 1978 in Bremen, Germany with 320 MW (1.2 GWh) installed capacity and the second plant was built in 1991 in Alabama, USA with $110 \mathrm{MW}(2.8 \mathrm{GWh})$ installed capacity.

The literature review reveals that CAES faced siting issues after starting some projects on the ground. In this regard, Agrawal et al. (2011) discussed the siting issues of some projects such as Seneca CAES plant in New York could not start due to deterioration of the salt cavern that was planned for the air storage. Similarly, the Iowa CAES plant faced problems with the aquifer formation that was intended for use as air storage. The Bethel energy centre project of $317 \mathrm{MW}$ in Texas was scheduled to begin its construction in the last quarter of 2015 to be completed in 2017. However, Apex Compressed Air Energy Storage LLC placed this project on hold until a new date is announced. However, contrary to the above situations, Toronto Hydro Ontario announced the successful completion of a CAES project with $660 \mathrm{kWh}$ capacity in November 2015 at three kilometers off the south shore of Toronto island, underneath 55 meters of water in Lake Ontario (Canadian Manufacturing 2015). The above discussion indicates that the identification of acceptable underground sites for large scale CAES is still a challenging issue.

Regarding PHES, the first known pumped hydro storage installation appeared in 1882 in Zurich, Switzerland (Agrawal et al. 2011). The operating principle of PHES is based on the gravitational potential energy of water that is stored in the upper reservoir by pumping water from a lower reservoir. The literature review shows that PHES is a proven feasible option at grid level having high power capacity and long life cycle duration (Yang et al. 2008). Various studies including ROAM Consulting (2012) and Fiske (2015) stated that PHES is a mature form of energy storage technology having over $99 \%$ of the total storage capacity of the world as shown in Figure 1.1. 

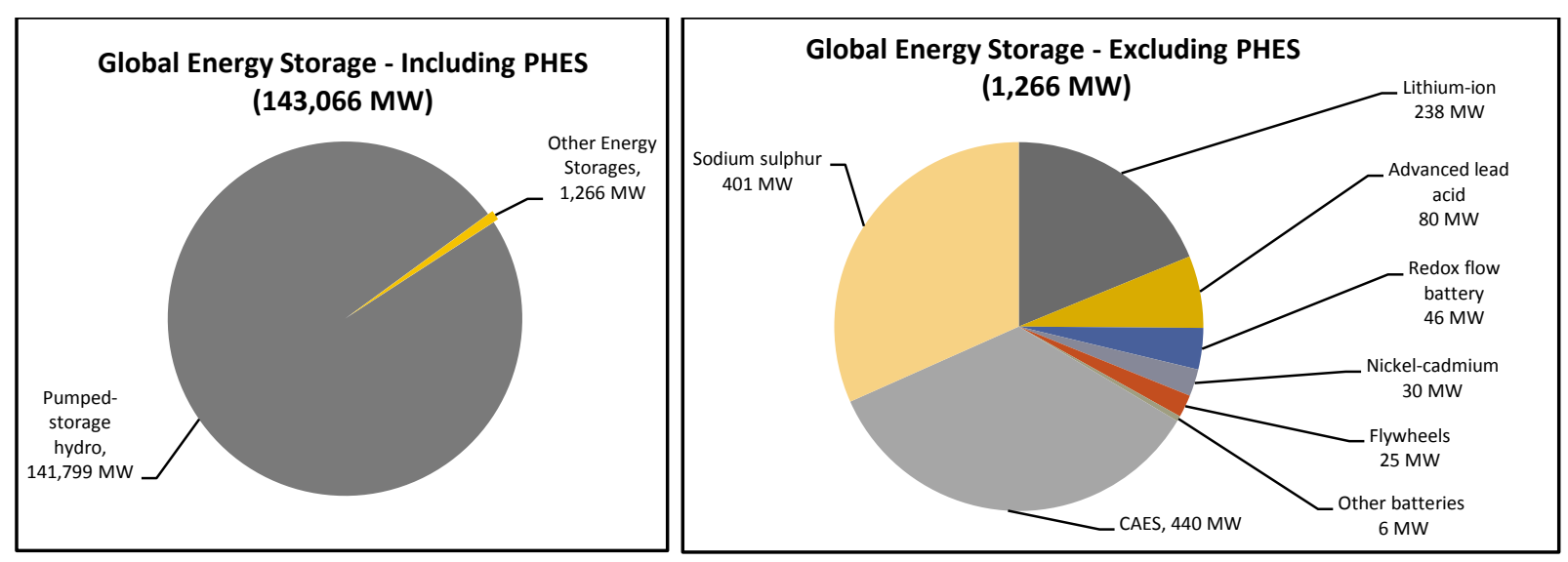

Figure 1.1 Pumped hydro energy storage share in the global energy storage system

Individual pump storage schemes up to 2000 MW generating capacity have been built in the USA, Europe, and other countries (ROAM Consulting 2012). It is widely believed that suitable sites are limited to build the new PHES facilities and identifying the feasible and most beneficial PHES locations in terms of capacity and economy is a difficult challenge for the energy providers.

In Canada, the citing situation is different as there is only one PHES plant in operation at Niagara Falls having 174 MW installed power capacity. In a white paper, Pejovic (2011) specifically pointed out that Ontario has sufficient potential PHES sites which are not yet explored. This paper recommended that evaluation of cost benefits of PHES system along with the exploration of modern technologies should be studied so that Ontario could take advantage of this opportunity to make an efficient, reliable and stable energy system. It was also recommended that long-term initiatives are needed to plan, finance, and implement energy storage. The renewables combined with energy storages may become a vital part of the supply-mix for the baseload as well as for peak power demands. The enhanced role of renewables with the integration of PHES system would be very helpful in providing a cleaner environment to Ontarians by reducing the pollution produced by the peak-hour power plants. Therefore, PHES needs to be clearly addressed in Ontario's energy policy to include in the future development process.

In this regard, Ontario's Ministry of Energy has taken some potential steps to optimize the supply-mix power system. It is important to note that the long term energy plan (LTEP) of Ontario focuses on substantial increase of renewable energy resources using energy storage and 
gradual diminution of fossil fuels to deliver clean and cheaper electricity to end users as well as providing an opportunity to power producers to earn better profit margin (Ontario Ministry of Energy 2013).

\subsection{Why is Pumped Hydro Energy Storage (PHES) Needed?}

Renewable energy resources such as wind and solar are intermittent in nature and as such, they lack in regular production and continuous supply of their total installed power potential capacities. As highlighted by Rehman et al. (2015), the wind has highly fluctuating meteorological parameters that have the tendency of changing hourly, daily, weekly, monthly and annually. This study further stated that a maximum of $25 \%$ to $50 \%$ wind penetration is feasible to firmly participate in the electricity system. More importantly, the feasibility of very high wind penetration decreases dramatically from $80 \%$ to $20 \%$ with an increase in the grid size from $0.1 \mathrm{MW}$ to $10 \mathrm{MW}$ respectively. This reduction can be mitigated by placing the energy storage in the grid system. Bakos (2002) stated that a storage capacity of one day to three days duration is required for $90 \%$ and above penetration of wind energy into the grid.

In order to utilize the maximum output of renewable energy resources as well as to assure the quality of power supply at the grid level, large energy storage systems are required. According to Hino and Lejeune (2012), Mitteregger and Penninger (2008), and Nazari et al. (2010), PHES plants are worldwide acceptable, mature and placed-in as useful tools in the electricity system. Additionally, PHES has several advantages which are briefly provided below (Rehman et al. 2015):

- Electricity time-shifting to take advantage of low and high price timings and hence PHES has the ability to track load changes and meeting time-varying demand;

- Large energy storage capacity to meet peak load demand;

- Load following capacity due to flexible start/ stop and fast response speed;

- Ability to modulate the frequency and maintaining the voltage stability;

- Renewable energy time-shifting to store excess production of renewable to discharge it during a high demand period;

- Technically capable of providing renewable support in capacity firming to make the renewable generation output constant; and

- Ability to increase penetration of renewables into the electricity market at grid level. 
More importantly, clean and inexpensive renewable energy resources are being considerably encouraged in the modern world. The growing trend of using intermittent energy resources has introduced the need to make a more modern and flexible energy transmission and distribution system. Due to this rapidly emerging trend, most electricity system operators are in the planning process of restructuring their electricity systems.

In electricity system, the optimal power flow (OPF) of electric power plants is also significant that maintains the optimal operating levels to meet the demands, usually with an objective of minimizing the operating cost. The scope of optimal power is broadened due to advancements in the development of ultra-high voltage grid connection and nationwide grid connection. The study of Zeng et al. (2013) discussed the importance of PHES role for its utilization at regional grid level and cross-regional interconnection grids in addition to the local grids. This study stated that larger grid needs more security to ensure safety and stability of the grid. For example, in 2003, the USA, UK, Sweden, Denmark, and Italy experienced their large-area power outage emergencies. These accidents illustrated the need for sufficient and quick start reserve capacity in the grid to strengthen the grid construction. In order to deal with transmission line accidents, reserve capacity is required in the region near the load centre by the receiving end. Keeping in view that the accident time is very short, instant action should be initiated to provide the services of reserve capacity, black start, and other measures to avoid system-wide collapse and to reduce losses under these emergency circumstances. The PHES plants play an instrumental role in the security and reliability of the grid by providing the ancillary services including rapid response, frequency modulation, phase modulation, and most importantly the black start capability.

Therefore, this research is aimed to apply an integrated approach using latest techniques to comprehensively plan the PHES system including identification of feasible PHES potential and to optimize the scheduling of this potential in a large supply-mix electricity system such as the electricity market operated by IESO in Ontario, Canada.

\subsection{Necessity of Developing an Integrated Planning Framework for PHES Systems}

The literature review reveals that complete planning of PHES system has not yet been provided in the past studies. Generally, the development of PHES has been considered in parts or discussed in support of the development of other power generators such as wind, solar, etc. Most 
of the studies stated that PHES is a worldwide used technology with regard to its particular services such as bulk energy storage having long discharge duration and quick response time, capacity firming of renewables, and instantly providing ancillary services to the utility operators. However, its complete integrated techno-economic study at a particular large grid-level electricity region area is missing. Moreover, PHES services have been generally considered in the interest of other power generators or utility operators without establishing it as a permanent participant of the power industry. It comes from the common observation that the decision makers at government level are generally reluctant to accept and adopt this technology for giving it a proper place in the electricity market system due to the absence of work on its technical development supported by a financial analysis to test the viability of PHES system. In this respect, Bradbury et al. (2014) reported that the lack of adequate economic information regarding PHES technology is one of the major obstacles for developing the ownership structures and required regulation strategies for PHES system. Similarly, Zakeri and Syri (2015) stated that the cost analysis of PHES system cannot be easily generalized as they are site specific. In addition, the economic characteristics of PHES system have remained obscure for energy system analysts, power suppliers, grid operators and policymakers due to the absence of PHES use on a commercial basis or failing to adopt this technology at grid level.

As a result, it seems necessary to develop a comprehensive integrated planning framework by conducting a study on developing a full package of PHES system in a grid level electricity region area utilizing all available resources. Hence, this particular research intends to develop an integrated planning framework for PHES systems at grid level including: (i) identification and ranking of PHES sites using all types of existing waterbodies to realize the feasible PHES potential, (ii) optimal use of PHES potential in the electricity market (considering the prevailing electricity market setup), and (iii) analyzing financial returns of PHES system for the life period of PHES plants to assess the cost-effectiveness and financial viability of PHES system. Therefore, this particular research is vital in the current transition stage of restructuring the power industry that intends to utilize the maximum penetration of renewable energy to produce clean, reliable and cost-effective electricity. 


\subsection{Problem Statement}

In a diverse supply-mix electricity system, the time-varying utilization of power needs a balanced and cost-effective electricity generation system. The baseload plants are needed to complement with bulk energy storage so that their surplus baseload generation can be utilized during peak hours' demand. Similarly, around $75 \%$ of the installed capacity of renewable energy resources such as wind and solar remains unutilized. The power from peaking plants is produced with significantly very high cost and these plants involve serious greenhouse gases (GHG) emission concerns.

In order to address the above problems, a research-based study is needed to develop energy storage facilities at the grid level to store unutilized variable power from wind and solar, as well as to optimally absorb the surplus power of nuclear and run-of-the-river hydro generators. Additionally, the large electricity market operators require potential dependable energy suppliers for providing ancillary services including operating reserve to ensure security, reliability, and sustainability of the electricity market system. This research, therefore, focuses on the study of PHES system planning for optimal utilization of surplus baseload generation including unutilized renewable energy production to complement the existing primary conventional energy generators using a case study of Ontario, Canada.

The Ontario Ministry of Energy (2013) forecasted the increasing electricity demand from 161.1 TWh in 2012 to 197.7 TWh in 2030. The review of the current energy situation reveals that the Ministry of Energy has completely phased-out the coal power generation due to its serious environmental impacts. Presently, the remaining supply-mix energy contributors are nuclear, hydroelectric, gas/oil, wind, solar, and bio-energy. The nuclear energy is perceived to be associated with high risks being generated from the source of radioactive substance and its waste is highly hazardous with expensive disposal. The hydroelectric energy is environmentally clean but the new dam sites involve high capital costs, lengthy regulatory approvals and long construction periods. The gas/ oil generators have been using fossil fuels which incur high energy generation cost and their use for energy generation is also an environmental concern. The bio-energy has a very small contribution to the supply-mix energy. In the wake of the sad situational factors, the Ministry of Energy intends to enhance the electricity generation by utilizing renewable energy resources as much as possible, particularly wind and solar at the grid 
level. The Ministry aims to provide clean, reliable, inexpensive and better quality energy to the consumers on a long-term basis.

The potential of PHES in Ontario has not yet been fully utilized as it requires special attention to explore feasible PHES sites to the possible extent. However, the major challenges include:

- Identification of potential PHES sites;

- Selection of feasible PHES sites for economic sustainability and practical acceptance in the current electricity market system;

- Developing an optimization model for PHES scheduling to apply on a case study; and

- Analysis of financial feasibility for integration of PHES system into current electricity market system of the case study.

In order to address the above challenges, a systematic comprehensive approach of integrated planning is adopted by setting the following research objectives.

\subsection{Research Objectives and Significance}

The objectives of this research are:

- To develop a GIS-based model using latest GIS techniques for identification of feasible PHES sites within a grid-scale electricity region;

- To develop an optimization model for scheduling of identified PHES energy potential in a grid level electricity market system;

- To conduct a case study of an existing grid-level electricity market system to test the applications of both GIS and optimization models; and

- To perform a financial analysis based on optimization results obtained for the life period of PHES plants to examine the financial viability of integrating the PHES system at grid level.

The results of the above objectives presented a systematic comprehensive planning approach for establishing and integrating the PHES system in an electricity market system at the grid level. The planning approach covered the life-cycle aspects of PHES system including the identification of feasible PHES sites, optimally utilizing their energy potential in an electricity market at grid level, and finally performing financial analysis for life period of PHES plants 
based on optimization outcome to test the financial viability of the PHES system. The anticipated contributions and related beneficiaries of this research are provided below.

The identification of feasible PHES sites can be supportive to the concerned government agencies to make a policy and plan for the utility regions at grid level to explore maximum available PHES potential within the region using all types of existing waterbodies. In this respect, the case study of this particular research is beneficial to the Ministry of Energy to include PHES development in its long-term energy plan to facilitate the electricity market system operated by IESO in Ontario, Canada.

The identified feasible PHES potential can certainly enhance the confidence level of concerned government agencies and utility operators to expeditiously execute clean energy plans with the increased proportion of renewable energy in supply-mix electricity market system, thereby reducing the energy contribution of primary conventional generators such as gas and nuclear which are posing serious environmental effects. The case study results can be helpful for the Ontario's Ministry of Energy to achieve the planned targets of utilizing wind and solar in the supply-mix system through its executing agencies including Ontario Power Generation (OPG) and IESO.

The PHES system can also be useful to provide the ancillary services including operating reserve as well as to meet the increasing real-time electricity demand during peak hours. This can reduce the load of peaking plants that is a major issue of utility operators throughout the world. In this regard, the case study of this research can be functional to the IESO in Ontario.

Furthermore, the financial analysis results can guide and strengthen the confidence of stakeholders of the energy storage system including: the Owners of PHES plants, wind farms, solar installations, and existing primary energy generators; electricity system operators; electricity transmission and distribution providers; and electricity end-users for integrating the PHES system at grid level. 
The overall systematic approach of integrated PHES planning presented in this research can be valuable for the policymakers, electricity system operators, PHES/ GPM developers, research scholars, engineers, financial analysts, and scientist community to work on further improvements in PHES system.

\subsection{Thesis Organization}

The chapter-wise organization of this thesis is as follows:

Chapter 1 explains the significance of the PHES system in the current restructuring of the electric power industry that has been focusing on increasing utilization of renewable energy resources. The key energy storage services needed for grid-level applications have been presented in this chapter, that points out PHES is the most suitable option of providing bulk energy storage services. This chapter defines the problem statement of this research and proposes a systematic comprehensive planning approach with specific objectives and significance of this research.

Chapter 2 presents the relevant literature review of energy storage technologies, predominantly conventional method of PHES and emerging technology of gravity power module (GPM) system. This chapter also reviews the GIS technique and optimization processes used in past studies. This chapter discusses the PHES cost data of previous studies and suggests the use of unit cost of individual PHES components for ranking of feasible PHES sites and the use of unit capital cost and O\&M cost in optimization process and financial analysis of this research.

Chapter 3 provides the complete methodological processes for identification of feasible PHES sites and optimization for scheduling of PHES system developed in this research. This chapter also explains the necessary financial indicators and their inter-related conditions to test the financial viability of the PHES system.

Chapter 4 discusses the case study of Ontario and explains the government policy on energy, renewable energy, energy storage, and possible development of pumped hydro energy storage. This chapter analyses the existing and future power demand and discusses the role of PHES providing ancillary services to IESO by utilizing the renewables to make their 
reliable participation in the supply-mix power system. This chapter also provides the input data used in the GIS-based model and optimization model for the case study of the province of Ontario.

Chapter 5 presents the applications of all methodological processes provided in chapter 3 . In this chapter, the developed models have been tested in a case study of Ontario. The GISbased model is used to identify the feasible PHES sites in the study area. The optimization model is applied in the case study using IESO data of the year 2016 to get the optimal scheduling of identified feasible PHES energy potential in Ontario. The optimization outcome is used for financial analysis of the PHES system. In order to take an initial step, this research study proposed partial development of the identified PHES and GPM energy potential.

Chapter 6 concludes the whole research work and provides the imperative contribution of this research. Finally, this chapter proposes future work for further research studies. 


\section{Literature Review}

\subsection{General}

Worldwide, the electricity demand is high in peak hours and low in off-peak hours during a day. The demand variation is usually different in different seasons for weekdays and weekends/ holidays in a year. This varying utilization of power requires a balanced power generation system. Hence, the power suppliers should complement their baseload plants with a minimum possible cost of power generation in peak hours and similarly, the surplus power generation should be either stopped in off-peak hours or stored for future use. Therefore, there is a need to adopt an electricity generation mechanism that should be operated to meet the time-varying system demand.

There are two main characteristics of electricity generation that lead to the concerned issues of electricity usage. In the first characteristic, the electricity is consumed at the same time when it is generated. This requires a proper amount of production to meet the particular demand. Any imbalance in supply and demand can damage the stability and quality of generated electricity. The stability requires perfect smoothness in generated quantity whereas the quality needs a perfect control on voltage and frequency of the power supply.

The second characteristic is that the generators and the consumers are not located in the same places. They are connected through the power grids to form a power system. There may be power congestion due to the concentration of extraordinary power flow. The failure of the transmission line may occur due to congestion or any other reason and the electricity supply can be interrupted.

The above circumstances suggest the need for developing a well-planned strategy that can overcome the concerned issues of both characteristics. Most importantly, there should be an arrangement of excess power to fulfill the demand during peak-hours and simultaneously any excess power during off-peak hours should be reasonably utilized. Moreover, the arrangement should mitigate the quality issues particularly related to voltage and frequency of the power supply. Additionally, there has been an increasing trend of utilizing the maximum generation of renewable energy which is inherently associated with stochastic problems as discussed in the previous chapter. Several studies have addressed the above issues and ultimately the suggested 
solution is to complement the power system with energy storage. Worldwide, revolutionary efforts have been made to develop efficient techno-economic models in the field of energy storage. In this regard, the available energy storage technologies are reviewed in the following section.

\subsection{Energy Storage Technologies}

There are a number of energy storage technologies that have been developed using different energy forms of their storage including mechanical, electrical, chemical, electrochemical, and thermal storage forms. The commonly used energy storage systems have been categorized worldwide for large-scale applications in their respective storage forms (Dunn et al. 2011) and (IEC 2011). The detail of energy storage technologies is available in various studies including IEC (2011), Joseph and Shahidehpour (2006), Díaz-González et al. (2012) and Yang et al. (2008). The handbook of energy storage for transmission and distribution applications by EPRI DOE (2003) also provides comprehensive guidance on the currently available energy storage technologies. Amongst the broad range of energy storage technologies, this research has focused on PHES technology.

\subsection{Pumped Hydro Energy Storage (PHES) Technology}

A PHES system can be characterized on the basis of different factors including existing topology; type of water storage used such as the open reservoir, pipes, balloons; medium surrounding the storage like open atmosphere, underground aquifer, in-ground soil, under ocean water; and the applied principle of generating the energy. Presently, the novel pumped hydro energy storage technologies are as follows:

- Conventional PHES

- In-ground storage pipe

- Underground reservoir

- Aquifer PHES

- Ocean PHES

- Archimedes screw

- Energy island

- In-reservoir tube with bubbles 
Amongst the above techniques, this research has focused on the conventional PHES with an adjustable-speed pump-turbine system and in-ground storage pipe using gravity power module (GPM) technique because these are the most suitable options for the main applications of bulk energy storage services recommended by Agrawal et al. (2011). The detail of other technologies can be viewed in the study report by Agrawal et al. (2011). The technological details of both conventional PHES system and GPM technique are provided in the following sections.

\subsection{Conventional PHES System}

The conventional PHES system consists of two reservoirs which are named primary reservoir and PHES reservoir. The primary reservoir is an existing waterbody and the PHES reservoir stores water from the primary reservoir through pumping, if located at a higher elevation, or through gravity flow, if located at a lower elevation than the primary reservoir. The reservoir at higher elevation is called the upper reservoir and the reservoir at lower elevation is called the lower reservoir. The fundamental principle is to raise the water to a higher level in the upper reservoir, creating potential energy with the advantage of natural topology. The potential energy can be converted into electric energy by using the differential head created by elevation difference between upper and lower reservoir levels. Generally, pumping of water takes place to create high potential head during off-peak hours when both electricity demand and prices are low. The high head water is passed through a turbine to regenerate the power during peak hours of high demand with high electricity price. Hence, the economic concept of PHES relies upon the price difference between offpeak and on-peak electricity prices as well as gaps between the generation and demand. Pumping of water and regeneration of power generally follow one day (24 hours) cycle. Weekly or seasonal cycles are also possible with the large capacity of PHES plants. An ideal pumped hydro site should have the following characteristics (Grieco and Brierley 2012):

- Large elevation difference to create potential head between the two reservoirs;

- High installed power capacity;

- Large energy storage capacity (preferably four hours or more at rated power);

- Negligible adverse environmental impacts;

- Proximity to a power substation or transmission lines; and

- Access to the major electricity market. 
The ideal PHES sites having all the above characteristics rarely exist. The US Army Corps of Engineers differentiates conventional PHES plants into two categories, pure PHES plants, and pump-back PHES plants.

Pure PHES plants entirely rely upon water that has been pumped to an upper reservoir from a lower reservoir. Pure PHES plants are also known as 'closed-loop' or 'off-stream' pumped storage facilities (Deane et al. 2010).

Pump-back PHES plants use a combination of pumped water and, simultaneously, the natural inflow of water to produce power similar to a conventional hydroelectric power plant. Pump-back plants may be located on rivers or valleys with glacial or hydro inflows. Figure 2.1 shows a schematic diagram of conventional technology for a pure PHES plant and a pump-back PHES plant.

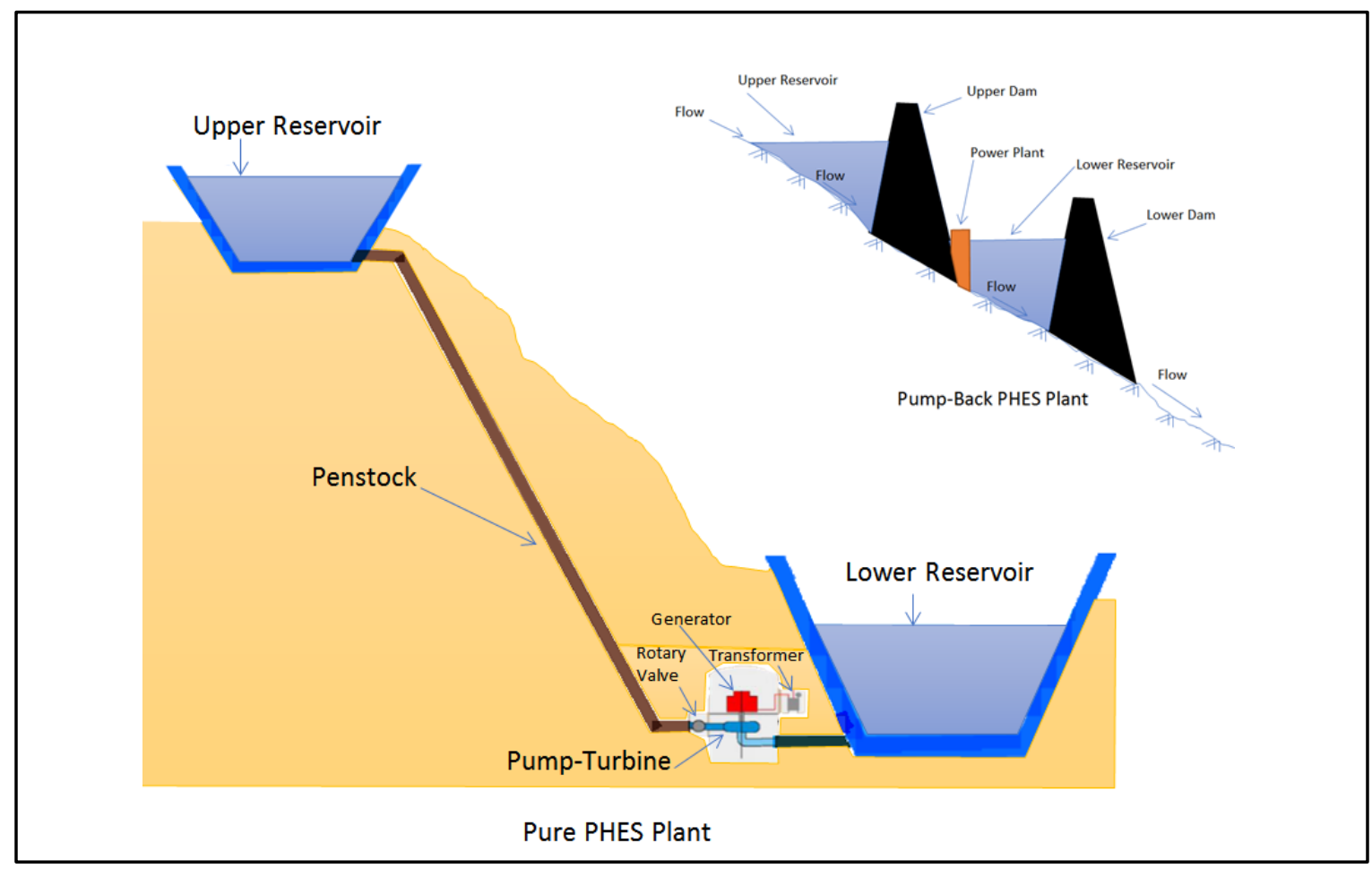

Figure 2.1 Schematic diagram of pure and pump-back PHES plants

Initially, the PHES plants were constructed using a single penstock system as they were designed for the purpose of maximizing the electricity generation from base-load power plants. When PHES plants are designed specially to integrate with fluctuating renewable energy resources, these facilities can be used for additional benefits in both charging and 
discharging modes at the same time. As shown in Figure 2.2, it can be achieved in a single PHES facility by installing two penstocks. This system allows energy charging with one penstock and discharging with other penstock at the same time. The combined unit of double penstocks system of PHES plants with renewable energies of intermittent nature becomes more promising in providing reliable power supplies thereby enhancing the opportunities of integrating wind and solar power in the grid system. The study by Connolly et al. (2012) has shown that both of these operating strategies were used to simulate storage capacity of $25 \mathrm{GWh}$ (equivalent to installed rated power of $2500 \mathrm{MW}$ ) with 10 hours operational period PHES facility on a projected 2020 Irish energy system.

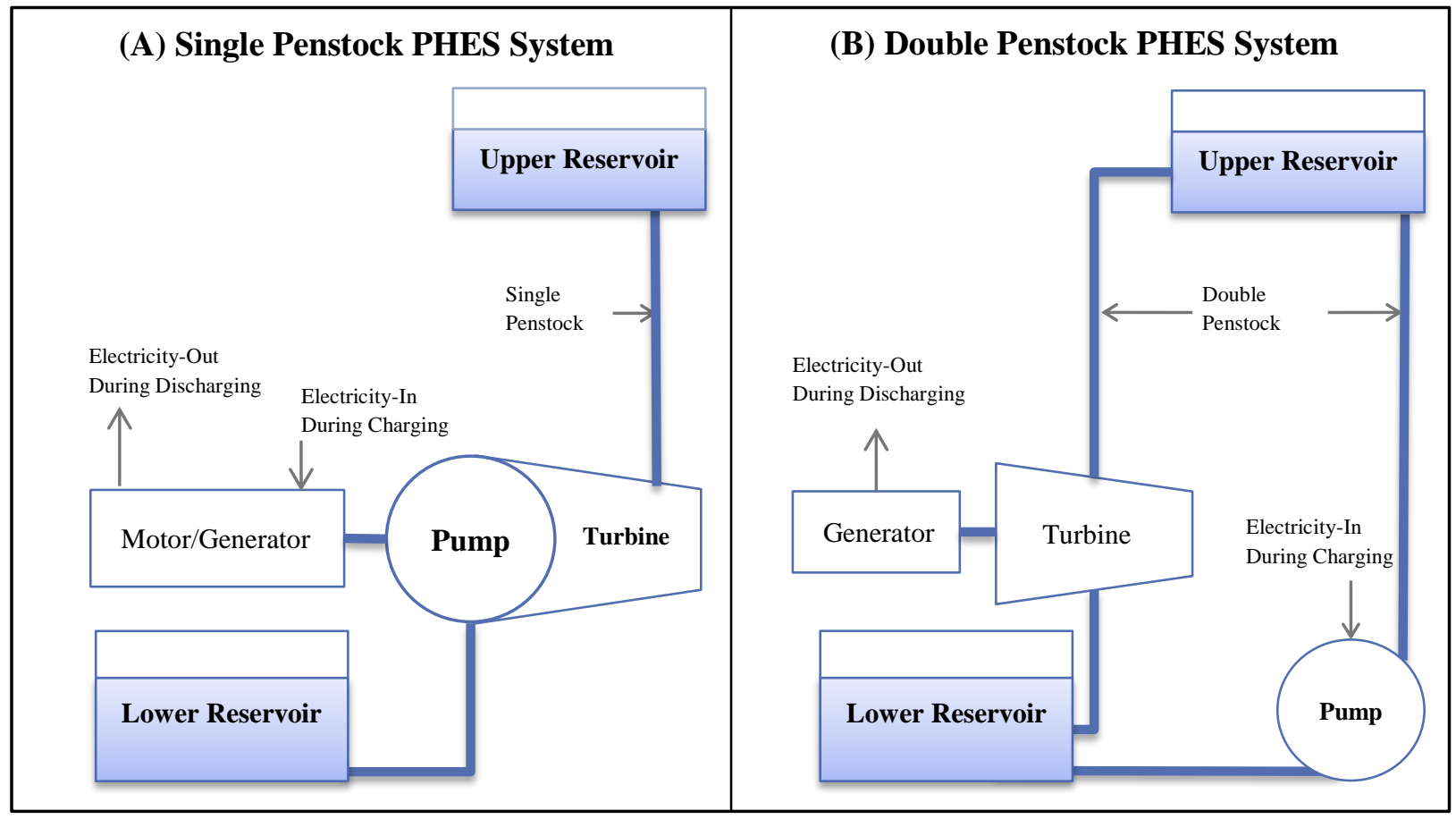

Figure 2.2 Schematic diagram showing single and double penstock in the PHES system

The flexible generation of PHES plants can provide both up and down regulation in the power system and additionally, their quick start competencies make them quite suitable for the black starts as well as fully satisfying the requirement for provision of spinning and standing reserves.

The PHES plants are generally used for peak load management. They are inherently well matched with renewable energy resources to offset their intermittency and uncertainty nature. PHES can firm up the electricity generation forecast when it is used in conjunction with renewable energy resources. The developers who already have their existing hydroelectric 
generation or own PHES facilities are focusing on modern efficient equipment and technologies to increase the operational efficiency of their existing plants (Deane et al. 2010).

\subsection{Technological Advancement in the PHES System}

The large-scale storage is a promising facility with emerging technologies since it can enhance the sustainability, reliability and asset utilization of large electricity systems at grid level. Several studies revealed that over the last decade, these technologies have shown considerable technical improvements with a significant drop in their production cost.

The large size energy grid deals with the slower time scale based energy storage. For a reliable grid system, the investment decision problems of selecting, sizing and placement of distributed energy resources are gaining importance. According to Hoffman et al. (Hoffman et al. 2010), it is critical to assess the technical and economic attributes of energy storage specifically reflecting the operational demands and opportunities presented by the smart grid environment.

For a large size energy grid system in the USA, the traditional pumped-turbine equipment was reversible single-stage Francis pump-turbine which acts as a pump in one direction and as a turbine in the other direction of discharging mode. The energy produced in discharging mode does not operate at peak efficiency during part load. The modification in speed allows the turbine to operate at peak efficiency over a large portion of its operational band. The increasing trend of utilizing the renewable energy has greatly focused on large size energy storages having novel adjustable speed pumping which is capable of adjusting the input power when carrying out automatic frequency control (AFC) while filling the upper reservoir. This flexibility is frequently employed by adjusting the speed of the pumping unit during light load periods. In addition, pump operation with adjustable speed enables more real-time response to grid conditions (NHA 2012).

Various studies including Connolly et al. (2010), Fitzgerald et al. (2012), ROAM Consulting (2012), Gimeno-Gutiérrez and Lacal-Arántegui (2015), Jiménez Capilla et al. (2016), and Rogeau et al. (2017) have described that the conventional PHES has attained the dominance in its maturity, durability, efficiency, large-scale, and cost-effectiveness along with the aforementioned significant advancements of adjustable-speed pumped storage technology. However, despite the dominance, it has a limited capacity of expansion as the sites needed to 
develop such facilities are few and far between. The limited availability of suitable sites with considerable environmental constraints prevents sufficient expansion of conventional PHES plants to meet future bulk storage requirements of electricity system operation throughout the world. In order to address this problem, a new concept of gravity power module (GPM) technology has emerged in recent years. This technology claims to overcome the limitations of facility siting, difficulties in permitting, time to secure land, secure transmission access, and upfront cost of construction.

The following sections describe the details of technological advancement in conventional PHES system and a newly emerged GPM technology, which is technically suited for bulk energy storage applications.

\subsubsection{Conventional PHES with Adjustable-Speed Pump-Turbines}

The term single speed was used to describe the conventional pumped storage units with synchronous speed machines. Presently, adjustable-speed generation system has been introduced using conventional PHES plants to modulate input pumping power and provide significant quantities of frequency regulation. In Japan, the use of the term variable speed is common, but in Europe and other parts of the world, the term adjustable speed is often used.

In Japan, the Okkawachi power station has the largest units that have been built with machines rated for 395 megavolt ampere (MVA) and with $72 \mathrm{MW}$ cycloconverters for the motor circuits. Similarly, in Europe, the Goldisthal power plant in Germany was commissioned with two 300 MW variable-speed units (Guzman 2010).

The adjustable-speed pump turbines provide the innovative integrated solutions using asynchronous motor-generator that allows the pump-turbine rotation speed to desired adjustable mode. As a result, the plants benefit from a high level of additional power flexibility including:

- Regulation of the amount of energy in pumping mode that facilitates energy storage when low power is available on the network. It reduces the number of starts and stops and most importantly, allows the selling of grid regulation service for network frequency and voltage;

- Operating closer to the optimal efficiency point of the turbines; 
- Smoother operation at partial loads and elimination of operation modes that are prone to hydraulic instability or cavitation;

- Operating over a wider head range; and,

- Instantaneous power output adjustment is helpful to rectify sudden voltage variations caused by network problems.

These benefits result in improved profitability of the storage plant owners and simultaneously, allow the network operators to improve grid reliability and quality of the power supplied to the end users.

Fen et al. (2012) tested a variable-speed turbine at the Hydraulic Machinery Laboratory (LAMH) at Laval University, Canada and a $300 \mathrm{~kW}$ prototype turbine was manufactured and installed in Ontario, Canada. This study further explained the technical advancement of this technology that this next-generation turbine is designed to operate at optimal rotational speed with varying flow rates to increase efficiency, improve fish survival and reduce overall costs.

\subsubsection{Gravity Power Module (GPM) System}

Presently, this technology is in its developing stage and needs feedback from the users. The developer believes that underground PHES system based on GPM technology can increase the storage capacity by adding mass and/ or the storage height. The developer claims that this new technology exploits widely available analogous sites by using the proven technological components of pumped hydro storage in a completely new way (Peltier 2013). This technology has considerable flexibility for size and depth of the storage unit and it is relatively easy to identify a potential site since it requires a considerably smaller area as compared to conventional PHES technology. Moreover, the facility could be expandable for meeting the increased energy storage demand. However, this technology needs to gain experience with its newly emerging technological background. Figure 2.3 shows a schematic diagram that explains the applied principle of GPM technique for energy storage at the grid scale. 


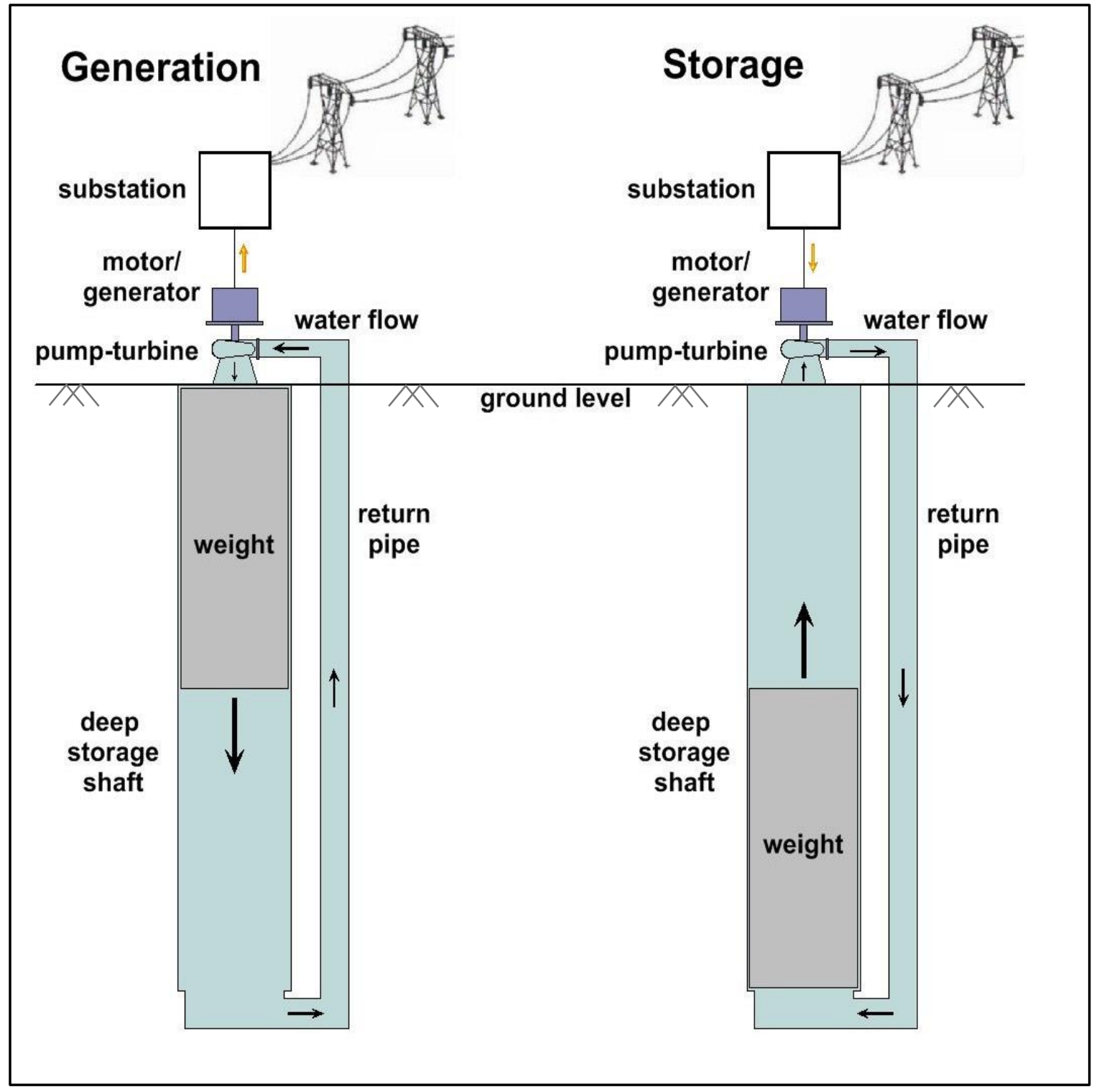

Figure 2.3 Schematic diagram showing GPM storage and generation at grid scale Source: (Grieco and Brierley 2012)

The gravity power company has devised a system that relied on two deep water-filled shafts, one comparatively much wider than the other. These shafts are connected directly at the lower end and at upper end through a pump-turbine unit. The wider shaft is the main water storage and the other shaft is working as a penstock. The main storage shaft is employed with a heavyweight piston and stores the clean water underneath the piston that moves vertically within the shaft to regenerate the energy through attached Francis Turbine unit. The smaller shaft (penstock) works as a return pipe and connects the piston shaft to the Francis pump-turbine installed at ground level. The system is filled with clean water only 
once and sealed. In power generation mode, the heavy piston falls and forces the water through pump-turbine to generate the electricity. In storage mode, the grid electricity drives the pump-turbine that forces at base plate of the piston to move it upward direction in the shaft. In this way, this completes the cycle of storage and regeneration of the energy. The main components of a GPM unit include:

- Main shaft

- Single piston (steel-lined)

- Piston base plate (reinforced)

- Penstock/ return pipe (steel-lined)

- Seal system

- Piston positioning devices

- Powerhouse

- Power equipment

The developer claims that the GPM facility can place many units at one site area to satisfy the storage demand. The units can be constructed either in a circular form or in parallel rows in the same area.

The Gravity Power (2014) presented a schematic diagram of building 160 MWh (40 MW x 4 hours) GPM unit to be constructed in Germany as shown in Figure 2.4. The construction components include powerhouse shaft, main shaft, turbine shaft, the piston of native rock and shaft for lower vertical conveyer. 


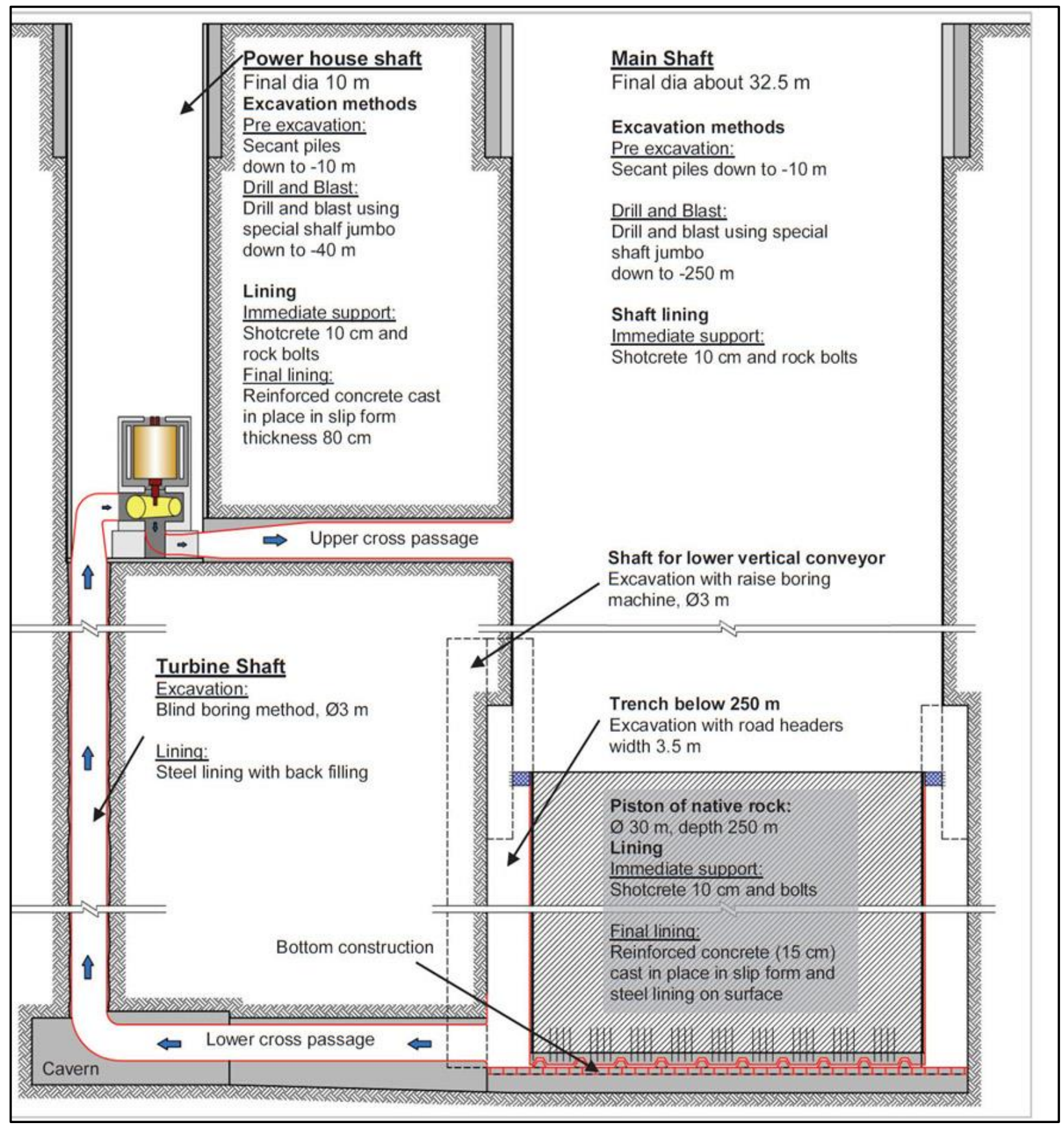

Figure 2.4 Schematic diagram showing construction details of GPM facility

Source: (Gravity Power 2014)

This research assumes that GPM technology is passing through its initial experience mode and, therefore, the market test report is still awaited for future comments. The information discussed in this report is available online at the website provided by its developer, Gravity Power LLC, California, USA. It is important to note that the present findings are based on the preliminary development stage of this technology which needs to be verified by the industrial users. 


\subsubsection{Selection of Turbines for PHES System}

In general, the available net head is used to select the type of turbines that are suitable for a particular site of a PHES plant, whereas the rate of flow determines the capacity of the turbine. Hydraulic turbines are generally classified as reaction turbine and impulse turbine which are briefly explained below.

\section{(A) Reaction Turbine}

This turbine operates with its runner that is fully flooded and develops torque due to a reaction of water pressure against the runner blades (Thapar 2002). The reaction turbines are further classified into the following two categories:

(a) Mixed-Flow Turbine: This turbine is called as Francis turbine

(b) Axle-Flow Turbine: This turbine is further classified into two categories on the basis of its blades type. The turbine with fixed blades is called as propeller turbine and the turbine with variable pitch blades is called as Kaplan turbine.

\section{(B) Impulse Turbine}

This turbine operates with its runner in the air and converts the water pressure energy into kinetic energy of a jet that impinges onto the runner buckets to develop the torque. Typical examples of this turbine are Pelton turbine, Turgo turbine and Cross flow turbine. Table 2.1 provides typical turbine types that are generally selected for various net head ranges.

Table 2.1 Turbines types based on various head ranges

\begin{tabular}{|llc|}
\hline Head Range & Turbine Type & Source \\
\hline $2 \mathrm{~m}$ to $40 \mathrm{~m}$ & Kaplan and Propeller turbine & 1 \\
$5 \mathrm{~m}$ to $200 \mathrm{~m}$ & Cross flow turbine & 1 \\
$15 \mathrm{~m}$ to $300 \mathrm{~m}$ & Turgo turbine & 2 \\
$15 \mathrm{~m}$ to $750 \mathrm{~m}$ & Francis turbine & 2 \\
$50 \mathrm{~m}$ to $1300 \mathrm{~m}$ & Pelton turbine & 1 \\
\hline
\end{tabular}

Source 1: (Otuagoma 2016)

Source 2: (Thapar 2002)

Thapar (2002) reported that Francis turbines generally exist in large numbers throughout the world as shown in Table A-1 of Appendix A. It is also reported that this turbine can be applied for power ranges from $0.25 \mathrm{MW}$ to $800 \mathrm{MW}$ per unit. 


\subsection{Review of Spatial Decision-Support Tools for PHES Siting}

Recent advances in GIS tools, GIS data and computing power have made it possible to comprehensively analyze and identify the feasible PHES sites which can be further tested for economical consideration to select the preferred sites. The literature review shows that the GIS techniques are effective, efficient and convenient for the engineers and scientist community to select the feasible sites of different nature facilities and for the decision-makers in policy plan and decision-making process. However, the intensity of the use depends on the detail of data needed and the assumptions behind the methodology of model development. Once the model is developed, improvements could be effectively applied with minimum efforts.

There are examples of using GIS platform to identify site locations of different facilities like small hydropower potential and PHES plants. The GIS-based approach is also used to assess the renewable energy potential such as wind and solar energy. The review of different GIS-based studies has been summarized below.

A computer program was developed by Connolly et al. (2010) to locate potential PHES sites using digital terrain model (DTM) in South West of Ireland. The program was used to evaluate a $20 \mathrm{~km} \times 40 \mathrm{~km}$ study area. The study identified five potential sites with a storage capacity of 8634 MWh. The results obtained from this study were discussed and concluded that the program was a positive step for identifying the new PHES sites. The actual code of the program was written in $\mathrm{C}++$ language that had taken 4 hours to cover a small area of $1 \mathrm{~km}^{2}$. The author, therefore, suggested that this program can be improved for many aspects like the use of fast processing tool such as the present GIS technique. This program has not considered the environmental constraints, the ranking of identified sites and the geology of feasible sites. Therefore, the efforts of this study were simply limited to only identify the preliminary site locations that needs further work to select the feasible PHES sites.

Larentis et al. (2010) employed GIS-based procedures for spotting and selection of hydropower potential in Brazil. This research presented a methodology for a large-scale survey of hydropower potential sites. The survey methodology developed a GIS-based computational program that was named as 'Hydrospot'. This program consists of the identification of potential sites in the river basin, pre-feasibility assessment and selection of the final sites. The study 
concluded that the application of this program has shown some limitations of Hydrospot and potentialities for mid-term and long-term planning of the electricity sector. However, the program was suitable for the short-term planning process. This study considered only the constraints covering topologic, hydrologic and legal characteristics in the survey phase of the planning stage. The methodology has not included the ranking of sites. The scope of the study was limited to the pre-feasibility stage and, therefore, further work is needed to include project costing to analyze the economic feasibility of finally selected sites.

Fitzgerald et al. (2012) developed a GIS-based methodology to calculate the potential for transforming conventional hydropower schemes and non-hydro reservoirs into PHES schemes. The methodology was tested on a case study of Turkey to produce country-level estimates of the theoretical and realizable PHES potential for such transformations. It was reported that more than 3800 GWh realizable energy storage potential was identified from over 400 sites in the country. This study presented a comprehensive methodology considering only the dams as primary reservoirs, excluding other options of waterbodies like lakes and rivers. Similarly, the geology of identified sites was not considered while applying the other constraints. Also, the identified sites were not ranked to facilitate the decision makers for developing sites on a priority basis. The total realizable potential has no link with the existing energy potential that does not provide the opportunity of conducting the feasibility analysis of identified PHES sites.

The GIS technique was used to assess the potential of PHES development in Australia. ROAM Consulting (2012) conducted this study for developing a GIS-based model to identify all feasible PHES sites to utilize $100 \%$ capacity of the renewables in the country. The approach of building both new upper and lower reservoirs was given less consideration in this study. The methodology was, therefore, developed from constructing only one reservoir in the vicinity of an existing reservoir. The assumed criteria included: horizontal distance $3.5 \mathrm{~km}$ between the two reservoirs, elevation difference $90 \mathrm{~m}$ between existing waterbody and the newly identified reservoir site, and wall height $30 \mathrm{~m}$ to $90 \mathrm{~m}$ of the new reservoir. The estimated cost was based only on the costs of dam walls, penstock/ tunnel, and pump-turbine including mechanical and electrical works. The capital cost using cost parameters for a 500 MW PHES plant was estimated at $\$ 3200 / \mathrm{kW}$. This study also included the option of seawater pumped storage in elevated valleys above the sea. 
The adopted assumptions are on the high side that restricts the available possible potential sites at the low head with wall heights less than $30 \mathrm{~m}$. Similarly, cost data includes limited individual cost components that do not give a clear picture of the costs. This study has not considered the screening of preliminary identified sites and directly provided the ranking of these sites.

Arántegui et al. (2012) discussed a GIS-based methodology using a digital elevation model (DEM) and the data of existing reservoirs including geographical coordinates of the dams and their water storage capacity. The GIS-based technique was used to assess the PHES potential in Europe. This report provided different possible scenarios of topologies to analyze new potential PHES sites. This study also presented a summary of the experts' discussions in a workshop held in the Netherlands in April 2012 on the assessment of the potential of pumped hydropower storage. Although, the recommendation covered a lot of aspects, the ranking criteria for final selection of sites while identifying more than one site for a primary reservoir and the cumulative impact of various sites in an electricity region was not discussed.

In a research study, Cortines (2013) has developed a GIS-based methodology to investigate the PHES potential in Norway. This study identified feasible PHES sites for existing primary reservoirs using assumed parameters. However, it was reported that the developed GIS tools need a deep study to establish new parameters for the user. This study used a GIS tool to locate only very specific characteristics of the pumped hydro facilities. This study considered the topology of the existing two reservoirs only to make the project economical and to avoid environmental concerns. Hence, GIS is used to simply locate the feasible link of two existing reservoirs in close vicinity. The screening involved limited calculations for the restricted parameters including distance from the lower reservoir to the power line, the distances from both reservoirs to nearest roads, gross pressure height, power production capacity, and the penstock/ tunnel length. The cost calculation used a rough estimation of some individual cost components including civil work, mechanical equipment, and electro-technical work.

Gimeno-Gutiérrez and Lacal-Arántegui (2015) assessed the PHES potential in Europe based on two existing reservoirs using GIS-based model. Theoretical and realizable potentials were computed for various European member countries using different scenarios by linking two existing reservoirs. The scenarios considered the distances of $1 \mathrm{~km}, 2 \mathrm{~km}, 3 \mathrm{~km}, 5 \mathrm{~km}, 10 \mathrm{~km}$ 
and $20 \mathrm{~km}$ in between the two reservoirs. The results have shown that the theoretical energy potential of 54 TWh was achieved with a maximum distance of $20 \mathrm{~km}$ between the considered existing reservoirs. After applying different constraints, the maximum realizable potential was 29 TWh which is around $50 \%$ of the theoretical potential. The study claimed that the theoretical potential is the best representation in the identification of PHES sites because the environmental impact on penstock and powerhouse can be very small. This study presented a limited scope of topologies using only the existing reservoirs. The PHES potential can be increased by including other topologies. The geology of the area can provide a better economic impact on the feasibility of the projects. The project cost could be more realistically estimated by considering various other individual cost components which can give better ranking results.

Palla et al. (2016) used GIS approach to assess the mini hydropower potential (MHP) at the Arrosica catchment area located in the western side of Liguria Region in Italy. This study performed a catchment morphometric analysis by setting the criteria for hydrological modelling to locate the weirs and power houses. Based on the defined criteria in the GIS tool, all the potential alternatives of 27 weir sections and related power houses were examined to figure out the optimal solution. The study concluded that GIS-based MHP analysis is a powerful tool to better support energy management strategies. The assessment can be strengthened by considering spatial data pertaining to actual water resources such as existing water concessions to ensure sustainable water resource management. It is important to note that aquatic ecosystems are generally disturbed due to the consequent impacts of big water falls. The GIS approach can be better utilized to control such type of problem by dividing the same river network into different reaches as cascades and developing small PHES plants on the reaches. Therefore, meticulous planning could be adopted by controlling the spatial distribution of water intakes.

Jiménez Capilla et al. (2016) determined the optimal locations of the upper reservoirs for PHES plants using AHP-based GIS application and multicriteria analysis (MA) for a selected area in South Spain. This typical technique used the weightages assigned to various factors and indicators following the analytical hierarchy process. The most important factors that affect the location, were considered as elevation difference, penstock length, geology, excavation work, existence of the base reservoir, power station allocation, distance to the transmission line, and proximity to low-cost electricity generator like a wind power plant. This study considered the 
suggestions provided by Arántegui et al. (2012) for broad site selection and screening steps. However, this work has not included any explicit economic evaluation and a final ranking of sites. Similarly, this work has only assigned the weightage of bedrock geology at the initial stage of site location work but actual data such as bearing capacity of the bedrock was not considered in the site identification process. All the types of existing waterbodies as primary reservoirs were not considered. In this regard, only the case of existing dams was considered. This work has not considered the aspects such as: (i) the geometry of PHES reservoir using dimensions of identified sites to determine the theoretical or realizable energy potential, and (ii) the capital cost and estimates of financial returns, prior to and after commissioning of the project, respectively to analyse the specific techno-economic feasibility of the study.

Rogeau et al. (2017) designed a generic GIS-based method to evaluate global PHES storage capacities at large-scale. The proposed method was applied to a test case study of France. The study estimated potential of $14 \mathrm{GWh}$ for small PHES developments by considering only existing lakes, and $33 \mathrm{GWh}$ energy potential when both lakes and depressions were considered. These estimations presented $8 \%$ and $18 \%$ of the current hydro storage capacity respectively in France. This study employed limited constraints application for screening of sites such as No-go zones for excluding pairings in sensitive areas and application of a structural filter for technical estimations such as the maximum distance between lakes, minimum head, maximum volume, etc. This structural filter was defined for evaluation of the realizable energy potential. This study also presented an optimization of the inter-connected pairing of two reservoirs to obtain noninterconnected pairing. The evaluated potential can hardly qualify the PHES schemes at utility scale. However, this potential may be useful for non-utility or off-grid areas such as for remote communities. The waterbodies like dams, medium or big lakes or rivers were not considered that ignored a considerable identifiable energy potential. Further, proper environmental constraints were not considered to identify feasible reckoned sites. The cost criteria or ranking of sites were completely disregarded in this study. Also, the study did not include necessary infrastructures such as the roads and transmission lines and bedrock geology for the screening of the sites.

Soha et al. (2017) analyzed the energy potential of small-scale PHES sites of the middle mountain region in Hungary. This study considered a small study area and applied only the restrictions of nature conservation areas. This study, therefore, lacks in applying all necessary 
restrictions for screening and ranking of preliminary identified sites and evaluating the project costs for the economic perspective of PHES schemes.

In order to summarize the gaps of above literature review, the past studies lack in identifying the combined PHES potential using all types of existing waterbodies such as dams, lakes and rivers as primary reservoirs in an existing large electricity market region. The abandoned mines have rarely been considered to explore the economic potential of PHES sites. Necessary environmental and other constraints have not yet applied to such a large electricity region area in most of the studies. The individual cost components and their realistic estimates are mostly missing for ranking the sites to select the most feasible sites. Therefore, there is a need to comprehensively address the missing aspects.

\subsection{Review of Optimization for PHES Scheduling}

There are studies that conducted optimization scheduling of pumped storage utilization with wind energy, solar energy, thermal generating units and nuclear power plants. The scope of work of the studies covered different objectives such as the evaluation of operational benefits of PHES plants, planning process of probabilistic energy production costs, expansion of electricity operation system, solving unit commitment problem, the operation of PHES plants using small and large reservoirs with continuous time-varying environment, etc. The studies assumed different optimization periods such as one day, weekly, yearly or sub-yearly according to their case study requirements. The review on the optimization of PHES scheduling for different studies has been provided below.

Galloway et al. (1966) investigated the pumped storage scheduling to optimize the reservoir size, the influence of cycle efficiency on PHES capacity factor and operating cost, and effect of load forecasting deviations on system economy. The optimum schedule was derived with an assumed PHES capacity of $6000 \mathrm{MWh}$ for a rated power of $600 \mathrm{MW}$ with 10 hours operation cycle. The study concluded that a little operating cost benefit was achieved for more than 10 hours rated generation and small deviations from the optimum schedule did not increase the operating cost. A large effect was noticed for the deviations in load for a fixed generation schedule. However, the system was optimized for only thermal generation with an installed capacity of $8700 \mathrm{MW}$ 
over a one-day period. This work has not considered the storage effect of other aspects such as surplus baseload for a nuclear generation or the storage of realizable potential of wind energy.

Ko et al. (1982) applied the optimization model using linear programming to evaluate the PHES policy in New York State, the USA for the intended planning study of electricity capacity expansion in near future. The results have shown that the present storage expansion plan up to $200 \mathrm{MW}$ may be justified with a $15 \%$ capacity factor. In this optimization model, the PHES unit was the part of the load section to balance the power generation from all generating units and total power demand including by the PHES plant. The PHES efficiency was considered as $75 \%$ and the stored energy capacity was $10 \%$ greater than that of discharging energy. This work did not consider the economic feasibility of PHES plant. Similarly, the option of combining renewable energy sources in energy generating units was not covered.

An algorithm presented by Conejo et al. (1990) for optimization of storage utilization of pumped hydro in a planning process of probabilistic production costing, proved that it is a significantly more efficient implementation of the building blocks of past algorithms. This study addressed the planning aspects of PHES plants integration for optimally utilizing the storage capacity in MWh and the extent of power generation in MW on a long-term basis. The utilization of reservoir capacity during a specific period like yearly or sub-yearly and to find the priority order of charging the reservoir in the presence of multiple reservoirs was studied as a medium-term decision. Similarly, the strategy to dispatch the generating system was determined as a shortterm decision. However, a complete solution of the storage problem is still needed to be addressed that requires growing determination of charging/ discharging order and to handle the cases of competing for two or more charging storages for the same thermal unit.

The study by He (1997) presented an optimization model for evaluating the operational benefits of PHES plants in China. The operational benefits include the electricity efficiency from pumped water, improvement of the overall units, and the increase of peak load capacity. In quantitative terms, PHES provided an average decrease of $5.1 \mathrm{gm} / \mathrm{kWh}$ coal consumption and a $600 \mathrm{MW}$ peak capacity for the Shanghai electrical network. Although the study addressed the PHES benefits to reduce the thermal generation during peak load hours and simultaneously consuming 
surplus off-peak electricity, the possible option of integrating renewable energy was not considered that could further reduce the oil consumption in thermal power plants.

Chen et al. (2008) used particle swarm optimization (PSO) model to solve the PHES scheduling problem. This approach combines the basic PSO with binary encoding/ decoding techniques as well as a mutation operation. These techniques were adopted to model the discrete characteristics of PHES plants during pumping mode and continuous characteristics in generating mode. The problem was formulated with water dynamics and the system constraints to seek the optimal generation schedules for both pumped hydro and thermal units. The author claimed that the proposed approaches have highly attractive properties and robust convergence behaviour for practical applications. This study utilized the PHES to provide spinning reserve requirements of the system and saved the thermal cost. The optimization was based on 24 hours schedule. The study was limited to simply cost savings of the operator. However, the economic feasibility of PHES units was not covered.

Aihara et al. (2012) evaluated the optimal operation scheduling of PHES plant with photovoltaic (PV) power generations which was expected to have an important role in future. The optimization was based on weekly scheduling using efficient economic load dispatching (ELD) in the optimization algorithm. The simulation results confirmed that the proposed method was very effective in terms of fast computation. However, this study has not considered the hot reserve capacity in the scheduling of thermal power plants.

Bose et al. (2012) studied the optimal placement of energy storage in order to maintain a consistent power supply in the grid while utilizing intermittent power resources. This study also evaluated the effect of storage capacity and power rating on generation costs and peak reduction using IEEE 14 and IEEE 30 bus benchmark systems. It resulted that energy storage provided flexibility to the power system and mitigated various concerns including power quality, stability, load following, peak reduction and reliability. This work represented a preliminary effect of wind power generation with zero marginal cost and varying storage budgets. However, the study has not discussed the sensitivity of the results to the selected wind profiles, effects of storage efficiencies, and their economic feasibility. 
Poullikkas (2013) carried out technical and economic analysis regarding the integration of PHES plants in a small isolated island power system in Cyprus. The optimization of PHES was employed using WASP IV software package which is widely used for optimum expansion planning of a generation system. In this study, the expansion plan was optimized for a given power generation system over a period of up to 30 years. The expansion planning included future candidate generating plants in addition to existing generation units. The cost components of both existing and future candidate generating units include fuel costs, fixed O\&M costs (such as staff cost, insurance charges, rates and fixed periodical maintenance), variable O\&M costs (spare parts, chemicals, oils, consumables, town water and sewage, etc.). The cost of energy not served (ENS) because of a shortage of capacity or interruptions was also taken into consideration. This study covered various aspects of both conventional generating units and renewable energy resources, but the features of PHES regarding the costs and possible services were not covered. The study results indicated that use of PHES system can be beneficial under certain parameters for the large-scale integration of renewable energy sources. However, there are many features which are beneficial to the system operation, like reducing problems of start-ups or shut-downs of conventional units and providing ancillary services. Similarly, collective use of PHES units can be useful for a big electricity system at grid level to make a reliable and secure power operation system.

The optimal power flow (OPF) problem optimizes a cost function, like generation cost and/or user utilities over variables such as real and reactive power outputs, voltages, and phase angles at a number of buses subject to capacity and network constraints. Gayme and Topcu (2013) proposed a formulation for OPF with storage dynamics along with a strategy to efficiently compute its optimal solution. This computational procedure was used to investigate the effects of different energy storage capacities and power rating on generation costs and peak reductions using modified versions of the IEEE 14 and IEEE 30 bus benchmark systems. In order to carry out these investigations, an OPF problem was formulated with simple charge/ discharge dynamics for energy storage as a finite-time optimal control problem. The resulting optimization problem was solved using KKT conditions and Lagrangian multiplier techniques with storage dynamics. However, this study investigated only the impact of large scale integration of energy storage. The assessment of the energy storage system was not employed to evaluate the issues 
like minimizing the energy losses at the grid level, reducing the need for transmission capacity expansion. Particularly PHES system can be assessed to address various concerns of the existing system such as the reliability, power quality and stability, load following, peak reduction, guaranteed reserve services like spinning reserve requirements.

The power systems have set ambitious targets for the integration of renewable energy into the grid system. Several jurisdictions provided incentives for integration of renewables such as the Feed-in-Tariff (FIT) in Ontario, Canada. These incentives are helpful for the renewables to competitively sell energy into electricity markets while overcoming the uncertainty and variability in their output. In order to follow this highly incentivized policy in Ontario, Opathella and Venkatesh (2013) proposed a Wind Generators Cooperative (WGC) model to trade in wind energy by using a combination of planned storage facilities with various wind farms that are geographically dispersed. A model to maximize the profits of the WGC was presented using a case study of Ontario, Canada. This study resulted that the WGC was benefited by a reduction in uncertainty, the temporal shift of energy and firm energy production capacity. However, this study worked out only the possible benefits for wind power plants and PHES plants were used as the rented units irrespective of their individual profitability or cost-effectiveness.

The study by Murage and Anderson (2014) developed a mathematical model using an optimal control approach to maximize the expected revenue of wind farm operators by integrating PHES with wind power into the Kenyan power system. The optimization problem was developed assuming wind power producers to be the independent producers and agreed to produce a fixed quantity of power per hour throughout the day and referred to as the committed power. In case of failure, the penalty was assumed to be charged on a per$\mathrm{kW}$ basis and is varying on a deterministic basis. This study resulted that extra generation can be stored using associated PHES plant or sell to the electricity market at a lower price. This study also resulted that if wind energy is optimally combined with energy storage, it can be more predictable, controllable and resulting in future benefit to the power system. However, this study simply used the beneficial role of PHES storage capacity and technoeconomic aspects of PHES were not evaluated. 
Ming et al. (2014) studied on solving the unit commitment problem (UCP) considering the integration of wind power and the PHES system. The proposed approach was implied on a system of ten thermal units, one wind power unit, and one PHES station. The study resulted that the most cost-optimal units can maintain on-line status in dispatching cycle, the economic benefit of UCP with PHES station was better than UCP alone, and a change of net load was observed because the difference between peak loads was reduced due to the regulation of PHES plants. However, this study considered very limited capacities of wind power and the associated PHES plant to compare the economic benefit of UCP with and without the PHES system. The scenario of the increase in wind power plants with a corresponding increase in PHES units was not considered to address the increasing trend of utilizing the renewables.

Sousa et al. (2014) studied the impact of PHES unit in price-maker mode on the integration of wind power in the electricity market. This study modelled and computed the optimal PHES weekly scheduling in both scenarios of price-taker and price-maker modes using PHES in standalone and integrated with other generation plants particularly wind and thermal power plants. The study concluded that the price-maker mode of PHES, under the standalone situation, integrated less wind power in comparison to price-taker mode in the same satiation. The optimization of PHES scheduling was conducted for a one-week period that may differ from a bigger period like one year that involve different seasons and different levels of demand and supply. The O\&M costs of both PHES and thermal power plants and the fuel costs of thermal power plants were assumed null that does not represent a realistic situation.

Vojvodic et al. (2016) developed the optimization model to obtain forward generation thresholds for operating a PHES plant in the real-time energy market with uncertain system prices over the next three days. The study resulted that the forward thresholds obtained using a stochastic programming framework was better than the forward thresholds from a deterministic model that can lead to efficiency gains for both the PHES plant owner as well as the overall system in the real-time electricity market.

Steffen and Weber (2016) derived operation programs for PHES plants using large and small reservoirs with the continuous time-varying environment but deterministic power prices. The model was applied on a case study of Germany that concluded that the profit potential from time 
spread arbitrage decreased significantly during 2008 - 2011 due to reduced variation in power prices which were reduced because of increasing renewable and thermal generation capacities. However, this study proved that the economics of energy storage is an important element of future power generation portfolios.

The review of the above studies shows that a combined effect of total feasible PHES potential has not yet optimized to test the cost-effectiveness of energy storage services in an electricity market system at grid level. Similarly, the financial feasibility analysis is also missing to test the financial viability of integrating the PHES system into an existing electricity market system. The missing aspects are highly needed to address in the present situation of electric power industry while it is passing through its transitional stage of increasing utilization of renewable energy resources and reducing the dependency on peaking thermal power plants. Therefore, there is a need to test the techno-economic effectiveness of all feasible potential in an existing large electricity market system.

\subsection{Review of PHES Costs}

\subsubsection{General}

The development of a new PHES project is generally divided into two stages for estimation of its total project cost. The first stage covers the initial investment cost which is incurred before the commissioning of the project. This cost is known as the capital cost of the project. The second stage starts after commissioning of the project that mainly covers the operation and maintenance $(\mathrm{O} \& \mathrm{M})$ cost, which is a regular expense to be incurred during the whole life period of PHES plant. Additionally, there are some other costs which are common in both stages of the project. The sum of these costs is known as owner's cost. In this way, the total cost of a PHES project is divided into three cost categories having different individual cost components as outlined below (IEA 1991; US Energy Information Administration 2010).

\section{Capital Cost}

The capital cost is divided into three parts as given below:

\section{Pre-Construction Cost}

- Land and land rights

- Assessment

- Design 
- Permits

\section{Construction Cost}

- Reservoir (Embankment dam of concrete, earthen or homogeneous material, excavation, earth transport)

- Penstock

(Pipe cost including transport and installation, tunnel excavation, earth transport, concrete foundation if installed on the surface)

- Equipment

(Pump, turbine, motor, generator, valves, governors, static and starting equipment)

- Civil structures

(Building, yard, power station structure and auxiliary structures)

- Powerhouse equipment

(Accessories of the electrical power plant, substation equipment, etc.)

- Transmission facilities

(Transmission lines and transformers)

- Access roads

\section{Indirect Cost}

- Undistributed construction expenses

- Engineering and project management

- Overhead/administration expenses

- Contingencies

\section{Operation and Maintenance $(\mathrm{O} \& M)$ Cost}

- Fixed O\&M cost

- Variable O\&M cost

\section{Owner's Cost}

- Property taxes

- Asset management fees

- Energy marketing fees

- Insurance 


\subsubsection{Defining the Unit of Energy Storage Cost}

The critical issue with storage technologies is that the storage devices have both components of power and energy in electricity applications due to their specified storage capacity. The study by ROAM consulting (2012) stated that the total cost of storage application must account for the ratings of both power and energy components.

It is important to note here that installed energy potential of a PHES is generally expressed in megawatt hours (MWh) that is a produced once by utilizing the total volume of upper reservoir water using total discharge time period in hours. This time period is called the operating hours of one cycle for that energy storage. During this operating cycle, the energy discharge in one hour is the installed rated power potential of the facility that is generally measured in megawatt (MW) unit. This installed rated power potential in MW can be used to calculate the installed energy potential with multiplying it by ' $h$ ' hours of the complete one cycle. Similarly, the installed energy potential can be used to calculate the installed power potential with dividing it by ' $h$ ' hours of the complete one cycle.

Therefore, the total cost of the PHES plant can be expressed in both $\$$ / MW and $\$$ / MWh. For example, a PHES project with a total capacity cost of 100 Million dollars designed with $100 \mathrm{MW}$ rated power for a total 5 hours operating time of one complete cycle, would have a unit capital cost of $\$ 100$ million/ $100 \mathrm{MW}$ equal to $\$ 1,000,000$ / MW using the component of installed rated power potential. Similarly, the same project would have a unit capital cost of \$ 100 million/ 100 MW x 5 hours equal to $\$ 200,000 /$ MWh using the component of installed rated energy potential.

\subsubsection{PHES Cost Needed for This Research Study}

This research has to develop systematic planning of establishing and integrating the PHES system with an existing electricity market at grid level. The planning process first identifies the feasible PHES sites around the existing waterbodies being considered as primary reservoirs located within the concerned electricity grid region. The identification of PHES sites is based on three sequential steps of GIS processing. The first step identifies the preliminary PHES sites for each primary reservoir. The second step selects the potential PHES sites out of the identified preliminary PHES sites. The third step ranks the potential PHES sites to select the most feasible sites for the respective primary reservoirs. The costing requirement of PHES plants starts from 
the third step of the ranking process. In this research, three types of PHES costs are needed at three stages of the planning process as explained below.

\section{Unit Cost of Individual PHES Components}

In the first stage, the costs of key individual PHES components are needed for the ranking of potential sites. Although the same individual PHES components at different sites may have the same unit cost the total cost of this component may vary due to their different sizes. Similarly, the site may have different energy potential due to its particular topographic location. Hence, the site having the lowest cost per unit energy potential is considered as the most feasible PHES site for its primary reservoir. Therefore, in the first stage, this research needs the 'unit cost of individual PHES components' to finalize the most feasible PHES sites for their primary reservoirs.

\section{Capital Cost of PHES Plants}

In the second stage, the initial investment costs of PHES plants are needed prior to the commissioning of their storage operation. The PHES reservoir to be built on identified feasible PHES site is paired with its primary reservoir to form a complete unit of PHES plant. The total cost incurred before starting the storage operation is the 'initial investment cost' that is also known as 'capital cost of the PHES plant'. After finalizing the capital cost, the PHES plant is commissioned to provide the storage services to the electricity system operator. The 'capital cost of PHES plant' is used to estimate the yearly revenues/ cash flows to compute the annual net present values (NPVs) as an important part of the planning process.

\section{O\&M Cost of PHES Plants}

In the third stage, the PHES plants start their operation and regularly provide services for their whole life period. At this stage, the 'operation and maintenance (O\&M) cost' of PHES plants is needed. This cost is generally estimated on a yearly basis which is known as 'yearly O\&M cost'. This cost component is also an important part of computing the annual net present values (NPVs). There are two types of yearly O\&M costs as explained below.

\section{Fixed O\&M Costs}

The fixed O\&M costs are defined as $\$ / \mathrm{kW} /$ year and projected yearly O\&M cost is often estimated as a percentage of initial capital cost (Fen et al. 2012). These costs typically 
include all fixed operating costs of the plant such as spares, major periodic maintenance, insurance, O\&M fees, property taxes and leases, office supplies, employee wages and asset management costs. The overhaul cost is also considered to be a part of maintenance and replacement costs (Kapila et al. 2017). It is important to note that fixed costs should not vary with changes in electricity generation levels.

\section{Variable O\&M Costs}

These costs, defined as $\$ / \mathrm{MWh}$, refer to the incremental operation and maintenance cost incurred upon increasing the level of production by one unit. These costs typically include minor unplanned maintenance and any cost generated due to wear-out and tears-up of electrical and mechanical equipment of the plant over time. Similarly, the civil works/ structures may need rehabilitation after decades since starting the plant operation services (Fen et al. 2012).

The capital cost and O\&M cost are used to calculate the net present values (NPVs) of each year cost flows for the life period of PHES plants, while performing the financial analysis of PHES system as part of the PHES planning under this research. Therefore, keeping in view the above PHES costing requirements, the cost data of previous studies and other relevant sources were reviewed.

The cost data reported in previous studies and collected from other sources may be used to estimate the different costs needed in developing the PHES projects at their particular locations. However, the available cost data should be converted first into the currency of the concerned project country and thereafter it should be projected as future value for the required estimating year, using an average inflation rate applicable in the concerned project country.

The Joint research center of the European Commission (Zubi 2012) suggested that the cost of PHES plants can be estimated by applying the following cost estimation practices:

\section{- Estimating PHES Cost using Data from Past Studies}

The cost data of past studies can be used to estimate the capital cost, O\&M cost, and cost of individual PHES components such as water reservoir, penstock, pumpturbine, electrical equipment, etc. 


\section{- Estimating PHES Cost using Site-Specific Empirical Formula}

The site-specific empirical formula can be used for estimating the unit capital cost of PHES plants.

\section{- Estimating PHES Cost using Data Collected from Existing Industry Suppliers}

The estimate of some equipment, materials, and services such as penstock pipes, pump-turbines, transformers, transport and installation of equipment, reinforced cement concrete (RCC) work, excavation/ drilling work, etc. can be collected from the existing suppliers and organizations.

A detailed review of PHES cost is provided in the forthcoming sections, following the abovementioned cost estimation practices.

\subsubsection{Estimating PHES Costs using Data from Past Studies}

Schoenung and Hassenzahl (2003) prepared a report on life-cycle cost analysis of various energy storage technologies for the US Department of energy and presented the results of their capital cost and yearly O\&M cost. Regarding PHES technology, the capital cost and O\&M cost of a typical pumped hydro storage facility having $395 \mathrm{MW}$ power potential were reported as US\$ $1050 / \mathrm{kW}$ and US $\$ 2.5 / \mathrm{kW}$ respectively. After cost conversion, from US dollar to Canadian dollar, the projected capital cost and O\&M cost for the year 2016 comes out to C\$1797/ kW and $\mathrm{C} \$ 4 / \mathrm{kW}$ respectively.

Levine (2007) reported the overnight capital cost per MW for PHES plants categorized in different plant scales and sizes. The term 'overnight cost' refers to the cost of the project as if no interest were incurred during its construction period. This study also reported the unit costs of pump-turbines with valves and governors at different projects as US\$119,877/ MW. The projected value of this cost is C\$147,971/ MW for the year 2016.

Brook (2010) provided a cost estimate of Tantangara-Blowering pumped hydro energy storage facility as US\$ 744/ kW in the year 2010 having 9000 MW power potential of the project. This cost is equivalent to $\mathrm{C} \$ 840 / \mathrm{kW}$ for the year 2016 . This study stated that the electricity storage 
association of USA (ESA 2009) provided a range for PHES costs from US\$ 500/ kW to US\$ $1500 / \mathrm{kW}$ which is converted to C\$565/ kW to C\$ 1694/ kW for the year 2016.

The study by Guzman (2010) reported the capital costs of PHES projects in China that have been converted in the Canadian dollar and estimated their projected values for the year 2016 as provided in Table 2.2.

Table 2.2 Capital costs of PHES plants

\begin{tabular}{|c|c|c|c|c|c|c|c|c|}
\hline \multirow{2}{*}{$\begin{array}{c}\text { Name of } \\
\text { Project }\end{array}$} & \multirow[t]{2}{*}{ Location } & \multirow{2}{*}{$\begin{array}{c}\text { Completion } \\
\text { Year }\end{array}$} & \multirow{2}{*}{$\begin{array}{c}\text { Installed } \\
\text { Capacity } \\
\text { (MW) }\end{array}$} & \multicolumn{2}{|c|}{ Total Cost } & \multicolumn{2}{|c|}{ Cost per kW } & \multirow[t]{2}{*}{ Remarks } \\
\hline & & & & $\begin{array}{c}\text { Reported } \\
\text { Year } \\
\text { (M US\$) }\end{array}$ & $\begin{array}{l}\text { Projected } \\
\text { Year 2016 } \\
\text { (M C\$) }\end{array}$ & $\begin{array}{l}\text { Reported } \\
\text { Year } \\
(\mathrm{US} \$ / \mathbf{k W})\end{array}$ & $\begin{array}{c}\text { Projected } \\
\text { Year 2016 } \\
(\mathrm{C} \$ / \mathrm{kW})\end{array}$ & \\
\hline Yixing & China & 2008 & 1000 & 574 & 692 & 574 & 692 & New facility \\
\hline \begin{tabular}{|l|} 
Hebei \\
Zhanghewan
\end{tabular} & China & 2009 & 1000 & 775 & 986 & 775 & 986 & New facility \\
\hline
\end{tabular}

The US Energy Information Administration (2010) presented an updated capital cost estimate of PHES plants with a nominal capacity of $250 \mathrm{MW}$. It was reported that the unit capital cost before contingency and fee is $\mathrm{C} \$ 4,745 / \mathrm{kW}$ and yearly fixed O\&M cost is $\mathrm{C} \$$ $14.72 / \mathrm{kW}$ for the year 2016. The updated capital cost was used as the base cost that needs to be multiplied by a defined locational factor (percentage) to estimate the capital costs of PHES plants at different locations throughout the USA.

Dean et al. (2010) reported the capital cost of PHES projects in various countries. The study particularly reported that the increase in capital cost of US projects after 1980 is particularly attributed to the higher licensing costs and construction delays due to technical and financial problems.

Krajacic et al. (2013) provided the cost estimate of the Island of Krk pumped hydro project in Europe. The installed power capacity of this project is $10 \mathrm{MW}$ (2 pump-turbine x $5 \mathrm{MW}$ each) with a new upper reservoir having $1 \mathrm{Mm}^{3}$ volume and $2000 \mathrm{~m}$ long penstock. The reported costs have been converted in the Canadian dollar and calculated their projected values for the year 2016 as given in Table 2.3 below. 
Table 2.3 Cost estimate for Island of Krk pumped hydro project

\begin{tabular}{|c|c|c|c|}
\hline \multirow[t]{2}{*}{ Individual Cost Component } & \multicolumn{3}{|c|}{ Estimated Cost } \\
\hline & $\begin{array}{c}\text { Year } 2011 \\
\text { (Euro) }\end{array}$ & $\begin{array}{c}\text { Year } 2011 \\
(C \$)\end{array}$ & $\begin{array}{c}\text { Year } 2016 \\
(C \$)\end{array}$ \\
\hline Hydro-turbine ( 2 x 5 MW each) & $2,860,157$ & $3,937,578$ & $4,252,348$ \\
\hline Pump (2 Nos.) & $1,106,961$ & $1,523,953$ & $1,645,778$ \\
\hline Penstock (2 x $2000 \mathrm{~m}$ each) & $4,112,296$ & $5,661,398$ & $6,113,970$ \\
\hline Reservoir $\left(1 \mathrm{Mm}^{3}\right)$ & $6,656,551$ & $9,164,074$ & $9,896,650$ \\
\hline Grid connection & 589,439 & 811,481 & 876,350 \\
\hline Control system & 235,775 & 324,591 & 350,539 \\
\hline Transportation of equipment & 353,663 & 486,888 & 525,810 \\
\hline Administration cost & $4,420,790$ & $6,086,102$ & $6,572,625$ \\
\hline Others & $1,031,518$ & $1,420,091$ & $1,533,613$ \\
\hline Total capital cost & $21,367,150$ & $29,416,155$ & $31,767,684$ \\
\hline Yearly O\&M cost & 427,343 & 588,323 & 635,354 \\
\hline Capital Cost/ kW & $2,137 / \mathrm{kW}$ & & $3,177 / \mathrm{kW}$ \\
\hline O\&M Cost/ kW & $42.73 / \mathrm{kW}$ & & $63.54 / \mathrm{kW}$ \\
\hline
\end{tabular}

The study by Krajacic et al. (2013) also provided the cost of Vindol pumped hydro storage project in Europe as $€ 917 / \mathrm{kW}$ with its power potential of $94.5 \mathrm{MW}$. This cost is equal to $\mathrm{C} \$ 1,314 / \mathrm{kW}$ for the year 2016. This study also reported the typical cost range of PHES projects in Europe from $€ 500 / \mathrm{kW}$ to $€ 3,600 / \mathrm{kW}$ which has been converted to $\mathrm{C} \$ 716 / \mathrm{kW}$ to $\mathrm{C} \$ 5,158 / \mathrm{kW}$ for the year 2016 .

Galvan-Lopez (2014) provided capital cost and annual O\&M cost of the year 2000 for three PHES projects in the USA. Table 2.4 shows the total costs of the projects that have been first converted into Canadian dollar and then estimated their projected values for the year 2016.

Table 2.4 Capital cost and yearly O\&M cost of PHES projects

\begin{tabular}{|c|c|c|c|c|c|c|c|c|}
\hline \multirow{2}{*}{$\begin{array}{l}\text { Pumped Storage } \\
\text { Facility }\end{array}$} & \multirow{2}{*}{$\begin{array}{c}\text { Power } \\
\text { Potential } \\
\text { (MW) }\end{array}$} & \multirow{2}{*}{$\begin{array}{c}\text { Daily } \\
\text { Generation } \\
\text { Capacity } \\
(\mathbf{M W h})\end{array}$} & \multicolumn{2}{|c|}{ Capital Cost } & \multirow{2}{*}{$\begin{array}{c}\begin{array}{c}\text { Capital Cost } \\
\text { per kW }\end{array} \\
\text { Projected } \\
\text { Year } 2016 \\
(C \$ / \text { Kw) }\end{array}$} & \multicolumn{2}{|c|}{ Yearly O\&M Cost } & \multirow{2}{*}{$\begin{array}{c}\begin{array}{c}\text { O\&M Cost } \\
\text { per kW }\end{array} \\
\text { Projected } \\
\text { Year 2016 } \\
(\mathrm{C} \$ / \mathrm{Kw})\end{array}$} \\
\hline & & & $\begin{array}{c}\text { Year 2000 } \\
\text { (M US\$) }\end{array}$ & $\begin{array}{c}\text { Projected } \\
\text { Year 2016 } \\
\text { (M C\$) }\end{array}$ & & $\begin{array}{c}\text { Reported } \\
\text { Year 2000 } \\
\text { (US\$) }\end{array}$ & $\begin{array}{c}\text { Projected } \\
\text { Year 2016 } \\
(C \$)\end{array}$ & \\
\hline Taum Sauk (USA) & 408 & 2,700 & 258 & 490 & 1,201 & $2,300,000$ & $4,369,103$ & 10.71 \\
\hline $\begin{array}{l}\text { Northfield } \\
\text { Mountain (USA) }\end{array}$ & 1000 & 8,500 & 543 & 1,031 & 1,031 & $5,280,000$ & $10,029,942$ & 10.03 \\
\hline Ludington (USA) & 2076 & 20,760 & 1249 & 2,373 & 1,143 & $4,400,000$ & $8,358,285$ & 4.03 \\
\hline
\end{tabular}

Table 2.4 shows that the O\&M costs have a declined trend with an increase in power potential of PHES projects in the USA. 


\subsubsection{Estimating PHES Costs using Site-Specific Empirical Formula}

Some studies provided the empirical formulae for calculating the capital cost of PHES projects. Connoly et al. (2011) provided an empirical formula for calculating the annual investment cost knowing the capacities and the costs of pump, turbine and storage units of a PHES project for a known lifetime period as given in equation (2.1).

$$
I_{\text {Annual }}=I_{P} C_{P}+I_{T} C_{T}+I_{S} C_{S}\left\{\left[\frac{i}{1-(1+i)^{n}}\right]+O \& M_{\text {Fixed }}\right\}
$$

Where,

$$
\begin{array}{ll}
\mathrm{I}_{\mathrm{annual}} & =\text { Annual investment cost } \\
\mathrm{i} & =\text { Percentage of interest rate } \\
\mathrm{I}_{\mathrm{P}} & =\text { Total investment cost of pump } \\
\mathrm{C}_{\mathrm{P}} & =\text { Installed capacity of pump } \\
\mathrm{I}_{\mathrm{T}} & =\text { Total investment cost of turbine } \\
\mathrm{C}_{\mathrm{T}} & =\text { Installed capacity of turbine } \\
\mathrm{I}_{\mathrm{S}} & =\text { Total investment cost of storage } \\
\mathrm{C}_{\mathrm{S}} & =\text { Installed capacity of storage } \\
\mathrm{n} & =\text { Life time period in years }
\end{array}
$$

Fen et al. (2012) presented the capital cost equation using 'three parameter power' as given in equation (2.2):

$$
\mathrm{C}_{\mathrm{P}}(\$ / \mathrm{kW})=\mathrm{a} \mathrm{H} \mathrm{H}^{\mathrm{b}} \mathrm{P}^{\mathrm{c}-1}
$$

Where,

$$
\begin{aligned}
& \mathrm{C}_{\mathrm{P}}=\text { Initial capital cost in } \$ / \mathrm{kW} \\
& \mathrm{H}=\text { Potential head in } \mathrm{m} \\
& \mathrm{P}=\text { Plant capacity in } \mathrm{kW}
\end{aligned}
$$

The study reported that the values of the coefficient $a$, and indices $b$ and $c$ were initially assigned their values as 566.9, 0.01218 and 1.14552 respectively on the basis of available sample data of past projects. After assigning these values in equation (2.2), the capital cost per kilowatt $\left(C_{P}\right)$ increases as the potential head or plant capacity increases. Similarly, $C_{P}$ would increase much faster as the coefficient $\mathrm{a}$, and indices $\mathrm{b}$ and $\mathrm{c}$ increases simultaneously which is contrary to the reality and engineering experience. The author therefore realized 
that intensive and extensive efforts are needed to collect the project cost data to increase the sample size and improve the accuracy of the results. The author further pointed out that the best way is to establish a reasonable cost tool to update the coefficient 'a' while keeping same values of the power indices ' $b$ ' and ' $c$ ' following the classic or widely recognized cost equations. Accordingly, the above equation was improved using classic empirical equations by changing the fixed values of power indices $b$ and $c$ as -0.35 and 0.70 respectively. The values of ' $a$ ' were determined 110,168 by linear regression analysis using the collected cost data. Accordingly, the improved capital cost equation was reported as given below:

$$
\mathrm{C}_{\mathrm{P}}(\$ / \mathrm{kW})=110,168 \mathrm{H}^{-0.35} \mathrm{P}^{-0.3}
$$

The equation (2.3) was also used to calculate the site-specific capital costs of this particular research case study as the particular sample data is not available in the province of Ontario, Canada to develop a new empirical cost equation for this region. However, the average cost of all identified sites in Ontario that are to be estimated using the formula will be compared with the average cost estimated based on past studies data and the greater one will be used for financial analysis.

\subsubsection{Estimating PHES Cost using Data from Industry Suppliers and Organizations}

Stantec (2009) provided the cost estimates for the construction of overhead transmission lines in Ontario, Canada. In Table 2.5, these costs have been projected for the year 2016.

\section{Table 2.5 Cost estimate of overhead transmission lines in Ontario}

\begin{tabular}{|l|c|c|}
\hline $\begin{array}{l}\text { Category of Overhead } \\
\text { Transmission Line }\end{array}$ & $\begin{array}{c}\text { Base Year Cost } \\
\text { (Year 2009) }\end{array}$ & $\begin{array}{c}\text { Projected Cost } \\
\text { (Year 2016) }\end{array}$ \\
\hline Single circuit $500 \mathrm{kV}$ line & $\mathrm{C} \$ 1,350,000 / \mathrm{km}$ & $\mathrm{C} \$ 1,503,465 / \mathrm{km}$ \\
\hline Double circuit $500 \mathrm{kV}$ line & $\mathrm{C} \$ 2,263,000 / \mathrm{km}$ & $\mathrm{C} \$ 2,520,252 / \mathrm{km}$ \\
\hline $200 \mathrm{kV}$ line & $\mathrm{C} \$ 592,000 / \mathrm{km}$ & $\mathrm{C} \$ 659,297 / \mathrm{km}$ \\
\hline
\end{tabular}

Hatch (2010) provided the preliminary cost estimates of BC Hydro pumped storage project at Mica generating station. The costs were estimated at the base year 2010 considering the project construction period as 5.25 years with $500 \mathrm{MW}$ rated power capacity (2 reversible pump-turbines x $250 \mathrm{MW}$ each). These costs have been projected for the year 2016 as given in Table 2.6. 
Table 2.6 Cost estimate of BC Hydro pumped storage project

\begin{tabular}{|l|c|c|}
\hline Individual Cost Component & $\begin{array}{c}\text { Base Year Cost } \\
\text { (Year 2010) }\end{array}$ & $\begin{array}{c}\text { Projected Cost } \\
\text { (Year 2016) }\end{array}$ \\
\hline Supply of pump-turbine and governors (250 MW) & $\mathrm{C} \$ 29,000,000$ & $\mathrm{C} \$ 31,803,694$ \\
\hline Supply of valves & $\mathrm{C} \$ 3,500,000$ & $\mathrm{C} \$ 3,838,377$ \\
\hline Supply of motor-generator and exciters & $\mathrm{C} \$ 18,500,000$ & $\mathrm{C} \$ 20,288,563$ \\
\hline Supply of starting equipment (lump-sum) & $\mathrm{C} \$ 10,000,000$ & $\mathrm{C} \$ 10,966,791$ \\
\hline Installation and commissioning of turbine-generator (lump-sum) & $\mathrm{C} \$ 23,000,000$ & $\mathrm{C} \$ 25,223,619$ \\
\hline Access road & $\mathrm{C} \$ 250 / \mathrm{m}^{2}$ & $\mathrm{C} \$ 1,467 / \mathrm{kW}$ \\
\hline $\begin{array}{l}\text { Total capital cost } \\
\text { (Two variable-speed reversible pump-turbine units) }\end{array}$ & $\mathrm{C} \$ 1,338 / \mathrm{kW}$ & $\mathrm{C} \$ 7.24 / \mathrm{kW}$ \\
\hline Annual fixed O\&M cost & $\mathrm{C} \$ 6.6 / \mathrm{kW}$ & $\mathrm{C} \$ 0.66 / \mathrm{MWh}$ \\
\hline Variable O\&M cost & $\mathrm{C} 0.6 / \mathrm{MWh}$ & $25 \%$ of capital cost \\
\hline Project contingency & $25 \%$ of capital cost & $8 \%$ of capital cost \\
\hline Environmental, engineering, administration and site inspection & $8 \mathrm{cost}$ \\
\hline
\end{tabular}

The cost estimates of some individual PHES components have been collected from the existing international industry suppliers and organizations as provided in Table 4.12.

\subsection{Significance of Study Area Size for Allocating PHES Sites}

The selection of area size to identify the PHES sites generally depends on two factors: the type of existing waterbodies that the sites are located around, and the area involved for the primary source of energy such as a wind farm, a small off-grid area, or a large gridconnected electricity region. The study by ROAM Consulting (2012) suggested that the schemes spread over a wide geographical area would provide a better opportunity than a small area. The topographical pattern generally differs in different geographical regions and therefore the selection of large area would provide an opportunity of exploring all possible potential sites in that area. It was further stated that the study over a wide area would provide a reliable supply in a $100 \%$ renewable system. Therefore, this study suggested for selecting the widest range of available options to explore all possible PHES potential.

It is important to note that the general methodology of identifying the PHES sites at small area can be applied as a proof of concept at grid level. However, the methodology for a particular type of waterbody such as the dams (or lakes) and rivers have different steps. Therefore, the general methodology needs to define the necessary methodological steps for a particular type of waterbody at grid level study area. 


\subsection{Effect of Temperature on PHES Operations}

In PHES operations, the qualitative properties of water for upper and lower reservoirs can be classified as physical and geochemical (abiotic) and ecological (biotic) types. Kobler (2018) stated that the effects of 'abiotic' property include: changes of water temperature, stratification, water level fluctuations, sediment resuspension, oxygen and nutrient cycling in the water column, and generation of ice-cover during the winter season that may be affected by PHES operations. The 'biotic' property include stranding of juvenile fish in littoral zones during dewatering, entrainment of the organism, and spreading of alien species from downstream to upstream. The author further remarked that the biotic impacts have been generally less studied. With regard to 'abiotic' characteristics, the study shows significant impacts of the water exchange between upper and lower reservoirs on the seasonal dynamics of temperatures and on the ice-cover during the winter season, especially in the upper reservoir. Accordingly, the study underlined the importance of the location of PHES intake and outlet structures. Similarly, it was further explained that the withdrawal depth defines the relevant implications of temperature effect on PHES operations.

Patocka (2014) stated that the water temperature during pumping operation is dependant on waterworks design such as the intake and outlet structures of the reservoirs. It was also stated that thermal and density stratification is a phenomenon that occurs in almost all the reservoirs impoundments in the cold region. However, a PHES reservoir is essentially different from a natural reservoir due to the complexity associated with dynamic outflows. The effect of temperature is mainly dependant on the temperature of the lower reservoir that works as a primary source of water for pumping operations. The waterworks, especially vertical placement of the intake structure are important for the design perspective.

The ice-cover generates forces on the structure, therefore the reservoir structure should be designed with consideration of these forces. The built-up frazil ice at the intake may result in blocking the intake that can be handled by placing the intake in deep water. Large fluctuations due to the operations of PHES during winter result in unstable ice-cover and therefore, it is of least importance with respect to PHES operations. 
Based on the above-mentioned literature review, this particular research has therefore excluded the effect of temperature on PHES operations due to its nominal implication at the macro level planning stage, except to suggest the above mentioned structural design recommendations to be considered at the detail design stage.

\subsection{Resources Allocation with Combined Spatial Siting and Optimization}

The GIS applications have been commonly used for spatial siting of different resources such as to allocate the sites of energy generators like wind energy farms, various types of energy storage plants, public hospitals, fire stations, public park-and-ride facilities, etc. However, there are certain existing system constraints such as environmental, infrastructure, geology, etc. which are generally applied for allocating the sites of specific resources. In order to achieve an objective of allocating a particular resource by satisfying the existing system constraints, the GIS-based spatial siting process can be combined with optimization to get optimal results of the objective.

Wang et al. (2004) applied an integrated approach of GIS-based spatial allocation model and optimization model at a watershed level using Lake Erahai basin in China. It was reported that the integration of two models allowed the consideration of economic, environmental, and physical factors which were used in the land use planning process. The model involved four objectives with necessary system constraints.

Farhan (2008) also used a multi-objective spatial optimization for siting the public park-andride facilities using a case study of Columbus, Ohio, USA. Rogeau et al. (2017) used the optimization tool for evaluation of small PHES potential at large scale using a generic GISbased method. This study first identified the pairs of PHES sites connected with existing reservoirs and thereafter applied the system constraints on all the identified pairs to eliminate the pairs that have not satisfied the system constraints. After applying the system constraints, the optimization tool was run among the selected pairs to meet the following three objective benefits: 
Objective I (Energy): This objective maximizes the energy that can provide the biggest energy storage capacity.

Objective II (Power): This objective strategy provides the biggest power with maximum water flow for each connection and, therefore favours the pairs having high head values.

Objective III (Cost-Energy Ratio): This ratio was defined as the capital cost divided by the available energy potential for a particular connection.

It is also pointed out that different objectives can provide different results such as the application of above objectives I and II that give different results because these objectives are based on the maximum energy or maximum power without involving the capital cost. Additionally, both these objectives may be the interest of electricity market operators to store maximum energy in the electricity market region, whereas the objective III may be the interest of both electricity market operator and the energy developer to store and regenerate the unutilized energy as cost-effective and sustainable support of PHES facility.

It is pertinent to mention here that this research case study of Ontario also used the optimization to meet the objective of the cost-energy ratio in $\mathrm{C} \$$ / MWh for the identified potential PHES sites that are paired with their respective primary reservoirs. However, the 'optimization process' was given a different title as 'ranking of potential PHES sites' that selects the feasible PHES sites. 


\section{Methodology}

\subsection{General}

The GIS-based model was developed to identify feasible PHES sites using both conventional and GPM methods. The spatial decision-support tools were used in ArcGIS to automate the process. The optimization model was developed to get optimal scheduling of feasible PHES energy potential during different electricity demand hours of the existing electricity market system. A case study was conducted to test the GIS and optimization models at grid level. Finally, a financial analysis of the developed PHES system was performed using optimization results. The overall methodological process has been systematically divided into the following four phases of this research:

- Developing a GIS-based model to identify feasible PHES sites using conventional and GPM methods;

- Developing an optimization model for scheduling of identified feasible PHES energy potential;

- Applying GIS and optimization models on a case study of the existing electricity market at grid level; and

- Performing financial analysis of PHES system using optimization results of the case study.

The detailed methodological process of the above phases has been provided in the forthcoming Sections. The methodological explanation of the above phases used various technical terms that have been defined in Section 3.2 as provided below. 


\subsection{Defining Technical Terms}

The definitions of the following terms have been taken from the Ontario Hydro Network (OHN) user guide for their use in GIS processing (Land Information Ontario 2015):

\section{Feature}

The feature is a point, line or polygon representation of all or a portion of real-world objects, such as a dam, lake, or river.

\section{Attribute}

The attribute is spatial information that defines the feature. It is generally provided in an associated table that contains different spatial information of a feature class. For example; widths, lengths, flows or drainage areas are the 'attributes' of the rivers (a feature class).

\section{Waterbody}

The waterbody is a polygon feature that represents bodies of surface water, such as reservoirs, lakes, or rivers.

\section{Reservoir}

The reservoir is a wholly or partially man-made body of water for storing and/ or regulating and controlling water.

\section{Dam}

The dam is a feature representing an obstacle that disturbs or impedes the flow of surface water excluding water-crossings and culverts.

\section{Lake}

The lake is a natural, usually flat, open body of water, which excludes wetlands, islands, surface rocks or other hazards to water flow and/ or navigation.

\section{River}

The river is a natural body of water through which water may flow, such as a river, stream or creek. 


\section{Perennial River}

The perennial river is considered as a permanent river that contains flowing water at least 9 months of the year.

\section{Non- Perennial River}

The non-perennial river is considered as an intermittent river that contains flowing water less than 9 months of the year.

\section{Negative Buoyancy}

The negative buoyancy of an object occurs when its density is higher than the density of fluid around it. This will make the object fully immersed in the fluid. For example, in a GPM unit, the piston made of natural rock material is denser than water stored in the main shaft. In this case, the piston has negative buoyancy.

\section{Low Flow Prediction of River (mQn)}

The low flow prediction of a river is denoted by $\mathrm{mQn}$ that represents $\mathrm{m}$-day average low flow in n-year return period. For example, 7Q10 means the seven consecutive day average low flow in 10 year return period.

\section{High Flood Prediction of River $\left(Q_{n}\right)$}

The high flood prediction of a river is denoted by $Q_{n}$ that represents the flood flow in n-year return period. For example, $Q_{50}$ represents the flood flow in a 50 year return period.

The following terms have been specifically defined for this particular research study to use in the methodological process:

\section{Primary Reservoir}

Primary reservoir is an existing reservoir such as a dam, lake or a river that qualifies assumed minimum required volume or flow of water (see Figure 3.1).

\section{PHES Reservoir}

This is a new reservoir to be built on a feasible PHES site, with assumed reservoir wall height, that is identified around a primary reservoir as a result of GIS model processing. The new reservoir has been termed as PHES reservoir (see Figure 3.1). 


\section{Preliminary PHES Sites}

These are the qualified surface regions identified around a primary reservoir, selected for the GIS screening process. These surface regions have been termed as preliminary PHES sites.

\section{Potential PHES Sites}

The surface regions that qualified the screening criteria along with their respective primary reservoir have been termed as potential PHES sites.

\section{Feasible PHES Sites}

The feasible PHES site is a rank-1 site amongst all the potential sites that have been ranked for a primary reservoir. This site has been termed as a feasible PHES site for a primary reservoir.

\section{Buffer Zone}

This is the land surface around a qualified primary reservoir specified within a defined buffer distance from the circumference boundary of the primary reservoir (see Figure 3.1).

\section{Surface Region}

The surface region is a piece of land surface identified at the initial stage of GIS processing using an assumed maximum surface slope, located within the buffer zone qualifying the assumed minimum elevation difference (ED) with reference to the primary reservoir (see Figure 3.1).

\section{Qualified Surface Region}

The qualified surface region is a surface region identified as a result of GIS processing that satisfies the minimum required area defined under the study. 


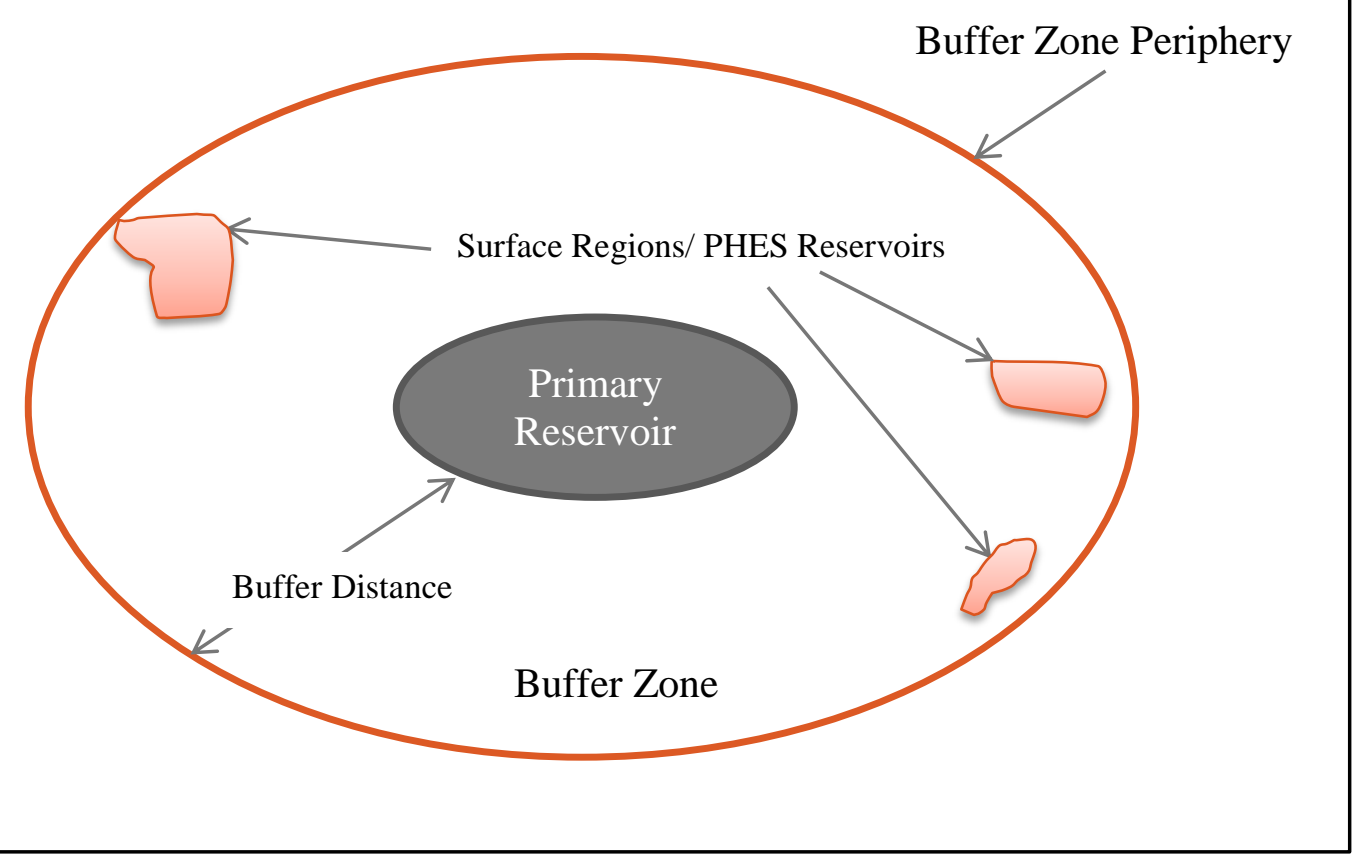

Figure 3.1 Schematic diagram showing primary reservoir, buffer zone and surface regions

\subsection{Developing GIS-based Model using Conventional and GPM Methods}

The methodology of model development was applied to both conventional PHES and GPM methods that have been divided into two stages. In the first stage, the model input database was developed and in the second stage, GIS processing was performed to identify the PHES sites. The model input includes the data of waterbodies existed in the study area. The waterbodies were used as primary reservoirs to provide water to the PHES reservoirs to be constructed on the identified feasible PHES sites around the waterbodies.

The model output resulted in PHES sites which were identified in the form of qualified surface regions satisfying the assumed criteria of their slope and area conditions. Additionally, in the conventional method, the surface regions were checked to qualify another condition of minimum elevation difference (ED) from their respective waterbodies.

The different types of waterbodies have their specific steps of GIS processing in both conventional and GPM methods. Therefore, the methodological process was presented using separate cases for each waterbody type and the abandoned mines. Conceptually, four cases were considered based on three types of waterbodies and the abandoned mines. First three cases are related to each individual type of waterbody including dams, lakes and rivers, and 
the fourth case is related to the abandoned mines. In the fourth case, the primary reservoir may be a dam/ lake or a river for a particular abandoned mine. Table 3.1 defines all the cases of existing waterbodies and abandoned mines to identify PHES sites.

Table 3.1 Defining cases of waterbodies and abandoned mine to identify PHES/ GPM sites

\begin{tabular}{|l|l|l|}
\hline Case & Existing Waterbody & PHES/ GPM Site \\
\hline Case I & $\begin{array}{l}\text { Existing dam qualifying minimum } \\
\text { required reservoir volume }\end{array}$ & $\begin{array}{l}\text { Identified sites around the dam, qualifying } \\
\text { minimum required surface area and } \\
\text { elevation difference from the respective dam }\end{array}$ \\
\hline Case II & $\begin{array}{l}\text { Existing lake qualifying minimum } \\
\text { required volume of water }\end{array}$ & $\begin{array}{l}\text { Identified sites around the lake, qualifying } \\
\text { minimum required surface area and } \\
\text { elevation difference from the respective lake }\end{array}$ \\
\hline Case III & $\begin{array}{l}\text { Existing river qualifying minimum } \\
\text { required flow of water }\end{array}$ & $\begin{array}{l}\text { Identified sites along the river, qualifying } \\
\text { minimum required surface area and } \\
\text { elevation difference from nearest point at } \\
\text { the respective river }\end{array}$ \\
\hline Case IV & $\begin{array}{l}\text { Existing dam or lake qualifying } \\
\text { minimum required volume of water, } \\
\text { or a river qualifying minimum } \\
\text { required flow of water }\end{array}$ & $\begin{array}{l}\text { Existing abandoned mine, to be used as } \\
\text { PHES/ GPM site, qualifying minimum } \\
\text { required storage volume for PHES sites }\end{array}$ \\
\hline
\end{tabular}

\subsubsection{Computation of Energy Potential}

The computation of energy potential for conventional PHES method and GPM method is given below.

\section{Conventional Method}

The energy potential of a PHES site is a function of storage volume of upper reservoir, elevation difference (ED) between upper and lower reservoirs, and round-trip system efficiency. The energy storage potential is generally expressed in megawatt hours (MWh) which is produced by utilizing the total volume of upper reservoir water in one operating cycle. The energy potential (E) of a PHES plant in watt-hours (Wh) can be calculated using Equation (3.1) as given below (Connolly et al. 2010):

$\mathrm{E}=\rho \mathrm{g} \mathrm{Vh} \eta / 3600$

Where, $\quad \rho=$ Density of water at $4^{\circ} \mathrm{C}\left(1000 \mathrm{~kg} / \mathrm{m}^{3}\right)$

$\mathrm{g}=$ Acceleration due to gravity $\left(9.81 \mathrm{~m} / \mathrm{s}^{2}\right)$

$\mathrm{V}=$ Volume of water stored in the upper reservoir $\left(\mathrm{m}^{3}\right)$

$\mathrm{h}=$ Elevation difference (ED) between upper and lower reservoirs (m)

$\eta=$ Round-trip efficiency of pump-turbine unit (\%) 


\section{GPM Method}

The energy storage potential of a GPM unit depends on the depths and diameters of both main water storage shaft and heavyweight piston, negative buoyancy of the piston and round trip efficiency of pump-turbine unit fixed at the ground level. The energy storage potential of a GPM unit is the energy produced in MWh by utilizing the total water stored in the main shaft in one operating cycle. The energy potential (E) of a GPM plant in watt-hours (Wh) can be calculated using Equation (3.2) as given below (Gravity Power 2014):

$$
\mathrm{E}=\left(\rho_{\mathrm{p}}-\rho_{\mathrm{w}}\right) \mathrm{g} \mathrm{V}_{\mathrm{p}} \mathrm{h} \eta / 3600
$$

$$
\text { Where, } \quad \begin{aligned}
\rho_{\mathrm{p}} & =\text { Density of piston material }\left(\mathrm{kg} / \mathrm{m}^{3}\right) \\
\rho_{\mathrm{w}} & =\text { Density of water at } 4^{\mathrm{o}} \mathrm{C}\left(1000 \mathrm{~kg} / \mathrm{m}^{3}\right) \\
\mathrm{g} & =\text { Acceleration due to gravity }\left(9.81 \mathrm{~m} / \mathrm{s}^{2}\right) \\
\mathrm{V}_{\mathrm{p}} & =\text { Volume of piston }\left(\mathrm{m}^{3}\right) \\
\mathrm{h} & =\text { Piston elevation change }(\mathrm{m}) \\
\eta & =\text { Round-trip efficiency of the pump-turbine unit }(\%)
\end{aligned}
$$

\subsubsection{Development of GIS Database}

The GIS database contains the data of a particular study collected from the reliable sources such as Scholars GeoPortal; Scholar's Portal Dataverse network; Open Data Portal (Canada); data.gov (USA); UN Data (International); research studies; local data services department established in the university libraries, etc.

The Scholars Geoportal tool provides access to geospatial datasets including land-based vector data, census geography, and orthophotography. Particularly in Ontario (Canada), the Scholar's Portal Dataverse network is a repository for research data collected by individuals and organizations associated with Ontario universities in Canada (https://learn.scholarsportal.info/allguides/dataverse/help/).

The data of this research study is broadly categorized into two main categories, input data and output data, as explained below: 


\section{(A) Input Data}

This data can be divided into two groups, actual geospatial data and assumed/ collected data which are given below:

\section{(i) Actual Geospatial Data}

This is the actual data that is available in the form of geospatial dataset files as given below:

- Shapefiles of waterbodies: dams, lakes and rivers

- Shapefile of abandoned mines

- Raster of DEM of the study area

- Shapefiles of infrastructures

○ Provincial road network

- Electricity transmission lines

- Shapefiles of environmental constraint layers:
○ Settlement areas
○ Built-up areas
- National parks
○ National wildlife areas
- Federal protected areas
- NGO nature reserve areas
- Floodplain areas
○ Wetlands
○ Bedrock geology

The environmental constraints may differ for particular regions in a country depending on the study area. Additionally, these constraints can be specified subject to the available data for a particular region.

\section{(ii) Assumed/ Collected Data}

This data can be divided into three categories as given below:

\section{(a) Assumed Data for Model Parameters}

This data is used in the identification process of PHES sites in both conventional and GPM methods. This data can be assumed on the basis of available past studies data or it can be defined with the realistic rationales. The final assumed data than becomes the 
default values of the model parameters. The Assumed necessary parameters used in conventional method are provided in Table 3.2.

\section{Table 3.2 Assumed parameters for the conventional method}

\begin{tabular}{|l|l|l|}
\hline Model Parameters & Unit & Assumed Criteria \\
\hline $\begin{array}{l}\text { Volume of water in lake/dam to be used as primary } \\
\text { reservoir }\end{array}$ & $\mathrm{Mm}^{3}$ & min volume \\
\hline Flow of a river to be used as primary reservoir & $\mathrm{m}^{3} / \mathrm{s}$ & min flow \\
\hline Ground slope of surface regions & degree & max slope \\
\hline $\begin{array}{l}\text { Distance between primary reservoir and PHES site (buffer } \\
\text { zone) }\end{array}$ & $\mathrm{km}$ & max distance \\
\hline Area of surface regions & $\mathrm{Mm}^{2}$ & min area \\
\hline ED between primary reservoir and surface region & $\mathrm{m}$ & min ED \\
\hline Round trip pump-turbine efficiency of a PHES plant & $\%$ & Average efficiency \\
\hline
\end{tabular}

In case of GPM method, the key assumptions are the selection of depths and diameters of the main shaft and piston, and diameter of the penstock. The other parameters are calculated on the basis of these assumptions. The Assumed data parameters used in GPM method are provided in Table 3.3 below.

\section{Table 3.3 Assumed parameters for GPM method}

\begin{tabular}{|l|l|l|}
\hline Model Parameters & Unit & Assumed Criteria \\
\hline Number of GPM units at one site & No. & GPM unit \\
\hline Depth of main shaft & $\mathrm{m}$ & Depth \\
\hline Diameter of main shaft & $\mathrm{m}$ & Diameter \\
\hline Depth of piston & $\mathrm{m}$ & Depth \\
\hline Diameter of piston & $\mathrm{m}$ & Diameter \\
\hline Inside diameter of penstock & $\mathrm{m}$ & Diameter \\
\hline Volume of water stored in main shaft & $\mathrm{m}^{3}$ & Volume \\
\hline Surface area of GPM site & $\mathrm{m}^{2}$ & Area \\
\hline Round-trip pump-turbine efficiency of GPM unit & $\%$ & Efficiency \\
\hline Output energy potential (full charge) & $\mathrm{MWh}$ & Energy potential \\
\hline Density of water & $\mathrm{kg} / \mathrm{m}^{3}$ & Water density \\
\hline Density of piston material (natural rock) & $\mathrm{kg} / \mathrm{m}^{3}$ & Rock density \\
\hline
\end{tabular}

\section{(b) Assumed Data for Screening Constraints}

This data is used in screening of the identified preliminary PHES sites to get potential PHES sites. This data defines the criteria for all constraint layers to be used in a screening process. The criteria for each layer clearly define that a preliminary PHES site is acceptable if it is situated at a given maximum or minimum distance from the constraints layer. Therefore, if it is situated at a permissible distance limit from a constraints layer, then it is an accepted site. For example, if the criteria for built-up area is minimum $500 \mathrm{~m}$, the PHES site must be located at a distance of $500 \mathrm{~m}$ or above from the built-up area. If a PHES site is found at or less distance (say $499 \mathrm{~m}$ or less), it 
will be rejected. Table 3.4 provides the assumed criteria for defining the constraints used in the screening process.

\section{Table 3.4 Assumed criteria for screening constraints}

\begin{tabular}{|l|l|l|}
\hline Constraint & Unit & Assumed Criteria \\
\hline Electricity transmission lines & $\mathrm{km}$ & max distance \\
\hline Provincial road network & $\mathrm{m}$ & min distance \\
\hline Settlement areas & $\mathrm{m}$ & min distance \\
\hline Built-Up areas & $\mathrm{m}$ & min distance \\
\hline Provincial parks & $\mathrm{m}$ & min distance \\
\hline National wildlife areas & $\mathrm{m}$ & min distance \\
\hline Federal protected areas & $\mathrm{m}$ & min distance \\
\hline NGO nature reserves & $\mathrm{m}$ & min distance \\
\hline Floodplain areas & $\mathrm{m}$ & min distance \\
\hline Wetlands & $\mathrm{m}$ & min distance \\
\hline Bedrock geology & $\mathrm{kPa}$ & min bearing capacity \\
\hline
\end{tabular}

\section{(c) Assumed/ Collected Cost Data for Individual PHES Components}

This data is used in the ranking process of the potential PHES sites to get the most feasible PHES sites. The individual components those have different estimates for different sites are considered in the ranking process of the sites of one primary reservoir. The assumed data for average unit cost of individual PHES components for a particular case study can be given as follows:

- Reservoir $\left(\$ / \mathrm{Mm}^{3}\right)$

- Pumps-turbines, valves and governors $(\$ / \mathrm{MW})$

- Penstock pipe:

- 12 inch diameter pipe $(\$ / \mathrm{m})$

- 18 inch diameter pipe $(\$ / \mathrm{m})$

- 24 inch diameter pipe $(\$ / \mathrm{m})$

- Transmission line $(\$ / \mathrm{km})$

- Access road $\left(\$ / \mathrm{m}^{2}\right)$

- Drilling work $\left(\$ / \mathrm{m}^{3}\right)$

- Reinforced cement concrete (RCC) work $\left(\$ / \mathrm{m}^{3}\right)$

It is important to note that the year in which the cost data is available is called the base year of the costs that have to be projected in the required cost estimating year using respective average currency conversion rates. 


\section{(B) Output Data}

The GIS processing output is the resultant PHES and GPM sites obtained at three stages. The resultant sites of first, second and third stages have been termed as preliminary sites, potential sites and feasible sites respectively. The final output of the model processing in each case is feasible PHES/ GPM sites. The model output can be presented as follows:

- Total primary reservoirs (No.)

- Total feasible PHES/ GPM sites (No.)

- Total volume of feasible PHES/ GPM sties $\left(\mathrm{Mm}^{3}\right)$

- Total energy potential of feasible PHES/ GPM sites (MWh)

\subsubsection{Methodological Approach of GIS Processing}

The methodological process is performed with ArcGIS software. The case study of this research used ArcGIS software version 10.2. The methodological approach of GIS processing adopted a systematic sequence of the following activities.

\section{(I) Loading of Input Data in ArcGIS Software}

The GIS processing starts with the loading of input data in ArcGIS for conventional and GPM methods. The input data required in each case of both methods is given below.

(i) Geospatial Dataset Files of Concerned Study Area:

- Shape file of dams (used only for case I and IV)

- Shape file of lakes (used only for case II and IV)

- Shape file of rivers (used only for case III and IV)

- Shape file of abandoned mines (used only for case IV)

- Raster file of DEM of concerned study area (used for cases I to IV)

- Shape files of infrastructures, environmental, and geology constraints (used for cases I to IV)

(ii) Assumed Criteria for Model Parameters (used for cases I to IV)

See Table 3.2 and Table 3.3 for conventional and GPM methods respectively.

(iii) Assumed Criteria for Screening Constraints (used for cases I to IV)

See Table 3.4 for conventional and GPM methods.

(iv) Average Unit Cost of Individual PHES Components (used for cases I to IV)

See Section 3.3.2 (A) (ii) (c) for conventional and GPM methods. 


\section{(II) ArcGIS Tools}

Various ArcGIS tools are used in GIS processing that are to be listed in the Section of input data. In the case study of this research, the ArcGIS tools have been listed in Section 4.7.3 of the case study chapter.

\section{(III) Preparing GIS Script}

This research used Python programming language to define the GIS script to automate the model process for performing the activities of cases I to IV for conventional and GPM methods.

\section{(IV) Performing GIS Process}

GIS processing is performed to identify the feasible PHES sites for each case of conventional and GPM methods. The GIS processing of each case is based on three sequential steps including identification of preliminary PHES sites, screening of preliminary PHES sites and ranking of potential PHES sites.

\section{(V) Presenting GIS Processing Results}

The output results of GIS processing are presented in a consistent form as explained in all the cases. The detailed methodological process has been explained separately for all the cases of conventional and GPM methods. 


\subsubsection{Case I: Identification of Feasible PHES/ GPM Sites with Dams}

The GIS processing of this case is explained as follows:

\section{Identification of Preliminary Sites}

The shapefile of dams was processed to check their volume and compared it with the assumed minimum volume of a primary reservoir. The dams qualified for assumed minimum volume were considered for further processing to identify their preliminary PHES/ GPM sites, whereas the remaining unqualified dams were rejected. If no dam is qualified, the processing stops with no output data for dams. The qualified dams were selected one by one for automated GIS process using defined sequence of the activities. First of all, the elevation of a selected dam as primary reservoir was extracted from the shapefile. A buffer zone of assumed distance was created outside the dam as a primary reservoir.

In the case of PHES sites, a raster named 'elevation raster' was created by extracting the raster of buffer zone from DEM. This is a part of the concerned area in DEM for which elevations are needed. Similarly, another raster named 'elevation difference (ED) raster' was created using the difference of dam elevation and the elevation raster values using the raster calculator.

The slope raster of the buffer zone was created. The surface regions were generated within the buffer zone satisfying the limits of assumed maximum slope for both PHES and GPM sites. Additionally, for PHES sites, the condition of minimum assumed ED was also applied. If no surface regions were generated, the dam is rejected and processing continued for the next dam.

The areas of generated surface regions were calculated and checked for assumed minimum area of a PHES/ GPM site. The selected surface regions were termed as 'preliminary PHES sites' for the current dam. If no surface region was selected, the dam is rejected and processing continued for the next dam.

The above process was repeated for each qualified dam to identify its preliminary PHES/ GPM sites. The qualified surface regions of all the dams were added in the list of preliminary PHES/ GPM sites. If no dam generates any surface regions, the processing stops with no output data for that dam. 


\section{Screening of Preliminary PHES/ GPM Sites}

The identified preliminary sites and their respective dam were selected one by one for their screening using screening constraints. The nearest constraint features were identified and their distances from all preliminary sites and the respective dam were calculated. This process was repeated using all defined constraint layers. The geology layer file was processed to determine bedrock geology for each site, thereby extracting the bedrock type and its bearing capacity from the respective geology. The sites were selected satisfying screening SQL query based on assumed criteria for all constraints including infrastructure, environmental and geology layers. The selected sites were termed as 'potential PHES/ GPM sites'. If no potential site is selected, the processing stops without any potential PHES/ GPM sites.

\section{Ranking of Potential PHES/ GPM Sites}

In this process, a ranking table was generated containing all possible pairs of the dams with PHES/ GPM sites. At this stage, some sites may be paired with more than one dam. Therefore, in order to eliminate this discrepancy, the most appropriate pair was selected amongst all the multiple pairs on the basis of the lowest unit cost/ MWh. For this purpose, the ranking table was joined with dams and potential sites. After this joining, the ranking table contains the data including: (i) distances between PHES/ GPM sites and their respective dams, (ii) distances from nearest roads and electricity transmission lines to each site and dam, (iii) average elevations of dams and PHES sites to find their respective EDs, and (iv) areas of all PHES/ GPM sites. The total cost of individual components for PHES/ GPM sites was calculated using the data from above items (i), (ii), (iii), and the individual cost component data provided in Section 3.3.2 (A) (ii) (c). The storage volumes of PHES sites were calculated using the data from item (iv) with an assumed reservoir wall height of a PHES site. The elevation difference (ED) for each site was calculated using item (iii). The energy potential of a PHES site was calculated using the energy Equation (3.1). The energy potential of each GPM site is the same because all the units have been designed as one module unit having the same dimensions of the piston and shaft. Finally, the unit cost/ MWh was calculated for each pair using the total costs and energy potential. 
The ranking table was sorted by dam ID for its pair containing lowest unit cost/ MWh. All the PHES/ GPM sites were ranked with respect to their dam on the basis of their unit cost/ MWh in ascending order. The Rank-1 site having the lowest unit cost/ MWh was selected from the ranking table and named as 'feasible PHES site'.

The flowchart illustrating the above methodological process of GIS-based model to identify feasible PHES/ GPM sites with dams is provided in Figure 3.2 as given below.

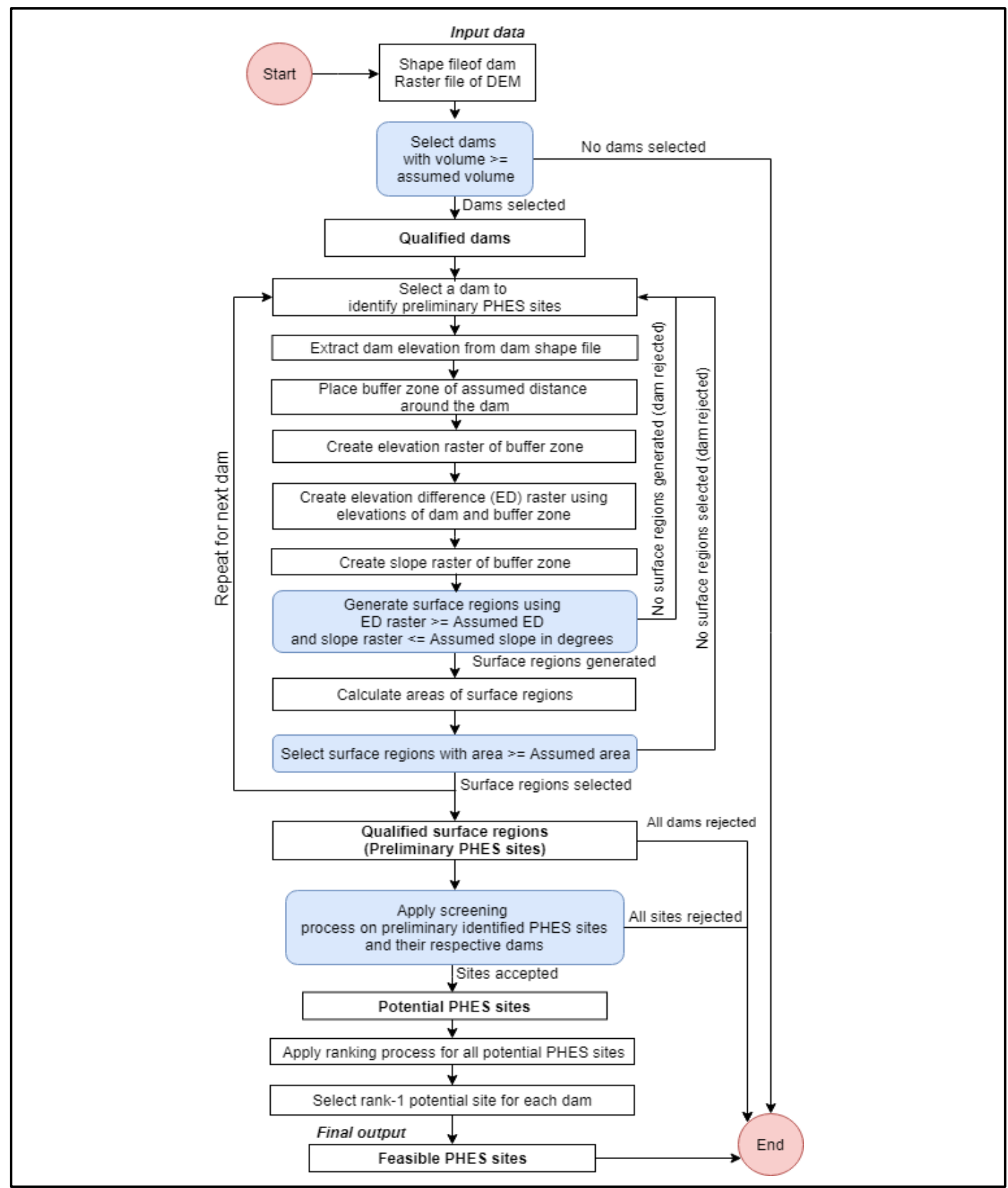

Figure 3.2 Flowchart of GIS processing for feasible PHES/ GPM sites with dams 


\subsubsection{Case II: Identification of Feasible PHES/ GPM Sites with Lakes}

The detail of GIS processing of this case is the same as explained in the case I except to replace the dams with lakes throughout the whole process.

\subsubsection{Case III: Identification of Feasible PHES/ GPM Sites with Rivers}

The detail of GIS processing of this case is provided below:

\section{Identification of Preliminary PHES Sites}

The shapefile of rivers was processed to check the assumed minimum river flow using hydrological data that is generally maintained by the concerned region of the respective country. The assumed minimum river flow should be equal to or greater than mean annual flow minus 7Q20 low flow of the river. The rivers qualified for assumed minimum flow condition were considered for their processing to identify the preliminary sites, whereas the remaining unqualified rivers were rejected. If all rivers are rejected, the processing stops with no output data for rivers.

The qualified rivers were selected one by one for the defined automated process of sequential activities. First of all, a buffer zone of assumed distance was created along the right and left banks of the river. The elevation raster of the buffer zone was created using DEM. The slope raster of the buffer zone was generated. The surface regions were generated within the buffer zone satisfying the limits of assumed maximum slope.

In the case of conventional PHES sites, the surface regions were selected one by one to check their area and ED conditions. The average elevation of each selected surface region was calculated. For each selected surface region, the nearest point at the river was located and its elevation was recorded. The elevation difference (ED) was calculated for each surface region and its nearest point located at the river. Finally, the surface regions were selected satisfying the assumed minimum area of a PHES site and assumed minimum ED limit. For GPM site, ED limit condition is not required. This process was repeated for all surface regions of the river under process to select its qualified surface regions ('Loop B' in Figure 3.3) for PHES sites only.

After completion of the above process for PHES sites, the process was repeated for the next river ('Loop A' in Figure 3.3). The processes of loop A and loop B (ED condition is not required for 
GPM site) were applied for all the rivers. The selected surface regions of the rivers were named as 'preliminary PHES/ GPM sites'. If none of the surface regions were selected, the processing stops with no output data for rivers.

\section{Screening of Preliminary PHES Sites}

This process is same as explained in Case I of the dams and the sites selected as a result of the screening process of rivers under this case were named as 'potential PHES/ GPM sites'. If no potential PHES site is selected, the processing stops without any potential PHES/ GPM sites.

\section{Ranking of Potential PHES Sites}

Again, this process is the same as described in Case I of the dams and finally selected PHES sites were named as 'feasible PHES/ GPM sites'.

The flow chart illustrating the GIS processing for identifying feasible PHES/ GPM sites with rivers is provided in Figure 3.3 as provided below. 


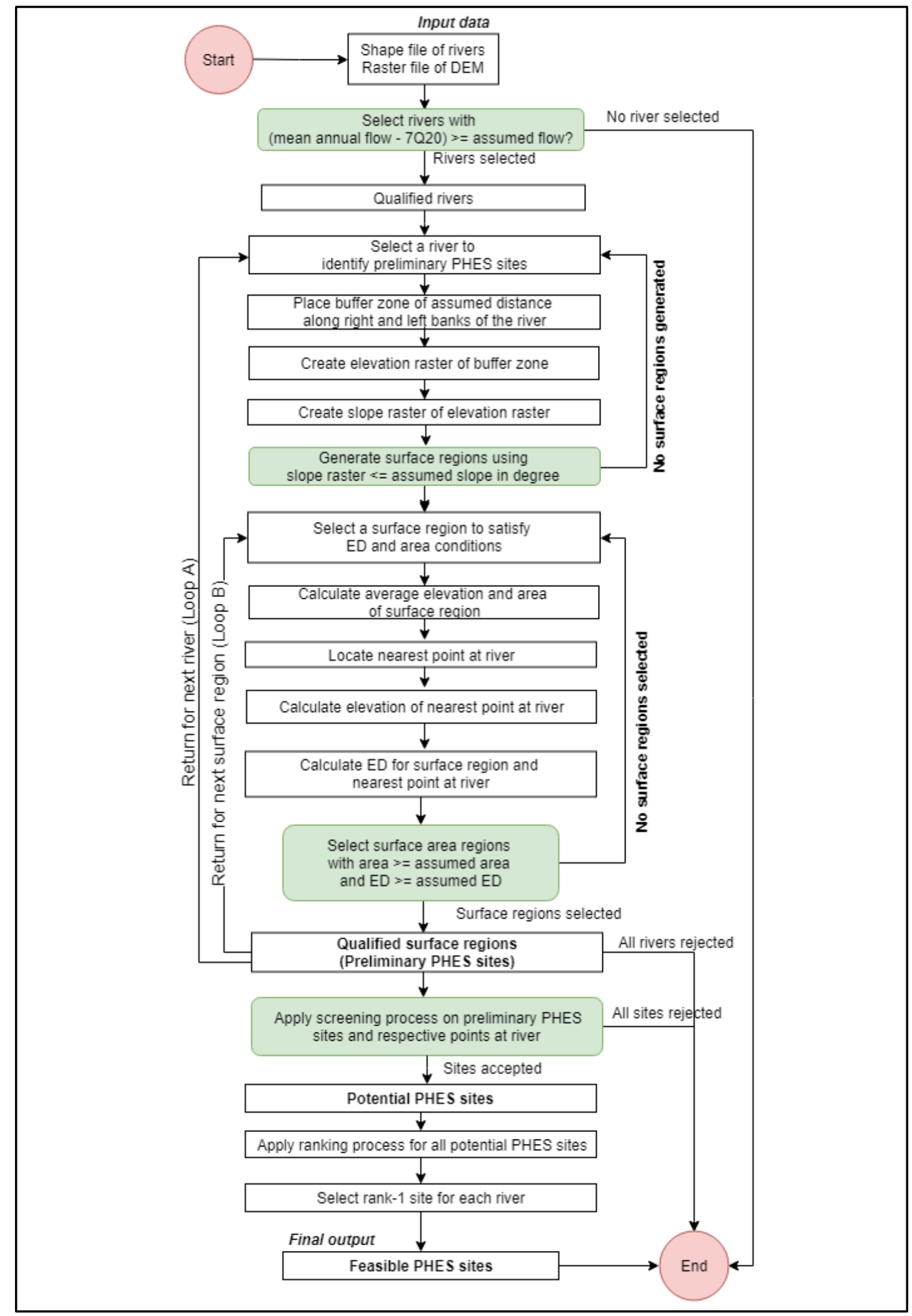

Figure 3.3 Flowchart of GIS processing for feasible PHES/ GPM sites with rivers 


\subsubsection{Case IV: Identification of Feasible PHES/ GPM Sites with Abandoned Mines}

The detail of GIS processing of this case is provided below:

\section{Identification of Preliminary Sites using Abandoned Mines}

In this case, an abandoned mine is used as a PHES/ GPM site and the primary reservoir may be a dam or lake qualifying minimum required volume of water, or it may be a river qualifying minimum required flow of water. The qualified dams, lakes and rivers were already available in their respective processing results as provided in previous sections. For PHES sites, the volume of all the mines was calculated using the available data and it was checked with the assumed minimum required volume of PHES reservoir. The mines qualifying the criteria were selected for further processing. If no mine is selected, the processing stops with no output data for mines.

The qualified mines were selected one by one for GIS processing using a defined sequence of activities. First of all, the waterbodies were located within the assumed buffer distance. If waterbodies are not found within the buffer distance, the processing continued for next mine. The resulting pairs of current mine and its respective nearby waterbodies were recorded in a table called 'near table'.

Only for the PHES case, the shapefile of nearby waterbodies were joined with near table to get their elevations. The surface elevation of mine was calculated using the DEM. The surface elevation of mine, depth of mine and elevation of waterbodies were used to calculate the elevation difference (ED) by deducting the sum of surface elevation and depth of mine from maximum elevation of dam/ lake or river. The calculated ED was checked with the assumed minimum ED value. The mines satisfying the minimum elevation difference were selected qualified mines as the 'preliminary PHES sites' along with their respective waterbodies. For GPM sites, this process is not required for qualifying the ED requirement.

The mines qualifying the above conditions were termed as preliminary PHES/ GPM sites. If no mine is qualified, the processing stops without any preliminary PHES site. 


\section{Screening of Preliminary PHES/ GPM Sites}

The screening process is same as explained in Case I. The mines selected as a result of the screening process were termed as 'potential PHES/ GPM sites'. If no potential mine site is selected, the processing stops without any potential mine sites.

\section{Ranking of Potential PHES Sites}

Again, this process is the same as described in Case I of the dams and finally selected PHES sites were termed as 'feasible PHES/ GPM sites'. The flowchart showing the methodological process of GIS-based model to identify feasible PHES/ GPM sites using abandoned mines is provided in Figure 3.4 below.

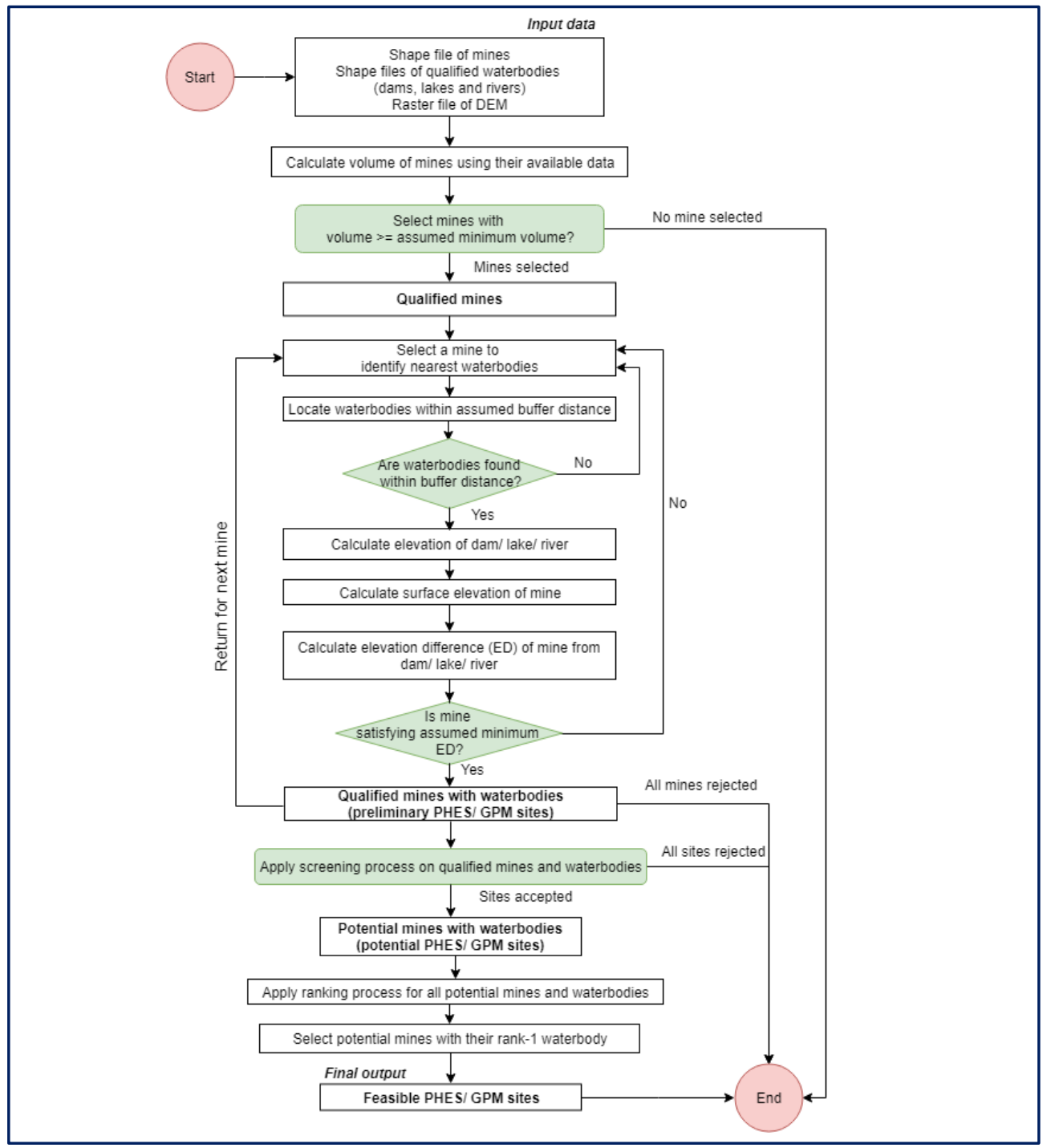

Figure 3.4 Flowchart of GIS processing for feasible PHES/ GPM sites with abandoned mines 


\subsection{Developing Optimization Model for PHES Scheduling}

\subsubsection{Introduction}

The literature review reveals that PHES can be used for providing ancillary services including operating reserve to the electricity market operators. The optimization of feasible PHES potential in a particular electricity market region at grid level is followed by the financial analysis to test the financial viability of the PHES system. Moreover, the PHES participation in the supply-mix bidding of providing real-time supply to meet the peak hours' demand is also considered in this research study.

The study by Opathella and Venkatesh (2013) assumed two hypothetical PHES facilities with wind generation without actual identification of feasible PHES potential in Ontario. Additionally, the optimization of assumed PHES potential was not performed and their services were directly used for two purposes: (i) to utilize the variable part of the wind power supply, and (ii) to meet any shortfall of the contracted firm part of wind power. Also, the association of PHES was not formed for collective use of feasible PHES potential. Therefore, the services of PHES plants were simply used on a rental basis without considering the techno-economic aspects of the PHES system. These gaps are also highlighted for other past studies in the literature review chapter.

In order to address the PHES tasks that are not considered in the past studies, this research study developed an optimization model for PHES scheduling and assumed that a large capacity of combined PHES storage can provide a large part of ancillary services as well as to meet the peak hours' demand. In this way, the collective operation of PHES plants can confidently support the system to enable large penetration of renewables as well as to utilize other surplus base-load generation (SBG) by managing the adequate storage capacity. The study by Poullikkas (2013) also advised that the collective use of PHES plants can be useful for a big electricity system at grid level to make a reliable and secure power operation system. Therefore, this research proposed that PHES plants can join together for their integration in a large existing electricity market of such as the IESO in Ontario, Canada.

This research has therefore applied a collective operation of PHES plants with a proposed cooperative association for their active participation in the electricity market to test the 
techno-economic viability of their integration in the market system. For this purpose, the optimization of the identified PHES potential is performed assuming that the PHES system is existed and qualified for the existing regulatory requirements of the market system operator. The other detailed assumptions have been summarized at the end of this section. The proposed cooperative association was assumed to have a contract with market operator for providing ancillary services and participating in the bidding process of real-time market. In this regard, an optimization model is developed that maximizes the revenue of PHES system by optimal scheduling to utilize the surplus baseload generation (SBG) including the renewable energy at a low purchase price for pumping and sale out the stored electricity at a high price. The revenue generation is particularly due to the difference in energy price that is lowest at the time of energy purchase and highest at the time of energy sale during on-peak hours. However, the round-trip energy conversion efficiency reduces the purchased energy potential at its generation time. The proposed cooperative association was named as 'Pumped Hydro Storage Association (PHSA)'.

The scheduling of participatory PHSA plants was optimized to set the model application in real term with continuous time-varying power prices. The profitable results can further encourage the inclusion of PHES plants to strengthen the association with more active participation in the electricity market. More importantly, the profitable optimization results can strengthen the confidence level of market operator upon renewable energy producers having their promising participation in electricity market as proposed in the study of Opathella and Venkatesh (2013).

Following an existing electricity operating system controlled by utility operator, a market operation is proposed to realize the benefits of PHES plants through PHSA. According to that, all PHES plants have the same contract within the PHSA that defines their operational working with the PHSA. The PHSA will maintain daily operation accounts for all participatory plants to record their respective contribution towards storage and electricity generation. Accordingly, the net profit will be divided among the participated PHES plants.

This research study developed a formulation for optimizing the PHES scheduling administered by the PHSA with the following assumptions: 
- All the member plants physically exist, grid-connected and ready to provide the required services to the market operator;

- The PHSA fully qualify the regulatory requirements of the market operator to become a supply-mix participant at grid level;

- The market operator is agreed to give a priority to PHSA over other competitors in market bidding to provide both operating reserve and real-time power demand at the same competitive electricity rates;

- The operational costs of PHSA include administrative cost of PHSA, and O\&M costs of individual PHSA plants; and

- The active storage energy (PSA) at real-time demand and total storage operating reserve (TSR) include the following components of power flows:

- Energy generation from active storage at real-time demand provided by PHSA to the grid is a positive (+) component;

○ Pumping energy to fill active storage at real-time supply provided by the grid to PHSA is a negative (-) component;

○ Energy generation from reserve storage at real-time demand provided by PHSA to the grid and maintaining fixed operating reserve in terms of filled storage capacity are the positive $(+)$ components; and

- Pumping energy to fill operating reserve storage at real-time supply provided by the grid to PHSA is a negative (-) component.

\subsubsection{Basic Operating Principles of the Model}

The basic operating principles are based on the following operations:

- PHSA purchases energy from the grid through the market operator at a low price for pumping operation using unutilized surplus base-load generation (SBG) including unutilized energy of renewables like wind and solar and surplus energy of nuclear plants and run-of-the-river hydro plants;

- PHSA directly supplies energy to the grid through market operator during peak hours' demand by taking part in real-time market bidding; and 
- PHSA has a firm contract with the market operator to provide ancillary services including operating reserve in two ways:

○ Maintaining regular operating reserve as fixed reserve storage capacity; and

$\circ \quad$ Providing operating reserve supply when it is needed by the system.

Therefore, the PHSA generates revenue from the following income sources:

- Sale of energy to market operator during peak hours demand;

- Sale of ancillary services including operating reserve to the market operator; and

- Maintaining the operating reserve to provide assured supply services to the market operator throughout the contract period.

The PHSA incurs expenses for the following costs:

- Purchase of pumping energy from the market operator through controlled grid operation;

- O\&M cost of PHES plants including administrative cost of PHSA; and

- The capital investment is used for computation of net cash flows.

\subsubsection{Model Network Mechanism}

The optimization was performed for life period of PHES plants covering all seasons of every year for maximum utilization of the power generated from PHES plants. The PHSA is responsible to safeguard the interest of all participatory PHES plants. The administration cost of PHSA will be shared by all participatory plants.

The PHSA is comprised of existing participatory PHES plants to form an association that has a contract with the market operator to provide ancillary services including operating reserve and to take part in real-time electricity market bidding. It is pertinent to point out that the option of Public-private partnership system can be considered for this model. Figure 3.5 shows the proposed electricity network mechanism of PHSA with its active role for providing reliable power supply to meet the continuous time-varying hourly demand of the system. 


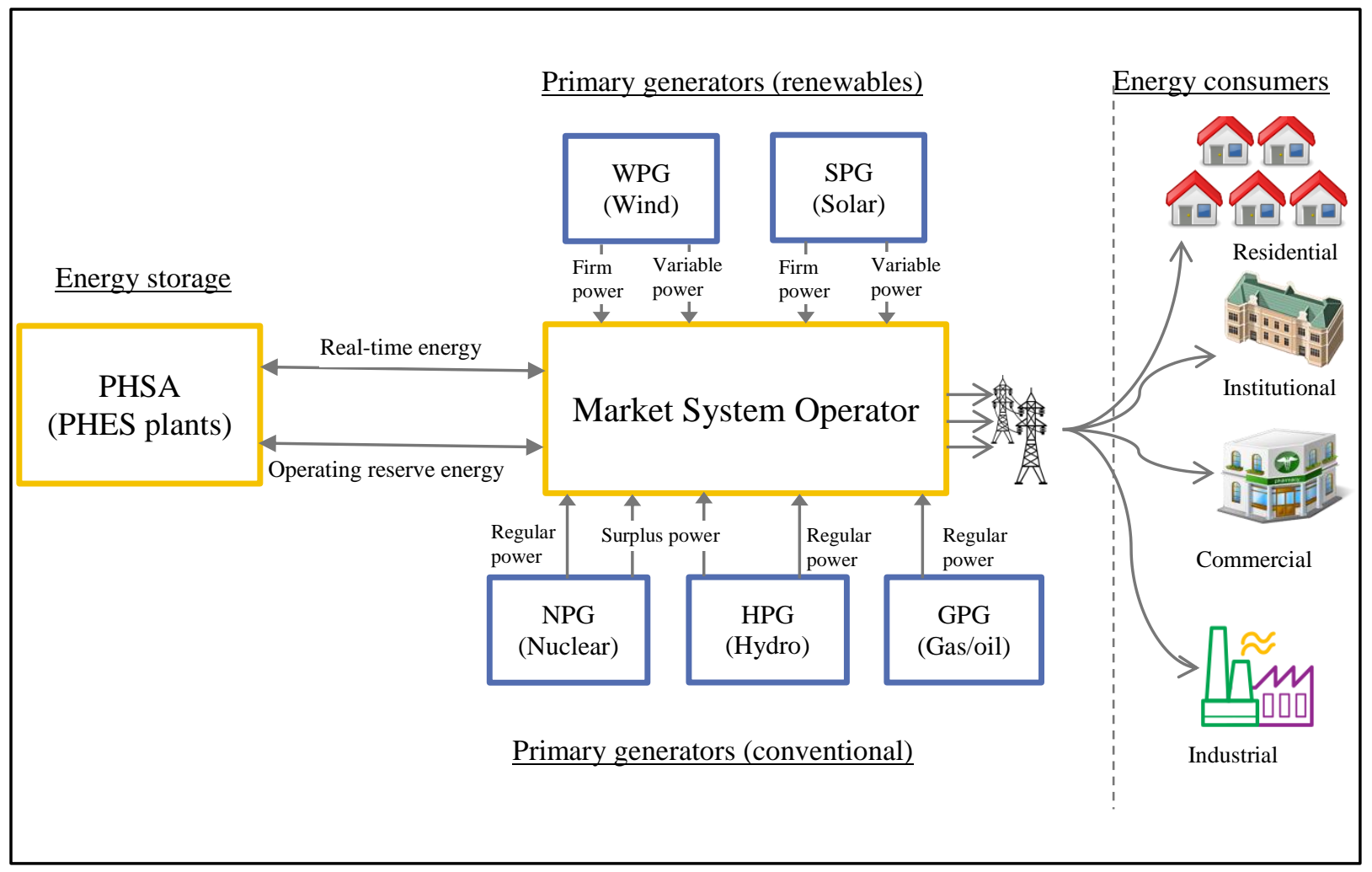

Figure 3.5 Schematic diagram showing model energy network mechanism of PHES plants

The mechanism of cash flows for revenue generation and expenses incurred by PHSA is presented in Figure 3.6 as given below. The system was optimized to maximize the profit of PHSA to be shared by all participatory PHES plants.

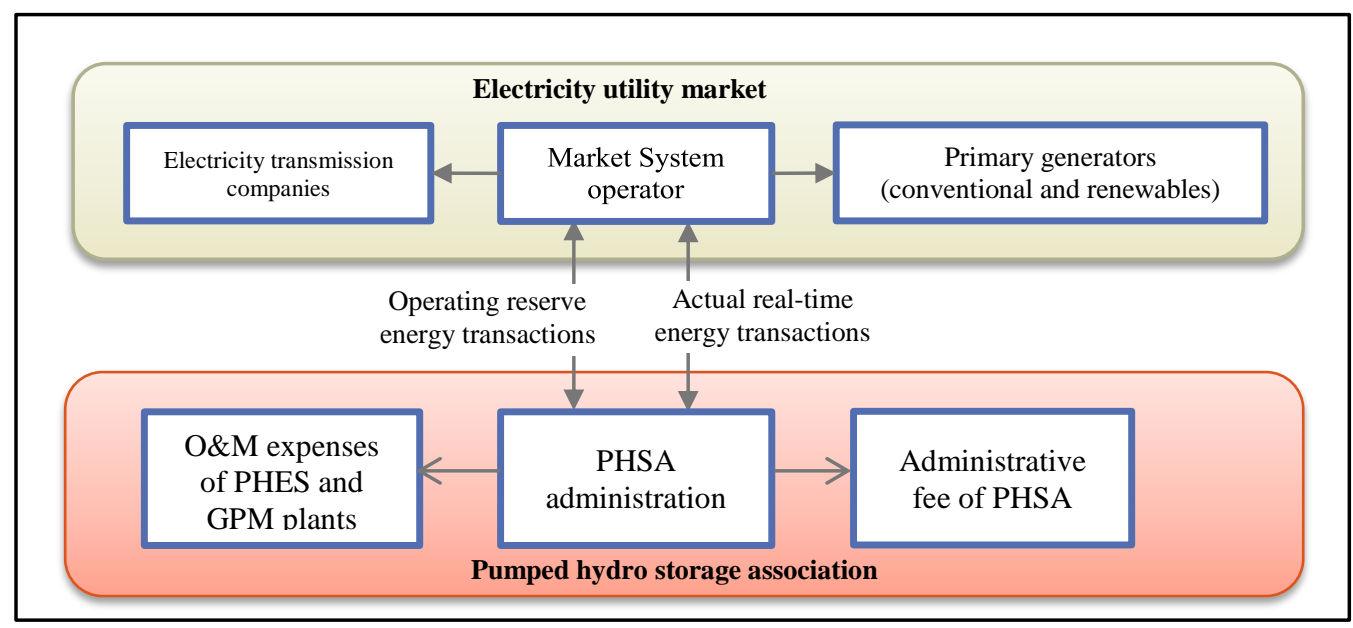

Figure 3.6 Schematic diagram showing cash flow system of PHSA model 


\subsubsection{Problem Formulation for Optimization Model}

The optimization is performed for the life period of PHES plants considering each year of $\mathrm{nS}$ seasons having $\mathrm{nD}_{\mathrm{s}}$ days in each season and $\mathrm{nT}$ hours in each day of 24 hours. This model is an hourly averaged model that optimizes energy storage output of PHSA in two forms: (i) 'real-time energy storage capacity' to supply electricity during peak hours demand while energy is purchased during off-peak hours, and (ii) 'operating reserve energy storage capacity' to provide ancillary services to the market operator by: (a) sale/ purchase of operating reserve energy supply (b) maintaining fixed operating reserve energy capacity. All the model parameters are dependent on each bidding period.

\section{Objective Function}

Maximize the revenue generated from sales and purchases of 'real-time storage energy (PSA)' and 'variable operating reserve energy (PVR)' at real-time demand of market operator, contractual rent of maintaining storage capacity for 'fixed operating reserve energy (PFR)', and minimize the total operational costs of energy storage (CST).

Let the selling rates for providing active storage energy, variable operating reserve energy and fixed operating reserve energy are BA, BR and BF respectively and their purchase cost rate is CA which is same for the purchase of all types of energy. Additionally, keeping in view that the PHES system is not 100 percent efficient, the efficiency of the system is assumed $\eta$ to take into account the loss of energy.

The objective function can be written as:

Revenue generated from sale and purchase of energy by PHSA - Total operational costs of PHSA

$$
\begin{aligned}
= & \operatorname{Rev}( \pm P S A)+\operatorname{Rev}( \pm P V R)+\operatorname{Rev}( \pm P F R)-C S T \\
=\sum_{s}^{n S} \sum_{d}^{n D} \sum_{h}^{n H}\left(P S A_{s, d, h} \times B A_{s, d, h}\right) & +\sum_{s}^{n S} \sum_{d}^{n D} \sum_{h}^{n H}\left(P V R_{s, d, h} \times B R_{s, d, h}\right)+\sum_{s}^{n S} \sum_{d}^{n D} \sum_{h}^{n H}\left(P F R_{s, d, h} \times B F_{s, d, h}\right) \\
& -\sum_{s}^{n S} \sum_{d}^{n D} \sum_{h}^{n H}\left(\frac{1}{\eta}\left(P S A_{s, d, h}+P V R_{s, d, h}\right) C A_{s, d, t}\right)-\sum_{h}^{n H}\left(\frac{1}{\eta}\left(P F R_{h}\right) \times C A_{h}\right) \\
& -\sum_{S}^{n S} \sum_{d}^{n D} \sum_{h}^{n H} C S T_{s, d, h} \ldots \ldots \ldots \ldots \ldots \ldots \ldots \ldots \ldots \ldots \ldots \ldots \ldots \ldots
\end{aligned}
$$




\section{System Constraints}

The system constraints are as follows:

1. Energy supply balance of PHSA

$$
\left(\mathrm{PSA}_{\text {off }_{s, d, h}}+\mathrm{PSA}_{\text {mid }_{s, d, h}}+\mathrm{PSA}_{\mathrm{on}_{s, d, h}}\right)+\mathrm{PVR}_{s, d, h}=\eta \mathrm{PBH}_{s, d, h}
$$

2. Total energy output of PHSA

$\mathrm{PBH}_{s, d, h}=\sum_{\mathrm{p}=1}^{\mathrm{nP}} \mathrm{PBH}_{\mathrm{p}, s, d, h}$

3. Energy storage balance of PHSA

$$
\left(\mathrm{PSA}_{\mathrm{off}_{s, d, h}}+\mathrm{PSA}_{\text {mid }_{s, d, h}}+\mathrm{PSA}_{\mathrm{on}_{s, d, h}}\right)+\mathrm{PVR}_{s, d, h}+\mathrm{PFR}_{s, d, h}=\mathrm{PSH}_{s, d, h}
$$

4. Total energy purchased and maintaining fixed operating reserve by PHSA

$$
\eta \mathrm{PBH}_{s, d, h}+\mathrm{PFR}_{s, d, h} \leq \mathrm{PSH}_{s, d, h}
$$

5. Energy output from all PHES plants

$\eta \mathrm{PBH}_{s, d, h} \leq\left(\mathrm{PDL}_{\mathrm{off}_{s, d, h}}+\mathrm{PDL}_{\mathrm{mid}_{s, d, h}}+\mathrm{PDL}_{\mathrm{on}_{s, d, h}}\right)+\mathrm{TSR}_{s, d, h}$

6. Total energy supply of active and reserve storage

$$
\begin{aligned}
& \left(\mathrm{PSA}_{\mathrm{off}_{s, d, h}}+\mathrm{PSA}_{\text {mid }_{s, d, h}}+\mathrm{PSA}_{\mathrm{on}_{s, d, h}}\right)+\mathrm{PVR}_{\mathrm{s}, d, h} \leq\left(\mathrm{PDL}_{\mathrm{off}_{s, d, h}}+\mathrm{PDL}_{\text {mid }_{s, d, h}}+\right. \\
& \left.\mathrm{PDL}_{\mathrm{on}_{s, d, h}}\right)+\mathrm{TSR}_{s, d, h}
\end{aligned}
$$

7. Active energy storage supplies during off, mid and on-peak hours

$$
\begin{aligned}
& \mathrm{PSA}_{\mathrm{off}_{s, d, h}} \leq \mathrm{PDL}_{\mathrm{off}_{s, d, h}} \ldots . \\
& \mathrm{PSA}_{\text {mid }_{s, d, h} \leq \mathrm{PDL}_{\text {mid }_{s, d, h}}} . \\
& \mathrm{PSA}_{\mathrm{on}_{s, d, h}} \leq \mathrm{PDL}_{\mathrm{on}_{s, d, h}} \ldots . .
\end{aligned}
$$

8. Total storage capacity of all participatory PHES plants

$$
\mathrm{PSH}_{s, d, h} \leq\left(\mathrm{PDL}_{\mathrm{off}_{s, d, h}}+\mathrm{PDL}_{\text {mid }_{s, d, h}}+\mathrm{PDL}_{\mathrm{on}_{s, d, h}}\right)+\mathrm{TSR}_{s, d, h}
$$

9. Proportions of fixed and variable operating energy reserve

$$
\begin{aligned}
& \mathrm{PTR}_{s, d, h} \leq \mathrm{q} \times \mathrm{PSH}_{s, d, h} \\
& \mathrm{PVR}_{s, d, h} \leq \mathrm{r} \times \mathrm{PTR}_{s, d, h}
\end{aligned}
$$

where, $\operatorname{PTR}_{s, d, h}=\mathrm{PFR}_{s, d, h}+\mathrm{PVR}_{s, d, h}$

10. Total operating cost of PHSA

$$
\sum_{\mathrm{s}}^{\mathrm{nS}} \sum_{\mathrm{d}}^{\mathrm{nD}} \sum_{\mathrm{h}}^{\mathrm{nH}} \mathrm{CST}_{\mathrm{s}, \mathrm{d}, \mathrm{h}}=\mathrm{kf}\left(\mathrm{PSH}_{s, d, h}\right)
$$

11. Non-negativity condition

$$
\mathrm{PSA}_{\text {off }_{s, d, h}}, \mathrm{PSA}_{\text {mid }_{s, d, h}}, \mathrm{PSA}_{\mathrm{on}_{s, d, h}}, \mathrm{PVR}_{s, d, t}, \mathrm{PFR}_{s, d, h} \text {, and } \mathrm{PBH}_{s, d, h} \geq 0
$$


Where,

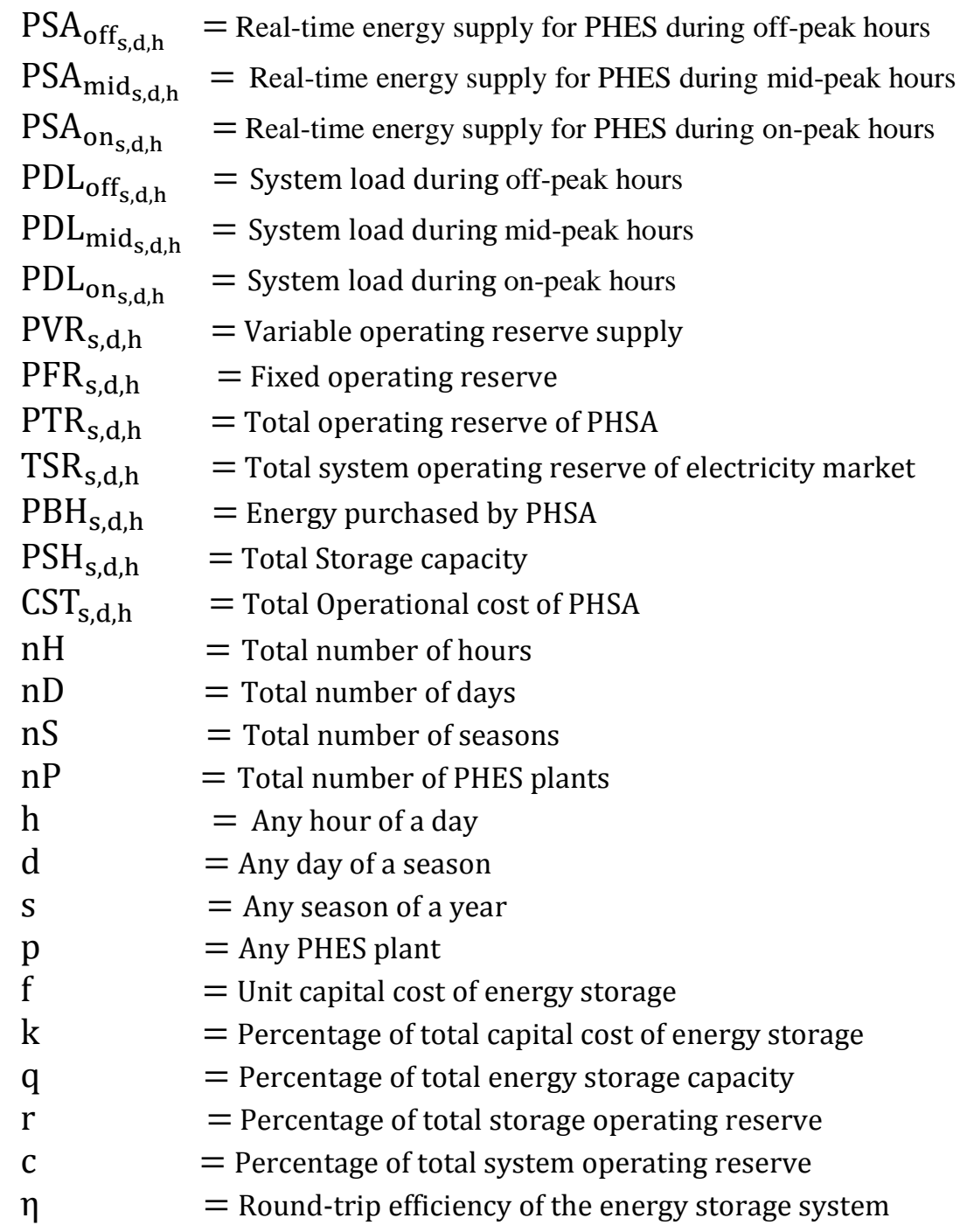

In this optimization problem, the input parameters are: $\mathrm{PDL}_{\mathrm{off}_{\mathrm{s}, \mathrm{d}, \mathrm{h}}}, \mathrm{PDL}_{\mathrm{mid}_{\mathrm{s}, \mathrm{d}, \mathrm{h}}}, \mathrm{PDL}_{\mathrm{on}} \mathrm{s}_{\mathrm{s}, \mathrm{h}}$, $\mathrm{TSR}_{\mathrm{s}, \mathrm{d}, \mathrm{h}}, \mathrm{PSH}$ and $\mathrm{CST}_{\mathrm{s}, \mathrm{d}, \mathrm{h}}$. 


\section{Decision Variables}

The decision variables have been selected for real-time energy supply by PHSA during offpeak, mid-peak and on-peak hours. These variables are used to calculate the energy revenue using the particular energy supply rates in respective hours. The supply of variable operating reserve is based on a flat rate in one operating cycle irrespective of the particular off-peak mid-peak and on-peak hours. Similarly, the cost of maintaining the fixed operating reserve is also based on a flat rate during an operating cycle. The energy purchased by PHSA is based on a single rate during one operating cycle. Total energy purchased in one operating cycle is the sum of all real-time energy supplies and operating reserve supply divided by the round-trip efficiency of the pump-turbine unit. The decision variables used in this optimization problem are: $\mathrm{PSA}_{\mathrm{off}_{\mathrm{s}, \mathrm{d}, \mathrm{h}}}, \quad \mathrm{PSA}_{\text {mid }_{\mathrm{s}, \mathrm{d}, \mathrm{h}}}, \mathrm{PSA}_{\mathrm{on}_{\mathrm{s}, \mathrm{d}, \mathrm{h}}}, \mathrm{PFR}_{\mathrm{s}, \mathrm{d}, \mathrm{h}}, \mathrm{PVR}_{\mathrm{s}, \mathrm{d}, \mathrm{h}}$, and $\mathrm{PBH}_{\mathrm{s}, \mathrm{d}, \mathrm{h}}$.

\section{Optimization Solution}

This optimization problem can be solved using any commercial linear programming (LP) software. This research used LINGO version 17 to solve the problem.

\subsubsection{Optimization Data}

The developed optimization model is to be applied in a particular case study of the existing electricity market system at the grid level. The energy potential of PHES plants identified in the GIS-based model is to be optimized to get the optimal scheduling results of PHSA. The actual applications of both GIS and optimization models have been provided in the forthcoming chapter of this research report. The data used in the optimization process was divided into the following two categories:
(A) Input data, and
(B) Output data

The detail of the above data is given below: 


\section{(A) Input Data}

The input data has been item-wise explained below:

(i) Total Hours in One Operating Cycle of Participatory PHSA Plants

The case study of this research assumes 24 hours of a day in one operating cycle.

(ii) Season-Wise Months, Days and Peak Hours of Particular Utility System

The particular study has to follow the off-peak, mid-peak and on-peak hours in one operating cycle defined by the concerned utility operator. These hours are generally different for different seasons in a year.

\section{(iii) Total Energy Potential of PHSA Plants}

This is the total energy potential of all PHES plants identified in the GIS-based model. The total potential has to be collectively utilized in the optimization process.

\section{(iv) Capital Cost of PHSA Plants}

This has to be estimated for a particular study of PHES plants. This cost is generally based on past studies data or it can be estimated with the empirical formula using sitespecific parameters of the plants.

\section{(v) Yearly O\&M Cost of PHSA Plants}

The O\&M cost of PHSA plants for the first starting year is generally estimated as the percentage of the capital cost of the PHES plants. The O\&M cost of the following years would be increased by yearly commodity price escalation rate of the concerned country.

(vi) System Load Parameters and Total Operating Reserve of Utility Market System

This is the energy demand and system operating reserve of the concerned electricity market that has to be met by the PHSA plants for which the optimization process is performed. This data can be collected from the concerned electricity market operator.

\section{(vii) Electricity Sale and Purchase Rates}

The optimization has to be performed using the objective function and system constraints. The prevailing electricity rates as input data are used to calculate the values of objective function using the resulted values of decision variables as model output 
results. These rates are different in off-peak, mid-peak and on-peak periods which are to be provided by the concerned electricity market operator.

These rates are to be projected for the life period of PHSA plants based on the average yearly energy-price inflation rate defined in the concerned electricity market system. The projected rates are estimated for yearly purchase and selling rates of real-time energy load and operating reserve for life period of PHSA plants.

\section{(viii) Life Period of PHES Plants}

The literature review reveals that the PHES plants are characterized by long asset life having typically life periods from 50 to 100 years (Deane et al. 2010; Torres 2011). The studies by Guzman (2010) and Galvan-Lopez (2014) assumed 50 years life period for PHES schemes that are on the lowest side of the given typical range. Foley et al. (2015) reported only the payback periods for PHES schemes which are typically from 40 to 80 years without mentioning the life periods of PHES schemes. Therefore, considering the past studies data, the case study of this research considered 60 years as life period of PHES plants.

The reliability of a PHES system depends on timely observing and executing the energy purchase and supply services by the PHES plant Owners. Regular operation and maintenance ensure optimum functionality of the system on regular basis. Appropriate and timely maintenance can save the rehabilitation expenses to some extent as it positively affects the life of various parts of the plant components. Appropriate maintenance will ultimately provide better residual value on completion of the plant life cycle.

A summary of input data has been provided in Table 3.5 as given below. 
Table 3.5 Input data used in the optimization process

\begin{tabular}{|c|c|c|}
\hline Input Parameter & Symbol & Unit \\
\hline \multicolumn{3}{|l|}{ System Load } \\
\hline System load during off-peak hours & $P D L_{o f f}$ & MWh \\
\hline System load during mid-peak hours & $P D L_{\text {mid }}$ & MWh \\
\hline System load during on-peak hours & $P D L_{\text {on }}$ & MWh \\
\hline Number of days in operational cycles & $\mathrm{d}$ & Days \\
\hline \multicolumn{3}{|l|}{ System Operating Reserve (OR) } \\
\hline Total system OR & TSR & MWh \\
\hline Max. total storage OR as percentage of storage capacity & $\mathrm{q}$ & Percent \\
\hline Max. variable OR as percentage of total storage reserve & $\mathrm{r}$ & Percent \\
\hline \multicolumn{3}{|l|}{ Energy Selling and Purchase Rates } \\
\hline Selling rate of real-time energy supply during off-peak hours & $\mathrm{BA}_{\mathrm{off}}$ & \$/ MWh \\
\hline Selling rate of real-time energy supply during mid-peak hours & $\mathrm{BA}_{\text {mid }}$ & $\$ / \mathrm{MWh}$ \\
\hline Selling rate of real-time energy supply during on-peak hours & $\mathrm{BA}_{\text {on }}$ & $\$ / \mathrm{MWh}$ \\
\hline Selling rate of maintaining fixed OR & $B F$ & \$/ MWh \\
\hline Selling rate of variable OR & $B R$ & $\$ / \mathrm{MWh}$ \\
\hline Purchase rate of real-time and reserve energy & $C A$ & \$/ MWh \\
\hline \multicolumn{3}{|l|}{ Capacity of Energy Storage } \\
\hline Total energy capacity of PHES and GPM plants & $\mathrm{PSH}$ & MWh \\
\hline \multicolumn{3}{|l|}{ Cost of Energy Storage } \\
\hline Unit capital cost of energy storage & $f$ & \$/ MWh \\
\hline First year O\&M cost as percentage of capital cost & $k$ & Percent \\
\hline Yearly increase in O\&M cost & $m$ & Percent \\
\hline \multicolumn{3}{|l|}{ Interest Rate of Return } \\
\hline Minimum acceptable rate of return (MARR) & $i$ & Percent \\
\hline \multicolumn{3}{|l|}{ Miscellaneous Data } \\
\hline Yearly energy-use increase in Ontario & $\mathrm{c}$ & Percent \\
\hline Round-trip efficiency of the energy storage system & $\eta$ & Percent \\
\hline Electricity transmission line losses in Ontario & $\mathrm{b}$ & Percent \\
\hline Life period of PHES plants & $\mathrm{y}$ & Years \\
\hline
\end{tabular}

\section{(B) Output Data}

The values of decision variables and objective function are the output results of the optimization process. The resultant data of the optimization solution can be provided season-wise in each year for the entire life period of PHSA plants. The values of decision variables and objective function can be presented in a tabular form for the life period of the PHES plants.

\subsection{Sensitivity Analysis for GIS and Optimization Model Parameters}

The sensitivity analysis is generally used to test the model quality with respect to its parameters. Through sensitivity analysis, the model process can be checked for producing better results that can be judged with the analysis results obtained by changing the values of originally used model parameters. Heuvelink (1998) stated that the sensitivity analysis is often referred to as error analysis of the model processing. For example, in this research, a greater number of resultant PHES sites are expected with an increase in the buffer zone distance and vice versa. Hence, the sensitivity analysis results can guide to select the appropriate values in the model processing. 
Crosetto and Tarantola (2001) stated that sensitivity analysis covers complimentary aspects of the models and particularly explains how the variations in model output can be apportioned in a quantitative and qualitative manner with variation of its different sources. Pianosi et al. (2016) provided sensitivity analysis methods as One-At-a-Time (OAT) or All-At-a-Time (AAT) techniques. The difference between these two methods is their different approaches to select the input samples. In OAT model, only one input parameter is changed at a time while keeping all others fixed. In AAT method, all the input factors are changed simultaneously without keeping any parameter fixed and sensitivity to each factor considers the direct effect of that factor as well as the joint influence of combined interactions. Drolc and Končan (1996) used OAT method to perform sensitivity analysis to find the most sensitive component in QUAL2E model that was used for water quality modelling of the river Sava, Slovenia.

The case study of this research also adopted the OAT approach to analyse the key input data used in both GIS and optimization models:

In GIS model, the values have been assigned to the parameter with maximum or minimum limits like minimum area of PHES sites, maximum distance of buffer zone between primary reservoirs and PHES site, minimum elevation difference (ED) between primary reservoir and PHES site, maximum slope of the surface area regions of PHES sites, etc. Similarly, the optimization model assigned the value to the surface slope, surface area, and buffer distance and elevation head parameters.

The sensitivity analysis of this study aims to study the model parameters that have the greatest impact on the model output, the senility analysis process would study the respective change in output values by changing the value of only one parameter under study, at a time and keeping the values of other parameters unchanged. This process is repeated for all key parameters by changing their values in the same manner.

\subsection{Financial Analysis of PHES System}

Financial analysis was performed on the basis of optimization results for life period of participating PHES plants. This analysis is helpful for taking decisions on potential investment to develop the PHES schemes. This analysis provides information regarding the worth of net profit (or loss) on the basis of financial indicators considering all revenues and costs during the life 
period of the respective projects. The most commonly used financial indicators by financial analysts are as follows:

- Net Present Value (NPV)

- Internal Rate of Return (IRR)

- External Rate of Return (ERR)

- Payback Period

○ Undiscounted Payback Period

- Discounted Payback Period

- Cost-Benefit Ratio

The calculations of above indicators require an interest rate of return that is generally called minimum acceptable rate of return (MARR) which is a minimum return rate that can be applied on capital investment to earn minimum interest on a project. The MARR is usually set by the owner of the project. Generally, it is considered as "guaranteed" success. The MARR is provided by the upper management to the engineers performing an economic evaluation of a project. Therefore, the engineers do not have to determine the MARR value.

The above indicators are used to assess the desirability of a potential investment opportunity. According to Whitman and Terry (2012), the explanation of these indicators is given below:

\section{Net Present Value (NPV)}

The NPV is a sum of present values of all cash flows calculated after their conversion at zero year (start of first year) of the life period of a project using MARR as the interest rate. For a project of ' $n$ ' years' life period, the NPV can be calculated using the following formula:

$$
\mathrm{NPV}=\sum_{\mathrm{j}=0}^{\mathrm{n}} \frac{\mathrm{CF}_{\mathrm{j}}}{(1+\mathrm{MARR})^{\mathrm{j}}} .
$$

Where,

$C F_{j} \quad=$ Cash flow for period $j$

$j \quad=$ Respective period of cash flow

$M A R R=$ Discount rate

$n \quad=$ Total number of periods 
A positive value of NPV indicates that the project earns an actual interest rate greater than MARR; the negative value indicates that it earns an actual interest rate less than the MARR, and zero value indicates that it earns the MARR. Therefore, these outcomes will determine the viability of the project. A positive NPV indicates that the project is acceptable.

\section{Internal Rate of Return (IRR)}

The IRR is an actual interest rate that discounts a series of cash flows to an NPV equal to zero. Therefore, NPV $=\sum$ Present Value of cash flows with interest rate equal to IRR $=0 \ldots$ (3.19)

This equation can be written as:

$$
\begin{aligned}
& \mathrm{NPV}=\sum_{\mathrm{j}=0}^{\mathrm{n}} \mathrm{CF}_{\mathrm{j}}\left(\frac{\mathrm{P}}{\mathrm{F}}\right)_{\text {IRR }, \mathrm{j}}=0 \\
& \text { Or, NPV }=\sum_{\mathrm{j}=0}^{\mathrm{n}} \frac{\mathrm{CF}_{\mathrm{j}}}{(1+\mathrm{IRR})^{\mathrm{j}}}=0 \ldots \ldots . .
\end{aligned}
$$

Where,

$$
\begin{array}{ll}
C F_{j} & =\text { Cash flow for period } j \\
j & =\text { Respective period of cash flow } \\
n & =\text { Total number of periods }
\end{array}
$$

Once the IRR is calculated, it is compared with MARR. If the IRR is greater than MARR, the project is considered acceptable to the investor.

\section{External Rate of Return (ERR)}

The ERR is an interest rate that satisfies the following equation:

$$
\left|\sum_{\mathrm{j}=0}^{\mathrm{n}} \mathrm{C}_{\mathrm{j}}\left(\frac{\mathrm{P}}{\mathrm{F}}\right)_{\mathrm{MARR}, \mathrm{j}}\right|=\left[\sum_{\mathrm{j}=0}^{\mathrm{n}} \mathrm{I}_{\mathrm{j}}\left(\frac{\mathrm{F}}{\mathrm{P}}\right)_{\text {MARR },(\mathrm{n}-\mathrm{j})}\right] \times\left(\frac{\mathrm{P}}{\mathrm{F}}\right)_{\mathrm{ERR}, \mathrm{n}} .
$$

Where,

$$
\begin{array}{ll}
C_{j} & =\text { Negative cash flow at period } \mathrm{j} \\
I_{j} & =\text { Positive cash flow at period } \mathrm{j} \\
n & =\text { life-cycle of the project }
\end{array}
$$

The ERR can be solved using the following equation (3.23):

$$
\operatorname{ERR}=\left(\frac{F_{\mathrm{I}}}{P_{\mathrm{C}}}\right)^{1 / \mathrm{n}}-1
$$


where,

$$
\begin{aligned}
& F_{I}=\sum_{j=0}^{n} I_{j}\left(\frac{F}{P}\right)_{\text {MARR, }(n-j)} \\
& P_{C}=\left|\sum_{j=0}^{n} C_{j}\left(\frac{P}{F}\right)_{\text {MARR,j }}\right| \ldots .
\end{aligned}
$$

Once the ERR is calculated, the relation between MARR, IRR, and ERR will confirm the viability of the project with the condition that ERR lies between the MARR and the IRR.

\section{Payback Period}

The payback period can be calculated with or without discounting the time value of the money.

\section{Undiscounted Payback Period}

If the payback period is calculated without discounting the time value of money (NPV), it is called the undiscounted payback period.

\section{Discounted Payback Period}

If the payback period is calculated using NPV values, it is called the discounted payback period.

\section{Cost-Benefit Ratio}

The cost-benefit ratio of any project is a ratio of the invested capital money to the net benefit incurred during the life period of the project. This ratio shows a key role of the money invested, particularly in terms of the net profit as a proportion of the capital investment. Cost-benefit ratio conceived as a toolkit for the selection of projects and policies, in general interest. In financial analysis, benefits are the revenues earned, and costs are the expenses incurred as payments of input values at market prices (Rus 2010).

The financial analysis results were used to test the viability of the PHES system for the case study area. The MARR, internal rate of return and external rate of return should satisfy the following condition for a viable PHES system:

$$
\text { MARR } \leq \text { ERR } \leq \text { IRR }
$$

Additionally, the NPV values for the whole life period of the PHES plants should result in positive amounts for a viable system. Similarly, the payback periods and the cost-benefit ratios should have satisfactory results. 


\section{Case Study of Ontario}

\subsection{Energy Policy of Ontario}

In 2009, the Ministry of Energy took an important step through Ontario's Green Energy Act (GEA) to include renewable energy resources in Ontario's electricity supply-mix system. The GEA was intended to meet the targets of increased utilization of renewable energy and reducing the consumption of fossil fuels. Consequently, the Ministry issued a directive to OPA to prepare a plan for maximum utilization of renewable energy resources in the supply-mix energy of Ontario. Accordingly, the OPA updated the integrated power system plan (IPSP) in 2010. Although energy storage was recognized as a valuable tool in the directive, a clear direction was not provided to incorporate the storage in updated IPSP (Ontario Ministry of Energy 2010).

The Ontario Ministry of Energy (2013) adapted a positive and pragmatic approach with five main principles: cost-effectiveness, reliability, clean energy, community engagement and conservation, and demand management. Additionally, the government fixed top priority to prudently move forward with cost-effective transmission projects to meet the present and future demand and especially to accommodate the renewable energy projects. The Ontario Ministry of Energy (2013) also indicated that Ontario is committed to providing an incentive of approximately two billion dollars in five priority projects to be completed within the next seven years to ensure a growing integration of renewable resources in the supply-mix. This approach generated the conjunctive use of energy storages with renewable energy generators to make them fully reliable as well as to ensure their maximum utilization in the supply-mix energy system.

Consequently, the Ontario Ministry of Energy (2013) launched an idea to gradually phased-in the energy storage in support of renewable energy resources for maximum utilization of their installed capacity. The Ontario government intended to include more renewables in supply-mix power at grid level. Accordingly, the IESO prepared a report on the planning outlook of the electricity system to support the intended developments of long-term energy plan 2013 (IESO 2016a). 


\subsubsection{Ontario's Policy on Renewable Energy}

The Ontario Ministry of Energy (2013) indicated that the government realized to develop the innovative technologies to initiate work on priority, to address regulatory barriers that limit the abilities of energy technologies to compete in the Ontario's electricity market. The specific plan indicated that renewable energy will account for about one half of Ontario's installed capacity of 20,000 MW by 2025. Ontario will phase in wind, solar and bioenergy with 10,700 MW by 2021 . It was planned that Ontario will annually review the targets of wind, solar, bioenergy and hydroelectric to publish in the Ontario Energy Report. The Minister of Energy has issued various directives to OPA in 2013 and 2014 on "Renewable Energy" to develop a new competitive process for the procurement of renewable energy projects larger than $500 \mathrm{~kW}$. Meanwhile, the OPA was merged with IESO on Jan 01, 2015 and therefore, all ongoing responsibilities of OPA were shifted to comply by IESO. The IESO released a list of LRP-I contracts representing a total target of $454.885 \mathrm{MW}$ of clean renewable energy capacity. Ontario's Ministry of Energy also introduced the FIT and LRP programs as defined below:

- Micro Feed-In-Tariff (FIT): a program that allows Ontario residents to develop a very small or micro-renewable electricity generation project of $10 \mathrm{~kW}$ or less in size on their properties. Under the MicroFIT program, the generators are paid a guaranteed price for all the electricity they produce for at least 20 years.

- Feed-In-Tariff (FIT): a guaranteed rate that provides stable prices through longterm contracts for energy generated using renewable resources. This program includes the projects of more than $10 \mathrm{~kW}$ to $500 \mathrm{~kW}$.

- Large Renewable Procurement (LRP): a competitive process for procuring large renewable energy projects generally larger than $500 \mathrm{~kW}$ respectively.

The IESO was directed in 2016 for future renewable procurement through LRPII, micro-FIT and Feed-In-Tariff (FIT) procurements. The highlighted points are as follows:

- The FIT 5 program shall include a base target of up-to $150 \mathrm{MW}$ procurement by Sep 1, 2016. This program shall also include available contract capacity from termination of previous small FIT program (greater than $10 \mathrm{~kW}$ and up to and including $500 \mathrm{~kW}$ ) and including microFIT procurements; 
- The IESO will procure 930 MW by May 01, 2018 under LRPII procurement process; and

- The IESO will develop a proposal to transition the target of $50 \mathrm{MW}$ under the microFIT program by January 01, 2017.

Presently, Ontario has 9,500 MW installed capacity of renewable energy resources (excluding hydroelectric). The government of Ontario has planned to add further $900 \mathrm{MW}$ of new capacity by the year 2018 for the FIT and micro-FIT programs. The FIT program started in 2014 greatly provides the opportunity of feeding renewable energy in the grid with very attractive energy prices. The wind, solar and bio are the main listed renewable energy contributors to Ontario's supply mixed electricity. However, these energy producers are neither reliable nor capable of producing dispatchable energy for the grid due to their uncertain and intermittent nature. Therefore, conjunctive use of energy storage has been considered inevitable to make the renewables reliable and capable of providing their maximum energy output.

A special report prepared by Environmental Commissioner of Ontario (2017) worked on development of the Long-Term Energy Plan (LTEP) 2017 that balances the government's goals and objectives for the energy sector, including: cost-effectiveness, reliability and resiliency, conservation, cleaner energy sources and emerging technologies, air emissions, and aboriginal and stakeholder consultation. Consequently, the Ministry of Energy (2017) issued Ontario's LTEP 2017 entitled 'Delivery Fairness and Choice' that identified the following key initiatives:

- Ensuring affordable and accessible energy;

- Ensuring a flexible energy system;

- Innovative technologies to meet the future;

- Improving value and performance for consumers;

- Strengthening the commitment to energy conservation and efficiency;

- Responding to the challenge of climate change;

- Supporting First Nation and Metis capacity and leadership; and

- Supporting regional solutions and infrastructure. 
Ontario's LTEP 2017 is principally focused on reliable and innovative energy system. This plan makes an important commitment, through delivering fairness and choice, to make energy more affordable and give customers more choices in their energy use.

\subsubsection{Ontario's Policy on Energy Storage}

The updated Ontario's long term energy plan identified continued commitment for investment in renewable technologies as well as to explore new options for energy storage facilities. The IESO was directed to develop a procurement process for energy storage facilities in two phases with a total target of $50 \mathrm{MW}$. Phase I was allocated $35 \mathrm{MW}$ and remaining $15 \mathrm{MW}$ was allocated to phase II process. The costs associated with these projects are expected to be approximately $\$ 9$ million/ year.

Phase-I and II projects will come into service in 30 months and their contract term saves three years and ten years respectively which will be effective from the date they start their services. After completion of phase I and phase II procurement process, the IESO was directed by the Ministry of Energy to prepare a report highlighting the experience on these procurements. Accordingly, IESO has released a technical report in March 2016 on energy storage that was prepared jointly with Energy Storage Ontario (ESO). The report focuses on the reliability needs of the Ontario power system to be addressed by energy storage technologies. The report highlighted a number of opportunities. The reported opportunities include those that can be availed by current storage technology regulation, voltage control, and fast activation to address variances from the forecast, load following and ramping, operating reserve, and providing congestion relief and defer transmission upgrade. The report has specifically divided the energy storage in three types and highlighted the system constraints and opportunities for their placement in the Ontario electricity grid system as given below:

\section{Type 1 - Energy Storage}

These technologies are capable of withdrawing electricity from the grid, storing such energy for a period of time, and then re-injecting this electricity back to the grid. Examples include, but are not limited to, PHES, CAES, flywheels, and batteries. 


\section{Type 2 - Energy Storage}

These technologies withdraw electricity from the grid and store the energy for a period of time. They use the stored energy for consumption of their host facility at a later time. They do not reinject back the electricity into the grid. Examples include, but are not limited to, heat storage or ice production for space heating or cooling respectively.

\section{Type 3 - Energy Storage}

These are the energy storage techniques that only withdraw electricity from the grid like other loads, but convert it into a storable form of energy or fuel that is subsequently used in residential, commercial or industrial processes. Examples include, but are not limited to, electric vehicles, steam production and fuel production like hydrogen or methane.

It is important to note that opportunities for energy storage technologies are based on their use, size and facility locations. The key findings of the IESO report are as follows:

- Energy storage facility can provide a wide range of services including regulation, voltage control, operating reserve, and flexibility. However, in order to provide the services, the storage facilities must be appropriately sized and located in the areas free of restrictions or limitations.

- Up to early 2020s, the energy storage technologies that withdraw and re-inject electricity into the grid can be used to manage some surplus baseload generation (SBG). Beyond this time frame, the opportunities to manage SBG will depend on various factors including electricity demand, weather, and the value of carbon, consumer behaviour, planned nuclear refurbishment and outage timeliness.

- Future procurements are expected to return better value to target specific services like regulation, voltage control and capacity instead of specific technologies.

Environmental Commissioner of Ontario (2017) studied how can Ontario further support innovative storage technologies to take advantage of Ontario's clean energy system. This report also found that energy storage can provide many of the services that are needed for operating reliability in Ontario's electricity system. In LTEP 2017, the Ministry of Energy realized the importance of energy storage and accepted that it is a game-changing technology. This plan stated that Ontario has made a priority since 2013 to understand the 
value of energy storage. The government has identified the market and regulatory barriers for energy storage and started updating the necessary regulations. This plan also stated that the government is seeking support from the IESO and Ontario Energy Board (OEB) to take steps with their respective codes and rules that prevent the cost-effective development of energy storage. However, as a matter of fact, the government has not yet prepared proper planning and necessary regulations to implement the participation of energy storage in the electricity market.

\subsubsection{Ontario's Policy on Pumped Hydro Energy Storage (PHES)}

The LTEP (2013) stated that Pumped hydro storage can be used to store energy when it is not needed and deliver it to the grid during periods of peak demand. The PHES projects would continue to be examined for determining their cost-effectiveness and their ability to provide value to ratepayers (Ontario Ministry of Energy 2013). It was also stated that the Ontario government is willing to utilize PHES facilities at grid level with the acceptable cost so that the stored energy could be provided to the ratepayers within the prevailing competitive energy prices. The LTEP 2017 admitted that PHES potential could play an important role to ensure the reliability of the electricity system particularly by managing the supply and demand of the system. However, a clear policy on the PHES system is not provided in both the plans. There is a need to address the necessary issues including the direction to explore feasible sites, the regulations for issuance of permits and direct the IESO to work on planning for the procedures to allow PHES plants to take part in the electricity market, the priorities to be given to PHES for purchase and sale of electricity to provide operating reserve and real-time supply, purchase during on-peak hours, cash flow system for PHES in the electricity market, possible incentives that can be provided to PHES system, etc.

Therefore, the existing policy on both renewable energy and energy storage warrants concentrating on research work for novel energy storage technologies, including PHES to make it cost-effective facility. This requires a comprehensive planning approach to develop a methodology to identify feasible PHES sites to perform an optimization process for PHES scheduling using the existing market mechanism to confirm the viability of PHES system as a qualified energy storage facility. Currently, Sir Adam Beck pumped storage facility at Niagara Falls is the only PHES facility in operation. There is a need to explore available potential to 
utilize pumped hydro energy storage in Ontario. The power companies may be prepared to show their interest in this technology. Recently, Northland Power Inc. has been working on the development of a $400 \mathrm{MW}$ pumped hydro storage project in Marmora, Ontario, using an old open pit mine and an upper reservoir closed-loop configuration with four times the height of Niagara Falls Pumping Station.

\subsection{Existing and Future Energy Demand in Ontario}

The existing and projected energy demand is given in Table 4.1 (Ontario Ministry of Energy 2013). The renewable generators are contributing only $7 \%$ of total capacity and are available $10 \%$ to $30 \%$ of the time. In absence of the required wind and solar generation, the available contributors are nuclear, gas and hydro plants. It is important to note that, nuclear and gas have their adverse impacts on the environment while hydro has a comparatively lesser impact.

Table 4.1 Existing and planned energy capacity of Ontario (TWh)

\begin{tabular}{|l|c|c|c|}
\hline $\begin{array}{l}\text { Supply-Mix Power } \\
\text { Component }\end{array}$ & $\begin{array}{c}\text { Existing Capacity } \\
(\mathbf{2 0 1 2})\end{array}$ & $\begin{array}{c}\text { Planned Capacity } \\
(\mathbf{2 0 3 0 )}\end{array}$ & $\begin{array}{c}\text { Percent } \\
\text { Increase/Decrease }\end{array}$ \\
\hline Nuclear & 85.6 & 91.1 & $6.4 \%$ \\
\hline Hydroelectric & 33.8 & 39.6 & $17.2 \%$ \\
\hline Wind, solar, and bio & 7.6 & 25.4 & $234.2 \%$ \\
\hline Gas & 22.2 & 13.9 & $-37.4 \%$ \\
\hline Coal & 4.3 & 0.0 & $-100.0 \%$ \\
\hline Conservation & 7.6 & 27.7 & $264.5 \%$ \\
\hline Total & $\mathbf{1 6 1 . 1}$ & $\mathbf{1 9 7 . 7}$ & $\mathbf{2 2 . 7 \%}$ \\
\hline
\end{tabular}

Table 4.1 provides the effect on non-renewable generators by 2030 with a projected increase in the capacities of wind, solar and bio (Ontario Ministry of Energy 2013). In 2012, the available capacity of nuclear, gas and hydro was 145.9 TWh that is reduced to $144.6 \mathrm{TWh}$ in 2030. This shows a significant growth of renewables in terms of their overall capacity while non-renewables generation capacity is reduced by $1.3 \mathrm{TWh}$.

Table 4.2 Effect of projected increase in renewable generation

\begin{tabular}{|c|c|c|c|c|}
\hline \multirow{2}{*}{ Year } & \multicolumn{4}{|c|}{ Existing and Planned Installed Energy Capacity (TWh) } \\
\cline { 2 - 5 } & $\begin{array}{c}\text { Total } \\
\text { Supply-Mix }\end{array}$ & $\begin{array}{c}\text { Wind, Solar and } \\
\text { Bio (Renewables) }\end{array}$ & Conservation & $\begin{array}{c}\text { Balance for Nuclear, } \\
\text { Hydro and Gas }\end{array}$ \\
\hline 2012 & 161.1 & 7.6 & 7.6 & 145.9 \\
\hline 2030 & 197.7 & 25.4 & 27.7 & 144.6 \\
\hline \multicolumn{4}{|c|}{ Reduction of Nuclear, Hydro and Gas by 2030 } \\
\hline
\end{tabular}




\subsection{Existing Energy Output by Fuel Type in Ontario}

The annual report prepared by IESO (2017a) is given in Table 4.3 for Ontario's monthly energy output by fuel type for the year 2016. This report provides actual monthly energy output used to meet market demand, grouped by primary fuel type generators registered as a market participant in Ontario. This data was used in the optimization process of this research.

Table 4.3 Ontario's energy output by fuel type for the year 2016

\begin{tabular}{|l|c|c|c|c|c|c|c|}
\hline Month & $\begin{array}{c}\text { Nuclear } \\
\text { (TWh) }\end{array}$ & $\begin{array}{c}\text { Gas } \\
\text { (TWh) }\end{array}$ & $\begin{array}{c}\text { Hydro } \\
\text { (TWh) }\end{array}$ & $\begin{array}{c}\text { Wind } \\
\text { (TWh) }\end{array}$ & $\begin{array}{c}\text { Solar } \\
\text { (TWh) }\end{array}$ & $\begin{array}{c}\text { Biofuel } \\
\text { (TWh) }\end{array}$ & $\begin{array}{c}\text { Total Output } \\
\text { (TWh) }\end{array}$ \\
\hline January & 8.46 & 1.08 & 3.41 & 1.20 & 0.01 & 0.04 & $\mathbf{1 4 . 2 0}$ \\
\hline February & 7.85 & 0.87 & 3.23 & 0.93 & 0.02 & 0.04 & $\mathbf{1 2 . 9 3}$ \\
\hline March & 7.92 & 0.75 & 3.25 & 0.66 & 0.04 & 0.05 & $\mathbf{1 2 . 6 6}$ \\
\hline April & 6.91 & 0.67 & 3.20 & 0.61 & 0.05 & 0.03 & $\mathbf{1 1 . 4 6}$ \\
\hline May & 6.09 & 1.02 & 3.39 & 0.60 & 0.06 & 0.05 & $\mathbf{1 1 . 2 1}$ \\
\hline June & 7.32 & 1.02 & 3.09 & 0.58 & 0.06 & 0.03 & $\mathbf{1 2 . 1 0}$ \\
\hline July & 8.24 & 1.58 & 2.80 & 0.52 & 0.06 & 0.04 & $\mathbf{1 3 . 2 5}$ \\
\hline August & 8.08 & 2.12 & 2.71 & 0.50 & 0.05 & 0.06 & $\mathbf{1 3 . 5 3}$ \\
\hline September & 7.70 & 1.09 & 2.58 & 0.57 & 0.05 & 0.04 & $\mathbf{1 2 . 0 2}$ \\
\hline October & 7.72 & 0.74 & 2.61 & 0.75 & 0.03 & 0.05 & $\mathbf{1 1 . 9 1}$ \\
\hline November & 7.53 & 0.90 & 2.57 & 0.96 & 0.03 & 0.03 & $\mathbf{1 2 . 0 2}$ \\
\hline December & 7.88 & 0.92 & 2.89 & 1.45 & 0.01 & 0.03 & $\mathbf{1 3 . 1 8}$ \\
\hline Total & $\mathbf{9 1 . 7 0}$ & $\mathbf{1 2 . 7 6}$ & $\mathbf{3 5 . 7 2}$ & $\mathbf{9 . 3 4}$ & $\mathbf{0 . 4 7}$ & $\mathbf{0 . 4 9}$ & $\mathbf{1 5 0 . 4 8}$ \\
\hline
\end{tabular}

In order to perform the optimization process of PHSA scheduling, one day output of existing nuclear and gas generators was assigned in the proportions of $15 \%$ and $80 \%$ respectively, as a maximum system load for one day operating cycle of PHSA in different peak hours. Table 4.4 and Table 4.5 provides the system load for PHSA as portions of one day output from nuclear and gas generators respectively.

Table 4.4 Proportion of nuclear for daily output as system load of PHSA for 2016

\begin{tabular}{|l|c|c|c|c|c|}
\hline \multirow{2}{*}{ Peak Hours } & \multirow{2}{*}{$\begin{array}{c}\text { Peak Hours } \\
\text { Proportion }\end{array}$} & \multicolumn{2}{|c|}{ Total Output } & \multicolumn{2}{c|}{$\begin{array}{c}\text { PHSA System Load } \\
\text { (15\% of Total Output per Day })\end{array}$} \\
\cline { 3 - 6 } & & $\begin{array}{c}\text { Winter } \\
\text { (182 Days) }\end{array}$ & $\begin{array}{c}\text { Summer } \\
(\mathbf{1 8 4} \text { Days })\end{array}$ & Winter & Summer \\
\cline { 3 - 6 } & (GWh) & (GWh) & (MWh/ day) & (MWh/ day) \\
\hline Off-Peak & 0.468 & 21,783 & 21,134 & 17,962 & 17,238 \\
\hline Mid-Peak & 0.262 & 12,195 & 11,831 & 10,045 & 9,640 \\
\hline On-Peak & 0.270 & 12,567 & 12,193 & 10,353 & 9,936 \\
\hline Total & 1.000 & 46,544 & 45,158 & $\mathbf{3 8 , 3 6 0}$ & $\mathbf{3 6 , 8 1 3}$ \\
\hline
\end{tabular}


Table 4.5 Proportion of gas for daily output as system load of PHSA for 2016

\begin{tabular}{|l|c|c|c|c|c|}
\hline \multirow{2}{*}{ Peak Hours } & \multirow{2}{*}{$\begin{array}{c}\text { Peak Hours } \\
\text { Proportion }\end{array}$} & \multicolumn{2}{|c|}{ Total Output } & \multicolumn{2}{c|}{$\begin{array}{c}\text { PHSA System Load } \\
\text { (80\% of Total Output per Day) }\end{array}$} \\
\cline { 3 - 6 } & & $\begin{array}{c}\text { Winter } \\
\text { (182 Days) }\end{array}$ & $\begin{array}{c}\text { Summer } \\
(\mathbf{1 8 4} \text { Days })\end{array}$ & Winter & Summer \\
\cline { 3 - 6 } & & (GWh) & $(\mathbf{G W h )}$ & $(\mathbf{M W h}$ day) & (MWh/ day) \\
\hline Off-Peak & 0.468 & 2,427 & 3,545 & 10,674 & 15,420 \\
\hline Mid-Peak & 0.262 & 1,359 & 1,984 & 5,969 & 8,623 \\
\hline On-Peak & 0.270 & 1,400 & 2,045 & 6,152 & 8,888 \\
\hline Total & 1.000 & 5,186 & 7,574 & $\mathbf{2 2 , 7 9 6}$ & $\mathbf{3 2 , 9 3 1}$ \\
\hline
\end{tabular}

Table 4.4 and Table 4.5 shows that total system load for PHSA in winter and summer seasons of the year 2016 is $61,156 \mathrm{MWh}(38,360 \mathrm{MWh}+22,796 \mathrm{MWh})$ and 69,744 MWh $(36,813 \mathrm{MWh}+$ 32,931 MWh) respectively. Therefore, the PHSA can supply its total energy potential to meet the system demand in winter and summer seasons.

\subsection{Existing Surplus Baseload Generation (SBG) in Ontario}

The report by IESO (2016b) explains that the baseload generation is produced by the following resources:

- In-service refurbished nuclear generation;

- Run-of-river hydroelectric generation;

- Off-peak variable wind capacity contribution (WCC); and

- Variable solar generation.

The IESO report further stated that the baseload supplies can be managed using a market mechanism that includes inter-tie scheduling, dispatch of hydroelectric generation and gridconnected renewable resources, and nuclear manoeuvring or shut-down. However, these actions cannot be exercised all the times when Ontario demand is at its lowest. Therefore, consumption of SBG is always a challenge for the IESO. Figure 4.1 shows the SBG forecast for 18 months period from January 2017 to June 2018. This figure shows that total baseload generation is around 16,000 MW and the baseload generation after exports is around 12,000 MW (for 12 hours). After wind and nuclear curtailment and export, the minimum SBG remains around 108,000 MWh (average 9,000 MW for 12 hours) that needs to be managed to consume or store using energy storage. This energy potential can be utilized by PHSA for pumping operation. 


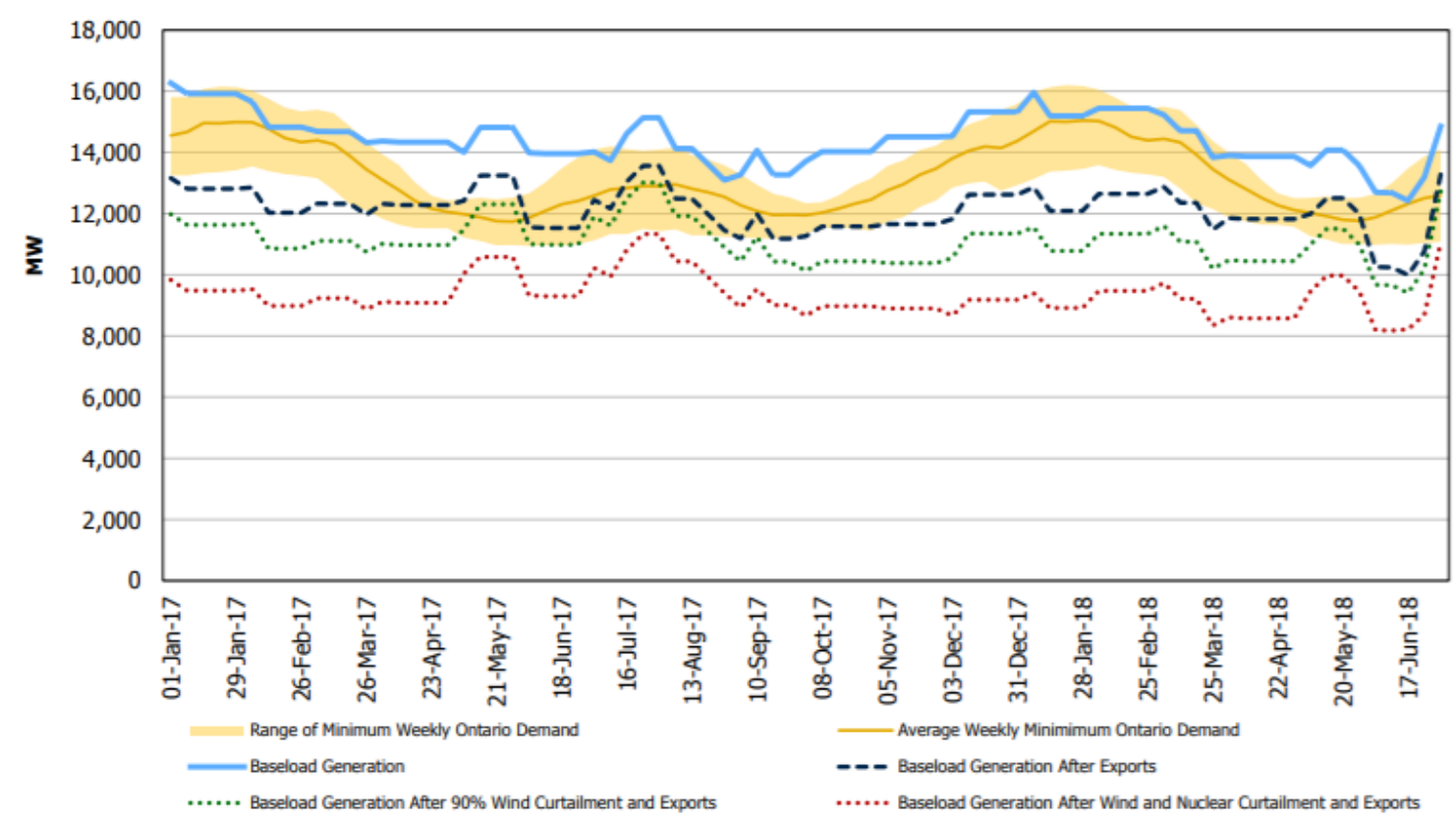

Figure 4.1 Minimum Ontario demand and baseload generation

Source: (IESO 2016b)

With regard to SBG from wind generation, Table 4.6 provides monthly off-peak WCC values based on actual wind output for the year 2016 (IESO 2016b).

Table 4.6 Monthly off-peak WCC values for 2016

\begin{tabular}{|l|l|l|l|l|l|l|l|l|l|l|l|l|}
\hline Month & Jan & Feb & Mar & Apr & May & June & Jul & Aug & Sep & Oct & Nov & Dec \\
\hline $\begin{array}{l}\text { Off-Peak } \\
\text { WCC }(\% \\
\text { of Installed } \\
\text { Capacity) }\end{array}$ & $32.8 \%$ & $32.8 \%$ & $32.0 \%$ & $34.5 \%$ & $24.7 \%$ & $14.4 \%$ & $14.4 \%$ & $14.4 \%$ & $19.3 \%$ & $29.4 \%$ & $32.9 \%$ & $32.8 \%$ \\
\hline
\end{tabular}

Table 4.6 shows that monthly average off-peak baseload generation from wind generators is $26.2 \%$ of installed capacity that has been utilized by the system operator, leaving unutilized $73.8 \%$ of installed capacity that can be utilized by PHSA. 


\subsection{Existing System Operating Reserve (OR) in Ontario}

The important part of system reliability is to have enough energy to meet Ontario's demand. Although IESO always schedules sufficient generation to meet the demand, unplanned events generally upset the balance of supply and demand such as:

- Sudden unexpected increase in demand;

- Generation losses occur when several generators are unable to follow their dispatch instructions; and

- Loss of transmission element which removes generation or results in a more restrictive operating limit that makes supply unavailable.

In order to manage the above situations, the IESO ensures to have enough standby resources in the form of operating reserve (OR). The operating reserve provides a supply cushion that can be called upon in the event of an unexpected shortfall.

The reliability standards that include OR requirements are set by the North American electricity reliability corporation (NERC) and the northeast power coordinating council (NPCC). These standards describe the required operating reserve, performance obligations, and the reserve sharing program available to IESO. The operating reserve is classified into three categories as given below:

- 10-Minute Synchronized (Spinning Reserve)

- 10-Minute Non-Synchronized (Non-Spinning Reserve)

- 30-Minute Reserve

Total operating reserve is the sum of above listed three types of the reserve. The total reserve margin for the year 2016 was reported as 1418 MW by IESO as given below (IESO 2017b):

- Reserve Margin for 10-Minute OR

- Reserve Margin for 30-Minute OR

- Total OR Margin
$945 \mathrm{MW}$

$473 \mathrm{MW}$

$1,418 \mathrm{MW}$

Therefore, Ontario's current OR is $1400 \mathrm{MW}$ per day (equivalent to $33,600 \mathrm{MWh}$ ) that can be used by PHSA in the optimization process. 


\subsection{Existing Electricity Rates of IESO Market in Ontario}

The market clearing price (MCP) is the competitive wholesale price for power in the province. This price is calculated and set for every 5-minute interval. It is based on the bids and offers from dispatchable facilities including neighbouring boundary entities as well as on the forecasted supply and demand of non-dispatchable facilities. For the case study of this research, the actual electricity prices have been downloaded from the IESO website for the year 2016.

\subsection{Case Study Data for GIS-based Model}

\subsubsection{Computation of River Flows}

The river flows are required to perform the methodological process for case III in both conventional and GPM methods. Generally, a hydrological database is used at country level to maintain the historical statistics of the river flows. This research case study area is a gridconnected electricity region operated by IESO in Ontario, where river flow data has been maintained by Environment Canada's hydrometric (HYDAT) database. Additionally, an Ontario Flow Assessment Tool (OFAT) was developed by the Ministry of Natural Resources Ontario in 2002 which is an online spatial-based application to automate the technical hydrology works. Currently, OFAT III is available online to calculate flow quantity estimation values. OFAT III uses HYDAT recorded hydrological statistics data to calculate the flow and drainage area for a particular pour point of a waterbody.

The availability of water with the minimum required flow in rivers is an essential requirement of the PHES system. It is the flow of water that should be available for pumping operation in excess to the minimum needed flow to maintain the ecosystem in the river. With regard to this research case study, it is important to clearly understand the concerned regulatory framework of water takings from existing waterbodies in Ontario that has been explained hereinafter.

Water taking from rivers in Ontario is governed under the Ontario Water Resources Act (OWRA) and the Ontario's Water Taking Regulations (O. Reg. 387/04) made under the Act. According to Section 34 of the OWRA, any person taking water more than a total of 50,000

litres of water on any day, by any means requires a permit from the concerned Director if the case relates to his jurisdiction otherwise he will refer the case to the Minister. Since 
2005, the risk-based approach has been used by the Ministry to categorize water takings. The permit categories that have been established are as follows:

Category 1 is the lowest risk category that considers that any user of water taking has no interference with other users and low risk of environmental impacts have been assigned to this category.

Category 2 has a higher potential to cause advance environmental impacts than category 1 water takings. All applicants of category 2 water takings are required to be a 'qualified person' to certify that the water taking meets Ministry criteria for this category.

Category 3 considered having more potential to cause adverse environmental impact than category 1 or 2 water takings. This category requires a submission of 'Technical Study' prepared by a 'Qualified Person' to satisfy the Ministry criteria.

The user manual of OFAT III stated that Section 34 of OWRA for the permit to Take Water (2007) along with R.S.O. 1990 and Water Taking Regulation O. Reg. 387/04 stipulated that permit to take water guideline recommendation for surface water taking of category 2 is "River and Streams ( $3^{\text {rd }}$ order or higher) takings less than $5 \%$ of 7Q20." Additionally, Section 2.3 of Environmental Activity and Sector Registry (EASR) 2011 stipulates that water may only be taken from perennially flowing rivers or streams that are flowing through all seasons for at least nine months of the year.

For public interest purposes, the water can be taken by the operating authority of a municipal drinking water system within the meaning of the 'Safe Drinking Water Act, 2002' and the system serves a major residential development within the meaning of that act. Similarly, water taking maybe allowed up to 19 Million litres (equivalent to $19,000 \mathrm{~m}^{3}$ ) for other qualified consumptive use.

With regard to PHES water takings, the specific regulation is not available. However, when developing a regulation to include a new activity/ sector such as the water taking by PHES plants, the Ministry undertakes a comprehensive technical analysis and consultation that includes the following steps: 
- Detailed scoping and technical assessment of activity/ sector including:

$\circ$ Engineering analysis;

○ Risk evaluation and modelling;

$\circ$ Jurisdictional review; and

- Evaluation of local concerns/ complaints

- Development of draft registry criteria and requirements

- Public consultation on a technical discussion paper

- Development of draft regulations

- Finalizing of regulation and implementation

It is pertinent to point out that the credit goes to PHES activity that it does not relate to the consumptive water use category. In contrast, the water taking by PHES for pumping operation is again discharged back into the river without deteriorating the water quality. However, the technical concerns of water taking and discharging back into the river are needed to satisfy the concerned authority. For example, the discharging of water into the river must be designed in accordance with the needed control measures for erosion and sedimentation.

Keeping in view the above discussion and required minimum flow of water for pumping operation of PHES plant, OFAT III was used for estimating the river flows based on prevailing regulations of Ontario government particularly 'Permit to Take Water (2007)' as discussed above. OFAT III currently contains the following three flow model categories:

- Low Flow Prediction Model (LOF): This model generates low flow predictions such as 7Q20 that has been defined in Section 3.2 of the methodology chapter.

- High Flood Prediction Model (HIF): This model generates flow predictions such as $\mathrm{Q}_{50}$ as defined in Section 3.2 of the methodology chapter.

- Mean Annual Flow Prediction Model (MAF): This model generates the mean annual flow for the watershed.

This case study used LOF and MAF models of OFAT III to estimate the river flows. However, it is pertinent to point out that OFAT III manual has strongly suggested consulting with a water professional before using any decision-making purposes. 
In GIS processing of this case study, the shapefile of Ontario's rivers was processed to qualify the rivers for minimum required flow for a PHES plant in the conventional method. After review of prevailing Ontario's water-related regulatory framework, it was decided that the river flows be checked for the following two conditions:

- Seasonality Condition: The river must be a perennial flow river.

- Minimum Available Flow Condition: The river must satisfy the low flow prediction requirement to maintain at least $95 \%$ of 7 Q20 base flow. Therefore, the river must satisfy the estimated values of LOF and MAF models such that: mean annual flow minus $95 \%$ of $7 \mathrm{Q} 20$ flow $\geq 24 \mathrm{~m}^{3} / \mathrm{s}$.

Accordingly, all the rivers were checked to qualify the above conditions. For example, the Michipicoten River, having mean annual flow $88.34 \mathrm{~m}^{3} / \mathrm{s}$ and 7Q20 flow $10.73 \mathrm{~m}^{3} / \mathrm{s}$, qualifies the criteria because, (i) it is a perennially flowing river and, (ii) the value 88.34

$\mathrm{m}^{3} / \mathrm{s}-0.95\left(10.73 \mathrm{~m}^{3} / \mathrm{s}\right)=78.17 \mathrm{~m}^{3} / \mathrm{s}$ is greater than $24 \mathrm{~m}^{3} / \mathrm{s}$ as the assumed minimum flow criteria for GIS processing of this research study.

\subsubsection{Estimating PHES Costs}

In order to integrate the PHES system in electricity market at the grid level, different PHES costs have been employed for this research case study. Basically, the capital cost depends on different PHES components that are site-specific such as length of penstock/ tunnel, the volume of embankment dam structure for the reservoir, power potential of pump-turbine, length of access road, length of transmission line to connect the PHES plant with the nearest grid transmission line, etc. The PHES projects with small elevation head, a short distance between upper and lower reservoirs, good geology, close to utility grid transmission line, involving less volume of embankment dam structure using natural landforms, etc. will contribute to significantly lower costs, whereas the projects with high measures of these components will contribute high cost.

The cost data available in past studies do not clearly provide such details of PHES components. There may be a chance of not considering some necessary components in the cost estimates or there may be a possibility of underestimation/ overestimation of some of the cost components. Therefore, careful consideration is needed to estimate the appropriate cost of 
PHES plants. The estimation of different costs used in this research case study has been explained below.

\section{Individual Component Cost}

In order to perform the ranking process for different potential PHES sites, the available unit costs of individual components have been first converted in the currency of Canadian dollars and then projected for the year 2016 to maintain the uniformity of comparing them with each other. The cost estimates of individual PHES components are provided in Table 2.3, Table 2.5, Table 2.6 and Table 4.12 that can be used to finalize the individual component cost for this research case study.

\section{Capital Cost}

As explained above, the unit capital costs of past studies have also been converted in the currency of Canadian dollars and projected for the year 2016 to compute the net present values (NPVs) to perform the financial analysis of PHES system. This is important to note that the capital cost of same energy potential plants may be different in different regions due to differences in various costs such as labour, equipment, transportation, government policies on taxes and customs duties on equipment, subsidies and incentive plans, etc.

Additionally, the capital cost of different individual components may be different in different areas due to different types of materials used and their different quality standards. For example, the cost of electricity poles may be different using different materials such as wood, steel or reinforced cement concrete (RCC). Similarly, the pump-turbine costs of the same rated power potential may be different due to different custom designs.

Brook (2010) reported that the experts having extensive experience on a wide range of energy projects always advocated for the smaller, eco-friendly and efficient storage projects which are designed to support the renewables. These projects generally fall in the cost range from US\$ $500 / \mathrm{kW}$ to US\$ $1,500 / \mathrm{kW}$ as reported by the electricity storage association of USA (ESA 2009). This research estimated the average cost using available data from past studies as well as using the site-specific empirical formula and then compared these two estimates. For the purpose of applying a realistic approach, the higher estimate cost was 
considered for this case study. The unit capital costs of various PHES plants reported in the past studies are provided in Table 4.7.

Table 4.7 Unit capital cost of various PHES plants

\begin{tabular}{|c|c|c|c|c|}
\hline Sr. No. & PHES Plants & $\begin{array}{c}\text { Power } \\
\text { Potential } \\
(\mathrm{MW})\end{array}$ & $\begin{array}{c}\text { Unit Capital } \\
\text { Cost } \\
(\mathrm{C} \$ / \mathbf{k W})\end{array}$ & Source \\
\hline 1 & Typical PHES Project USA & 10 & 4320 & (Guzman 2010) \\
\hline 2 & Typical PHES Project USA & 50 & 3086 & (Guzman 2010) \\
\hline 3 & Typical PHES Project USA & 200 & 2222 & (Guzman 2010) \\
\hline 4 & Typical PHES Project USA & 250 & 1605 & (Guzman 2010) \\
\hline 5 & Yixing (China) & 1000 & 692 & (Guzman 2010) \\
\hline 6 & Hebei Zhanghewan (China) & 1000 & 986 & (Guzman 2010) \\
\hline 7 & Tantangara-Blowering (Australia) & 9000 & 840 & (Brook 2010) \\
\hline 8 & Typical PHES Project - Lower Range (USA) & 250 & 565 & (Brook 2010) \\
\hline 9 & Typical PHES Project - Upper Range (USA) & 250 & 1694 & (Brook 2010) \\
\hline 10 & Linthal 2015 - Nestil (Switzerland) & 140 & 783 & (Deane et al. 2010) \\
\hline 11 & Linthal 2015 -Linthal (Switzerland) & 1000 & 1097 & (Deane et al. 2010) \\
\hline 12 & KWO Plus - Ginsel III (Switzerland) & 400 & 877 & (Deane et al. 2010) \\
\hline 13 & Foz Tua (Portugal) & 324 & 1151 & (Deane et al. 2010) \\
\hline 14 & Alqeueva II - Expansion (Portugal) & 240 & 685 & (Deane et al. 2010) \\
\hline 15 & La Muela II - extension (Spain) & 720 & 533 & (Deane et al. 2010) \\
\hline 16 & LIMBERG II (Austria) & 480 & 834 & (Deane et al. 2010) \\
\hline 17 & REIJSECK II (Austria) & 430 & 854 & (Deane et al. 2010) \\
\hline 18 & Feldsee (Germany) & 140 & 588 & (Deane et al. 2010) \\
\hline 19 & Hornbergn II (Austria) & 1000 & 768 & (Deane et al. 2010) \\
\hline 20 & Avce PHES Plant (Slovenia) & 180 & 557 & (Deane et al. 2010) \\
\hline 21 & Typical PHES Project, USA & 250 & 6320 & (USEIA 2010) \\
\hline 22 & Island of Krk PHES Project, EU & 10 & 3177 & (Krajacic et al. 2013) \\
\hline 23 & Vindol Project (EU) & 94.5 & 1314 & (Krajacic et al. 2013) \\
\hline 24 & Taum Sauk (USA) & 408 & 1201 & (Galvan-Lopez 2014) \\
\hline 25 & Northfield Mountain (USA) & 1000 & 1031 & (Galvan-Lopez 2014) \\
\hline 26 & Ludington (USA) & 2076 & 1143 & (Galvan-Lopez 2014) \\
\hline \multicolumn{3}{|c|}{ Average Unit Capital Cost } & 1497 & \\
\hline
\end{tabular}

The average cost of the listed plants in past studies was calculated as C\$ $1497 / \mathrm{kW}$ that has been graphically presented in Figure 4.2 shows a horizontal line. 


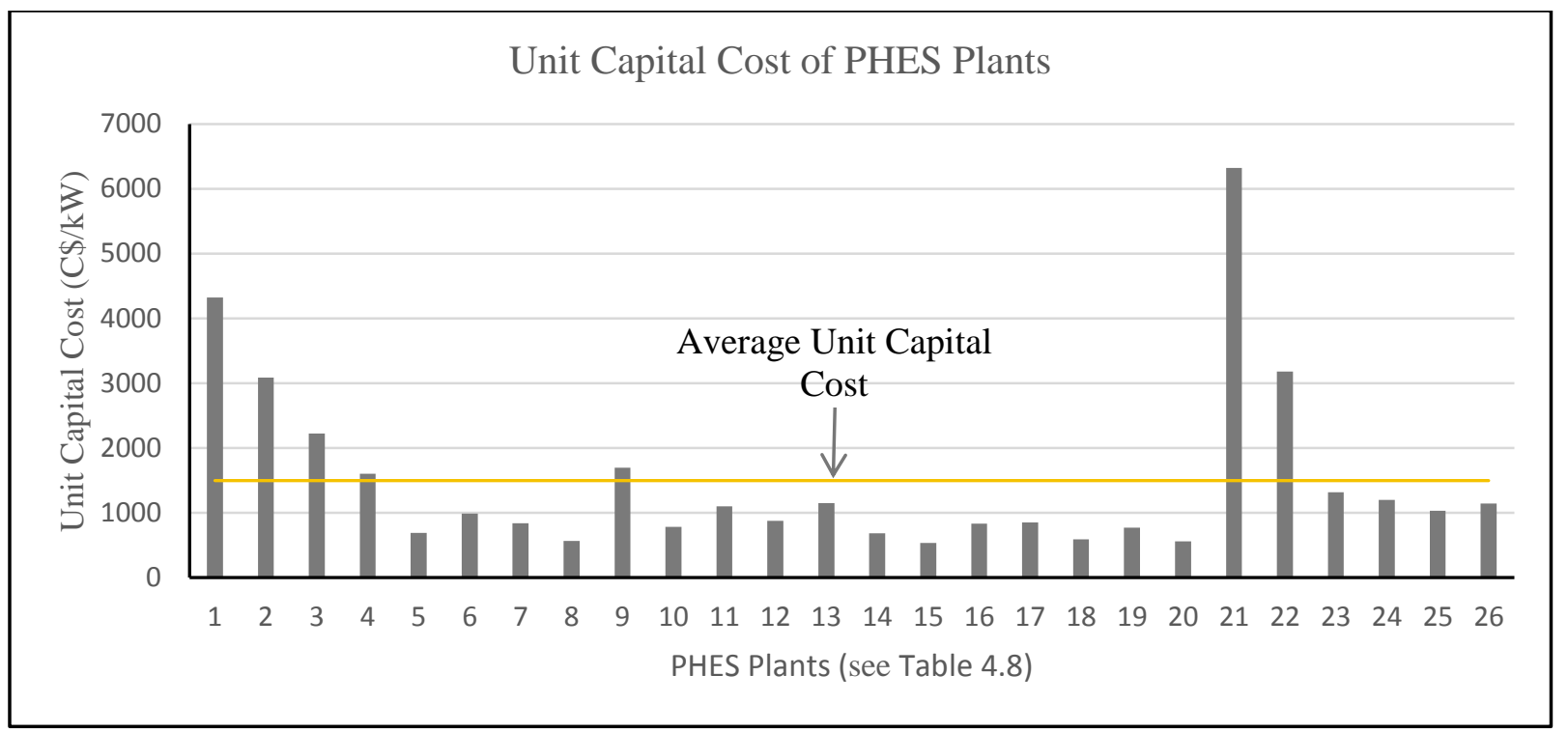

Figure 4.2 Average unit capital cost of PHES plants

In addition to the above average unit capital cost, the empirical formula (Equation 2.2) was also used to calculate the unit capital cost of identified feasible PHES sites that is based on site-specific parameters of potential head and rated power potential of the PHES plants. The average unit capital cost of past studies and the capital cost calculated with empirical formula were compared and a higher cost of C\$ 1625/ kW (equivalent to C\$ 135,426/ MWh) was used in the case study.

\section{O\&M Cost}

It was observed that the O\&M cost is rarely provided in past studies. The literature review reveals that most of the past studies simply used yearly O\&M cost without mentioning the fixed and variable components of O\&M costs. For example, Galvan-Lopez (2014), Kapila et al. (2017), Ma et al. (2014), McLean and Kearney (2014), Torres (2011), Schoenung (2011) simply used the term of O\&M cost. Moreover, the available data of some projects is not consistent with other projects such as Galvan-Lopez (2014) reported O\&M costs as $0.89 \%, 0.97 \%$, and $0.35 \%$ of the respective capital cost for Tom Sauk, Northfield Mountain, Ludington projects in the USA. Iliadis and Gnansounou (2016), US International Energy Agency (2010), Schoenung and Hassenzahl (2003), Connoly et al. (2011), Hatch (2010), Zakeri and Syri (2015) have clearly used the term of fixed O\&M costs. 
With regard to variable O\&M cost, the available reported cost is inconsistent having zero dollars to a considerably high amount of cost. For example, US International Energy Agency (2010) and Schoenung and Hassenzahl (2003) have reported the variable O\&M costs as zero dollars, whereas Connoly et al. (2011), Zakeri and Syri (2015), and Iliadis and Gnansounou (2016) reported variable O\&M costs as $€ 1.5 / \mathrm{MWh}(\mathrm{C} \$ 2.23 / \mathrm{MWh}), € 0.22 / \mathrm{MWh}(\mathrm{C} \$ 0.32$ / MWh)and $€ 4.14 /$ MWh (C\$ 6.07 / MWh) respectively which are highly inconsistent. Table 4.8 provides yearly O\&M cost reported in the past studies.

Table 4.8 Yearly O\&M cost of PHES plants

\begin{tabular}{|c|l|c|c|c|l|}
\hline No. & PHES Project & $\begin{array}{c}\text { Capital } \\
\text { Cost } \\
(\mathrm{C} \$ / \mathrm{kW})\end{array}$ & $\begin{array}{c}\text { O\&M Cost } \\
(\mathrm{C} \$ / \mathrm{kW})\end{array}$ & $\begin{array}{c}\text { O\&M Cost as a } \\
\text { Percentage of Capital } \\
\text { Cost } \\
(\%)\end{array}$ & Source \\
\hline 1 & Typical PHES Plant (USA) & 1797 & 4 & 0.22 & Schoenung and Hassenzahl (2003) \\
\hline 2 & Horsetooth PHES (USA) & 3086 & 15.11 & 0.49 & Levine (2007). \\
\hline 3 & Nominal PHES Plant (USA) & 6320 & 14.72 & 0.23 & International Energy Agency (2010) \\
\hline 4 & Ludington (USA) & 1143 & 4.03 & 0.35 & Galvan-Lopez (2014) \\
\hline 5 & $\begin{array}{l}\text { Hydro Electric Pump Storage } \\
\text { Plant (Switzerland) }\end{array}$ & 6516 & 20.30 & 0.311 & Sliadis (2016) \\
\hline 6 & $\begin{array}{l}\text { Pumped Hydro Variable Speed } \\
\text { (USA) }\end{array}$ & 1050 & 2.5 & 0.238 & Hatch (2010) \\
\hline 7 & $\begin{array}{l}\text { Pumped Storage at Mica } \\
\text { Generating Station, BC } \\
\text { (Canada) }\end{array}$ & 1230 & 6.07 & 0.493 & \\
\hline
\end{tabular}

Figure 4.3 shows the graphical presentation of O\&M cost of past projects, where a horizontal line is used to show the average O\&M cost.

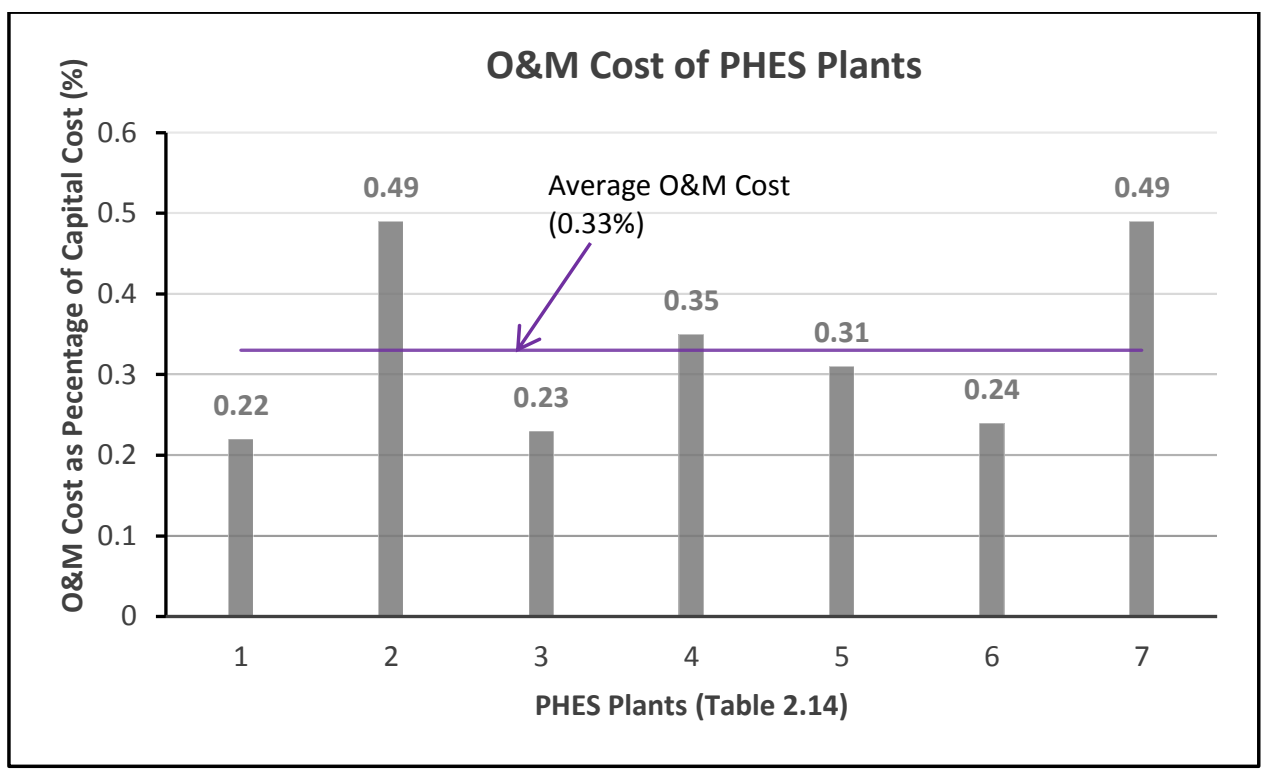

Figure 4.3 Average $O \& M$ cost as a percentage of capital cost 
Figure 4.3 provides the estimate of average $O \& M$ cost as $0.33 \%$ of the capital cost.

This research has therefore realized that the impact of variable O\&M cost is very small at the macro level planning stage. However, in order to consider a realistic estimate, this research has considered the component of variable O\&M cost and a yearly fee of pumped hydro storage association (PHSA) in the yearly fixed O\&M cost by increasing its percentage from $0.33 \%$ to $0.50 \%$ that is a multiplying factor of the initial capital cost.

The above discussion concludes that adequate cost data is not available in the past studies and therefore, the lack of information regarding PHES costs is a major issue in the development of the PHES system.

\subsubsection{Developing GIS Database}

The database was prepared for a geospatial dataset of shapefiles including the waterbodies, abandoned mines, DEM, infrastructures, environmental and geology constraints of Ontario. Table 4.9 provides concerned geospatial dataset of Ontario that was downloaded from the website: https://library.ryerson.ca/gmdc/madar/geo-data/search-2/. This website was retrieved from geospatial maps and data center, established in the Ryerson University Library and Archive (RULA), Toronto. The model parameters were appropriately assumed on the basis of defined rationales as explained in Appendix B. Table 4.10 provides the assumed criteria for model parameters of conventional PHES and GPM methods of this research study. Table 4.11 provides the distance limits applied for screening of PHES and GPM sites and their respective waterbodies being used as primary reservoirs. 
Table 4.9 Geospatial Dataset of Ontario

\begin{tabular}{|c|c|c|c|}
\hline Data Files & Citing Date & Source & Last Revision \\
\hline \multicolumn{4}{|l|}{ Waterbodies } \\
\hline Dams & 2015-07-10 & $\begin{array}{l}\text { (Ontario Ministry of Natural Resources and } \\
\text { Forestry 2015) }\end{array}$ & 2013-06-17 \\
\hline Lakes & 2015-07-10 & (Land Information Ontario 2015) & 2010-08-09 \\
\hline Rivers & 2015-07-10 & (Land Information Ontario 2015) & 2010-08-09 \\
\hline $\begin{array}{l}\text { Abandoned Mines } \\
\text { Abandoned Mines }\end{array}$ & $2015-08-15$ & $\begin{array}{l}\text { (Ontario's Ministry of Northern Development } \\
\text { and Mines 2014) }\end{array}$ & 2014-11-01 \\
\hline \multicolumn{4}{|c|}{ Digital Elevation Model (DEM) } \\
\hline Ontario DEM (3.0) & $2015-07-10$ & (Ontario Ministry of Natural Resources 2015) & 2015-04-30 \\
\hline \multicolumn{4}{|l|}{ Infrastructures } \\
\hline Electricity Transmission Lines & 2015-11-10 & (DMTI Spatial Inc 2015) & 2015-09-01 \\
\hline Ontario Road Network (ORN) & 2015-11-10 & (Ontario Ministry of Natural Resources 2012) & $2012-03-22$ \\
\hline \multicolumn{4}{|l|}{ Environmental Constraints } \\
\hline Settlement Area & 2015-11-10 & (DMTI Spatial Inc. 2014) & $2014-05-15$ \\
\hline Built-Up Area & 2015-11-10 & (Ontario Ministry of Natural Resources 2003) & $2006-09-30$ \\
\hline Provincial Park Regulated & 2015-11-10 & $\begin{array}{l}\text { (Ontario Ministry of Natural Resources } \\
\text { 2008a) }\end{array}$ & 2008-06-07 \\
\hline National Wildlife Area & 2015-11-10 & (Ontario Ministry of Natural Resources 2005) & 2005-09-08 \\
\hline Federal Protected Area & 2015-11-10 & $\begin{array}{l}\text { (Ontario Ministry of Natural Resources } \\
\text { 2008b) }\end{array}$ & 2008-07-09 \\
\hline NGO Nature Reserve & 2015-11-10 & (Ontario Ministry of Natural Resources 2009) & 2009-09-16 \\
\hline Floodplain Ontario & 2015-11-10 & (Ontario Ministry of Natural Resources 1991) & 1991-12-31 \\
\hline Wetland & 2015-11-10 & $\begin{array}{l}\text { (Ontario Ministry of Natural Resources and } \\
\text { Forestry 2013) }\end{array}$ & 2013-06-17 \\
\hline $\begin{array}{l}\text { Geology } \\
\text { Bedrock Geology Of Ontario } \\
\text { Note: Any feature on the gec }\end{array}$ & 2016-04-11 & $\begin{array}{l}\text { (Ministry of Northern Development and } \\
\text { Mines 2010) } \\
\text { urate within } 5000 \text { meters. }\end{array}$ & $2015-12-31$ \\
\hline
\end{tabular}




\section{Table 4.10 Assumed criteria for model parameters}

\begin{tabular}{|l|c|}
\hline Model Parameters & Assumed Criteria \\
\hline Conventional Method & \\
\hline Volume of water in lake/dam to be used as primary reservoir & $>=1 \mathrm{Mm}^{3}$ \\
\hline Water flow of a river being used as primary reservoir & $>=28 \mathrm{~m}^{3} / \mathrm{s}$ \\
\hline Ground slope of surface region for PHES site & $<=3 \mathrm{degree}$ \\
\hline Distance between primary reservoir and PHES site (buffer zone) & $<=5 \mathrm{~km}$ \\
\hline Volume of PHES reservoir (with 10 m wall height) & $>=0.5 \mathrm{Mm}^{3}$ \\
\hline Elevation difference (ED) between primary reservoir and PHES site & $>=33 \mathrm{~m}$ \\
\hline Round trip system efficiency of a PHES plant & $80 \%$ \\
\hline & \\
\hline GPM Method & One unit \\
\hline Number of GPM units at one site & $500 \mathrm{~m}$ \\
\hline Depth of main shaft & $33 \mathrm{~m}$ \\
\hline Diameter of piston & $250 \mathrm{~m}$ \\
\hline Depth of piston & $213,716 \mathrm{~m}^{3}$ \\
\hline Volume of water stored in main shaft (calculated) & $>=12,500 \mathrm{~m}^{2}$ \\
\hline Surface area of GPM site & $80 \%$ \\
\hline Round trip system efficiency of a GPM unit & $<=3 \mathrm{degree}$ \\
\hline Ground slope of surface region for a GPM site & $<=5 \mathrm{~km}$ \\
\hline Distance between waterbody and GPM site (buffer zone) & $250 \mathrm{~m}$ \\
\hline Elevation change by piston & $1000 \mathrm{~kg} / \mathrm{m}^{2}$ \\
\hline Density of water & $2500 \mathrm{~kg} / \mathrm{m}^{3}$ \\
\hline Density of natural rock & $175 \mathrm{MWh}$ \\
\hline Output energy potential (calculated) & \\
\hline
\end{tabular}

\section{Table 4.11 Assumed criteria for screening constraint features}

\begin{tabular}{|l|c|}
\hline Screening Constraint Features & Assumed Criteria \\
\hline Infrastructure & The distance limits applied on both PHES and GPM sites \\
Electricity Transmission Lines & $<=10 \mathrm{~km}$ \\
Ontario Road Network (ORN) & $>=200 \mathrm{~m}$ \\
& \\
Environmental & $>=500 \mathrm{~m}$ \\
Settlement Area & $>=500 \mathrm{~m}$ \\
Built-Up Area & $>=500 \mathrm{~m}$ \\
Provincial Park Regulated & $>=500 \mathrm{~m}$ \\
National Wildlife Area & $>=500 \mathrm{~m}$ \\
Federal Protected Area & $>=500 \mathrm{~m}$ \\
NGO Nature Reserve & $>=500 \mathrm{~m}$ \\
Floodplain Ontario & $>=200 \mathrm{~m}$ \\
Wetlands & \\
Geology & Bearing capacity $>=300 \mathrm{kPa}$ \\
Bedrock Geology &
\end{tabular}


The ranking of potential PHES sites was performed using average unit costs of individual PHES components that were assumed either using data of PHES projects provided in past studies or data collected from the industry related international vendors. The available cost data in past studies related to a particular base year estimate. Therefore, the available costs of all the studies or international venders have been projected for the same year 2016 using $1.55 \%$ average annual inflation rate of Ontario, Canada (Statistics Canada 2018). Accordingly, Table 4.12 provides the average unit costs of individual PHES components for the year 2016 in Canadian dollars.

Table 4.12 Average unit cost of individual PHES components

\begin{tabular}{|c|c|c|c|c|}
\hline Individual Component & $\begin{array}{l}\text { Average Unit } \\
\text { Cost }\end{array}$ & $\begin{array}{l}\text { Base } \\
\text { Year }\end{array}$ & $\begin{array}{c}\text { Unit Cost for } \\
2016\end{array}$ & Source \\
\hline Reservoir & US $\$ 9,252,606 / \mathrm{Mm}^{3}$ & 2011 & $\mathrm{C} \$ 9,883,036 / \mathrm{Mm}^{3}$ & 1 \\
\hline $\begin{array}{l}\text { Pump-Turbines, Valves and } \\
\text { Governors }\end{array}$ & US\$ $119,877 / \mathrm{MW}$ & 2007 & $\mathrm{C} \$ 147,971 / \mathrm{MW}$ & 2 \\
\hline $\begin{array}{l}\text { Penstock (Fiberglass): } \\
\text { A) 12" Diameter Pipe } \\
\text { B) 18" Diameter } \\
\text { C) } 24 " \text { Diameter }\end{array}$ & $\begin{array}{l}\mathrm{C} \$ 345 / \mathrm{m} \\
\mathrm{C} \$ 541 / \mathrm{m} \\
\mathrm{C} \$ 591 / \mathrm{m}\end{array}$ & $\begin{array}{l}2016 \\
2016 \\
2016 \\
\end{array}$ & $\begin{array}{l}\mathrm{C} \$ 345 / \mathrm{m} \\
\mathrm{C} \$ 541 / \mathrm{m} \\
\mathrm{C} \$ 591 / \mathrm{m}\end{array}$ & $3 *$ \\
\hline Transmission Line & $\mathrm{C} \$ 458,000 / \mathrm{km}$ & 2011 & $\mathrm{C} \$ 494,613 / \mathrm{km}$ & 4 \\
\hline Access Road (8m Wide) & $\mathrm{C} \$ 250 / \mathrm{m}^{2}$ & 2010 & $\mathrm{C} \$ 274 / \mathrm{m}^{2}$ & $5 \& 6$ \\
\hline Drilling Work & $\mathrm{US} \$ 130 / \mathrm{m}^{3}$ & 2012 & $\mathrm{C} \$ 138 / \mathrm{m}^{3}$ & 7 \\
\hline Reinforced Cement Concrete (RCC) & $\mathrm{C} \$ 271 / \mathrm{m}^{3}$ & 2016 & $\mathrm{C} \$ 271 / \mathrm{m}^{3}$ & 8 \\
\hline
\end{tabular}

Source 1: (Krajacic et al. 2013)

Source 2: (Levine 2007)

Source 3 (American Water Works Association 2014).

* The given rates are applicable in the year 2016

Source 4: (SNC Lavalin 2011)

Source 5: (Hatch 2010)

Source 6: (City of London Ontario 2017)

Source 7: (Einarsson et al. 2012)

Source 8: (Azabi et al. 2016)

The average conversion rates from US\$ to $C \$$ in the respective years were downloaded from the website of Bank of Canada, as given below:

- Year 2007 : US\$1 = C $\$ 1.0748$

- Year 2010 : US\$1 = C\$1.0299

- Year 2011 : US\$1 = C\$0.9891

- Year 2012 : US\$1 = C $\$ 0.9917$

- Year 2016 : US \$ 1 = C $\$ 0.7548$

Source: (Bank of Canada 2018) 


\subsubsection{Case Study Data for Conventional and GPM Methods}

The input data including geospatial dataset, assumed model parameters, average unit cost of individual PHES components, and ArcGIS tools used for GIS processing of cases I to IV for both methods are given below:

- Geospatial Dataset (see Table 4.9)

a) Shapefile of dams in Ontario (used only for case I and IV)

b) Shapefile of lakes in Ontario (used only for case II and IV)

c) Shapefile of rivers in Ontario (used only for case III and IV)

d) Shapefile of abandoned mines in Ontario (used only for case IV)

e) Raster file of Ontario DEM 3.0 (used for cases I to IV)

f) Shapefiles of infrastructures, environmental, and geology constraint features (used for cases I to IV)

- Assumed Criteria for Model Parameters (see Table 4.10)

- Assumed Criteria for Screening Constraint Features (see Table 4.11)

- Average Unit Cost of Individual PHES Components (see Table 4.12)

- ArcGIS Tools

The following tools were used in ArcGIS to automate the process:

Select Tool, Buffer Tool, Extract By Mask Tool, Raster Calculator Tool, Slope Tool, Get Raster Properties Tool, Clip Tool, Near Tool, Spatial Join Tool, Generate Near Table Tool, Add Join Tool and Sort Tool.

Source: (ESRI 2014)

The methodology of GIS processing is fully automated for all the cases and it is based on the following three sequential steps:

- Identification of preliminary PHES sites;

- Screening of identified preliminary PHES sites to find potential PHES sites; and

- Ranking of potential PHES sites to finally select feasible PHES sites.

The GIS processing for the above steps, explained in Sections 3.3.4 to 3.3.7 of methodology chapter, was applied for all the cases of both conventional PHES and GPM methods using their respective input data as provided above. 


\subsection{Case Study Data for Optimization Model}

The proposed PHSA model was applied to electricity grid region operated by IESO in Ontario, Canada. In order to apply the model, the PHES and GPM plants were considered as existing qualified participants in the electricity market of Ontario.

The maximum energy output of PHSA in one day operating cycle is a part of total Ontario demand in different timings of a day. Therefore, a portion of the total output of existing gas and nuclear generators was considered as the maximum system load for PHSA as explained in Section 4.3 above. The electricity market prices are different for different timings and seasons that were taken from IESO statistics of the year 2016 which is available online at IESO website. The optimization processing data for the case study of Ontario was divided into the following two categories:

\section{(A) Input Data}

The input data was used in the model processing to solve the optimization problem. The detail of input data is provided hereinafter.

\section{(B) Output Data}

The output data is the end result of model processing that was obtained in the form of decision variables which have been provided in Section 5.6.2 as the solution of the optimization problem.

\section{(A) Input Data}

The following input data was used to perform the optimization process of participatory member plants of PHSA:

\section{(i) Total Hours in One Operating Cycle of Participatory PHSA Plants}

This study assumed 24 hours of one day as a complete operating cycle of PHSA plants. The first cycle starts at 0:00 hours on January 01, 2016 and ends at 24:00 hours on December 31, 2016. In this way, there are total of 181 operating cycles in the winter season and 184 cycles in summer season during one year period. 


\section{(ii) Season-Wise Months, Days and Peak Hours of IESO Electricity System}

The different load hours in a day are also termed as base-load, intermediate-load, and peakload hours which are defined in the IESO website: http://www.ontario-hydro.com/currentrates. The respective peak hours of one day cycle, the number of days and months in each season are provided in Table 4.13 as given below:

Table 4.13 Season-wise months, days and peak hours of IESO electricity system

\begin{tabular}{|c|c|c|c|c|}
\hline \multirow[t]{2}{*}{ Season } & \multicolumn{3}{|c|}{ Peak Hour's Timings } & \multirow[t]{2}{*}{ Months and Days } \\
\hline & Off-Peak & Mid-Peak & On-Peak & \\
\hline Winter & $\begin{array}{l}7 \mathrm{pm}-7 \mathrm{am} \\
\text { (12 hours) }\end{array}$ & $\begin{array}{l}11 \mathrm{am}-5 \mathrm{pm} \\
\text { (6 hours) }\end{array}$ & $\begin{array}{l}7 \mathrm{am}-11 \mathrm{am} \\
5 \mathrm{pm}-7 \mathrm{pm} \\
(6 \text { hours })\end{array}$ & $\begin{array}{l}\text { Jan to Apr and } \\
\text { Nov to Dec } \\
\text { (181 days) }\end{array}$ \\
\hline Summer & $\begin{array}{l}7 \mathrm{pm}-7 \mathrm{am} \\
(12 \text { hours })\end{array}$ & $\begin{array}{l}7 \mathrm{am}-11 \mathrm{am} \\
5 \mathrm{pm}-7 \mathrm{pm} \\
(6 \text { hours })\end{array}$ & $\begin{array}{l}11 \mathrm{am}-5 \mathrm{pm} \\
(6 \text { hours })\end{array}$ & $\begin{array}{l}\text { May to Oct } \\
\text { (184 days) }\end{array}$ \\
\hline
\end{tabular}

\section{(iii) Total Energy Potential of PHSA}

The total energy potential of participatory PHES and GPM plants was taken from Table 5.11 of the model applications chapter that is the cumulative potential of feasible PHES and GPM sites which were identified in Ontario using conventional PHES and GPM methods. The total energy potential was estimated as 56,268 MWh.

\section{(iv) Capital Cost of PHSA Plants}

The overall unit capital cost of participatory PHSA plants has been considered as $\mathrm{C} \$ 135,426$ / MWh which is the average unit capital cost of identified feasible PHES sites in Ontario that was calculated using site-specific empirical formula. This cost figure is higher than the average capital cost calculated using past studies data.

\section{(v) Yearly O\&M Cost of PHSA}

The first year fixed O\&M cost for PHSA was considered as $0.33 \%$ of initial capital cost as explained in Section 4.7.2 of this chapter. In order to account the effect of variable O\&M and fee of PHSA, the fixed O\&M cost percentage has been increased to $0.50 \%$ of the capital cost and named as yearly O\&M cost. The O\&M cost of each successive year was increased by $1.55 \%$ of the previous year cost which is an average inflation rate of the Ontario province in Canada (Statistics Canada 2018). 


\section{(vi) Total System Load and Total Operating Reserve of IESO Electricity Market}

The Ontario's hourly power supply data was taken from the IESO database under Section 'Generator Output by Fuel Type Hourly Report' for the year 2016 as explained in Section 4.3 of this chapter. Similarly, the operating reserve requirement was taken from the IESO database provided under Section 'Real-Time Operating Reserve in Market Report' for the year 2016 reported in IESO's monthly report of January 2017 as explained in Section 4.5 of this chapter. The system load and total system operating reserve (TSR) were projected for the life period of participatory PHSA plants using Ontario's average population increase rate as 1.3\% (Ministry of Finance Information Centre 2016).

\section{(vii) Estimated Electricity Rates for Life Period of PHSA Plants}

The optimization was performed for 60 years life period of participatory PHSA plants to study their net financial gain. Actual data of electricity rates was downloaded from the IESO website for the year 2016. These rates were projected for the life period of participatory PHES plants using Ontario's average inflation rate as 2.65\% (Statistics Canada 2018). The electricity selling rates were divided into three categories including off, mid, and on-peak hours. The fixed operating reserve rate $(\mathrm{BF})$ is an actual monthly average operating reserve rate provided in the online data of IESO. The operating reserve supply rate (BR) was considered as 2.5 times of the on-peak rates. The energy purchase rate (CA) for pumping operation was considered as $60 \%$ of the off-peak selling rate.

\section{(viii) Electricity Transmission Line Losses in Ontario}

It was observed that the identified feasible PHES potential sites are mostly located far away from the distribution points allocated for the electricity end-users that involve considerable power losses due to the long distance of the electricity transmission lines between the PHES

plants and the electricity distribution points. These power losses are known as electricity transmission line losses. The approximate amount of electricity transmission line losses in Ontario is $6.5 \%$ as reported by The ECOReport (2014). 


\section{Summary of Input Data for Year 2016}

As explained above, Table 4.14 provides a summary of the input data used in the optimization process for the year 2016.

Table 4.14 Input data used in the optimization process for the year 2016

\begin{tabular}{|c|c|c|c|c|}
\hline \multirow[t]{2}{*}{ Input Parameter } & \multirow[t]{2}{*}{ Symbol } & \multirow[t]{2}{*}{ Unit } & \multicolumn{2}{|c|}{ Season } \\
\hline & & & Winter & Summer \\
\hline \multicolumn{5}{|l|}{ System Load } \\
\hline System load during off-peak hours & $P D L_{\text {off }}$ & MWh & 28637 & 32658 \\
\hline System load during mid-peak hours & $P D L_{\text {mid }}$ & MWh & 16014 & 18263 \\
\hline System load during on-peak hours & $P D L_{o \eta}$ & MWh & 16505 & 18823 \\
\hline Number of days in operational cycles & $\mathrm{d}$ & Days & 181 & 184 \\
\hline \multicolumn{5}{|l|}{ System Operating Reserve (OR) } \\
\hline Total system OR & TSR & MWh & 33600 & 33600 \\
\hline Max. total storage OR as percentage of storage capacity & $\mathrm{q}$ & Percent & $50 \%$ & $50 \%$ \\
\hline Max. variable OR as percentage of total storage reserve & $\mathrm{r}$ & Percent & $85 \%$ & $85 \%$ \\
\hline \multicolumn{5}{|l|}{ Energy Selling and Purchase Rates } \\
\hline Selling rate of real-time energy supply during off-peak hours & $\mathrm{BA}_{\text {off }}$ & $\$ / \mathrm{MWh}$ & 8.30 & 11.77 \\
\hline Selling rate of real-time energy supply during mid-peak hours & $\mathrm{BA}_{\text {mid }}$ & $\$ / \mathrm{MWh}$ & 11.60 & 18.14 \\
\hline Selling rate of real-time energy supply during on-peak hours & $\mathrm{BA}_{\text {on }}$ & $\$ / \mathrm{MWh}$ & 15.48 & 25.59 \\
\hline Selling rate of maintaining fixed OR & $B F$ & \$/ MWh & 6.38 & 6.54 \\
\hline Selling rate of variable OR & $B R$ & \$/ MWh & 38.70 & 63.98 \\
\hline Purchase rate of real-time and reserve energy & $C A$ & \$/ MWh & 4.98 & 7.06 \\
\hline \multicolumn{5}{|l|}{ Capacity of Energy Storage } \\
\hline Total energy capacity of PHES and GPM plants & PSH & $\mathrm{MWh}$ & 56,268 & 56,268 \\
\hline Partial energy capacity of 10 PHES plants & PSH & MWh & 6,017 & 6,017 \\
\hline Partial energy capacity of 10 GPM plants & PSH & MWh & 1,750 & 1,750 \\
\hline \multicolumn{5}{|l|}{ Cost of Energy Storage } \\
\hline Unit capital cost of energy storage & $f$ & \$/ MWh & 135,426 & 135,426 \\
\hline First year O\&M cost as percentage of capital cost & $k$ & Percent & $0.50 \%$ & $0.50 \%$ \\
\hline Yearly increase in $O \& M$ cost & $m$ & Percent & $1.55 \%$ & $1.55 \%$ \\
\hline \multicolumn{5}{|l|}{ Interest Rate of Return } \\
\hline Minimum acceptable rate of return (MARR) & $i$ & Percent & $3.33 \%$ & $3.33 \%$ \\
\hline \multicolumn{5}{|l|}{ Miscellaneous Data } \\
\hline Yearly energy-use increase in Ontario & $\mathrm{c}$ & Percent & $1.3 \%$ & $1.3 \%$ \\
\hline Round-trip efficiency of energy storage system & $\eta$ & Percent & $80 \%$ & $80 \%$ \\
\hline Electricity transmission line losses in Ontario & b & Percent & $6.5 \%$ & $6.5 \%$ \\
\hline Life period of PHES plants & $\mathrm{y}$ & Years & 60 & 60 \\
\hline
\end{tabular}




\section{Application of GIS and Optimization Models on Case Study of Ontario}

\section{$5.1 \quad$ Introduction}

The GIS-based model was applied to identify the feasible PHES sites in Ontario using both conventional and GPM methods. The site identification processes of both methods were performed individually for all the four cases composed of the existing waterbodies and the abandoned mines as explained in Section 3.3 of the methodology chapter.

This is pertinent to mention here that the GIS model development was initially started in Model Builder of ArcGIS. However, it became very slow due to large input data, such as the huge data of waterbodies including the lakes and rivers in Ontario. In order to optimize the performance, the scripts were generated in Python programming language using ArcPy library for ArcGIS (version 10.2). The study by Arántegui et al. (2012) also suggested using Python script for GIS processing. The pseudocodes of scripts and model results have been provided in each case of PHES and GPM methods.

The energy potential of selected feasible PHES sites was used for optimization of PHES scheduling. The optimization was performed using the total energy potential of all PHES and GPM plants to provide the ancillary services including operating reserve and real-time energy supply to the IESO. The optimization process was applied as explained in Section 3.4 of the methodology chapter using the IESO electricity market data.

The total storage capacity was optimally utilized in different demand periods of a day to reduce the energy output of gas and nuclear plants in respective periods following Ontario's policy on renewable energy and energy storage. It is pertinent to point out that the quantum of utilizing the storage capacity depends on the available surplus baseload generation including variable generation of the renewables that can be added in the supply-mix thereby reducing the equivalent portion of gas and nuclear generators. Consequently, the energy storage also strengthens the reliability of renewables that is an important objective of the energy policy. Therefore, the optimal use of PHES in the supply-mix system is harmonious with Ontario's policy on both renewable energy and energy storage to achieve the planned targets. 


\subsection{Applying GIS-based Model using Conventional Method}

\subsubsection{Case I: Identification of Feasible PHES Sites with Dams}

A systematic methodological process was performed as explained in Section 3.3.4 of methodology chapter. The input data for the GIS processing is provided in Section 4.7.4 of this report. The pseudocode of the Python script is provided in Listing 5.1 as given below.

\section{Listing 5.1 Pseudocode for identification of feasible PHES sites with dams}

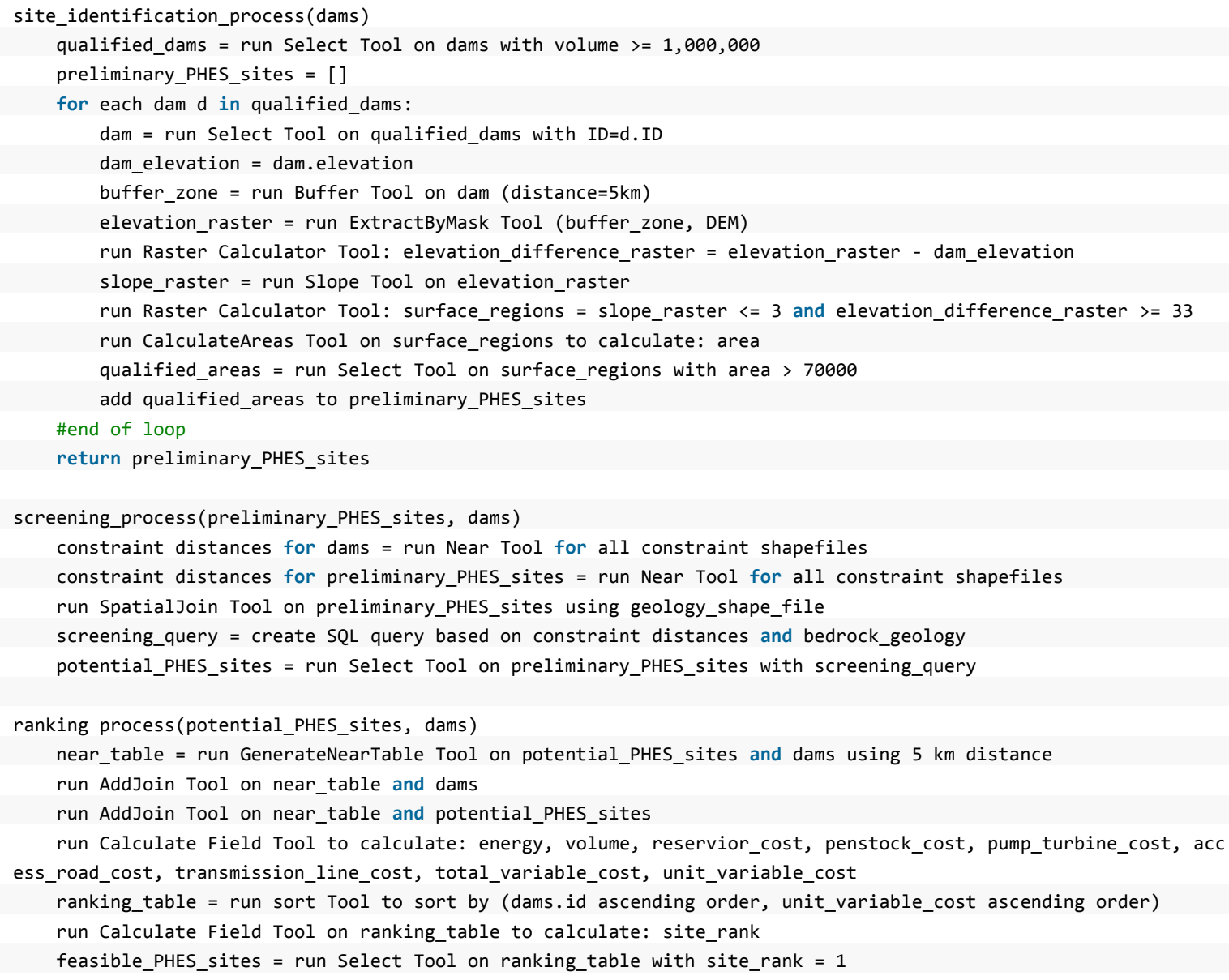




\section{Summary of GIS Processing Results}

Table 5.1 provides the GIS processing results of this case as given below.

Table 5.1 Summary of identified PHES sites with dams

\begin{tabular}{|c|c|c|c|}
\hline \multirow[t]{3}{*}{ Particulars } & \multicolumn{3}{|c|}{ GIS Processing Results } \\
\hline & Identification of Sites & Screening of Sites & Ranking of Sites \\
\hline & Preliminary PHES Sites & Potential PHES Sites & Feasible PHES Sites \\
\hline Dams (No.) & 89 & 14 & 14 \\
\hline PHES Sites (No.) & 981 & 78 & 14 \\
\hline \multicolumn{3}{|c|}{ Storage Volume $\left(\mathrm{Mm}^{3}\right)$} & 15.18 \\
\hline \multicolumn{3}{|c|}{ Energy Potential (MWh) } & 3,122 \\
\hline
\end{tabular}

Figure 5.1 shows the script generated 14 feasible PHES sites which are paired with their respective 14 dams. In this figure, the inset zoomed image shows that two feasible PHES sites having ID 375 and 441 are paired with McPhail and High Falls dams respectively.

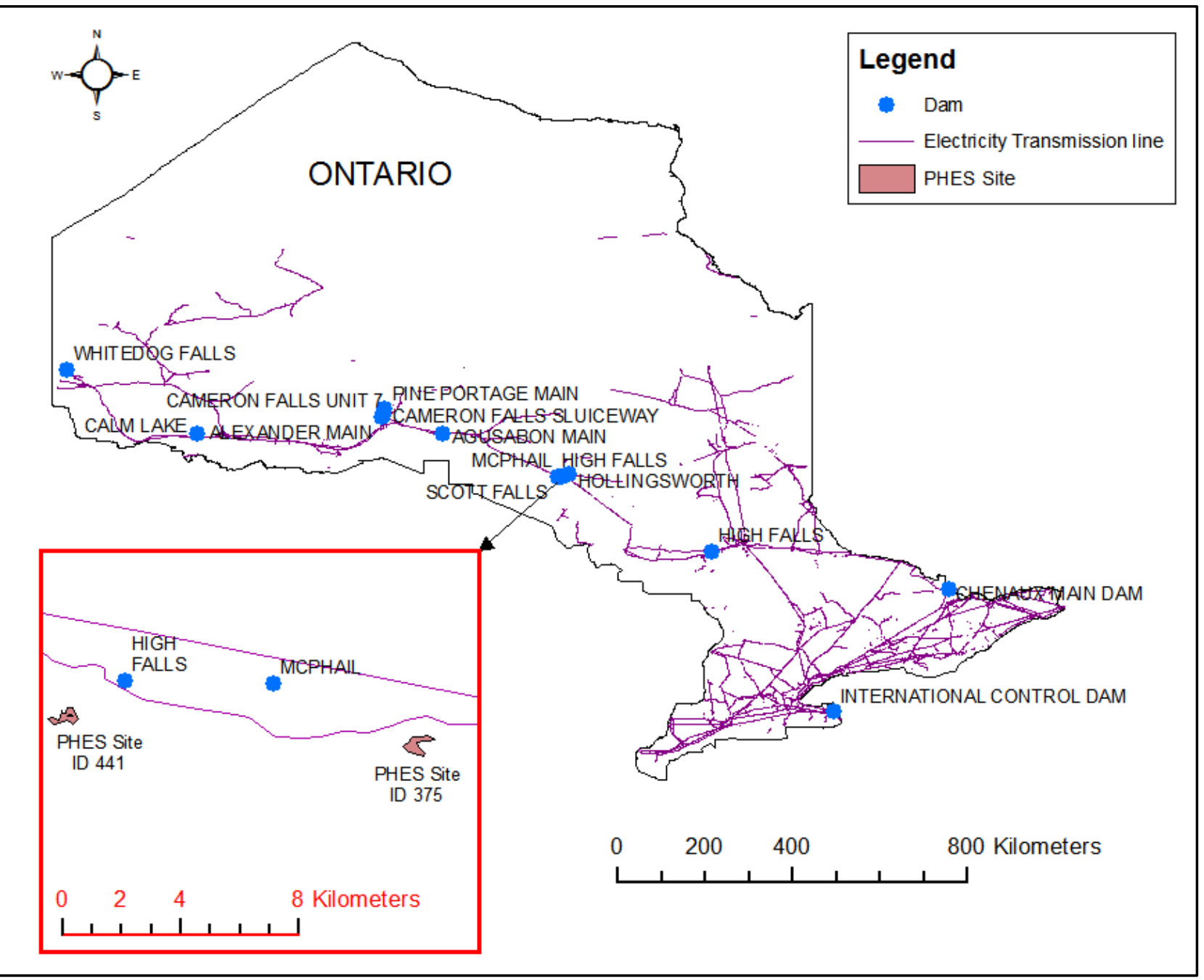

Figure 5.1 Feasible PHES sites with dams as primary reservoirs 


\subsubsection{Case II: Identification of Feasible PHES Sites with Lakes}

The detail of GIS processing and pseudocode of the Python script of this case are same as of the dams except to replace the dams with lakes. The input data is provided in Section 4.7.4 of this report. The model results of this case are given below.

\section{Summary of GIS Processing Results}

The GIS processing results of this case are provided in Table 5.2 for identifying the feasible PHES sites with lakes.

Table 5.2 Summary of identified PHES sites with lakes

\begin{tabular}{|c|c|c|c|}
\hline \multirow[t]{3}{*}{ Particulars } & \multicolumn{3}{|c|}{ GIS Processing Results } \\
\hline & Identification of Sites & Screening of Sites & Ranking of Sites \\
\hline & Preliminary PHES Sites & Potential PHES Sites & Feasible PHES Sites \\
\hline Lakes (No.) & 220 & 189 & 144 \\
\hline PHES Sites (No.) & 784 & 572 & 144 \\
\hline \multicolumn{3}{|c|}{ Storage Volume $\left(\mathrm{Mm}^{3}\right)$} & 190.43 \\
\hline \multicolumn{3}{|c|}{ Energy Potential (MWh) } & 28,051 \\
\hline
\end{tabular}




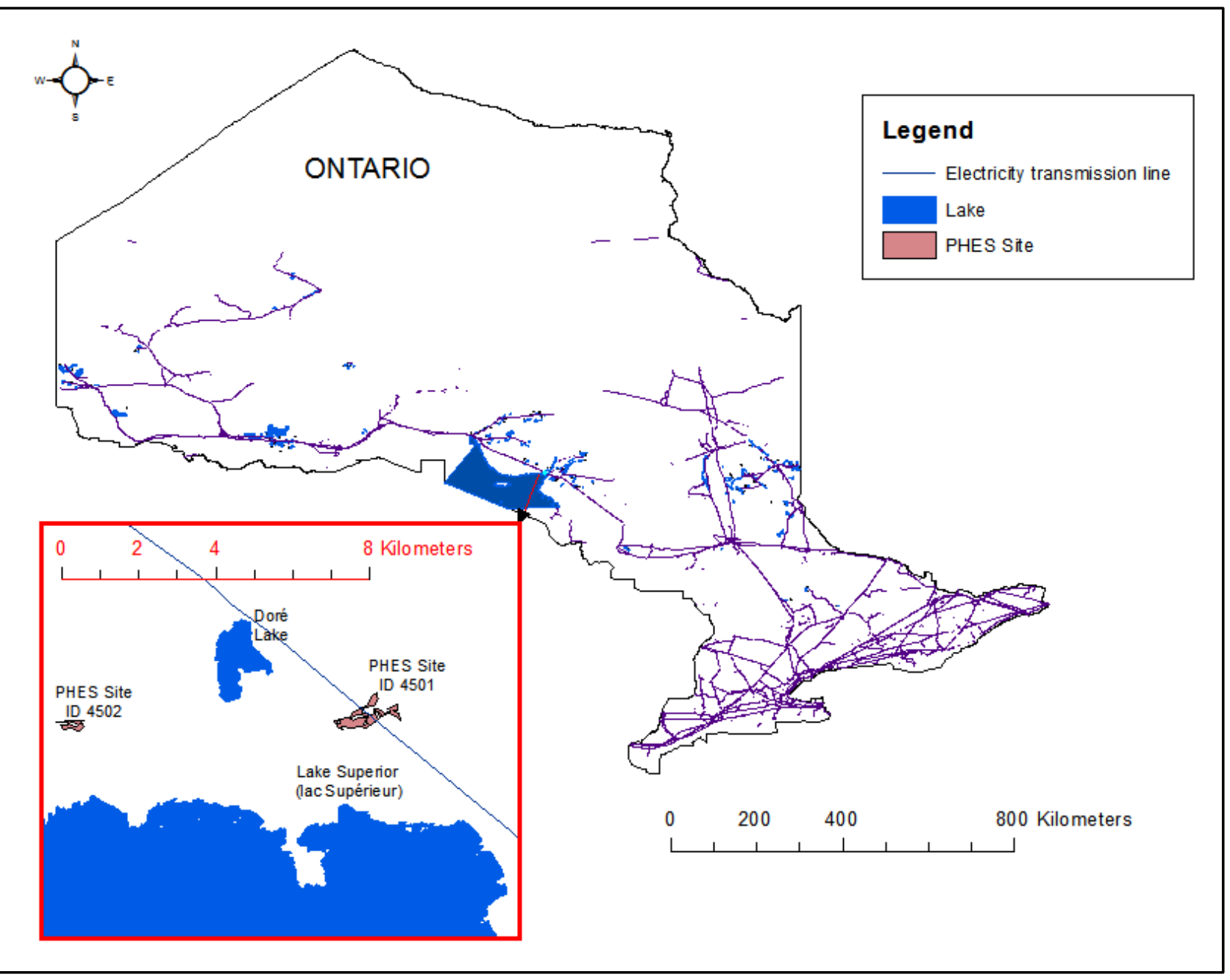

Figure 5.2 Feasible PHES sites with lakes as primary reservoirs

Figure 5.2 shows the respective pairs of 144 feasible PHES sites with 144 lakes as primary reservoirs. As an example, Lake Superior and Dore Lake have been zoomed to clearly show their feasible PHES sites bearing ID 4501 and 4502 respectively. 


\subsubsection{Case III: Identification of Feasible PHES Sites with Rivers}

A systematic methodological process of this case was performed as explained in Section 3.3.6 of methodology chapter. The input data is provided in Section 4.7.4 of this report. The pseudocode of the Python script is provided in Listing 5.2 as given below.

\section{Listing 5.2 Pseudocode for identification of feasible PHES sites with rivers}

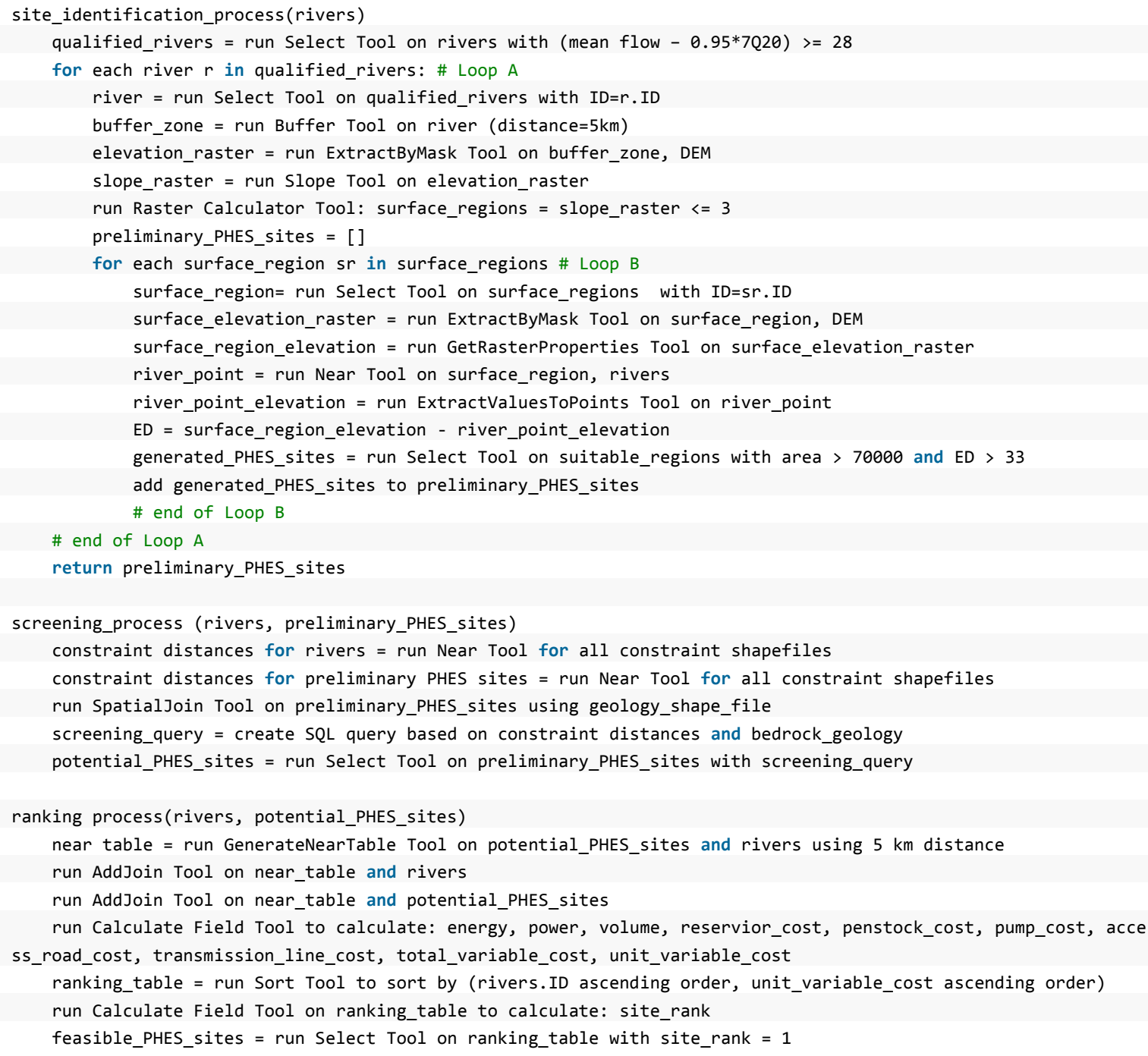




\section{Summary of GIS Processing Results}

The GIS processing results of all sequential steps of this case are provided in Table 5.3 to identify feasible PHES sites with rivers.

Table 5.3 Summary of identified PHES sites with rivers

\begin{tabular}{|l|l|l|l|}
\hline \multirow{3}{*}{ Particulars } & \multicolumn{3}{|c|}{ GIS Processing Results } \\
\cline { 2 - 4 } & Identification of Sites & Screening of Sites & Ranking of Sites \\
\cline { 2 - 4 } & Preliminary PHES Sites & Potential PHES Sites & Feasible PHES Sites \\
\hline Rivers (No.) & 41 & 8 & 8 \\
\hline PHES Sites (No.) & 162 & 36 & 8 \\
\hline Storage Volume (Mm $\left.{ }^{3}\right)$ & & 7.2 \\
\hline Energy Potential (MWh) & \multicolumn{3}{|l|}{} \\
\hline
\end{tabular}

Figure 5.3 shows the script generated 8 feasible PHES sites paired with their respective 8 rivers. In this figure, Michipicoten River was zoomed to clearly show its cross-section point paired with a feasible PHES site having ID 1844.

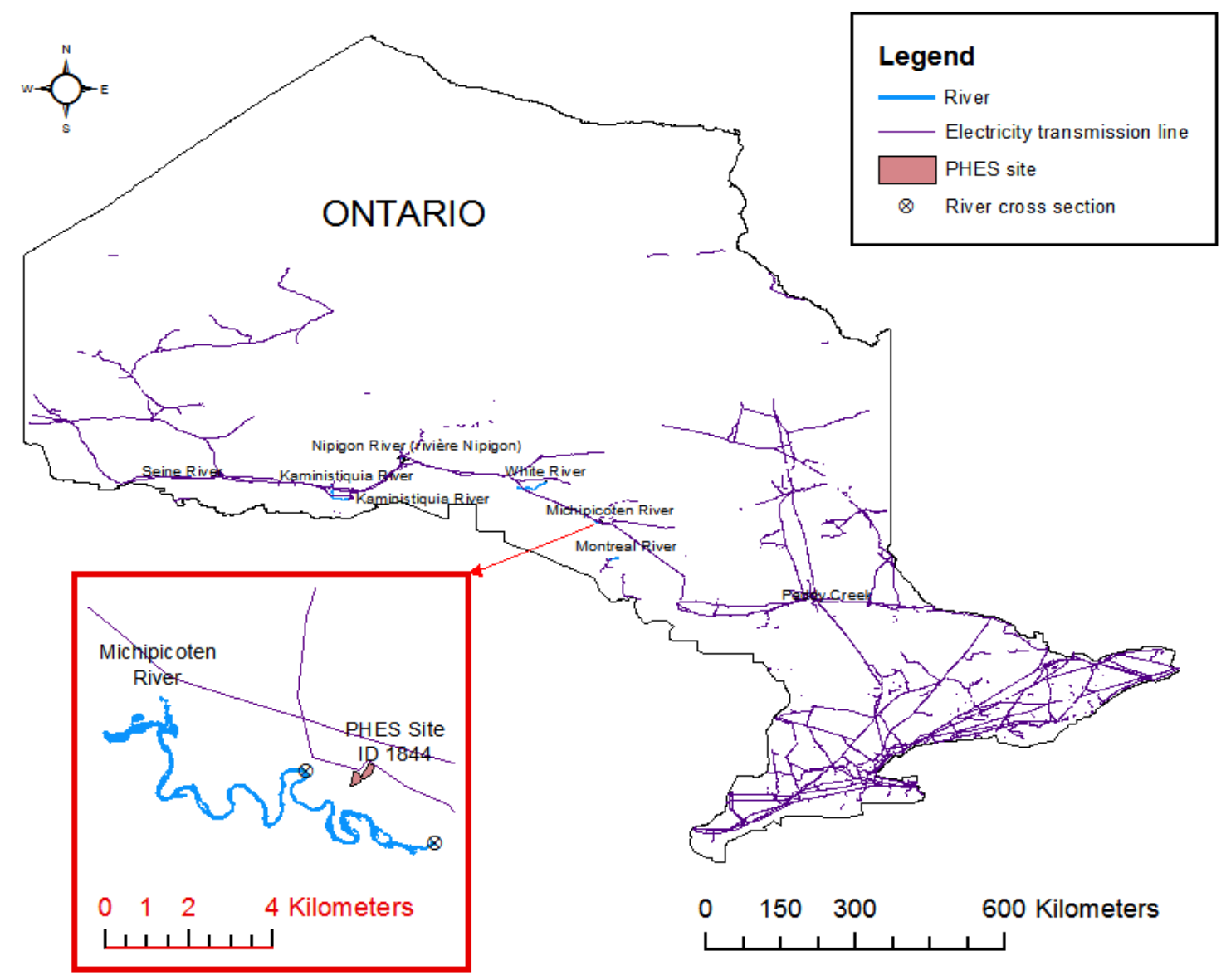

Figure 5.3 Feasible PHES sites with rivers as primary reservoirs 
As suggested in Section 4.7.1 of case study chapter, the finally selected rivers were rechecked to estimate 7Q20 and mean annual flows at the cross-section points established with respect to their feasible PHES sites. The estimated flows have been provided in Table C-1 of Appendix C to verify water taking condition for each feasible site. The final results have confirmed that all the PHES sites are qualified for water takings from their respective rivers.

\subsubsection{Case IV: Identification of Feasible PHES Sites using Abandoned Mines}

A systematic methodological process of this case was performed as explained in Section 3.3.7 of methodology chapter. The input data is provided in Section 4.7 .4 of case study chapter. The pseudocode of the Python script is provided in Listing 5.3 as given below.

\section{Listing 5.3 Pseudocode for identification of feasible PHES sites using abandoned mines}

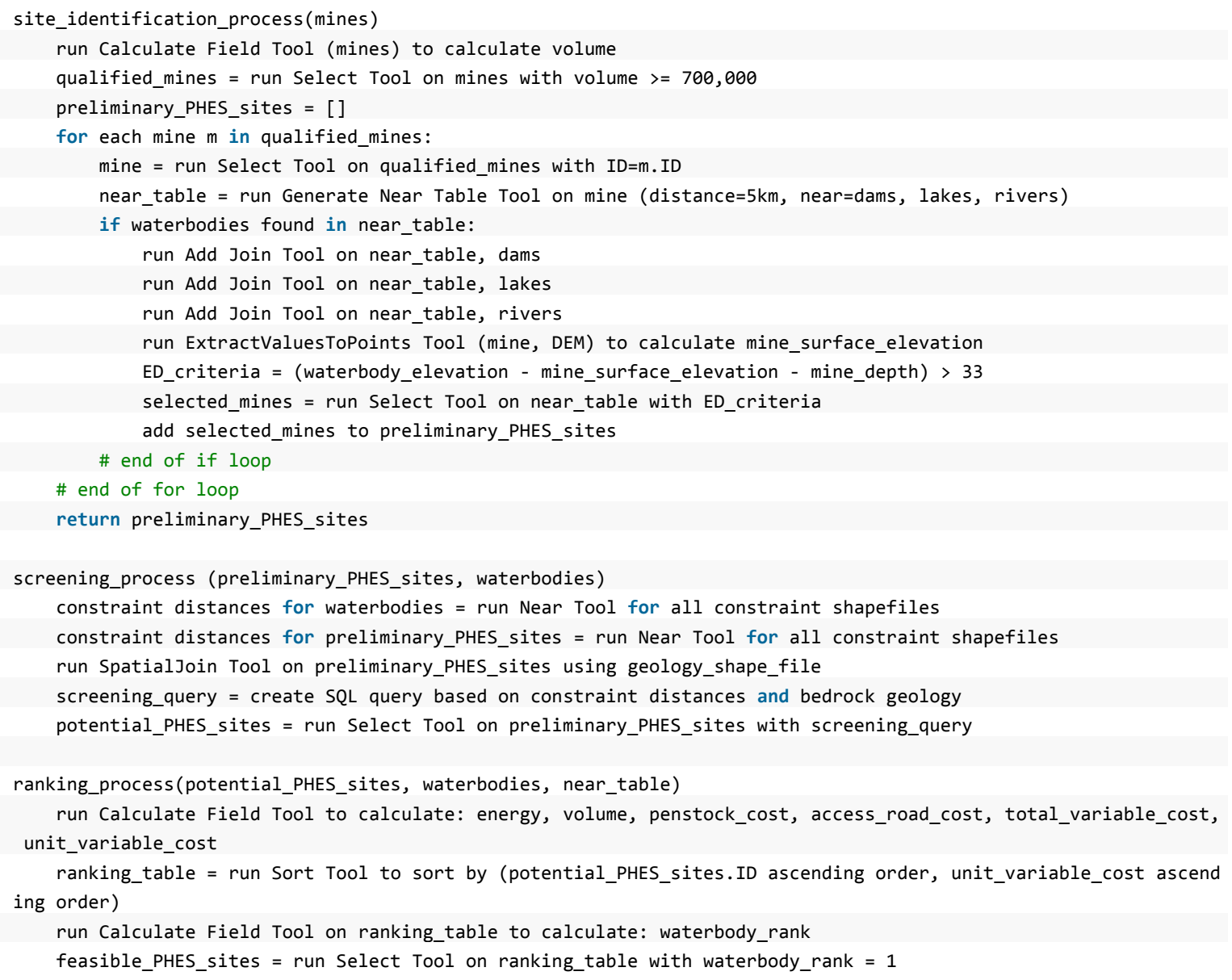


Figure 5.4 presents the selected feasible mines after the screening process. In this figure, Kamkotia mine was zoomed to clearly show this mine selected as a feasible PHES site with Kamiskotia Lake as its primary reservoir.

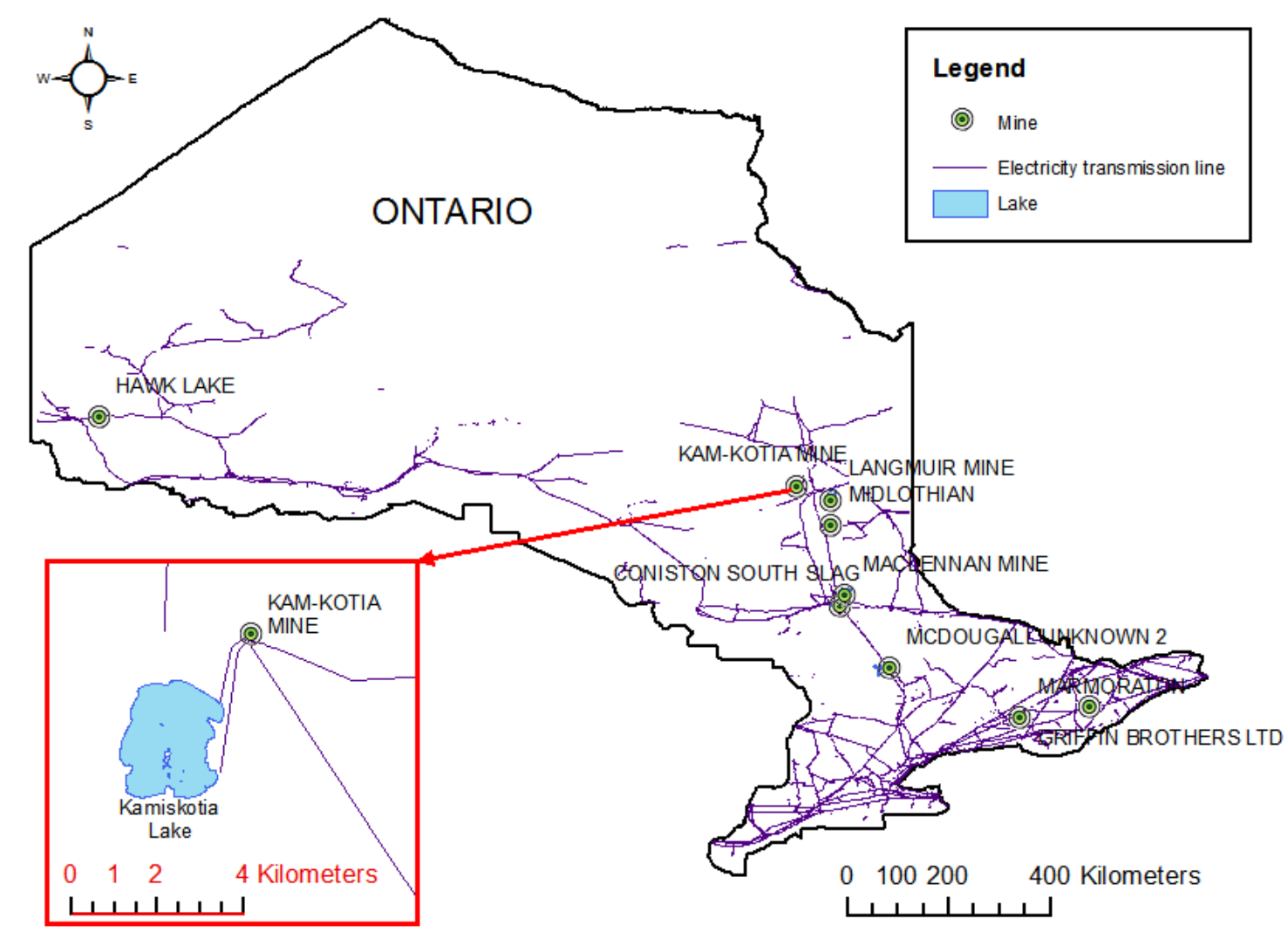

Figure 5.4 Feasible abandoned mines selected as PHES sites

\section{Summary of GIS Processing Results}

The GIS processing results for all sequential steps of this case are provided in Table 5.4 to select abandoned mines as feasible PHES sites.

Table 5.4 Summary of abandoned mines selected as feasible PHES sites

\begin{tabular}{|c|c|c|c|}
\hline \multirow[t]{3}{*}{ Particulars } & \multicolumn{3}{|c|}{ GIS Processing Results } \\
\hline & Identification of Sites & Screening of Sites & Ranking of Sites \\
\hline & Preliminary PHES Sites & Potential PHES Sites & Feasible PHES Sites \\
\hline Abandoned Mines (No.) & 15 & 9 & 9 \\
\hline PHES Sites (No.) & 15 & 9 & 9 \\
\hline \multicolumn{3}{|l|}{ Storage Volume $\left(\mathrm{Mm}^{3}\right)$} & 35.74 \\
\hline Energy Potential (MWh) & & & 4,451 \\
\hline
\end{tabular}




\subsubsection{Summary of Feasible PHES Sites in Ontario}

Table 5.5 provides a summary of feasible PHES sites in Ontario which are identified as a GIS processing results using the conventional method.

Table 5.5 Summary of feasible PHES sites in Ontario

\begin{tabular}{|l|c|c|c|}
\hline \multirow{2}{*}{$\begin{array}{l}\text { Primary Reservoirs } \\
\text { and Abandoned Mines }\end{array}$} & \multicolumn{3}{|c|}{ Feasible PHES Sites } \\
\cline { 2 - 4 } & Sites & Storage Volume & Energy Potential \\
\cline { 2 - 4 } & $\mathbf{( N o . )}$ & $\left(\mathbf{M m}^{\mathbf{3}}\right)$ & $\mathbf{M W h})$ \\
\hline Dams & 14 & 15.18 & 3,122 \\
\hline Lakes & 144 & 190.43 & 28,051 \\
\hline Rivers & 8 & 7.20 & 4,394 \\
\hline Mines & 9 & 35.74 & $\mathbf{3 7}, \mathbf{0 1 8}$ \\
\hline Total & $\mathbf{1 7 5}$ & $\mathbf{2 4 8 . 5 5}$ & $\mathbf{3}$ \\
\hline
\end{tabular}

Figure 5.5 graphically illustrates the overall results of feasible PHES sites using conventional method. This figure shows a clear picture of total feasible PHES sites, storage volume and energy potential in Ontario with dams, lakes, rivers and abandoned mines.

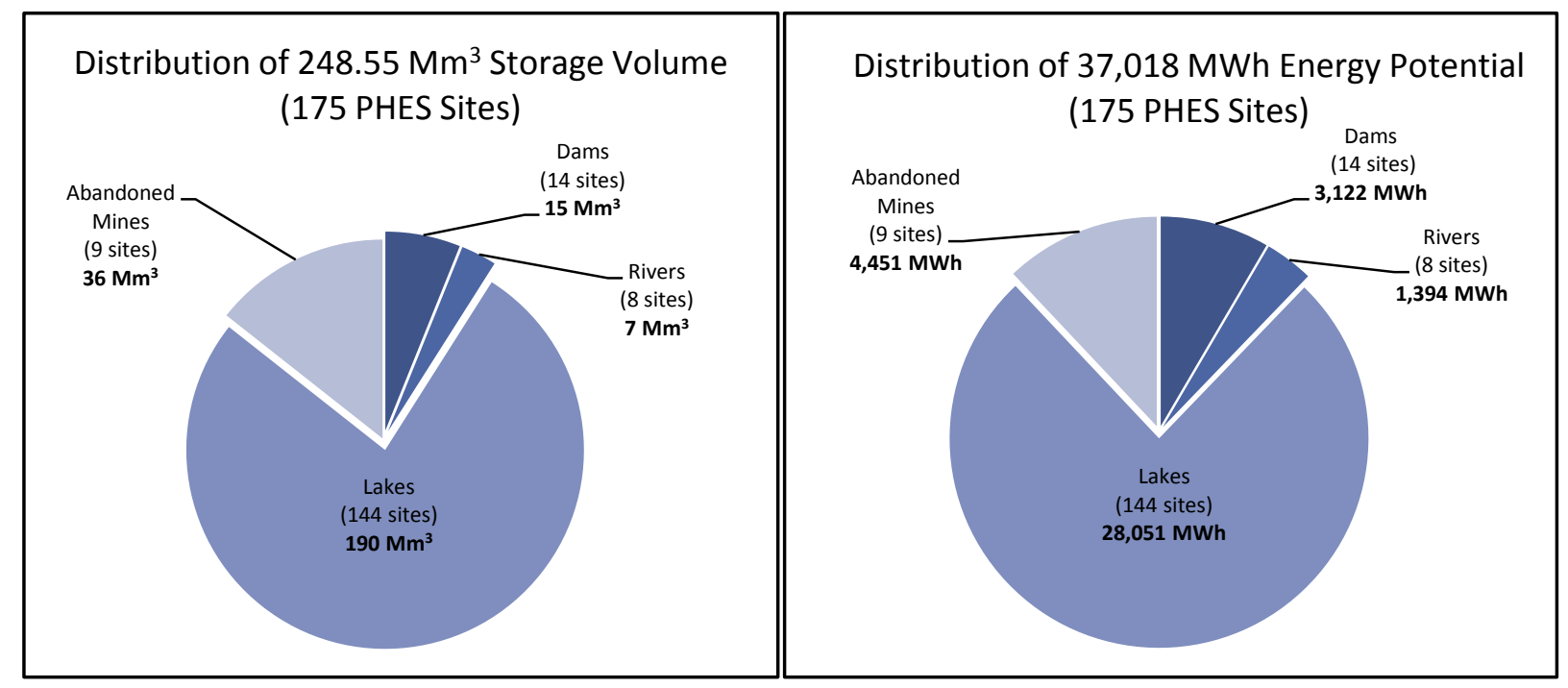

Figure 5.5 GIS processing results of feasible PHES sites in Ontario

Figure 5.6 presents the GIS results in Ontario map for all the feasible PHES sites showing their respective energy potentials in five different interval sizes with different color shades of dams, lakes, rivers and abandoned mines. 


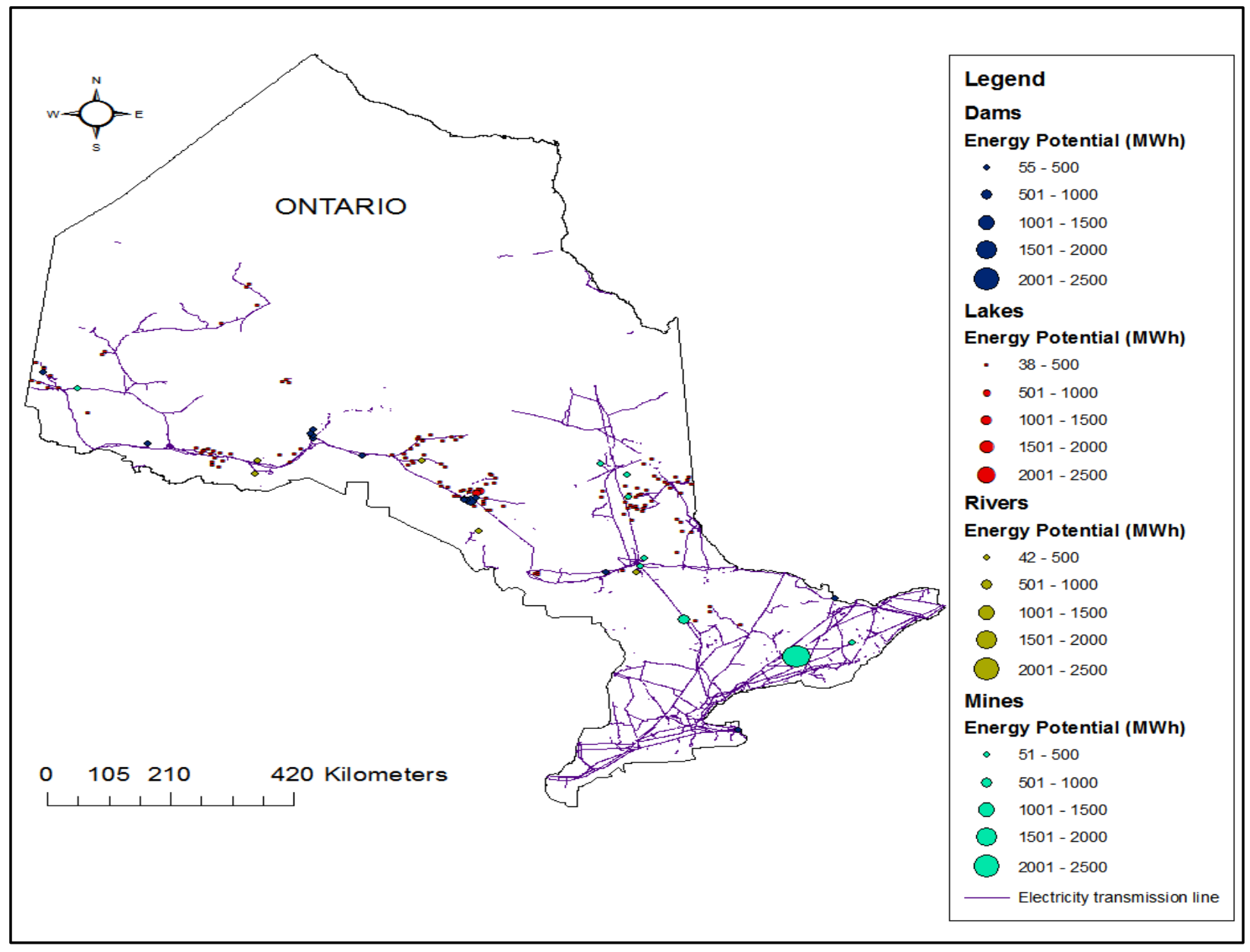

Figure 5.6 GIS results showing the energy potential of feasible PHES sites in Ontario 


\subsection{Applying GIS-based Model using GPM Method}

\subsubsection{Case I: Identification of Feasible GPM Sites with Dams}

A systematic methodological process of this case was performed as explained in Section 3.3.4 of methodology chapter. The input data used in GIS processing of this case is provided in Section 4.7.4 of case study chapter. Listing 5.4 provides the pseudocode of Python script prepared for this case.

\section{Listing 5.4 Pseudocode for identification of feasible GPM sites with dams}

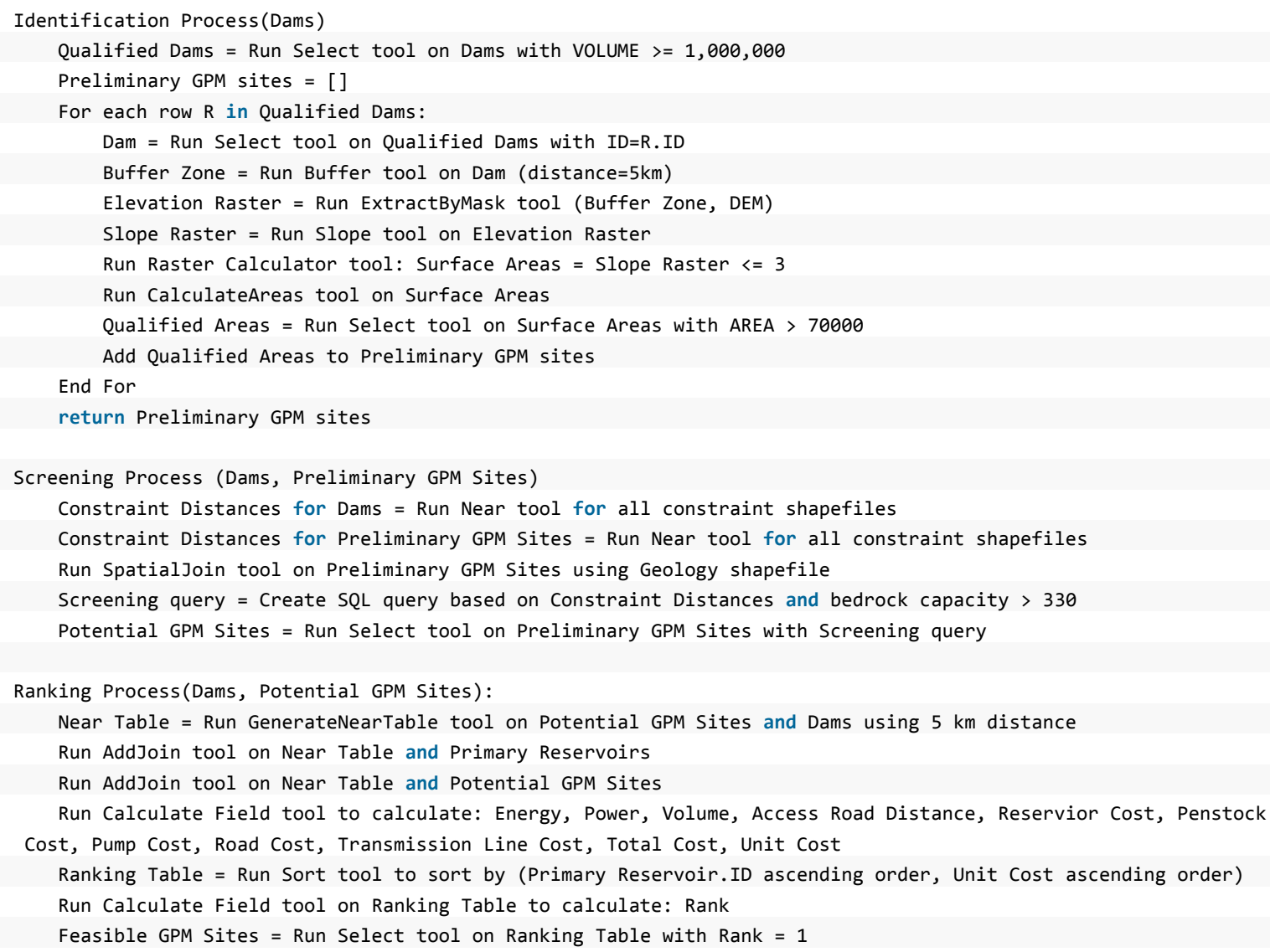

\section{Summary of GIS Processing Results}

The GIS processing results of all sequential steps are provided in Table 5.6 to identify feasible GPM sites with dams. 
Table 5.6 Summary of identified GPM sites with dams

\begin{tabular}{|c|c|c|c|}
\hline \multirow[t]{3}{*}{ Particulars } & \multicolumn{3}{|c|}{ GIS Processing Results } \\
\hline & Identification of Sites & Screening of Sites & Ranking of Sites \\
\hline & Preliminary PHES Sites & Potential PHES Sites & Feasible PHES Sites \\
\hline Dams (No.) & 98 & 21 & 21 \\
\hline GPM Sites (No.) & 1086 & 78 & 21 \\
\hline \multicolumn{3}{|c|}{ Storage Volume $\left(\mathrm{Mm}^{3}\right)$} & 4.49 \\
\hline \multicolumn{3}{|c|}{ Energy Potential (MWh) } & 3,675 \\
\hline
\end{tabular}

\subsubsection{Case II: Identification of Feasible GPM Sites with Lakes}

The details of GIS processing and Python script for this case are the same as given in Section 5.3.1 above, except to replace the dams with lakes. The input data used in GIS processing of this case is provided in Section 4.7.4 of this report. The model results of this case are provided below.

\section{Summary of GIS Processing Results}

The GIS processing results of all sequential steps are provided in Table 5.7 to identify feasible GPM sites with lakes.

Table 5.7 Summary of identified GPM sites with lakes

\begin{tabular}{|c|c|c|c|}
\hline \multirow[t]{3}{*}{ Particulars } & \multicolumn{3}{|c|}{ GIS Processing Results } \\
\hline & Identification of Sites & Screening of Sites & Ranking of Sites \\
\hline & Preliminary PHES Sites & Potential PHES Sites & Feasible PHES Sites \\
\hline Lakes (No.) & 624 & 57 & 57 \\
\hline GPM Sites (No.) & 2729 & 112 & 57 \\
\hline \multicolumn{3}{|c|}{ Storage Volume $\left(\mathrm{Mm}^{3}\right)$} & 12.18 \\
\hline \multicolumn{3}{|c|}{ Energy Potential (MWh) } & 9,975 \\
\hline
\end{tabular}

\subsubsection{Case III: Identification of Feasible GPM Sites with Rivers}

The details of GIS processing, input data and Python script for this case is also the same as given in Section 5.3.1 above, except to replace the dams with rivers. The model results of this case are provided below.

\section{Summary of GIS Processing Results}

The GIS processing results of all sequential steps are provided in Table 5.8 to identify feasible GPM sites with rivers. 
Table 5.8 Summary of feasible GPM sites with rivers

\begin{tabular}{|c|c|c|c|}
\hline \multirow[t]{3}{*}{ Particulars } & \multicolumn{3}{|c|}{ GIS Processing Results } \\
\hline & Identification of Sites & Screening of Sites & Ranking of Sites \\
\hline & Preliminary PHES Sites & Potential PHES Sites & Feasible PHES Sites \\
\hline Rivers (No.) & 166 & 23 & 23 \\
\hline GPM Sites (No.) & 3109 & 199 & 23 \\
\hline \multicolumn{3}{|c|}{ Storage Volume $\left(\mathrm{Mm}^{3}\right)$} & 4.92 \\
\hline \multicolumn{3}{|c|}{ Energy Potential (MWh) } & 4,025 \\
\hline
\end{tabular}

\subsubsection{Case IV: Identification of Feasible GPM Sites using Abandoned Mines}

A systematic methodological process of this case was performed as explained in Section 3.3.7 of methodology chapter. The input data used in GIS processing of this case is provided in Section 4.7.4 of this report. Listing 5.5 provides the pseudocode of Python script prepared for this case.

\section{Listing 5.5 Pseudocode for identification of feasible GPM sites using abandoned mines}

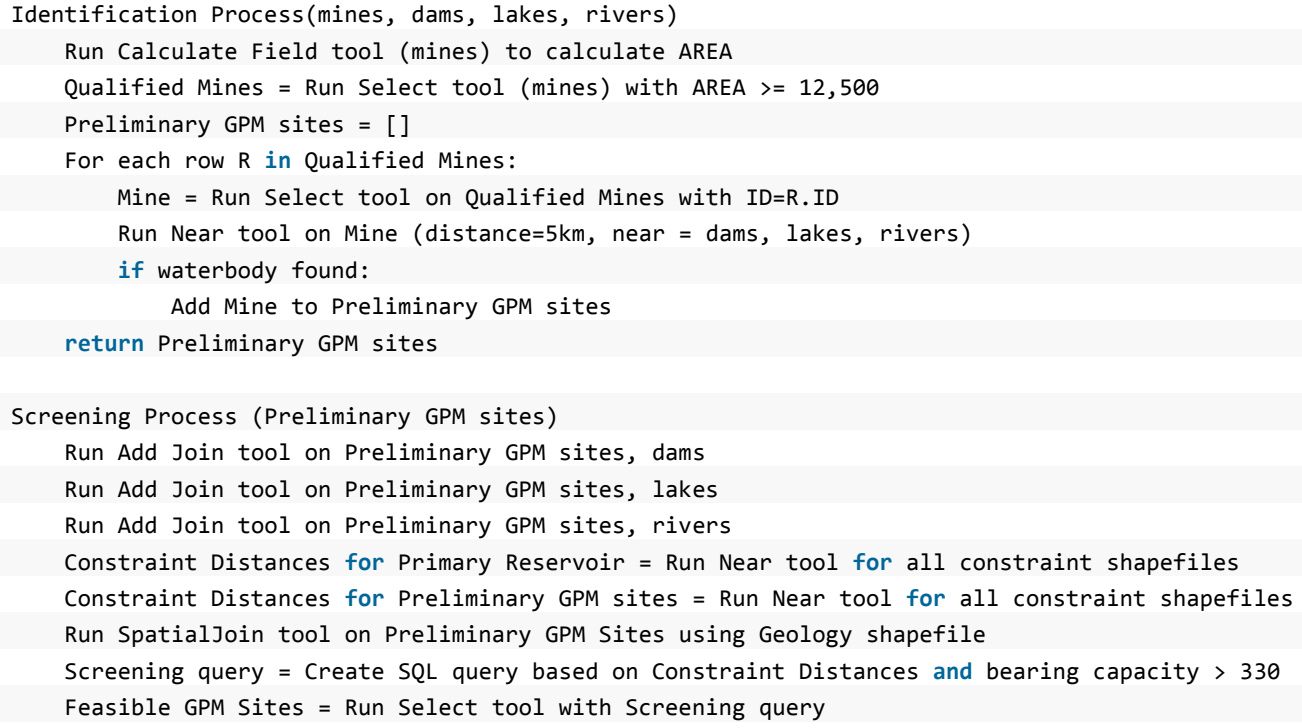

\section{Summary of GIS Processing Results}

The GIS processing results of all sequential steps are provided in Table 5.9 to identify feasible GPM sites using the abandoned mines.

Table 5.9 Summary of feasible abandoned mines selected as GPM sites

\begin{tabular}{|c|c|c|c|}
\hline \multirow[t]{3}{*}{ Particulars } & \multicolumn{3}{|c|}{ GIS Processing Results } \\
\hline & Identification of Sites & Screening of Sites & Ranking of Sites \\
\hline & Preliminary PHES Sites & Potential PHES Sites & Feasible PHES Sites \\
\hline Primary Reservoirs (No.) & 9 & 9 & 9 \\
\hline GPM Sites (No.) & 9 & 9 & 9 \\
\hline \multicolumn{3}{|l|}{ Storage Volume $\left(\mathrm{Mm}^{3}\right)$} & 1.92 \\
\hline Energy Potential (MWh) & & & 1,575 \\
\hline
\end{tabular}




\subsubsection{Summary of Feasible GPM Sites in Ontario}

A summary of feasible GPM sites in Ontario is given in Table 5.10. It is important to mention here that the total identified GPM sites are much high in numbers due to its flexible siting requirements as compared to the conventional PHES method. Therefore, only the selected GPM sites that are located in the close vicinity of the existing power generators have been provided in this report. In GPM method, a major difference is that GPM technology does not need additional PHES reservoir location with an adequate elevation head as required in the conventional PHES method.

Table 5.10 Summary of feasible GPM sites in Ontario

\begin{tabular}{|l|c|c|c|}
\hline \multirow{2}{*}{$\begin{array}{l}\text { Primary Waterbodies and } \\
\text { Abandoned Mines }\end{array}$} & \multicolumn{3}{|c|}{ Feasible GPM sites } \\
\cline { 2 - 4 } & Sites & Storage Volume & Energy Potential \\
\cline { 2 - 4 } & $\mathbf{( N o . )}$ & $\mathbf{( M m}^{\mathbf{3}} \mathbf{)}$ & $\mathbf{( M W h )}$ \\
\hline Dams & 21 & 4.49 & 3,675 \\
\hline Lakes & 57 & 12.18 & 9,975 \\
\hline Rivers & 23 & 04.92 & 4,025 \\
\hline Mines & 9 & 01.92 & 1,575 \\
\hline Total & $\mathbf{1 1 0}$ & $\mathbf{2 3 . 5 1}$ & $\mathbf{1 9 , 2 5 0}$ \\
\hline
\end{tabular}

Figure 5.7 shows the graphical presentation of all resultant feasible GPM sites in Ontario and Figure 5.8 illustrates the position of feasible GPM sites in Ontario map showing the electricity transmission line and existing power generators in Ontario.
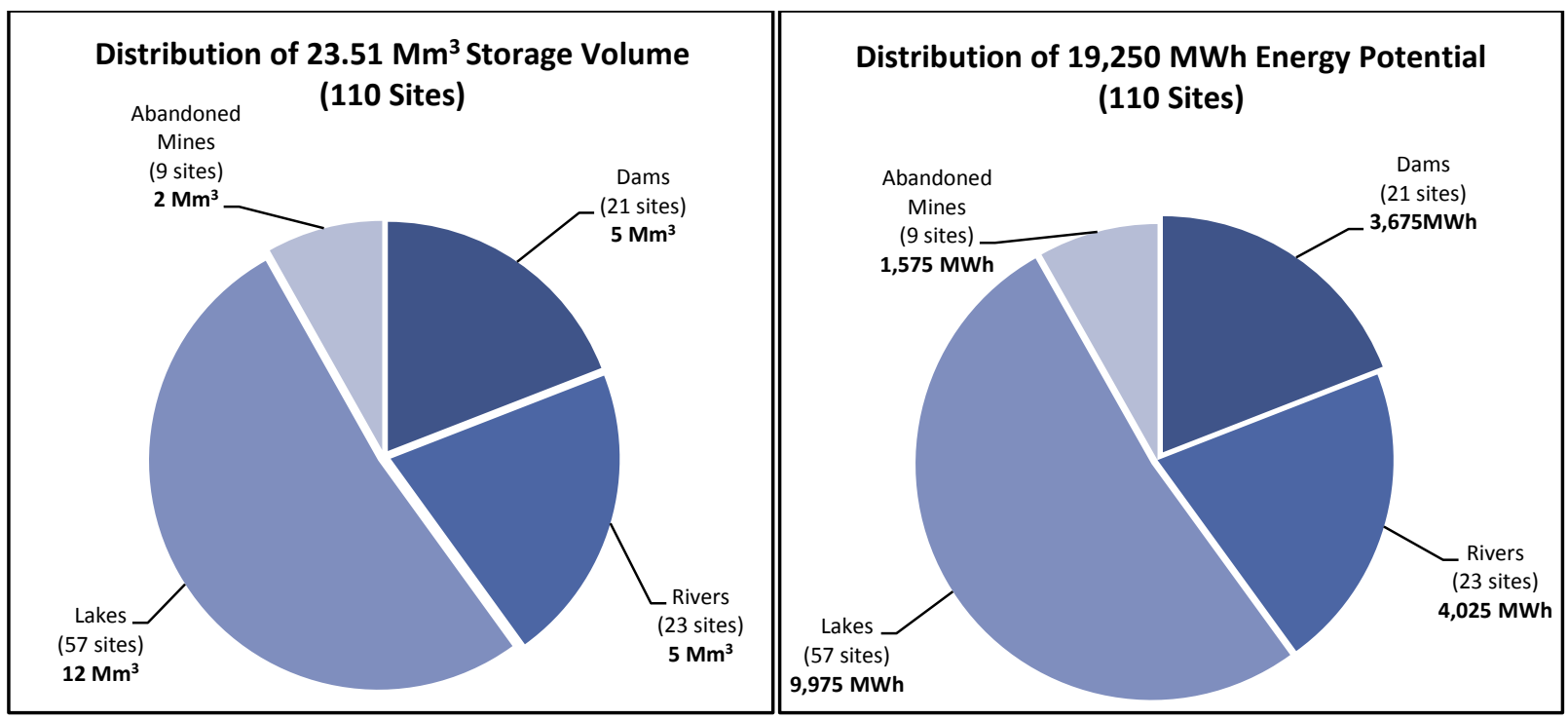

Figure 5.7 GIS processing results of feasible GPM sites in Ontario 


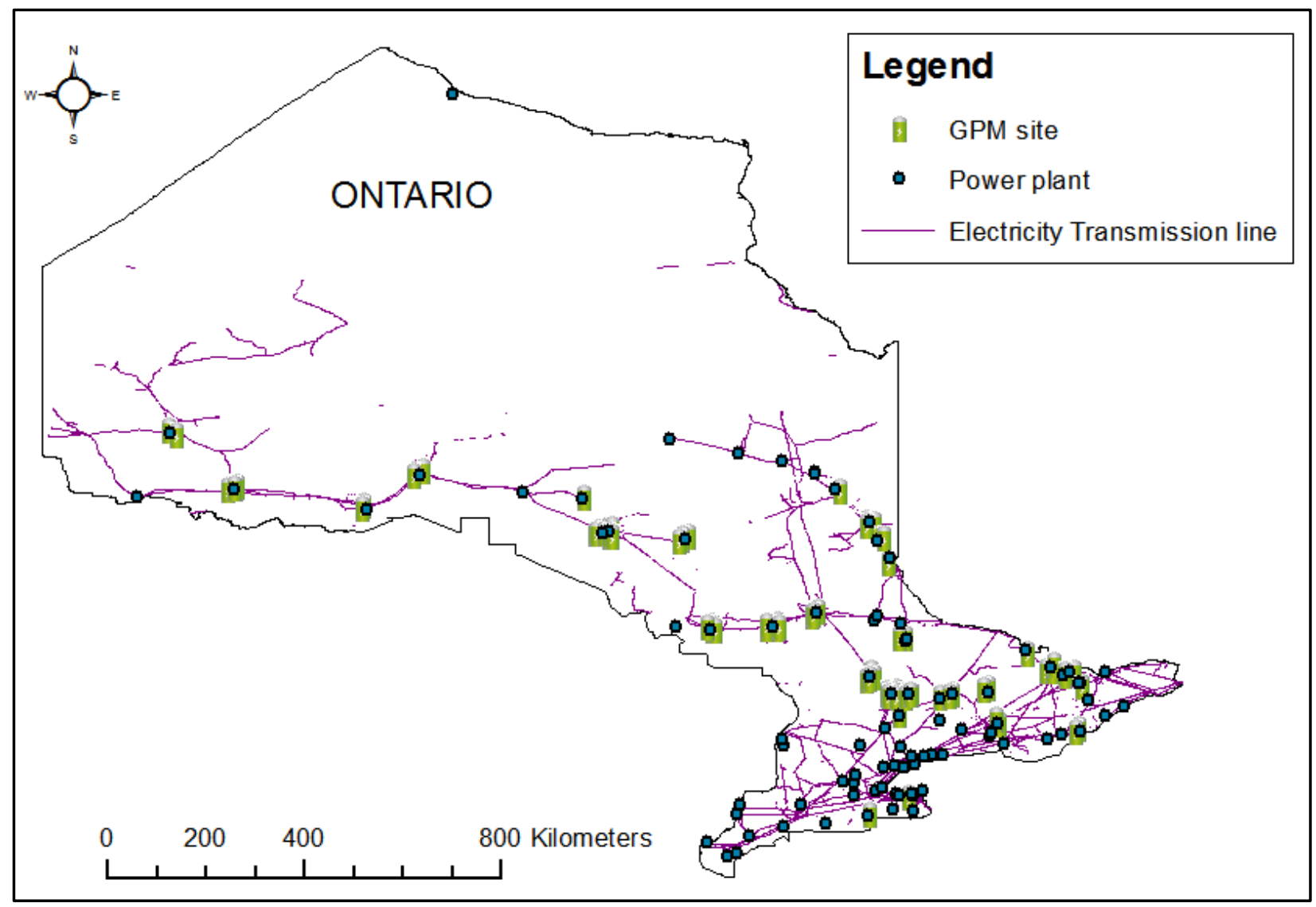

Figure 5.8 GIS results showing feasible GPM sites in Ontario

\subsection{Summary of Feasible PHES and GPM Sites in Ontario}

A summary of combined feasible PHES and GPM sites in Ontario is provided in Table 5.11 as given below.

Table 5.11 Summary of combined feasible PHES and GPM sites in Ontario

\begin{tabular}{|l|c|c|c|}
\hline \multirow{2}{*}{ Particulars } & \multicolumn{3}{|c|}{ Feasible Sites in Ontario } \\
\cline { 2 - 4 } & PHES & GPM & Total \\
\hline Feasible Sites (No.) & 175 & 110 & $\mathbf{2 8 5}$ \\
\hline Total Volume $\left(\mathbf{M m}^{\mathbf{3}}\right)$ & 248.55 & 23.51 & $\mathbf{2 7 2 . 0 6}$ \\
\hline Total Energy Potential (MWh) & 37,018 & 19,250 & $\mathbf{5 6 , 2 6 8}$ \\
\hline
\end{tabular}


The total storage volume and total energy potential for all the PHES and GPM plants are graphically presented in Figure 5.9 below.

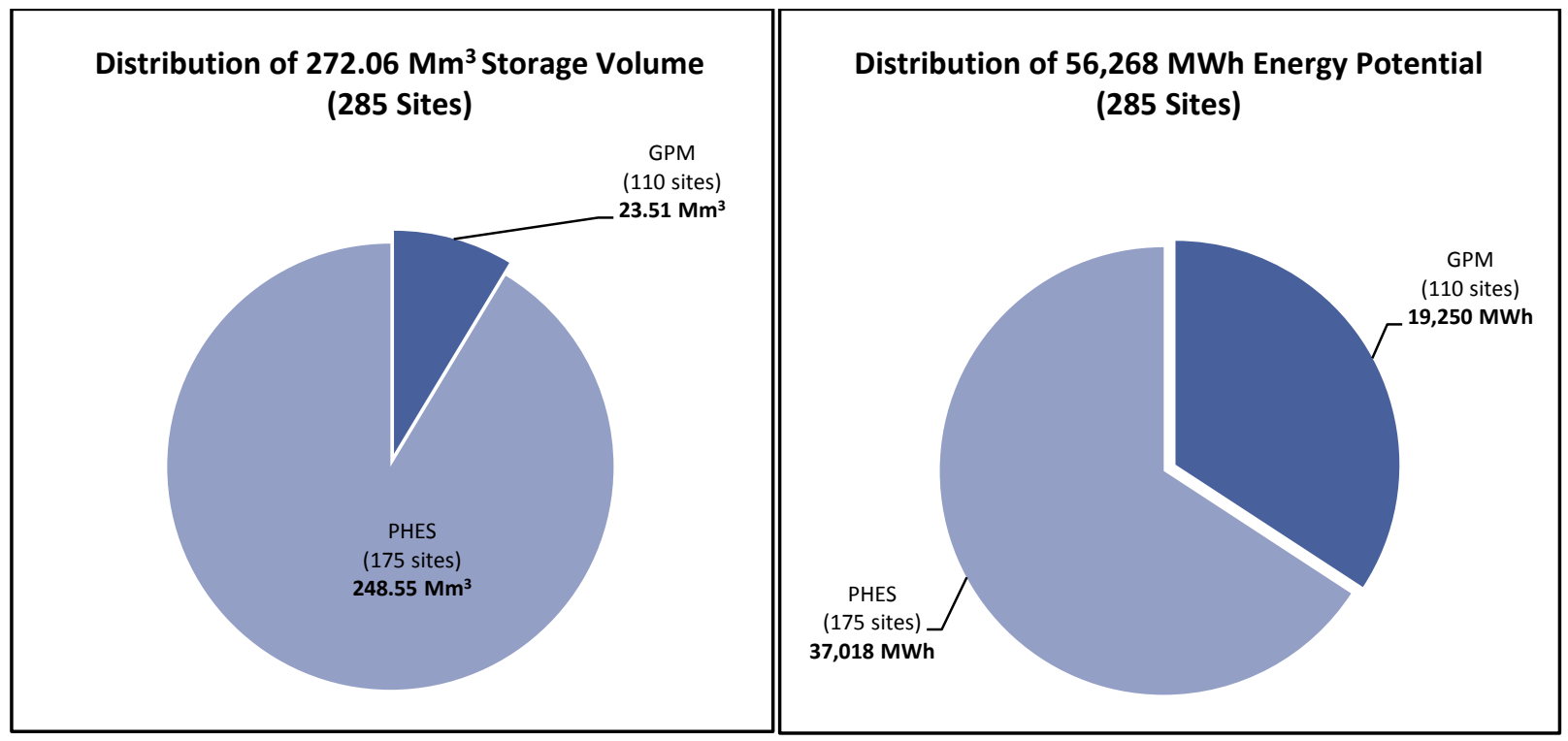

Figure 5.9 GIS processing results of combined feasible PHES and GPM sites in Ontario

\subsection{Validation of GIS-based Model Results}

The case study of Ontario has only one existing in operation PHES project known as Sir Adam Beck pumped hydro energy storage project at Niagara Falls operating since 1957. There is another PHES project known as Marmora PHES project which is currently under construction stage on an abandoned Marmoraton Mine. The data of this new project is used to validate the parameters of Marmora PHES site, identified under this research using GIS-based model. It was observed that the model parameters of the Marmora PHES site are almost closed to the Marmora project data. The mean absolute percent change (MAPC) of these parameters is provided in Table 5.13 as given below.

Table 5.12 Comparison of GIS-based model results with existing Marmora project data

\begin{tabular}{|l|c|c|c|c|}
\hline PHES Parameter & $\begin{array}{l}\text { Parameter Value at } \\
\text { Marmora Project }\end{array}$ & $\begin{array}{l}\text { Parameter Value } \\
\text { in Model Result }\end{array}$ & \multicolumn{1}{|c|}{$\begin{array}{c}\text { Percent } \\
\text { Change }(\%)\end{array}$} & $\begin{array}{c}\text { MAPC } \\
(\%)\end{array}$ \\
\hline Topographical Parameters & 186 & 179 & -3.8 \\
\hline Average Elevation Head (m) & 2000 & 2027 & 1.4 \\
\hline Installed Energy Potential (MWh) & 4.33 & 5.20 & 20 \\
\hline Activated Reservoir Volume (Mm $\left.{ }^{3}\right)$ & & & \\
\hline Financial Parameters & 350,000 & 135,426 & -61.3 & 61.3 \\
\hline $\begin{array}{l}\text { Unit Capital Cost } \\
\text { (approx. C\$/ MWh) }\end{array}$ & & & \\
\hline
\end{tabular}


The validation of results shows that the percent change from actual project data for topographical parameters varies from $1.4 \%$ to $20 \%$ having maximum variation in activated reservoir volume. This variation is mainly due to the differences in elevation height and total energy potential. The MAPC for all topographical parameters is calculated as $8.4 \%$.

With regard to financial parameter data, it is pertinent to mention that Marmora project is the first project of its nature in Ontario, after Sir Adam Beck PHES project at Niagara Falls with a long gap of many decades. The approximate capital cost of this project is online reported as $\mathrm{C} \$$ 700 million in 2014 which is projected to C\$ 744 million in 2018 using average $1.55 \%$ yearly inflation rate from the Bank of Canada. More importantly, the capital costs of the projects have not clearly provided the breakup of its various necessary cost components. It is generally believed that the cost of this nature of the project is considerably higher than the normal projects that are constructed in the same region with previous experiences and practices. Considering this aspect, this new project may experience the appreciation of capital cost due to facing difficulties in various matters such as delays in approvals of administrative, technical, financial, regulatory and licensing matters, etc. Similarly, the delays may occur so as to meet the budgetary requirements, finalizing the social and environmental issues, etc., because of the lack of previous experiences and practices. Considering these factors, the project cost of this nature may further be increased due to miscellaneous contingencies which can be estimated by considering the example that Hatch (2010) used project contingency as $25 \%$ of the capital cost for BC Hydro pumped storage project at Mica Generating Station, BC, Canada. Accordingly, the current project cost could range up to $\mathrm{C} \$ 930$ million.

The above discussion concludes that the validation of project cost is a highly critical issue, which generally involves the complexities of different socio-economic matters. However, it is believed that the successful completion of Marmora project would open an easy gateway for other future projects of this nature in Ontario that may considerably reduce their project costs as compared to the Marmora project cost. 


\subsection{Exploring Valuable Developments Associated with PHES Projects}

It is pertinent to point out that the financial profit calculations in this study only considered the PHES services provided to the electricity market system operated by the IESO in Ontario. However, the PHES facilities could make additional profit by performing the activities other than energy sectors as highlighted in a report by Recharge Marmora (2014) particularly in respect of Marmora PHES project. This report highlighted a positive economic impact of tourism development that can be associated with any PHES project. The key factors of attracting the developments at Marmora project are outlined below:

- Easy access to nature and outdoor activities with numerous historical and natural attractions;

- Easy travel access to Marmora due to direct highway routes such as highway (HWY) 401 and HWY 407 are connected with HWY 35/ 115 that allows a mix of seasonal and yearround opportunities;

- Easy access to the highly attractive natural beauty of the Marmoraton mine that has been already attractive to the visitors;

- Further, the completion of Marmora PHES plant would help to attract a huge number of visitors similar to the other worldwide PHES projects such as :

- Electric Mountain, pumped storage facility, UK;

- Raccoon Mountain pumped storage facility, Tennessee Valley, USA; and

- Bath County pumped storage facility, USA.

Based on the above developments, Recharge Marmora (2014) highlighted the following socioeconomic impacts:

- Revenue generation in the municipal, provincial and federal taxes due to annual tourismrelated development;

- The social sector developments may include numerous jobs to Hastings county including Marmora and Lake; and

- Potential increase in total wages earned by Marmora and Lake Residence.

In addition to above, the Marmora city is ideally located in considering that the Marmora PHES project proceeding could easily trigger the growth in residential development along with other commercial developments. Therefore, the above-mentioned development factors would certainly 
be able to enhance the revenue of local, provincial and federal governments. Additionally, these developments would ultimately enhance the financial capabilities of the local residents including the neighbouring cities.

Therefore, this research study concludes that considering the project developments in the energy sector together with other socio-economic developments, can make the PHES project sites economically better and internationally famous similar to the Niagara Falls.

\subsection{Discussion on GIS-based Model Results}

This study developed integrated planning of PHES system in Ontario's electricity market at the grid level. The basic methodological aspects adopted in this research for identifying the PHES sites have been already validated in a two days' workshop held in April, 2012 at Petten, The Netherlands, with a participation of international experts from different PHES related fields such as energy storage, renewable energy, GIS, economy, planning and development, energy system evaluation, energy security, etc., as documented by Arántegui et al. (2012).

The input data that was needed to feed in the GIS-based model was downloaded from the database: https://library.ryerson.ca/gmdc/madar/geo-data/search-2/ developed in Ryerson University, Toronto, Ontario. The shapefiles of waterbodies, Ontario's DEM, infrastructures, geology and necessary environmental constraints were used in the analysis. The cost data was taken from past studies as well as existing industry suppliers and or organizations. The ranking process was applied to get the results of finally selected the most feasible PHES sites.

The methodology was fully automated that saved the time of lengthy calculations and employed the different dataset information in a systematic way. The overall research study was divided into three phases including the identification of feasible sites to establish the PHES plants, optimizing the scheduling of established PHES plants, and performing a financial analysis of the PHES plants using the optimal scheduling results. The different parameters were used for the broad site selection of feasible PHES sites. The respective results of individual phases have been discussed in the following Sections. 


\subsubsection{Water Availability in Primary Reservoirs}

Three types of primary reservoirs were considered in this research: dams, lakes and rivers. At the beginning of GIS process, a total number of 508 dams, 113,751 lakes and 13,199 rivers were incorporated in the GIS database out of which 122 dams and 10,973 lakes qualified the assumed water availability criteria of minimum $1 \mathrm{Mm}^{3}$ volume and 214 rivers qualified the assumed

minimum $24 \mathrm{~m}^{3} / \mathrm{s}$ flow of water. The condition of minimum water availability was based on the minimum rated power potential of the PHES plants required by the IESO to take part in the electricity market system.

The permitted volume of water for a primary reservoir that can be utilized for pumping operation, is directly linked to the maximum volume of the PHES reservoir and hence to the maximum stored energy potential. Therefore, the available volume of water in primary reservoirs can be used to finalize the maximum volume of PHES reservoirs. In this situation, the wall height of PHES reservoir can be raised because the site area is limited. The PHES plant owners are required to take permit from the concerned regional authority of the primary reservoir for maximum withdrawal of water in one operating cycle of 24 hours period in this research study. There may be some additional restrictions such as, not to exceed the maximum allowable water flow for pumping of water to maintain the eco-system of the primary reservoir within the permissible limits.

\subsubsection{Site-Specific Parameters}

These parameters are related to the topography of the sites such as slope and area of surface regions, horizontal distance and elevation head between primary and PHES reservoirs which have been discussed below.

\section{Surface Region Slope}

The slope of surface regions was considered as 0-3 degree for identification of PHES sites. The ground slope is directly linked to PHES costs involving cut and fill cost of the ground surface. It is obvious that higher values of the ground slope will result in more quantities of cutting and filling, whereas the lower values will result in fewer quantities. However, sometimes it is difficult to locate the sites with a lower slope. In this situation, there is no way except to adopt the higher slope values within the possible extent. 
In this research study, the sensitivity analysis shows that the increase in slope resulted in more sites as compared to the decrease in slope value. However, decreased sites are very close to the original result, whereas the increased sites have a large difference that would result in higher construction cost. Therefore, this analysis supports the suitability of assumed 3 degree slope value.

\section{Distance Between Primary and PHES Reservoirs (Buffer Zone)}

The buffer zone is the defined surrounding area of a primary reservoir with an assumed maximum distance which is linked with the cost of penstock pipes. In this research study, the buffer distance was considered as $5 \mathrm{~km}$. The large buffer distance can result in a long distance between primary and PHES reservoirs in comparison to small buffer distance. The long distance may cause difficulty in laying of penstock pipes due to possible crossings for roads, railways, rivers, etc. in addition to the increased capital cost. In order to determine the suitability of assumed $5 \mathrm{~km}$ buffer distance, the effect of increase/ decrease with the same percentage of the assumed distance was analyzed in the sensitivity analysis provided in Section 5.8. The long penstocks pipes are associated with a risk of water friction inside the pipe due to long size and increased number of bends in the pipe. This situation would reduce the system efficiency in both pumping and generation modes. Therefore, large buffer distances are avoided for both technical and economic concerns.

\section{Surface Region Area}

The area of the surface region is used to define its minimum size so that the minimum volume of the upper reservoir can be determined with the assumed wall height. Although, upper limited of the area is not provided it is linked with the minimum volume of water in the primary reservoir to be used for pumping operation. Additionally, the size of the area is linked with the size of the reservoir wall length which is equivalent to the perimeter of the area and hence it is linked with the cost of the reservoir. The effect of increase and decrease with the same percentage was also analyzed for this perimeter in the sensitivity analysis. It is important to note that the large area size would not only reduce the number of sites but would also increase the reservoir cost. Therefore, the assumed value of the minimum area was found suitable in the case study of Ontario. 


\section{Elevation Head}

This is the elevation difference between primary and PHES reservoirs. This perimeter is most important as it is directly linked with the energy potential of a PHES site. It has a minor effect on the cost of the penstock. Generally, the upper limit of the elevation head is not imposed because this can exclude the technically viable sites and more height would generate more energy. In the conventional method, feasible sites have different elevation heads providing particular energy potential of each site. The suitability of elevation head was analyzed for each waterbody type. Figure 5.10 shows the histogram generated for a minimum elevation of 33 meter and a maximum elevation of 182 meters in this case study. It was observed that a large proportion of elevation heads are in between 33 and 46 meters. The next proportion of elevation is in between 46 and 78 meters.

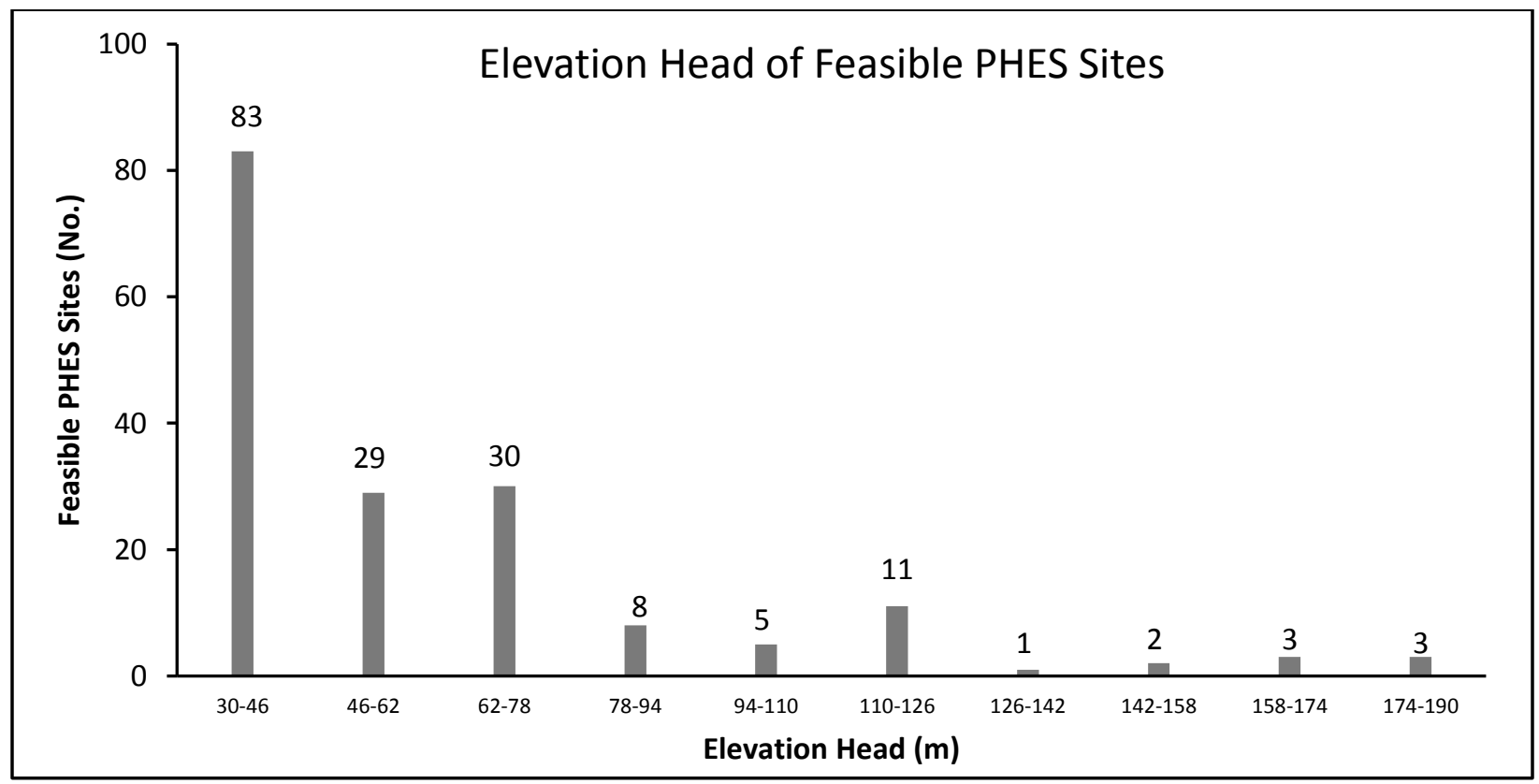

Figure 5.10 Histogram showing elevation head distribution of feasible PHES sites

The effect of an increase/decrease in the default value of this parameter was studied in the sensitivity analysis. The default value of $33 \mathrm{~m}$ head is the corresponding limit using minimum assumed area of a PHES site with 10 meter wall height to generate the minimum energy potential required by IESO in Ontario. 


\subsubsection{Screening of Identified Preliminary PHES Sites}

Jiménez Capilla et al. (2016) stated that this step should be flexible enough so that the final decision may be left with the concerned expert engineer's judgement that can be influenced by the regional conditions. In this research study, a complete set of criteria has been provided in Table 4.11 for broad site selection and screening steps. The screening was based on three types of constraints including environmental, infrastructures and the bedrock geology. These constraints were applied to check the public safety concerns, any possible risk involvement, unreasonable increase in construction costs, and suitability of reservoir foundation strata for selection of the site.

The constraints such as settlement area, built-up area, provincial parks, national wildlife areas, federal protected areas and NGO nature reserves were applied to check the public safety protection and to follow the government policies for special matters.

The infrastructure constraints were applied to keep the capital cost as minimum as possible. In this case, two types of individual component cost were considered: access road and electricity transmission lines.

The geology constraint was applied for both technical and economical point of view. It is important to note that expert engineers would not like to compromise the quality of structure on the cost. However, possible measures can be made after knowing the bedrock strata. The foundation stability, construction costs of PHES reservoirs, and sealing to avoid water losses depends on the bedrock geology. The related geotechnical parameters such as stability, excavation, and permeability have been explained hereinafter.

\section{Stability}

For reservoirs, the stability of foundations of the dams or reservoir wall is an important factor. It determines the risk and cost involved in the construction of PHES plants. The stability can be checked with the bearing capacity of the bedrock. Knowing the maximum load of the dam or reservoir wall, the minimum value can be assumed for stability purposes. In this research, 330 $\mathrm{kPa}$ was assumed as the minimum bearing capacity of the rock. It was observed that the bedrock of all PHES sites has qualified the minimum bearing capacity limit. 


\section{Excavation}

Excavation determines the risk and costs of PHES plants. For example, limestone is very difficult to dig, but a reservoir could be built on it. The surface ground and bedrock strata can be found in different terms such as loose ground, weak ground, hand ground, field transition ground, soft rock, hard rock, and very hard rock.

Excavation is an important factor to be carefully examined while identifying PHES sites. Einarsson et al. (2012) claimed that current technological advancements in excavation techniques have resolved the excavation issues of any hard rock and suggested spatial methods and tools do this job with involving less cost. After examining the online information of their techniques and rates, this research selected these rates for estimation of excavation cost component. The conventional method involves a small part of excavation component, but in GPM method, this component has a major part.

\section{Permeability}

For reservoirs, the sensitiveness of the foundation leakages is also an important factor. The possible permeability may be of different nature with different bedrock formations such as metamorphosed formations, granite formations, formations of sands or sandstone, intermediate fissured formations, and much-fissured limestone. This study has not included the permeability factor as it can be avoided at the macro level planning stage.

\subsubsection{GIS Processing Results}

The feasible PHES and GPM sites were identified as 175 and 110 respectively having their storage potential as 37,018 MWh and 19,250 MWh respectively. Similarly, their respective storage volumes are $248.55 \mathrm{Mm}^{3}$ and $23.51 \mathrm{Mm}^{3}$. The final output of PHES sites in conventional method was identified with an assumed $10 \mathrm{~m}$ wall height that is a lower limit of the range from $10 \mathrm{~m}$ to $30 \mathrm{~m}$ generally adopted in the past studies. Hence, the wall height can be increased subject to the availability of water in the primary reservoir. In the case of increasing the wall height, the energy potential and volume of the plant would be increased in the same proportions according to the energy formula provided in Equation (3.1). For example, if the wall height is increased two times, the energy volume would be increased in the proportion their by increasing the energy values by two times of its original value. Therefore, assuming the ideal condition of 
satisfying the water availability in the primary reservoir, the possible increase in wall height would yield the respective increases in storage volume and resultantly the energy potentials as given in Table 5.13 below.

Table 5.13 Effect on PHES volume and energy potential with change in wall heights

\begin{tabular}{|c|c|c|}
\hline $\begin{array}{c}\text { Reservoir Wall Height } \\
(\mathbf{m})\end{array}$ & $\begin{array}{c}\text { Storage Volume } \\
\left(\mathbf{M m}^{\mathbf{3}}\right)\end{array}$ & $\begin{array}{c}\text { Energy Potential } \\
(\mathbf{M W h})\end{array}$ \\
\hline 10 & 248.55 & 56,268 \\
\hline 15 & 372.83 & 84,402 \\
\hline 20 & 497.10 & 112,536 \\
\hline 25 & 621.38 & 140,670 \\
\hline 30 & 745.65 & 168.804 \\
\hline
\end{tabular}

The increase in wall height can be decided on a case to case basis for the PHES sites, if possible. Similarly, in the case of GPM, there is an option of increasing the depth and diameter of the main shaft. The GPM developer suggested that the range of increase in diameter and depth of main shaft of GPM unit can be selected in various ranges as given in Table 5.14 below.

Table 5.14 Effect on GPM potential with change in depth and diameter of main shaft

\begin{tabular}{|c|c|c|}
\hline $\begin{array}{c}\text { Depth of Main Shaft } \\
(\mathbf{m})\end{array}$ & $\begin{array}{c}\text { Diameter of Main Shaft } \\
(\mathbf{m})\end{array}$ & $\begin{array}{c}\text { GPM Energy potential } \\
(\mathbf{M W h})\end{array}$ \\
\hline 500 & 33 & 160 \\
\hline 700 & 27 & 200 \\
\hline 700 & 62 & 1,225 \\
\hline 700 & 70 & 1,600 \\
\hline 1000 & 77 & 4,000 \\
\hline 1000 & 84 & 4,800 \\
\hline 1000 & 96 & 6,400 \\
\hline
\end{tabular}

Table 5.14 shows that the energy potential of GPM plants would increase in accordance with increase in depth and diameter of the main shaft. In this research study, the lowest range of the parameter was adopted in both conventional and GPM methods at the initial planning stage. The selection of higher values was left for the concerned expert engineers to take decision according to the site conditions and applicable government policies. 


\subsection{Sensitivity Analysis for GIS-based Model Parameters}

The sensitivity analysis was performed using the case of dams as primary reservoirs. The key model parameters and the effect of change in their values are provided in Table 5.15. A combined effect of the parameters was measured by the estimated mean absolute percent change (MAPC) for all the parameters as shown in Table 5.15.

Table 5.15 Estimating MAPC with change in parameter values

\begin{tabular}{|c|c|c|c|c|c|c|}
\hline \multirow[t]{2}{*}{ Model Parameters } & \multicolumn{2}{|c|}{ Percent Decrease } & \multirow[t]{2}{*}{ Default Value } & \multicolumn{2}{|c|}{ Percent Increase } & \multirow{2}{*}{$\begin{array}{c}\text { MAPC } \\
(\%)\end{array}$} \\
\hline & $-20 \%$ & $-10 \%$ & & $10 \%$ & $20 \%$ & \\
\hline Surface Slope (degree) & 2.4 & 2.7 & 3 & 3.3 & 3.6 & \multirow{3}{*}{4.05} \\
\hline Preliminary Sites (No.) & 960 & 966 & 981 & 1026 & 1059 & \\
\hline Absolute Percent Change (\%) & 2.14 & 1.53 & $\mathrm{~N} / \mathrm{A}$ & 4.59 & 7.95 & \\
\hline Surface Area $\left(\mathrm{m}^{2}\right)$ & 56,000 & 63,000 & 70,000 & 77,000 & 84,000 & \multirow{3}{*}{17.76} \\
\hline Preliminary Sites (No.) & 1260 & 1103 & 981 & 852 & 814 & \\
\hline Absolute Percent Change (\%) & 28.44 & 12.44 & $\mathrm{~N} / \mathrm{A}$ & 13.15 & 17.02 & \\
\hline Buffer Distance (km) & 4 & 4.5 & 5 & 5.5 & 6 & \multirow{3}{*}{31.63} \\
\hline Preliminary Sites (No.) & 604 & 788 & 981 & 1205 & 1428 & \\
\hline Absolute Percent Change (\%) & 38.43 & 19.67 & $\mathrm{~N} / \mathrm{A}$ & 22.83 & 45.57 & \\
\hline Elevation Head (m) & 26.4 & 29.7 & 33 & 36.3 & 39.6 & \multirow{3}{*}{17.41} \\
\hline Preliminary Sites (No.) & 1181 & 1070 & 981 & 868 & 700 & \\
\hline Absolute Percent Change (\%) & 20.39 & 9.07 & $\mathrm{~N} / \mathrm{A}$ & 11.52 & 28.64 & \\
\hline
\end{tabular}

The model results performing the sensitivity analysis were compared with respect to the preliminary sites originally identified with their default values. The model output results were recorded using $-20 \%,-10 \%, 10 \%$ and $20 \%$ changes in the default value of one parameter while keeping other parameters unchanged. This process was applied one by one for all the parameters and the results were recorded as given in Table 5.15 above. The individual results of changes with respect to the default values of the parameters were plotted as provided in the Figure 5.11, Figure 5.12, Figure 5.13 and Figure 5.14 for the parameters of surface slope, surface area, buffer distance, and elevation head respectively.

Figure 5.11 shows the model results with increased/ decreased percentages of default values. The surface slope got decreased values of preliminary sites with $20 \%$ decrease in slope parameter value whereas the increase of both $10 \%$ and $20 \%$ in slope parameter value resulted in increased preliminary sites. It was observed that the increasing effect on sites was higher than the decreased values of preliminary sites. For example, a 20\% reduction in the default value of slope 
resulted in $2 \%$ fewer sites, whereas a $20 \%$ increase in slope resulted in $8 \%$ increase in resulted preliminary PHES sites as given below:

Number of sites identified with 3 degree slope (default value) 981

Number of sites identified with 2 degree slope (20\% decrease) 960 (reduced by 2\%)

Number of sites identified with 4 degree slope (20\% increase) 1059 (increased by $8 \%$ )

The estimated mean absolute percent change (MAPC) for surface slope parameter is $4.05 \%$ as provided in Table 5.15 .

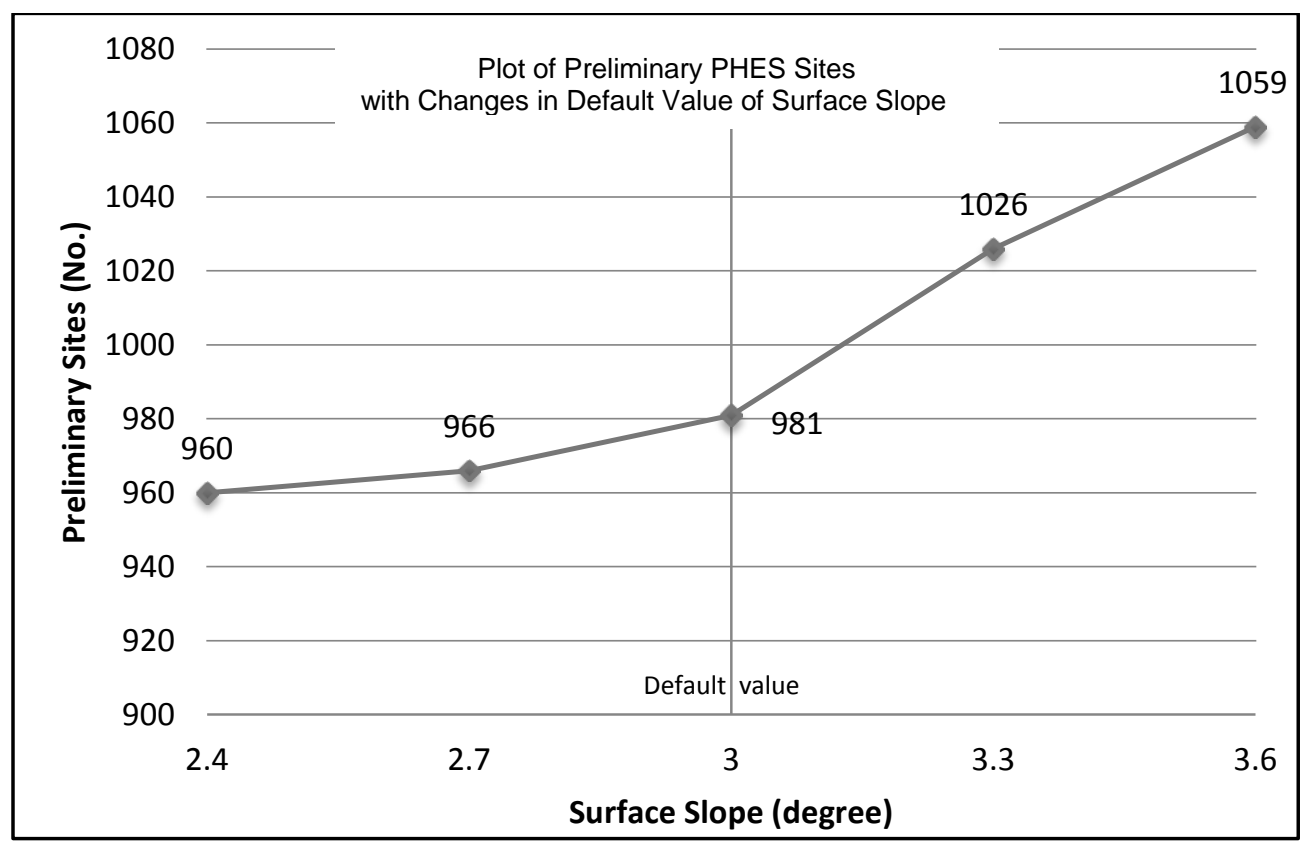

Figure 5.11 Effect on preliminary sites with respective change in surface slope

Figure 5.12 shows that the preliminary sites are increasing with decrease in the percentages of the default value of surface area, whereas this trend is adverse while increasing the percentages of the default value. The effect of percentage decrease $(-10 \%$ and $-20 \%)$ in default value is more than percentage increase (10\% and $20 \%)$ in default values which shows that would result in more preliminary sites by reducing the surface area. It was observed that a $20 \%$ reduction in the area resulted in a $20 \%$ increase in sites, whereas the same increase in percentage resulted in a $30 \%$ decrease in sites. The estimated mean absolute percent change (MAPC) for surface area parameter is $17.76 \%$ as provided in Table 5.15 . 


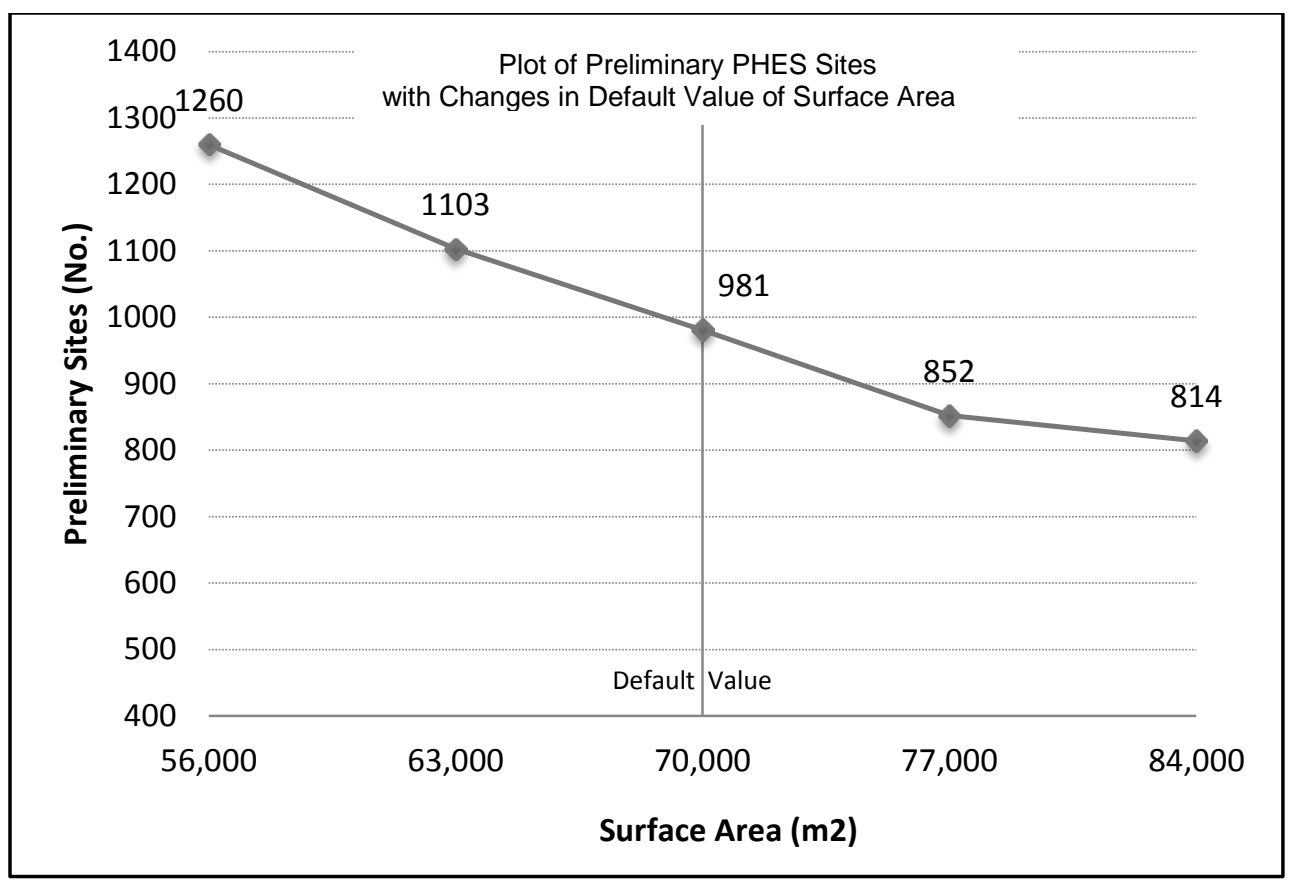

Figure 5.12 Effect on preliminary sites with a respective change in surface area

Figure 5.13 shows that the preliminary sites are decreasing with a percentage decrease in default values of the buffer zone and increasing with increase in percentage increase in default values. The trend of change in increase of preliminary sites is higher than the decrease in preliminary sites. For example, a $20 \%$ reduction in buffer distance resulted in $20 \%$ fewer sites, whereas the same percentage increase resulted in a $28 \%$ increase in preliminary sites. The estimated mean absolute percent change (MAPC) for buffer distance parameter is $31.63 \%$ as provided in Table 5.15 . 


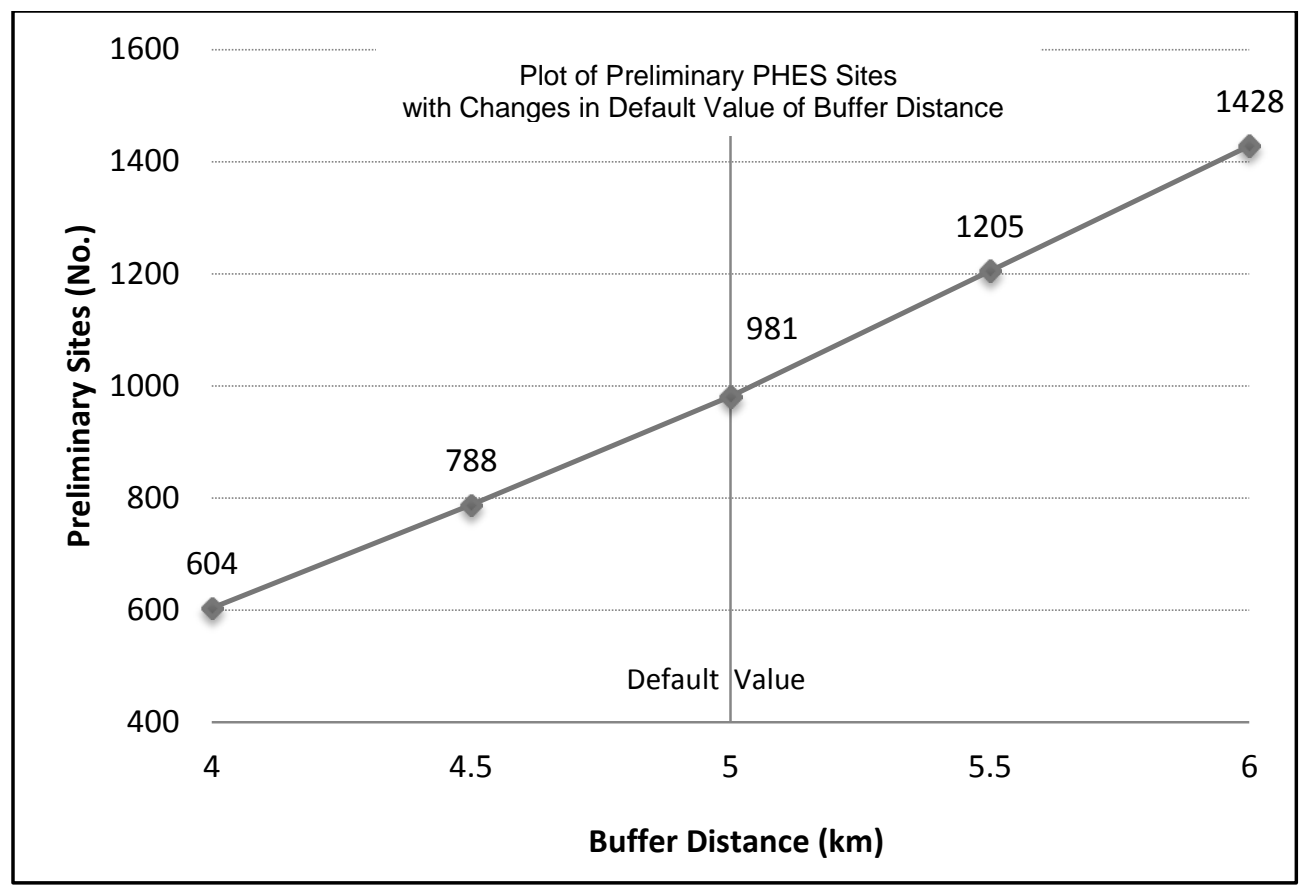

\section{Figure 5.13 Effect on preliminary sites with respective change in buffer distance}

Figure 5.14 shows that the preliminary sites are increasing with a percentage decrease in the default value of elevation head, whereas the preliminary sites are decreasing with the percentage increase in the default value. The $20 \%$ increase in elevation head gives $29 \%$ reduction in sites, whereas $20 \%$ decrease gives a $20 \%$ increase in sites. Therefore, the effect of the percentage increase is higher than the effect of percentage decrease. The estimated mean absolute percent change (MAPC) for elevation head parameter is $17.41 \%$ as provided in Table 5.15. 


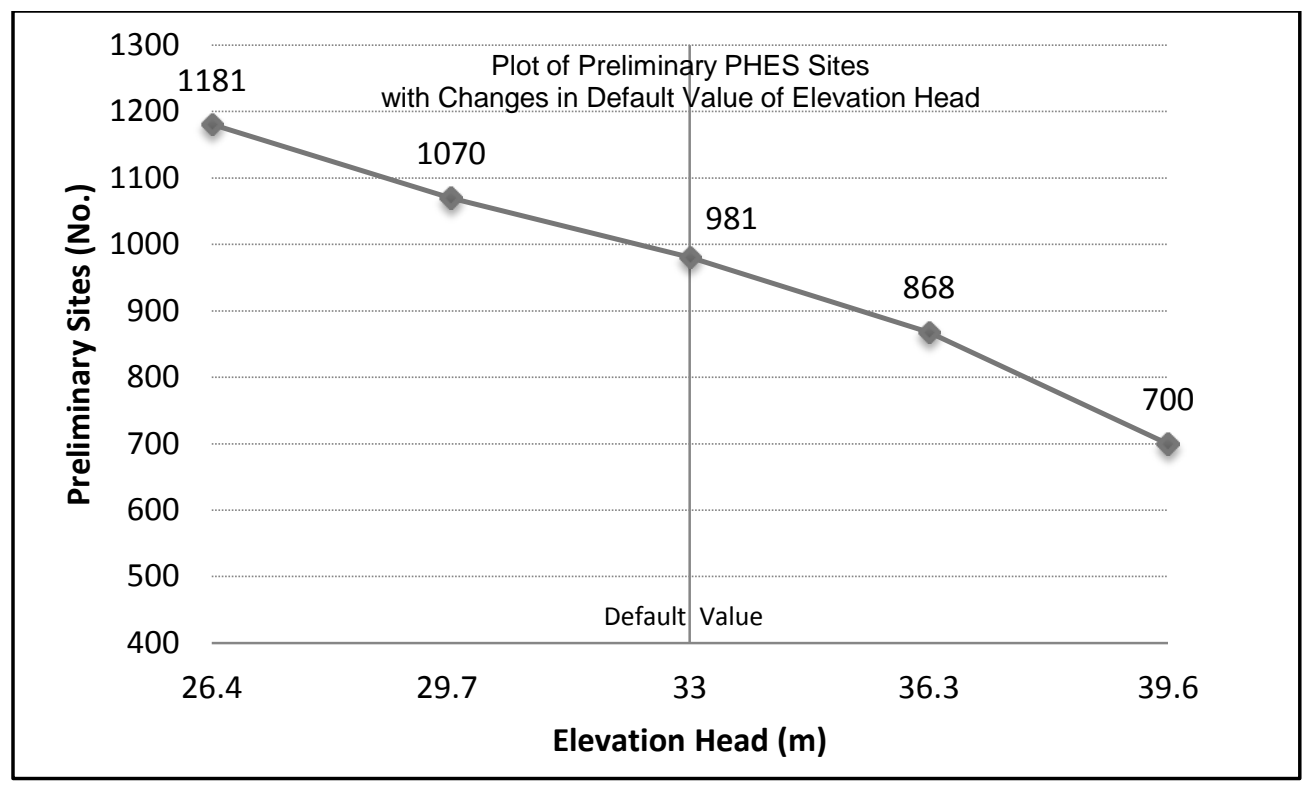

Figure 5.14 Effect on preliminary sites with respective change in elevation head

The results of all the parameters have been plotted together Figure 5.15 below to find the combined effect of these parameters. It was observed that the buffer zone is the most sensitive parameter, whereas surface area slope is the lowest sensitive model parameter.

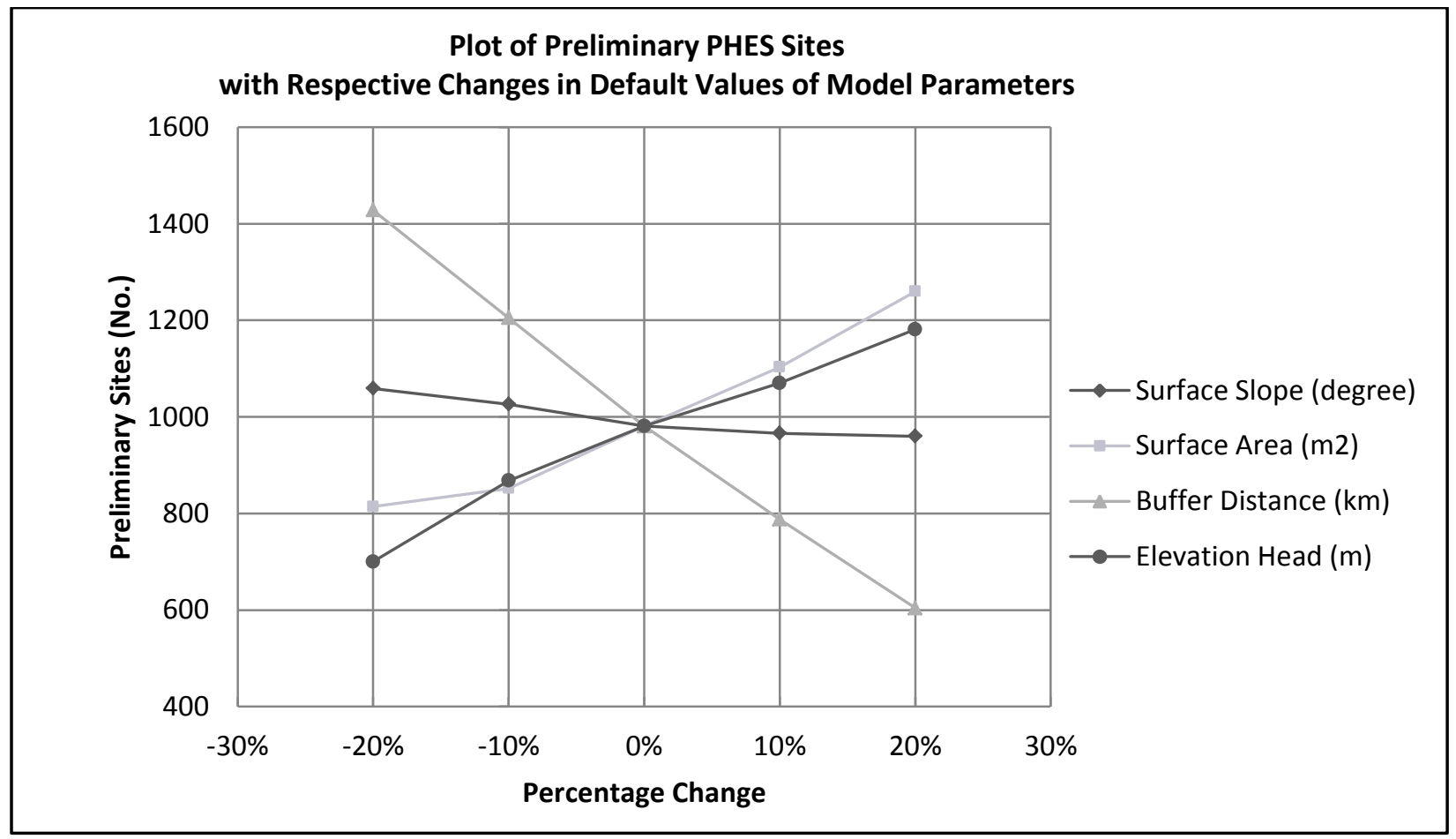

Figure 5.15 Preliminary sites with percent changes in default values of model parameters 


\subsection{Applying Optimization Model on Case Study of Ontario}

\subsubsection{Defining Optimization Problem}

The objective function and system constraints have been defined in Section 3.4.4 of methodology chapter. The optimization model was applied in the case study of Ontario using input data provided in Section 4.8 of case study chapter, for both winter and summer seasons of each year for entire 60 years life period of PHSA plants. Accordingly, the objective function and system constraints of the case study were formulated using decision variables along with their respective coefficients and the constant values defined under this case study.

\subsubsection{Solution of Optimization Problem}

The optimization problem was solved using LINGO software (version 17). The problem solution resulted in the form of decision variables and objective function values of winter and summer season in each year for the life period of PHSA plants that has been provided in Table 5.16.

The solution of the year 2016 shows that PHSA optimally utilized an average 65,060 MWh per day in both winter and summer seasons in terms of energy purchased by the storage (PBH) against the available SBG of 108,800 MWh as provided in Section 4.4 of case study chapter. Therefore, PHSA purchased $59.80 \%$ of available SBG.

Similarly, PHSA supplied 28,134 MWh per day in both winter and summer seasons against the system load (PDL) requirement of 61,156 MWh per day in winter and 69,744 MWh per day in summer season as provided in Section 4.3 of case study chapter. Therefore, PHSA provided $46 \%$ of PDL in winter and $40.34 \%$ of PDL in the summer season.

With regard to operating reserve, PHSA supplied variable operating reserve as $23,914 \mathrm{MWh}$ per day and maintained fixed operating reserve as 4,220 MWh per day that makes a total 28,134 MWh in both winter and summer seasons against the total system operating reserve requirement of 33,600 MWh per day in each season as given in Section 4.5 of case study chapter. Therefore, PHSA provided $83.73 \%$ of the total system reserve requirement. 
Table 5.16 Resulted values of decision variables and objective function

\begin{tabular}{|c|c|c|c|c|c|c|c|c|c|c|c|c|c|c|c|}
\hline \multirow{5}{*}{ Year } & \multicolumn{12}{|c|}{ Decision variables (Average Daily Energy Supply and Purchase) } & \multicolumn{3}{|c|}{ Objective Function Values } \\
\hline & \multicolumn{6}{|c|}{ Winter } & \multicolumn{6}{|c|}{ Summer } & \multirow{3}{*}{ Winter } & \multirow{3}{*}{ Summer } & \multirow{3}{*}{ Total } \\
\hline & \multicolumn{3}{|c|}{$\begin{array}{c}\text { Real-Time Supply } \\
\text { (PSA) }\end{array}$} & $\begin{array}{r}\text { Oper } \\
\text { Rese }\end{array}$ & $\begin{array}{l}\text { ting } \\
\text { rve }\end{array}$ & $\begin{array}{c}\text { Energy } \\
\text { Purchase }\end{array}$ & & $\begin{array}{l}\text { 1-Time } \\
\text { (PSA) }\end{array}$ & Supply & $\begin{array}{r}\text { Ope } \\
\text { Res }\end{array}$ & $\begin{array}{l}\text { ating } \\
\text { erve }\end{array}$ & $\begin{array}{c}\text { Energy } \\
\text { Purchase }\end{array}$ & & & \\
\hline & OFF & MID & ON & PFR & PVR & PBH & OFF & MID & ON & PFR & PVR & PBH & & & \\
\hline & (MWh) & (MWh) & (MWh) & (MWh) & (MWh) & (MWh) & (MWh) & (MWh) & (MWh) & (MWh) & (MWh) & (MWh) & (C\$) & (C\$) & (C\$) \\
\hline 2016 & 0 & 11629 & 16505 & 4220 & 23914 & 65060 & 0 & 9311 & 18823 & 4220 & 23914 & 65060 & $184,400,590$ & $321,746,168$ & $506,146,758$ \\
\hline 2017 & 0 & 11414 & 16720 & 4220 & 23914 & 65060 & 0 & 9066 & 19068 & 4220 & 23914 & 65060 & $189,441,884$ & $330,616,764$ & $520,058,648$ \\
\hline 2018 & 0 & 11197 & 16937 & 4220 & 23914 & 65060 & 0 & 8818 & 19316 & 4220 & 23914 & 65060 & $194,622,934$ & $339,736,150$ & $534,359,084$ \\
\hline 2019 & 0 & 10977 & 17157 & 4220 & 23914 & 65060 & 0 & 8567 & 19567 & 4220 & 23914 & 65060 & $199,947,692$ & $349,111,466$ & $549,059,157$ \\
\hline 2020 & 0 & 10754 & 17380 & 4220 & 23914 & 65060 & 0 & 8313 & 19821 & 4220 & 23914 & 65060 & $205,420,219$ & $358,750,062$ & $564,170,281$ \\
\hline 2021 & 0 & 10528 & 17606 & 4220 & 23914 & 65060 & 0 & 8055 & 20079 & 4220 & 23914 & 65060 & $211,044,698$ & $368,659,506$ & $579,704,204$ \\
\hline 2022 & 0 & 10299 & 17835 & 4220 & 23914 & 65060 & 0 & 7794 & 20340 & 4220 & 23914 & 65060 & $216,825,431$ & $378,847,591$ & $595,673,022$ \\
\hline 2023 & 0 & 10067 & 18067 & 4220 & 23914 & 65060 & 0 & 7530 & 20604 & 4220 & 23914 & 65060 & $222,766,846$ & $389,322,339$ & $612,089,185$ \\
\hline 2024 & 0 & 9832 & 18302 & 4220 & 23914 & 65060 & 0 & 7262 & 20872 & 4220 & 23914 & 65060 & $228,873,500$ & $400,092,011$ & $628,965,512$ \\
\hline 2025 & 0 & 9594 & 18540 & 4220 & 23914 & 65060 & 0 & 6991 & 21143 & 4220 & 23914 & 65060 & $235,150,082$ & $411,165,115$ & $646,315,197$ \\
\hline 2026 & 0 & 9353 & 18781 & 4220 & 23914 & 65060 & 0 & 6716 & 21418 & 4220 & 23914 & 65060 & $241,601,418$ & $422,550,410$ & $664,151,828$ \\
\hline 2027 & 0 & 9109 & 19025 & 4220 & 23914 & 65060 & 0 & 6437 & 21697 & 4220 & 23914 & 65060 & $248,232,475$ & $434,256,915$ & $682,489,390$ \\
\hline 2028 & 0 & 8862 & 19272 & 4220 & 23914 & 65060 & 0 & 6155 & 21979 & 4220 & 23914 & 65060 & $255,048,363$ & $446,293,921$ & $701,342,284$ \\
\hline 2029 & 0 & 8611 & 19523 & 4220 & 23914 & 65060 & 0 & 5870 & 22264 & 4220 & 23914 & 65060 & $262,054,345$ & $458,670,993$ & $720,725,338$ \\
\hline 2030 & 0 & 8358 & 19776 & 4220 & 23914 & 65060 & 0 & 5580 & 22554 & 4220 & 23914 & 65060 & $269,255,835$ & $471,397,983$ & $740,653,818$ \\
\hline 2031 & 0 & 8100 & 20034 & 4220 & 23914 & 65060 & 0 & 5287 & 22847 & 4220 & 23914 & 65060 & $276,658,407$ & $484,485,037$ & $761,143,444$ \\
\hline 2032 & 0 & 7840 & 20294 & 4220 & 23914 & 65060 & 0 & 4990 & 23144 & 4220 & 23914 & 65060 & $284,267,796$ & $497,942,607$ & $782,210,403$ \\
\hline 2033 & 0 & 7576 & 20558 & 4220 & 23914 & 65060 & 0 & 4689 & 23445 & 4220 & 23914 & 65060 & $292,089,909$ & $511,781,454$ & $803,871,363$ \\
\hline 2034 & 0 & 7309 & 20825 & 4220 & 23914 & 65060 & 0 & 4384 & 23750 & 4220 & 23914 & 65060 & $300,130,824$ & $526,012,665$ & $826,143,489$ \\
\hline 2035 & 0 & 7038 & 21096 & 4220 & 23914 & 65060 & 0 & 4076 & 24058 & 4220 & 23914 & 65060 & $308,396,798$ & $540,647,660$ & $849,044,458$ \\
\hline 2036 & 0 & 6764 & 21370 & 4220 & 23914 & 65060 & 0 & 3763 & 24371 & 4220 & 23914 & 65060 & $316,894,271$ & $555,698,200$ & $872,592,471$ \\
\hline 2037 & 0 & 6486 & 21648 & 4220 & 23914 & 65060 & 0 & 3446 & 24688 & 4220 & 23914 & 65060 & $325,629,875$ & $571,176,402$ & $896,806,278$ \\
\hline 2038 & 0 & 6205 & 21929 & 4220 & 23914 & 65060 & 0 & 3125 & 25009 & 4220 & 23914 & 65060 & $334,610,437$ & $587,094,748$ & $921,705,185$ \\
\hline 2039 & 0 & 5920 & 22214 & 4220 & 23914 & 65060 & 0 & 2800 & 25334 & 4220 & 23914 & 65060 & $343,842,984$ & $603,466,095$ & $947,309,078$ \\
\hline 2040 & 0 & 5631 & 22503 & 4220 & 23914 & 65060 & 0 & 2471 & 25663 & 4220 & 23914 & 65060 & $353,334,751$ & $620,303,689$ & $973,638,440$ \\
\hline 2041 & 0 & 5338 & 22796 & 4220 & 23914 & 65060 & 0 & 2137 & 25997 & 4220 & 23914 & 65060 & $363,093,188$ & $637,621,178$ & $1,000,714,366$ \\
\hline 2042 & 0 & 5042 & 23092 & 4220 & 23914 & 65060 & 0 & 1799 & 26335 & 4220 & 23914 & 65060 & $373,125,964$ & $655,432,622$ & $1,028,558,586$ \\
\hline 2043 & 0 & 4742 & 23392 & 4220 & 23914 & 65060 & 0 & 1457 & 26677 & 4220 & 23914 & 65060 & $383,440,978$ & $673,752,505$ & $1,057,193,483$ \\
\hline 2044 & 0 & 4438 & 23696 & 4220 & 23914 & 65060 & 0 & 1110 & 27024 & 4220 & 23914 & 65060 & $394,046,360$ & $692,595,755$ & $1,086,642,115$ \\
\hline 2045 & 0 & 4130 & 24004 & 4220 & 23914 & 65060 & 0 & 758 & 27376 & 4220 & 23914 & 65060 & $404,950,484$ & $711,977,749$ & $1,116,928,233$ \\
\hline 2046 & 0 & 3818 & 24316 & 4220 & 23914 & 65060 & 0 & 403 & 27731 & 4220 & 23914 & 65060 & $416,161,971$ & $731,914,334$ & $1,148,076,305$ \\
\hline 2047 & 0 & 3502 & 24632 & 4220 & 23914 & 65060 & 0 & 42 & 28092 & 4220 & 23914 & 65060 & $427,689,699$ & $752,421,840$ & $1,180,111,539$ \\
\hline 2048 & 0 & 3181 & 24953 & 4220 & 23914 & 65060 & 0 & 0 & 28134 & 4220 & 23914 & 65060 & $439,542,812$ & $772,494,182$ & $1,212,036,995$ \\
\hline 2049 & 0 & 2857 & 25277 & 4220 & 23914 & 65060 & 0 & 0 & 28134 & 4220 & 23914 & 65060 & $451,730,726$ & $792,965,278$ & $1,244,696,004$ \\
\hline 2050 & 0 & 2528 & 25606 & 4220 & 23914 & 65060 & 0 & 0 & 28134 & 4220 & 23914 & 65060 & $464,263,136$ & $813,978,858$ & $1,278,241,994$ \\
\hline 2051 & 0 & 2195 & 25939 & 4220 & 23914 & 65060 & 0 & 0 & 28134 & 4220 & 23914 & 65060 & $477,150,030$ & $835,549,298$ & $1,312,699,327$ \\
\hline 2052 & 0 & 1858 & 26276 & 4220 & 23914 & 65060 & 0 & 0 & 28134 & 4220 & 23914 & 65060 & $490,401,692$ & $857,691,354$ & $1,348,093,046$ \\
\hline 2053 & 0 & 1517 & 26617 & 4220 & 23914 & 65060 & 0 & 0 & 28134 & 4220 & 23914 & 65060 & $504,028,716$ & $880,420,175$ & $1,384,448,891$ \\
\hline 2054 & 0 & 1171 & 26963 & 4220 & 23914 & 65060 & 0 & 0 & 28134 & 4220 & 23914 & 65060 & $518,042,014$ & $903,751,310$ & $1,421,793,324$ \\
\hline 2055 & 0 & 820 & 27314 & 4220 & 23914 & 65060 & 0 & 0 & 28134 & 4220 & 23914 & 65060 & $532,452,823$ & $927,700,720$ & $1,460,153,543$ \\
\hline 2056 & 0 & 465 & 27669 & 4220 & 23914 & 65060 & 0 & 0 & 28134 & 4220 & 23914 & 65060 & $539,036,534$ & $952,284,789$ & $1,491,321,322$ \\
\hline 2057 & 0 & 105 & 28029 & 4220 & 23914 & 65060 & 0 & 0 & 28134 & 4220 & 23914 & 65060 & $554,059,185$ & $977,520,336$ & $1,531,579,521$ \\
\hline 2058 & 0 & 0 & 28134 & 4220 & 23914 & 65060 & 0 & 0 & 28134 & 4220 & 23914 & 65060 & $568,963,603$ & $1,003,424,624$ & $1,572,388,228$ \\
\hline 2059 & 0 & 0 & 28134 & 4220 & 23914 & 65060 & 0 & 0 & 28134 & 4220 & 23914 & 65060 & $584,041,139$ & $1,030,015,377$ & $1,614,056,516$ \\
\hline 2060 & 0 & 0 & 28134 & 4220 & 23914 & 65060 & 0 & 0 & 28134 & 4220 & 23914 & 65060 & $599,518,229$ & $1,057,310,784$ & $1,656,829,013$ \\
\hline 2061 & 0 & 0 & 28134 & 4220 & 23914 & 65060 & 0 & 0 & 28134 & 4220 & 23914 & 65060 & $615,405,462$ & $1,085,329,520$ & $1,700,734,982$ \\
\hline 2062 & 0 & 0 & 28134 & 4220 & 23914 & 65060 & 0 & 0 & 28134 & 4220 & 23914 & 65060 & $631,713,707$ & $1,114,090,753$ & $1,745,804,459$ \\
\hline 2063 & 0 & 0 & 28134 & 4220 & 23914 & 65060 & 0 & 0 & 28134 & 4220 & 23914 & 65060 & $648,454,120$ & $1,143,614,158$ & $1,792,068,278$ \\
\hline 2064 & 0 & 0 & 28134 & 4220 & 23914 & 65060 & 0 & 0 & 28134 & 4220 & 23914 & 65060 & $665,638,154$ & $1,173,919,933$ & $1,839,558,087$ \\
\hline 2065 & 0 & 0 & 28134 & 4220 & 23914 & 65060 & 0 & 0 & 28134 & 4220 & 23914 & 65060 & $683,277,565$ & $1,205,028,811$ & $1,888,306,376$ \\
\hline 2066 & 0 & 0 & 28134 & 4220 & 23914 & 65060 & 0 & 0 & 28134 & 4220 & 23914 & 65060 & $701,384,421$ & $1,236,962,074$ & $1,938,346,495$ \\
\hline 2067 & 0 & 0 & 28134 & 4220 & 23914 & 65060 & 0 & 0 & 28134 & 4220 & 23914 & 65060 & $719,971,108$ & $1,269,741,569$ & $1,989,712,677$ \\
\hline 2068 & 0 & 0 & 28134 & 4220 & 23914 & 65060 & 0 & 0 & 28134 & 4220 & 23914 & 65060 & $739,050,342$ & $1,303,389,721$ & $2,042,440,063$ \\
\hline 2069 & 0 & 0 & 28134 & 4220 & 23914 & 65060 & 0 & 0 & 28134 & 4220 & 23914 & 65060 & $758,635,176$ & $1,337,929,549$ & $2,096,564,725$ \\
\hline 2070 & 0 & 0 & 28134 & 4220 & 23914 & 65060 & 0 & 0 & 28134 & 4220 & 23914 & 65060 & $778,739,009$ & $1,373,384,682$ & $2,152,123,690$ \\
\hline 2071 & 0 & 0 & 28134 & 4220 & 23914 & 65060 & 0 & 0 & 28134 & 4220 & 23914 & 65060 & $799,375,592$ & $1,409,779,376$ & $2,209,154,968$ \\
\hline 2072 & 0 & 0 & 28134 & 4220 & 23914 & 65060 & 0 & 0 & 28134 & 4220 & 23914 & 65060 & $820,559,045$ & $1,447,138,529$ & $2,267,697,575$ \\
\hline 2073 & 0 & 0 & 28134 & 4220 & 23914 & 65060 & 0 & 0 & 28134 & 4220 & 23914 & 65060 & $842,303,860$ & $1,485,487,700$ & $2,327,791,560$ \\
\hline 2074 & 0 & 0 & 28134 & 4220 & 23914 & 65060 & 0 & 0 & 28134 & 4220 & 23914 & 65060 & $864,624,912$ & $1,524,853,124$ & $2,389,478,037$ \\
\hline 2075 & 0 & 0 & 28134 & 4220 & 23914 & 65060 & 0 & 0 & 28134 & 4220 & 23914 & 65060 & $887,537,473$ & $1,565,261,732$ & $2,452,799,205$ \\
\hline
\end{tabular}




\subsection{Discussion on Optimization Model Results}

The optimization of PHES scheduling was performed to ascertain optimal limits of providing energy services by the storage to IESO particularly including (i) energy supply at real-time during on-peak and mid-peak hours, (ii) instant energy supply for ancillary services including the variable operating reserve, and (iii) maintaining a fixed operating reserve. The energy storage purchases energy during off-peak hours for pumping operations to provide the above services.

For the winter season, Figure 5.16 shows the above-mentioned services for an average one operating cycle of 24 hours. The graph shows that total energy purchased by energy storage $(\mathrm{PBH})$ is more than the total energy storage potential (PSH). It is because the energy storage is not $100 \%$ efficient and therefore, the storage has to purchase the energy 1.25 times the sale of energy for PSA-ON, PSA-MID and PVR services.

It was observed that the energy sale of PSA-ON is increasing from 2016 to 2058 and then after it remains constant up to 2075, while PDL-ON is increasing every year. Contrary to PSA-ON, the PSA-MID is decreasing from 2016 to 2057 and then after it remains zero up to 2075, whereas PDL-MID is also increasing every year. The increase in PSA-ON and decrease in PSA-MID is due to the difference in energy sale prices. The sale price of PSA-ON is higher than PSA-MID price. Additionally, the energy utilization in both periods is governed by the following constraints:

$$
\begin{aligned}
& \text { PSA-ON } \leq \text { PDL-ON } \quad(=16,505 \mathrm{MWh} \text { in 2016 }) \\
& \text { PSA-MID } \leq \text { PDL-MID }(=16,014 \mathrm{MWh} \text { in 2016 }) \\
& \text { PSA-OFF } \leq \text { PDL-OFF }(=28,637 \mathrm{MWh} \text { in 2016) }
\end{aligned}
$$

From the above constraints, it is clear that the PSA values cannot go up beyond the PDL limits. Moreover, following the other system constraints, the energy storage gives first priority to PFR and PVR, and then after to PSA-ON. The remaining potential is utilized for PSA-MID. In the year 2016, the storage first utilized 4,220 MWh and 23,914 MWh for PFR and PVR respectively making a total of 28,134 MWh. After this, the optimization allows PSA-ON as 16,505 MWh, because this is the maximum limit of PDL-ON. Under this situation, the remaining capacity is 11,629 $\mathrm{MWh}(=56,268 \mathrm{MWh}-28,134 \mathrm{MWh}-16,505 \mathrm{MWh})$ utilized for PSA-MID which is 
less than the maximum limit 16,014 MWh for PDL-MID. The same pattern of storage utilization was followed in each year.

Although, total system operating reserve (TSR) is increasing every year, the PFR and PVR remains constraint throughout from 2016 to 2075 because the maximum limit of total storage operating reserve (PFR + PVR) is $50 \%$ of the total storage capacity (PSH) and the maximum limit of PVR is $85 \%$ of (PFR + PVR).

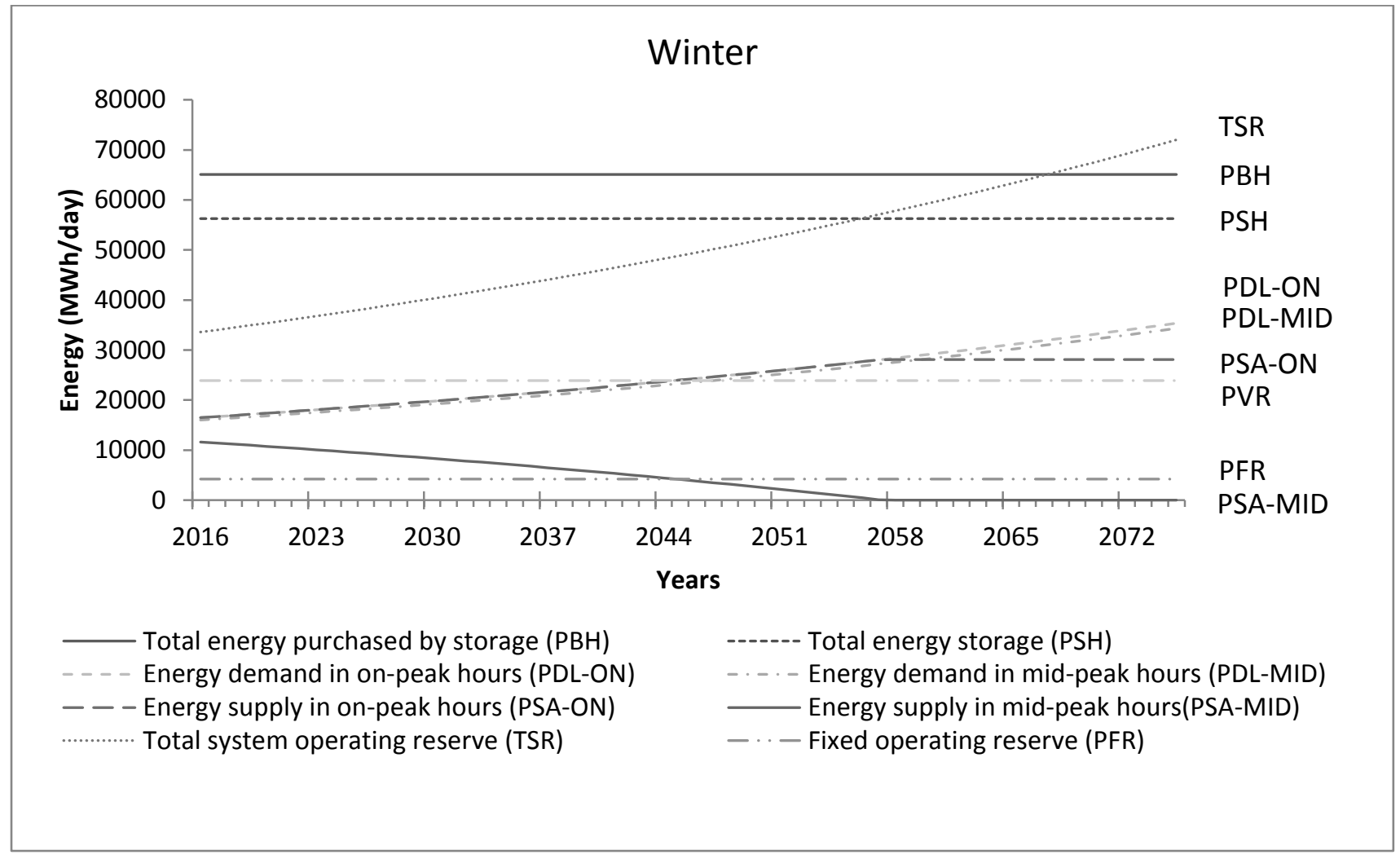

Figure 5.16 Energy supply by PHSA in one operating cycle of the winter season

For the summer season, Figure 5.17 shows that almost the same trend of energy utilization was observed as explained in the winter season, except that the energy utilized in summer is more than the winter season. In summer, PSA-ON increasing from 2016 to 2048 and beyond this year it remains constant. The PSA-MID is reducing from 2016 that becomes zero in 2048. The variable operating reserve (PVR) and fixed operating reserve (PFR) are also constant as explained in the winter season. 


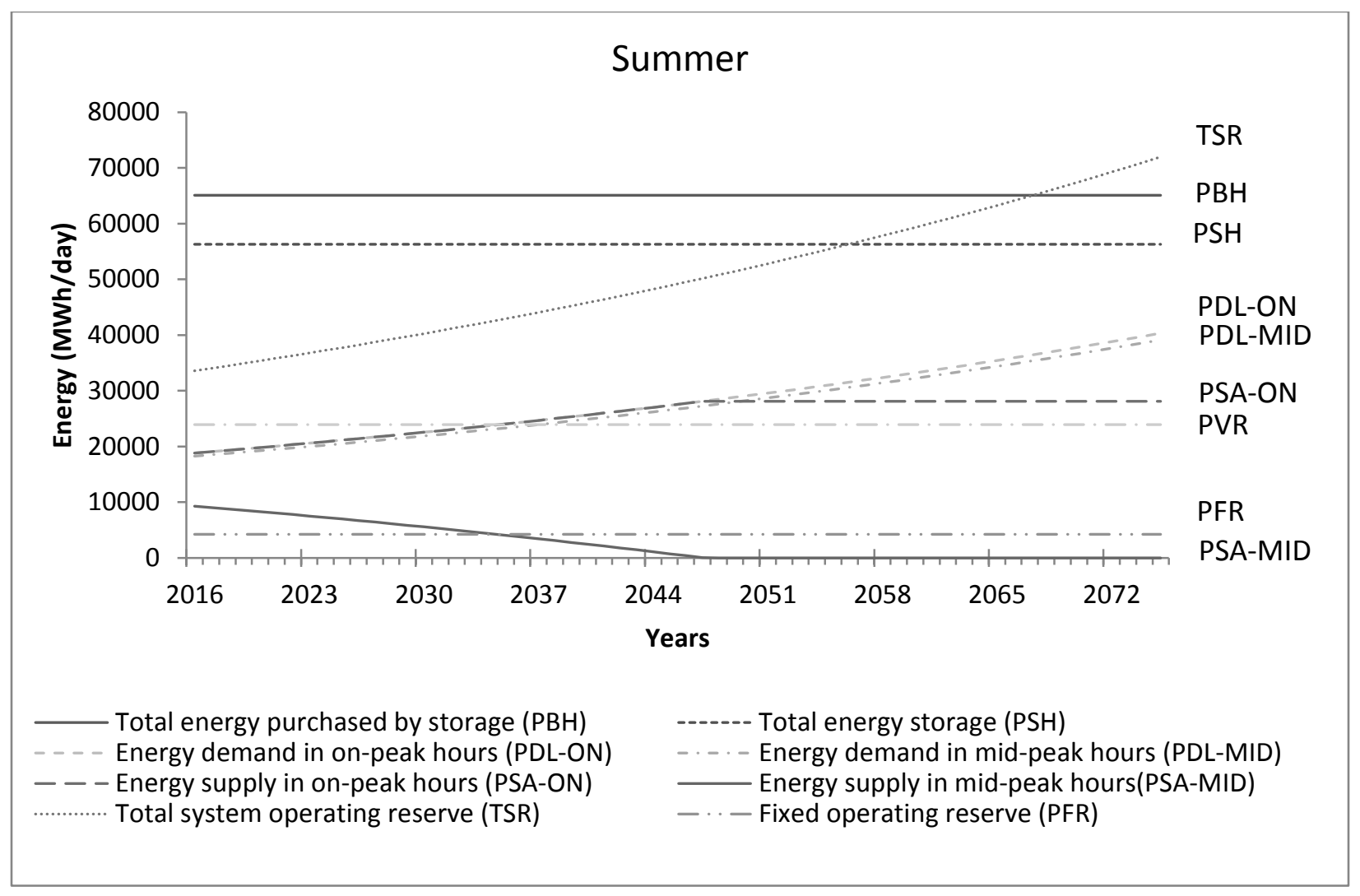

Figure 5.17 Energy supply by PHSA in one operating cycle of the summer season

For the year 2016, the optimization process ultimately provided the optimal results as given in Table 5.17 below.

Table 5.17 Detail of energy supply and purchase for the year 2016

\begin{tabular}{|lll|}
\hline Energy Supply and Purchase & Winter Season & Summer Season \\
\hline Energy Supply & $16,505 \mathrm{MWh}$ & $18,823 \mathrm{MWh}$ \\
Energy supply in on-peak hours (PSA-ON) & $11,629 \mathrm{MWh}$ & $9,311 \mathrm{MWh}$ \\
Energy supply in mid-peak hours (PSA-MID) & $23,914 \mathrm{MWh}$ & $23,914 \mathrm{MWh}$ \\
Energy supply for variable operating reserve (PVR) & $52,048 \mathrm{MWh}$ & $52,048 \mathrm{MWh}$ \\
Total energy supply at PHES plants & $48,665 \mathrm{MWh}$ & $48,665 \mathrm{MWh}$ \\
Total net energy supply at distribution points & & \\
(considering 6.5\% transmission line losses) & & \\
\hline & & $65,060 \mathrm{MWh}$ \\
Energy Purchase & $65,060 \mathrm{MWh}$ & \\
Energy purchased by energy storage (PBH) & & \\
\hline
\end{tabular}


The above results show that the PHES system can utilize 65,060 MWh surplus baseload generation (SBG) due to run-of-river hydroelectric generation, nuclear generation and unutilized variable wind energy. Accordingly, the return supply of this energy would increase wind energy penetration. Similarly, the total net energy supply at the distribution point, after considering the transmission line losses, is 48,665 MWh that will enable to reduce the equal amount of gas and nuclear generation. Hence, the PHES system shared this energy load that accounts for the reduction of environmental problems.

It is pertinent to mention here that the energy storage has to take part in both real-time energy supply as well as to provide the ancillary services including operating reserve as a policy matter so that PHES should become a regular participant in Ontario's supply-mix system particularly to reduce the environmental as well as high electricity cost problems of peaking plants and simultaneously, to provide an opportunity to the renewables to utilize their maximum installed capacity in the supply-mix.

Finally, it can be concluded that the satisfactory performance of energy storage would be helpful to initiate the partial development of the PHES plants and to develop the regulatory framework for the PHES system. This would also provide a chance to the PHES system to achieve equal status as that of other primary generators and hence to become a permanent participant of the supply-mix power. 


\subsection{Sensitivity Analysis for Optimization Model Parameters}

The sensitivity analysis was performed for the key parameters including storage total OR, storage variable OR, energy-use increase and unit capital cost. The process is same as explained in the sensitivity analysis of GIS model parameters. The respective results of the analysis have been provided in Table 5.18 and compared with the results of the respective default parameters.

Table 5.18 Estimating MAPC with change in model parameters

\begin{tabular}{|c|c|c|c|c|c|c|}
\hline \multirow[t]{2}{*}{ Model parameters } & \multicolumn{2}{|c|}{ Parameter Increase by } & \multirow{2}{*}{$\begin{array}{c}\text { Parameter } \\
\text { Default Value }\end{array}$} & \multicolumn{2}{|c|}{ Parameter Decrease by } & \multirow{2}{*}{$\begin{array}{c}\text { MAPC } \\
(\%)\end{array}$} \\
\hline & $-20 \%$ & $-10 \%$ & & $10 \%$ & $20 \%$ & \\
\hline Storage Total OR (\%) & 40 & 45 & 50 & 55 & 60 & \multirow[t]{3}{*}{13.20} \\
\hline Total NPV (C\$) & $13,199,213,657$ & $14,667,422,080$ & $16,104,051,041$ & $17,505,755,943$ & $18,866,463,491$ & \\
\hline Absolute percent change (\%) & 18.04 & 8.92 & 0.00 & 8.70 & 17.15 & \\
\hline Storage Variable OR (\%) & 68 & 77 & 85 & 94 & & \multirow[t]{3}{*}{13.21} \\
\hline Total NPV (C\$) & $12,913,957,517$ & $14,509,004,279$ & $16,104,051,041$ & $17,699,097,803$ & & \\
\hline Absolute percent change (\%) & 19.81 & 9.90 & 0.00 & 9.90 & & \\
\hline Energy-price Inflation Rate (\%) & 2.12 & 2.39 & 2.65 & 2.92 & 3.18 & \multirow[t]{3}{*}{16.69} \\
\hline Total NPV (C\$) & $12,859,266,633$ & $14,404,325,173$ & $16,104,051,041$ & $17,976,046,829$ & $20,040,041,706$ & \\
\hline Absolute percent change (\%) & 20.15 & 10.55 & 0.00 & 11.62 & 24.44 & \\
\hline Energy-use Increase Rate (\%) & 1.04 & 1.17 & 1.30 & 1.43 & 1.56 & \multirow[t]{3}{*}{0.31} \\
\hline Total NPV (C\$) & $16,024,806,230$ & $16,068,427,417$ & $16,104,051,041$ & $16,133,625,529$ & $16,158,663,928$ & \\
\hline Absolute percent change (\%) & 0.49 & 0.22 & 0.00 & 0.18 & 0.34 & \\
\hline Unit Capital Cost (\$/ MWh) & 108341 & 121883 & 135426 & 148969 & 162511 & \multirow[t]{3}{*}{8.24} \\
\hline Total NPV (C\$) & $17,873,231,365$ & $16,988,641,203$ & $16,104,051,041$ & $15,219,460,879$ & $14,334,870,717$ & \\
\hline Absolute percent change (\%) & 10.99 & 5.49 & 0.00 & 5.49 & 10.99 & \\
\hline
\end{tabular}

The respective changes in results of the parameters with respect to change in their default value have been plotted in Figure 5.18, Figure 5.19, Figure 5.20, Figure 5.21, and Figure 5.22 for the model parameters of storage total OR, storage variable OR, energy-price inflation rate, energyuse increase rate and unit capital cost respectively. The respective trends of their changes have been explained as follows: 
Figure 5.18 presents the trend of changing the values of storage total OR showing that this parameter has greater change by decreasing the values in comparison to the increase in values. For example, a $20 \%$ decrease in value resulted in $18.04 \%$ decrease in NPV, whereas $20 \%$ increase in value resulted in $17.15 \%$ increase in NPV. The estimated mean absolute percent change (MAPC) for storage total OR parameter is $13.20 \%$ as provided in Table 5.18.

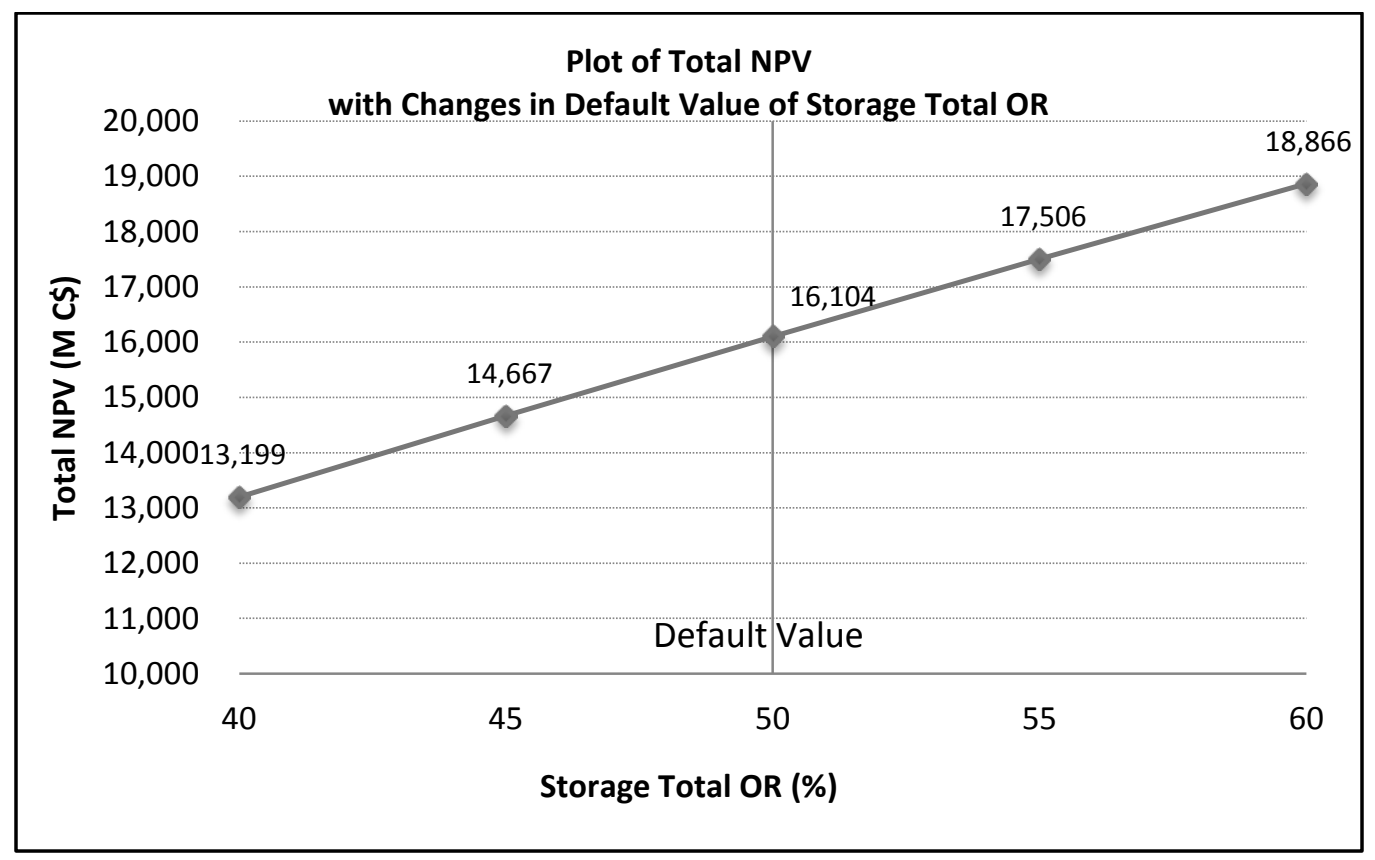

Figure 5.18 Total NPV with respective change in storage total OR 
Figure 5.19 presents that variable OR has more impact on decreasing the value than increasing its value. The positive increase in percentage is only $10 \%$ because a further increase will cross $100 \%$ utilization of the operating reserve which is against reality. It was observed that $10 \%$ decrease in value resulted in $9.9 \%$ decrease in NPV, whereas a $10 \%$ increase in value resulted in 9.9\% increase in NPV. The estimated mean absolute percent change (MAPC) for storage variable OR parameter is $13.21 \%$ as provided in Table 5.18 .

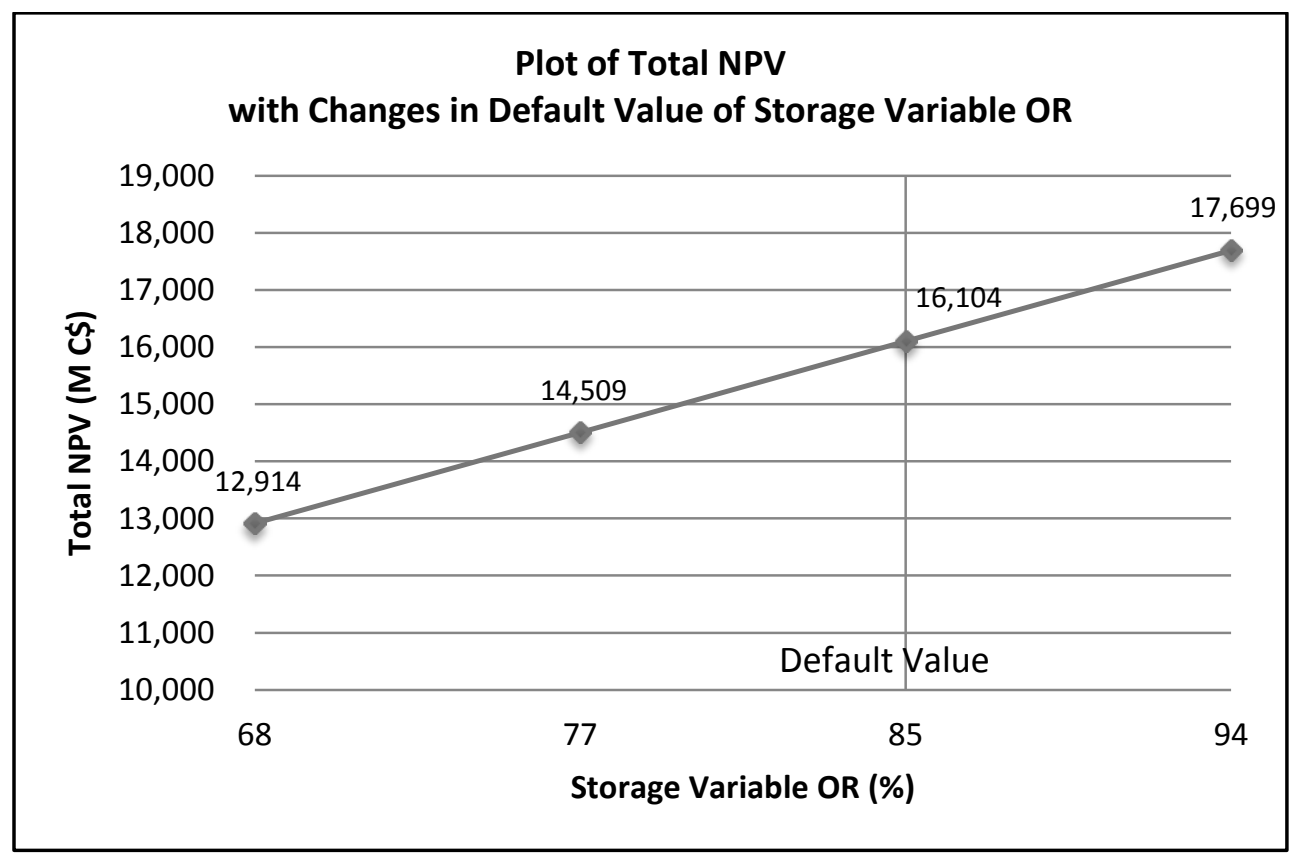

Figure 5.19 Total NPV with respective change in storage variable OR 
Figure 5.20 shows the change impact of increasing the value of energy-price inflation rate is higher than decreasing the original default values. For example, a $20 \%$ decrease in value resulted in a $20.15 \%$ decrease in NPV, whereas $20 \%$ increase in value resulted in a $24.44 \%$ increase in NPV. The estimated mean absolute percent change (MAPC) for energy-price inflation rate parameter is $16.69 \%$ as provided in Table 5.18 .

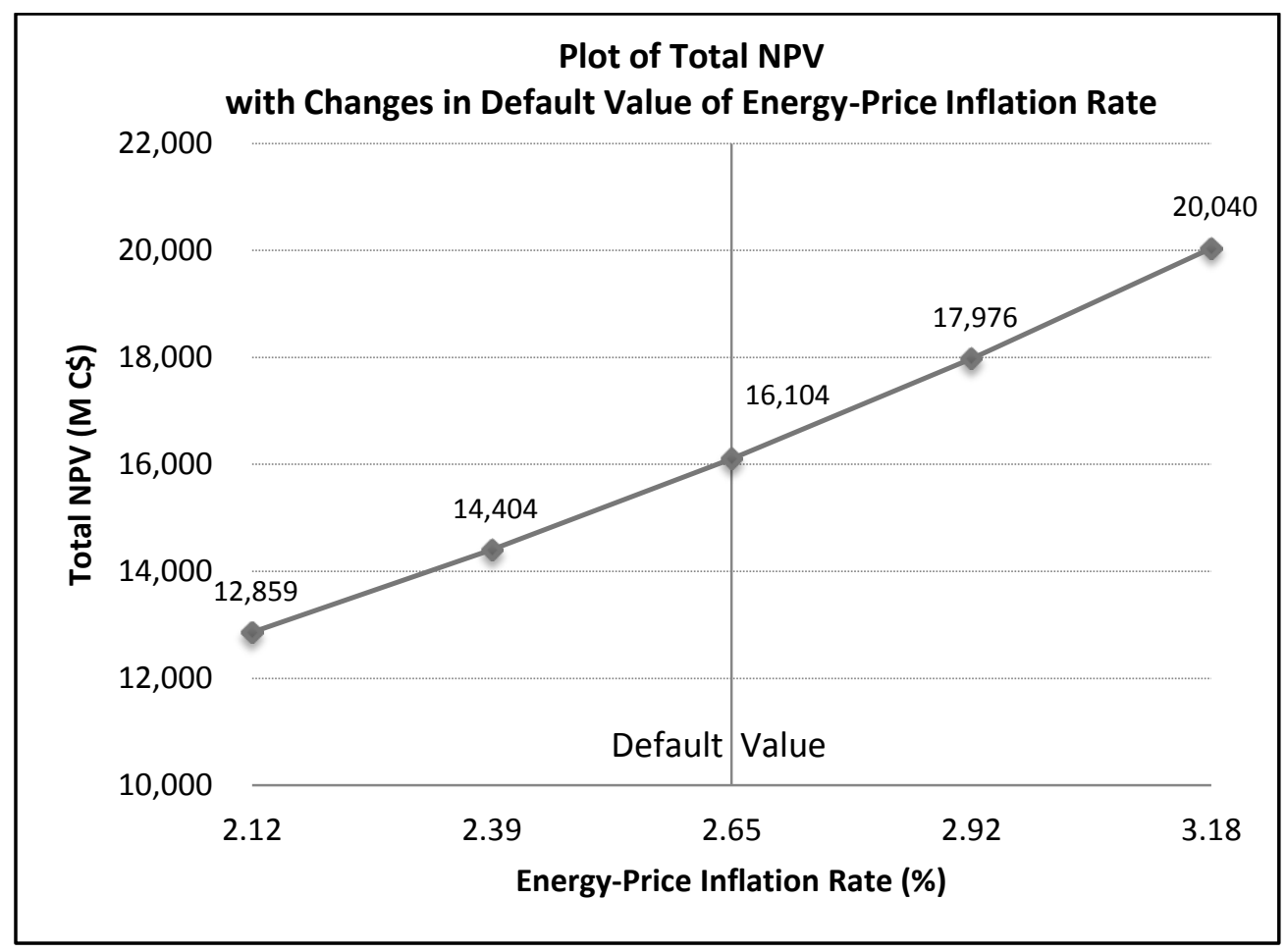

Figure 5.20 Total NPV with respective change in energy-price inflation rate 
Figure 5.21 shows the impact of changing the values of energy-use increase. It was observed that the trend is almost the same in both increasing and decreasing in its values which is very small. For example, a $20 \%$ decrease in value resulted in $0.49 \%$ decrease in NPV, whereas $20 \%$ increase in value resulted in a $0.34 \%$ increase in NPV. The estimated mean absolute percent change (MAPC) for energy-use increase parameter is $0.31 \%$ as provided in Table 5.18.

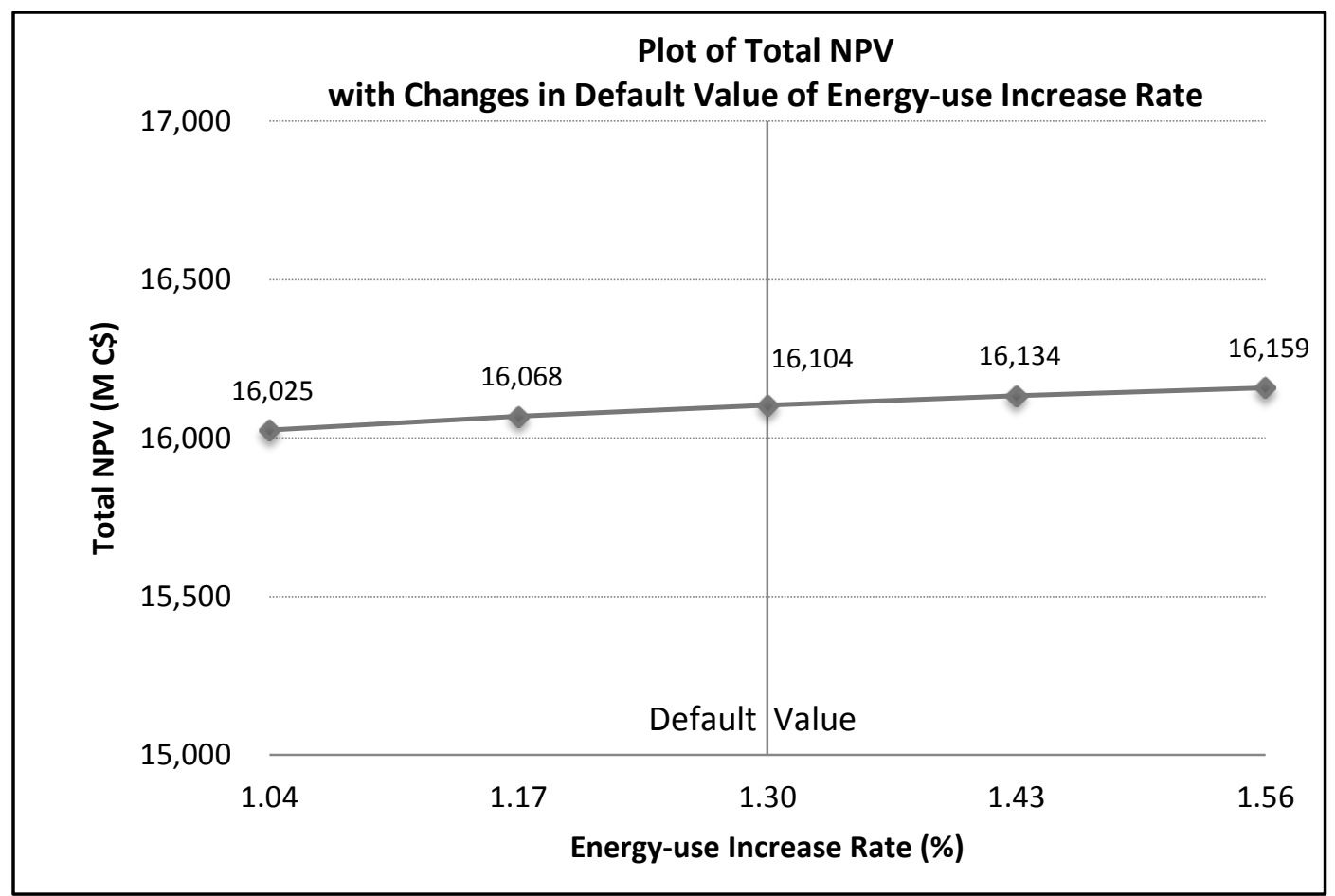

Figure 5.21 Total NPV with respective change in energy-use increase rate 
Figure 5.22 shows the impact on total NPV with increase/ decrease in the original values of unit capital cost. It was observed that the impact of decreasing/ increasing the values is the same. For example, a $20 \%$ decrease in value resulted in a $10.99 \%$ increase in NPV, and $20 \%$ increase in value also resulted in $10.99 \%$ decrease in NPV. The estimated mean absolute percent change (MAPC) for energy-use increase parameter is $8.24 \%$ as provided in Table 5.18.

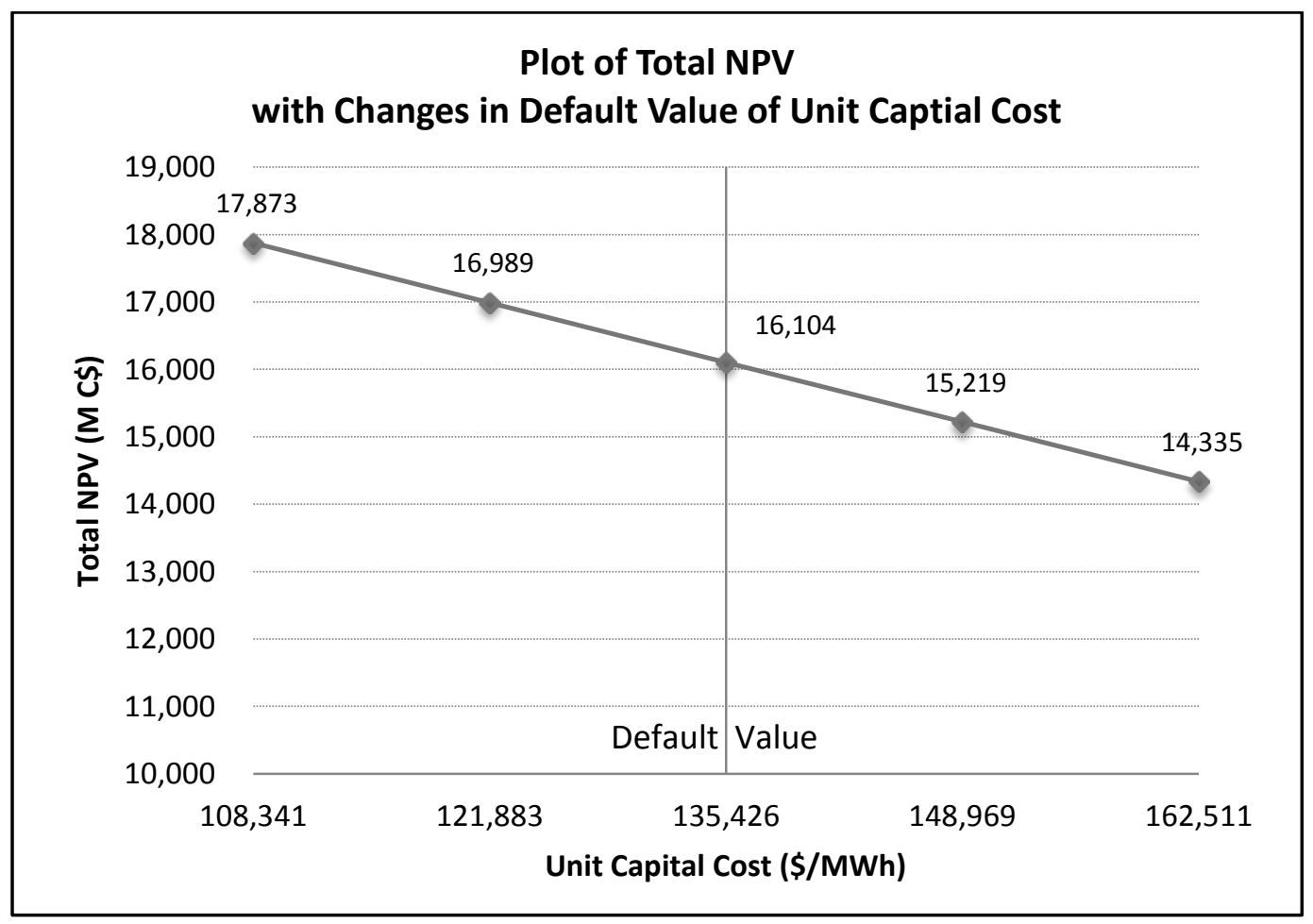

Figure 5.22 Total NPV with respective change in unit capital cost 
In order to find the comparative impact of all the key parameters, the model results have been plotted in Figure 5.23 which shows that energy-price inflation rate has the greatest impact on total NPV having its MAPC as $16.69 \%$ and energy-use increase has the least impact having MAPC as $0.31 \%$ as provided in Table 5.18 .

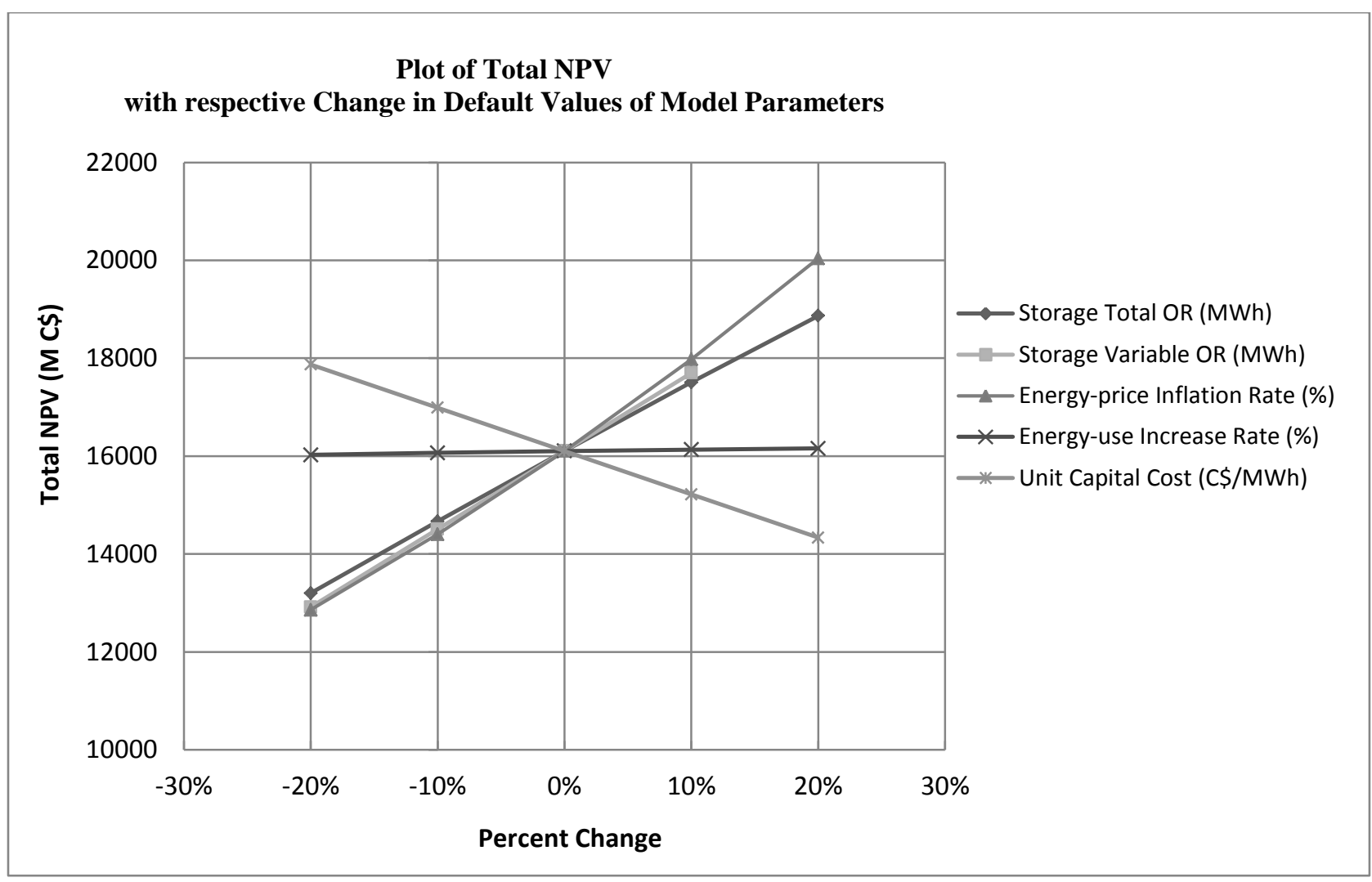

Figure 5.23 Total NPV with percent changes in default values of model parameters

\subsection{Financial Analysis of PHES System for Case Study of Ontario}

The optimization results were used to calculate the optimal returns of participatory PHES and GPM plants based on their optimal scheduling of energy supplies in different timings of one operating cycle of 24 hours for winter and summer seasons of each year for entire 60 years life period of the plants. Accordingly, the financial analysis of optimal returns was carried out for the computation of the financial indicators as provided in Section 3.6 of the methodology chapter. The PHES costs used in this analysis have been explained as given below. 


\section{Yearly Net Cash Flows}

The yearly net cash flows for a year is the sum of total revenues generated in the winter and summer seasons of that year which was calculated in the objective function of each year. The revenue of a season is the net cash flow generated through the sale and purchase of the energy in that particular season.

\section{Unit Capital Cost}

The unit capital cost of PHES plants was estimated as C\$ 135,426/ MWh using the average site-specific PHES capital costs estimated by applying the empirical formula. This cost was compared with the average unit capital cost that was estimated based on the past studies data. It was observed that the site-specific unit capital cost is comparatively higher than the cost estimated with past studies data. Therefore, keeping in view the extra precautionary measures to get better realistic results, the higher capital cost was used in the case study of this research.

\section{Fixed O\&M Cost}

The first year fixed O\&M cost was estimated as $0.33 \%$ of the capital cost of PHES plant using available cost data of the past studies (see Section 4.7.2). The O\&M cost of the following years was further increased by $1.55 \%$ of the previous year O\&M cost based on the average inflation rate of Ontario.

\section{Variable O\&M Cost and Administrative Fee of PHSA}

The amount of both yearly variable O\&M cost and the yearly administrative fee of PHSA is very small as explained in Section 2.8.3 of the literature review chapter. Therefore, in order to account the variable O\&M cost of PHES plants and a yearly administrative fee of PHSA, the average yearly fixed O\&M cost percentage was increased from $0.33 \%$ to $0.50 \%$ in this research study.

\section{Minimum Acceptable Rate of Return (MARR)}

This research study used a 3.33\% MARR value which was adopted on the basis of estimation of the average interest rate of Bank of Canada.

The detailed calculations for all the financial indicators have been provided the following Section. 


\subsubsection{Net Present Value (NPV)}

The year-wise sample calculations for NPV values are given below:

Year 0, NPV for $2015=\left(\right.$ Net Cash Flow of 2015) $/(1+\text { MARR })^{0}$

$=(-$ Capital investment cost - Initial storage filling cost $) /(1+\text { MARR })^{0}$

$=(-\mathrm{f} * \mathrm{PSH}-\mathrm{CA} * 0.5 \mathrm{PSH} * 1 / \mathrm{\eta}) /(1.0333)^{0}$

$=(-7,620,150,168-175,134) / 1$

$=-\mathrm{C} \$ 7,620,325,302$

Year 1, NPV for $2016=\left(\right.$ Net Cash Flow of 2016) $/(1+\text { MARR })^{1}$

$=($ Total objective function value of $2016-$ First year $(2016)$ O\&M Cost $) /(1+\text { MARR })^{1}$

$=(\mathrm{C} \$ 506,146,758-\mathrm{k} * \mathrm{f} * \mathrm{PSH}) /(1.0333)^{1}$

$=\mathrm{C} \$ 452,962,361$

Year 2, NPV for $2017=\left(\right.$ Net Cash Flow of 2017) $/(1+\text { MARR })^{2}$

$=($ Total objective function value of $2017-(1+\mathrm{m}) *$ year 2016 O\&M cost $) /(1+\mathrm{MARR})^{2}$

$=(\mathrm{C} \$ 520,058,648-(1+\mathrm{m}) *(\mathrm{k} * \mathrm{f} * \mathrm{PSH})) /(1.0333)^{2}$

$=\mathrm{C} \$ 450,841,367$

Year 3, NPV $2018=($ Total objective function value of $2018-(1+\mathrm{m}) *$ year 2017 O\&M cost $) /(1+\text { MARR })^{3}$

$=\left(\mathrm{C} \$ 534,359,084-(1+\mathrm{m})^{2} *(\mathrm{k} * \mathrm{f} * \mathrm{PSH})\right) / 1.0333^{3}$

$=\mathrm{C} \$ 448,730,529$

\footnotetext{
Year 59, NPV $2074=($ Total objective function value of $2074-(1+\mathrm{m}) *$ year 2073 O\&M cost $) /(1+\mathrm{MARR})^{59}$$$
=\mathrm{C} \$ 2,389,478,037-(1+\mathrm{m})^{58} *(\mathrm{k} * \mathrm{f} * \mathrm{PSH}) /(1.0333)^{59}
$$$$
=\mathrm{C} \$ 332,435,628
$$

Year 60, NPV $2075=($ Total objective function value of $2075-(1+\mathrm{m}) *$ year 2074 O\&M cost $)+$ Residual value of PHES plants $(=15 \%$ of capital cost $)) /(1+\text { MARR })^{60}$

$=\left(\mathrm{C} \$ 2,452,799,205-(1+\mathrm{m})^{59} *(\mathrm{k} * \mathrm{f} * \mathrm{PSH})+\mathrm{C} \$ 1,143,022,525\right) /(1.0333)^{60}$

$=\mathrm{C} \$ 490,519,837$

Total NPV = C $\$ 16,104,051,041$
}

Where, $\mathrm{f}=\mathrm{C} \$ 135,426 / \mathrm{MWh}, \mathrm{PSH}=56,268 \mathrm{MWh}, \mathrm{CA}=\mathrm{C} \$ 4.98, \mathrm{\eta}=80 \%, \mathrm{MARR}=3.33 \%, \mathrm{k}=0.50 \%, \mathrm{~m}=1.55 \%$. 


\subsubsection{Internal Rate of Return (IRR)}

The internal rate of return was calculated by changing MARR values to make the total NPV value equivalent to zero. The resultant IRR value was $8.77 \%$ for both PHES and GPM plants that made the total NPV value equal to zero.

\subsubsection{External Rate of Return (ERR)}

The external rate of return was calculated using the formula provided in Equation (3.23) of the methodology chapter. Accordingly, the calculation of ERR of PHES plants is given below:

$$
E R R=\left(\frac{F_{I}}{P_{C}}\right)^{\frac{1}{n}}-1
$$

Where, $\quad F_{I}=$ Future values of all positive cash flows determined by MARR interest rate.

$$
P_{C}=\text { Present values of all negative cash flows which are brought back to time } 0
$$
using MARR interest rate.

$n=$ Life period in years

$$
\begin{aligned}
E R R & =\left(\frac{169,348,193,430}{7,620,325,302}\right)^{\frac{1}{60}}-1 \\
& =5.30 \%
\end{aligned}
$$

\subsubsection{Payback Period}

The payback period was calculated using the formula provided in Section 3.6 of the methodology chapter. The calculations for undiscounted and discounted payback periods are given below:

$$
\begin{aligned}
\text { Undiscounted Payback Period } & =13+\frac{-379,896,617-0}{-379,896,617-(294,294,484)}(14-13) \\
& =13.56 \text { years } \\
\text { Discounted Payback Period } & =17+\frac{-201,365,290-0}{-201,365,290-(216,962,650)}(18-17) \\
& =17.48 \text { years }
\end{aligned}
$$

\subsubsection{Cost-Benefit Ratio}

The cost-benefit ratio was calculated using the formula provided in Section 3.6 of the methodology chapter. The calculation of cost-benefit ratio is given below:

Cost-benefit ratio $=$ Total cost amount $/$ Total benefit amount

$=\mathrm{C} \$ 7,620,150,168 / \mathrm{C} \$ 23,724,201,209$

$$
=0.32
$$




\subsection{Discussion on Financial Analysis Results}

The final outcome of financial analysis was based on the optimization results of PHES and GPM plants. The financial viability of any project is determined by analyzing the following conditions:

For a viable project,

(i) NPV should be positive in each year for the life period of the project; and

(ii) The values of MARR, IRR and ERR should satisfy the following condition:

$$
\text { MARR } \leq \mathrm{ERR} \leq \mathrm{IRR}
$$

In order to check the above conditions, a summary of financial indicators is given in Table 5.19:

Table 5.19 Financial indicators in the case study of Ontario

\begin{tabular}{|l|c|}
\hline Financial Indicator & Computed Values of Indicator \\
\hline NPV & $16,104,051,041$ \\
\hline IRR & $8.77 \%$ \\
\hline ERR & $5.30 \%$ \\
\hline Undiscounted Payback Period & 13.56 years \\
\hline Discounted Payback Period & 17.48 years \\
\hline Cost-Benefit Ratio & 0.32 \\
\hline
\end{tabular}

The discount rate versus total NPVs has been plotted in Figure 5.24 as presented below.

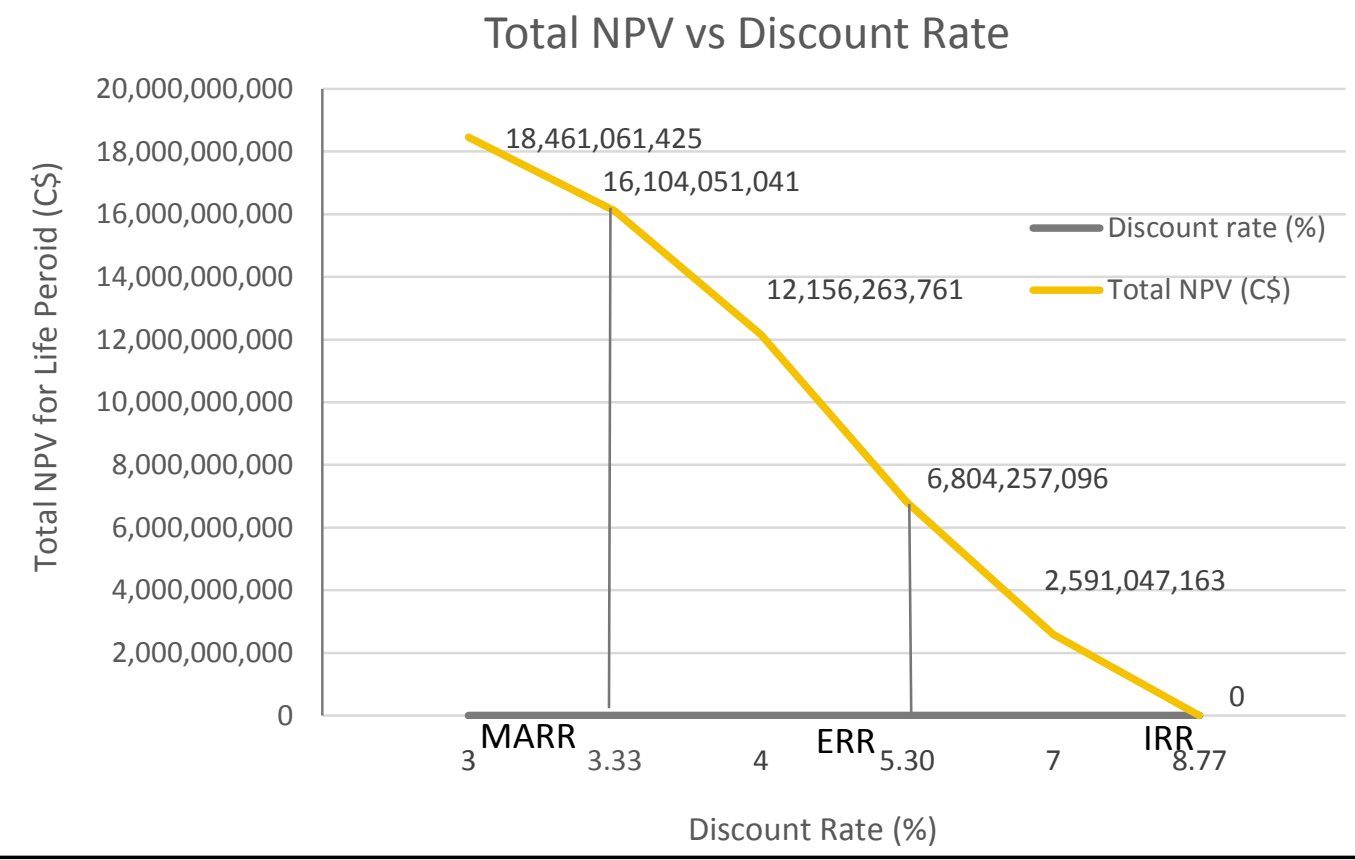

Figure 5.24 Total NPV versus discount rates of PHSA for the case study of Ontario 
Table 5.19 and Figure 5.24 provide the following information:

- Total NPVs for each year of the entire life period are positive

- The computed values of ERR and IRR satisfied the following condition:

$$
\begin{aligned}
& \text { MARR } \leq \mathrm{ERR} \leq \mathrm{IRR} \\
& 3.33 \% \leq 5.30 \% \leq 8.77 \%
\end{aligned}
$$

Additionally, it was observed that undiscounted and discounted payback periods have reached within their first half-life periods of the plants. Similarly, the cost-benefit ratio for the PHES system is also satisfactory having value less than 0.5 .

Therefore, financial analysis results have confirmed that the integration of PHES system in the existing electricity market of Ontario at grid level is viable for both PHES and GPM plants.

\subsection{Initiating Partial Development of PHES and GPM Plants in Ontario}

Ontario's LTEP 2017 intends to increase the component share of renewable energy resources in the supply-mix energy system that would ultimately reduce the respective utilization of fossil fuels. This policy provides an opportunity to gradually develop the energy storage plants for their integration with the existing supply-mix electricity market system of Ontario. In this regard, it is pertinent to note that Ontario's Ministry of Energy has already directed the IESO to focus and monitor the cost-effective participation of the energy storage technologies.

In order to follow the above policy, this research proposed to initially start with the partial development of the top-most feasible energy potential of both PHES and GPM technologies, as identified in this study. Accordingly, it was proposed to initially start with the utilization of $25 \%$ unutilized installed capacity of wind generation as provided below:

Existing Installed wind power capacity for transmission system 4,468 MW

Monthly average wind capacity contribution (WCC) to IESO (26.2\%)

1,171 MW

Balance unutilized installed wind power capacity (73.8\%) 3,297 MW

Proposed utilization of available unutilized wind power capacity $(25 \%)$ $824 \mathrm{MW}$

Available equivalent wind energy capacity (for 12 hours per day) 9,888 MWh/ day

Required energy capacity of PHES system (round-trip efficiency 80\%) 7,910 MWh/ day 
In order to supply the above-required energy capacity of 7,910 MWh, it was proposed to initially develop 25\% of the total identified feasible PHES potential using top-most PHES plants and the remaining balance required energy potential may be covered by developing the top-most GPM plants.

Accordingly, the combination of PHES and GPM plants is given below:

(a) Proposed 25\% of total identified feasible PHES potential 6,017 MWh/ day (Top-most 10 PHES plants)

(b) Balance required energy potential covered by GPM plants $1,750 \mathrm{MWh} /$ day (Top-most 10 GPM plants)

Total energy potential to be supplied by PHES and GPM plants:

7,767 MWh/ day

Net energy supply of PHSA at distribution point $7,262 \mathrm{MWh} /$ day

(considering the transmission line losses 6.5\%)

Based on the above proposal, Figure 5.25 shows a location map of the participatory 10 PHES plants and 10 GPM plants for their initial development in Ontario. 


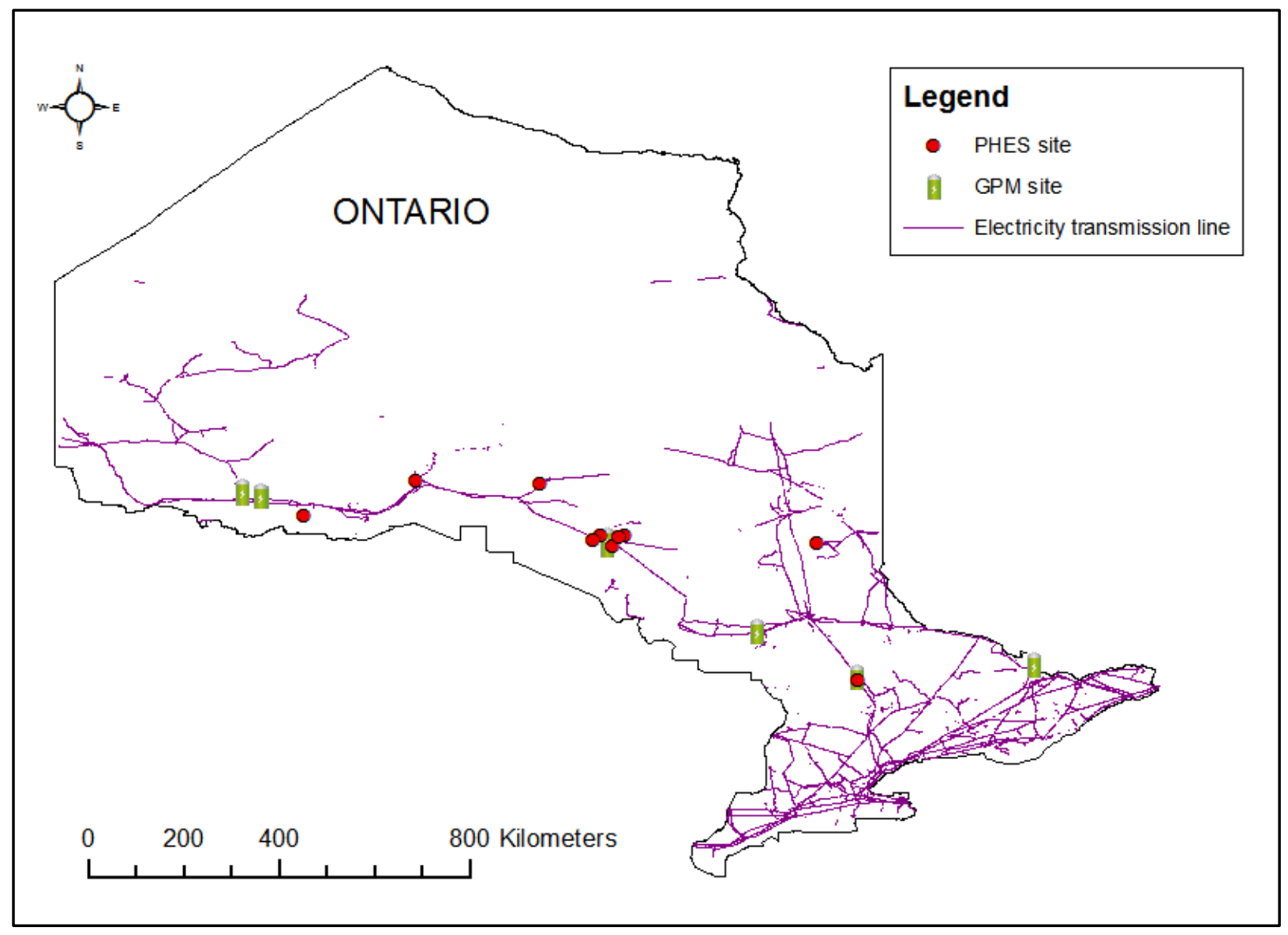

Figure 5.25 Location map of partial development for PHES and GPM plants in Ontario

The total required 7,767 MWh energy potential was optimized using the optimization model as explained in Section 5.9. The optimal results were used to get the financial output for the entire life-period of all partially developed PHES and GPM plants. The optimization results show that the total initial investment cost of all partially developed PHES and GPM plants is C\$ 1,051,853,742 and total NVP earned for their life-period is C\$2,273,084,913. 


\subsection{Distribution of Net Profit in Partially Developed PHES and GPM Plants}

The net profit of PHSA for the life period of partially developed PHES and GPM plants was calculated based on the optimal utilization of their services provided to the electricity market of Ontario as given below:

- Total NPV earned by participatory PHES and GPM plants during their life-period

$$
=\mathrm{C} \$ 2,273,084,913
$$

- Total energy provided by PHES and GPM plants for different services

$$
=7,767 \mathrm{MWh} / \text { day x } 365 \text { days x } 60 \text { years }=170,097,300 \mathrm{MWh}
$$

- Profit earned as NPV by a unit energy potential capacity $=\mathrm{C} \$ 13.36 / \mathrm{MWh}$

The net profit share of each participatory PHES and GPM plant can be calculated by multiplying the above unit profit share C $\$ 13.36 /$ MWh with their respective installed energy potential as given in Table 5.20 below.

\begin{tabular}{|c|c|c|c|c|}
\hline No. & $\begin{array}{l}\text { Plant ID } \\
\text { (No.) }\end{array}$ & Primary Reservoir & $\begin{array}{l}\text { Energy } \\
\text { Potential } \\
\text { (MWh) }\end{array}$ & $\begin{array}{c}\text { Net Profit Share/ Day } \\
\text { @ C\$ 13.36/ MWh } \\
(\text { C\$) }\end{array}$ \\
\hline \multicolumn{5}{|c|}{ Participatory PHES Plants: } \\
\hline 1 & 4350 & Manitowik Lake & 830 & 11,089 \\
\hline 2 & 6494 & Mill Lake & 720 & 9,619 \\
\hline 3 & 14835 & Lake ID 200295614 & 711 & 9,499 \\
\hline 4 & 4381 & Whitefish Lake & 686 & 9,165 \\
\hline 5 & 4400 & Black Trout Lake & 584 & 7,802 \\
\hline 6 & 375 & MCPHAIL Dam & 546 & 7,295 \\
\hline 7 & 4502 & Doré Lake & 494 & 6,600 \\
\hline 8 & 13599 & Kekekuab Lake & 490 & 6,546 \\
\hline 9 & 267 & ALEXANDER MAIN DAM & 485 & 6,480 \\
\hline 10 & 1164 & Barehead Lake & 471 & 6,293 \\
\hline \multicolumn{5}{|c|}{$\begin{array}{l}\text { Participatory GPM Plants: } \\
\text { The energy potential of each GPM plant is } 175 \mathrm{MWh} \text {. Therefore each plant would receive the net } \\
\text { profit share as } 175 \mathrm{MWh} * \mathrm{C} \$ 13.36 / \mathrm{MWh} \text { per day }=\mathrm{C} \$ 2,338 \text { per day }\end{array}$} \\
\hline
\end{tabular}

Table 5.20 Profit share of participatory PHES and GPM plants 


\section{Conclusion}

\subsection{Conclusion}

This research study applied a systematic approach for developing an integrated planning framework of PHES system in the grid-connected electricity market of international standard that was tested on a case study of the Province of Ontario, Canada. The critical analysis of this study stems that PHES is a viable means of storing unutilized energy generation from surplus baseload generation of primary generators including the renewables. This research divulges that PHES can cost-effectively employ the maximum penetration of renewables in the supply-mix system and PHES would help by keeping the electricity region environmentally friendly. The study clearly reflects that PHES can be a wonderful resource for the significant reduction in the magnitude of peaking energy generating plants which would shed off the burden of the utility operators.

The wide-ranging methodology used in this research is based on the identification of feasible PHES and GPM sites, optimization of PHES scheduling and financial analysis of PHES system. A GIS-based generic model together with its fully automated processing was developed that identifies the feasible PHES and GPM sites. It became pragmatically possible through the optimization of PHES scheduling to optimally utilize the services of energy storage to meet the real-time energy demand during mid-peak and on-peak hours, as well as to provide the ancillary services including operating reserve. The financial analysis encourages the decision makers and other stakeholders to integrate the PHES system in the current worldwide adopted supply-mix energy market system.

The developed GIS-based model was applied on a large electricity market area operated by the IESO utilizing all types of existing waterbodies as primary reservoirs and favourable topology of Ontario to explore the possible PHES and GPM potential. The model identified 285 feasible PHES and GPM sites with a total 56,268 MWh energy potential at the plant's site that would be able to supply 52,611 MWh of electricity at distribution points after considering the average 6.5\% transmission line losses. After identifying the feasible PHES and GPM sites, the sensitivity analysis of GIS model parameters resulted that 'buffer distance' has the greatest impact on model results, whereas the 'surface slope' has the lowest impact. The optimization of identified PHES and GPM energy potential resulted: 28,134 MWh/ day real-time energy supply, 23,914 MWh/ day variable OR supply, 4,220 MWh/ day fixed OR, and 65,060 MWh/ day as total energy 
purchase for pumping operation. The sensitivity analysis of optimization model parameters resulted that 'energy-price increase rate' has the greatest impact on model results, whereas the 'energy-use increase rate' has the lowest impact. The financial analysis of PHES system provided resultant financial indicators including C\$ 16,104 Million total NPV, 8.77\% IRR, $5.30 \%$ ERR, 13.56 years undiscounted payback period, 17.48 years discounted payback period, and 0.32 as the cost-benefit ratio. Accordingly, the results of the optimization process and financial analysis have confirmed that the proposed PHES system is technically and financially viable to integrate with a large electricity market system.

This research proposed that the government of Ontario may like to take an initial step for partial development of the identified PHES and GPM energy potential. In this regard, this research selected the top-most feasible 10 PHES and 10 GPM plants with a total 7,767 MWh/ day energy potential that would be able to supply 7,262 MWh energy demand at the electricity distribution

point after considering $6.5 \%$ transmission line losses. It is important to note here that this will ultimately reduce the GHG emission in the same proportion and hence, will dilute the pressure of related environmental problems. The optimization process performed for partially selected energy potential resulted in a net unit profit share as C\$ 13.36/ MWh for each participatory PHES and GPM plant.

Last but not the least, the overall planning approach of this research study is helpful in developing and integrating the PHES systems in the electricity market of international standard, as well as to motivate the decision makers to prepare the necessary regulatory framework for integration of the PHES system at grid level.

\subsection{Research Contribution}

The main contributions of this research are as follows:

- The generic GIS-based model can be applied for the electricity market system operated at grid level such as the electricity system operated by IESO in the Province of Ontario, Canada subject to availability of the requisite data. 
- This research performed the following major tasks:

- Addressed the gaps identified in past studies through literature review;

○ Identified the PHES sites using GIS-based model considering all types of existing waterbodies as primary reservoirs, and used existing abandoned mines to find the potential PHES sites;

- Applied necessary environmental and infrastructure constraints on both primary reservoirs and preliminary identified PHES sites to find potential PHES sites;

○ Applied optimization model for optimal scheduling of the identified PHES energy potential; and

- Performed financial analysis using optimal cash flows of the PHES system.

- This research addressed techno-economic issues of PHES system and presented a solution to utilize surplus baseload generation (SBG) that ultimately supported renewable energy resources particularly wind and solar for maximum utilization of their installed energy potential. More importantly, this research resulted that a gridconnected electricity system can confidently provide clean, reliable and affordable electricity with the integration of PHES system.

- The proposed cooperative model of PHES plants can provide an incentive to the decision makers and the investors for the rapid growth of PHES development. It may also enhance the confidence of plant owners to participate in the market, having adequate storage capacity. Moreover, this may lead to a great achievement of the PHES system to become a trusted member in the current electric power industry.

- The PHES system can reduce the load of peaking plants and hence it can significantly reduce the environmental problems.

- The satisfactory results of the financial analysis are helpful for both utility operators and the plant owners to take decisions for building more PHES schemes throughout the world, particularly in Ontario, Canada.

- This research is also helpful for the decision makers to confidently plan their targets of developing sustainable electricity system with increased utilization of wind and solar energy by developing a reliable energy storage system. 


\subsection{Future Work}

The future work may include but not limited to the following tasks:

- To study the PHES planning aspects not covered in this research such as developing the regulatory framework for PHES system; proposing necessary actions at government level to initiate the execution of PHES system in an existing utility market, and commissioning of the PHES system within an existing periphery.

- The GPM technique seems to be a useful development as it is less site-specific than conventional technology. Future research work can investigate the options for further development of GPM technology.

- Another aspect to study the social issues that are necessary for the acceptance of PHES projects.

- In addition to providing PHES services in the energy sector, valuable socio-economic developments may be studied that can be associated with PHES schemes to generate additional revenues for the PHES as well as for the concerned local, provincial and federal governments in terms of various taxes. 
Appendices 


\section{Appendix A - Selection of Turbines for PHES Plants}

Table A-1 Types of turbines used at PHES plants in various countries

\begin{tabular}{|c|c|c|c|c|}
\hline PHES Projects & Country & $\begin{array}{r}\text { Rated Power } \\
\text { (MW) }\end{array}$ & $\begin{array}{r}\text { Turbine Units and Types } \\
(\text { No. } \times \text { MW) }\end{array}$ & Source \\
\hline \multicolumn{5}{|l|}{ (a) Operational Projects } \\
\hline Ludington Pumped Storage Power Plant, Michigan & USA & 1,872 & $6 \times 312$ reversible pump turbine & 1 \\
\hline Rocky Mountain Hydroelectric Plant, Georgia & USA & 1,095 & $3 \times 365$ reversible pump turbine & 2 \\
\hline Helms Pumped Storage Plant, California & USA & 1,212 & $3 \times 400$ reversible pump turbine & 3 \\
\hline Castaic Power Plant, California & USA & 1,247 & $6 \times 270$ reversible pump turbine & 4 \\
\hline Blenheim-Gilboa Hydroelectric Power Station, New York & USA & 1,134 & 4 x 286 Pump Turbine & 5 \\
\hline Bath County Pumped Storage Station, Virginia & USA & 3,003 & $6 \times 500$ Francis & 6 \\
\hline Raccoon Mountain Pumped-Storage Plant, Tennessee & USA & 1,652 & Data not available & 7 \\
\hline Seawater PHES, Okinawa & Japan & 30 & Data not available & 8 \\
\hline Shimogo Pumped Storage Power Station, Fukushima & Japan & 1,000 & $\begin{array}{r}4 \times 250 \\
\text { Vertical axis pump turbine -Francis }\end{array}$ & 9 \\
\hline Shintoyone Pumped Storage Power Station, Aichi & Japan & 1,125 & $\begin{array}{r}5 \times 230 \\
\text { Single shaft flush pump turbine }\end{array}$ & 10 \\
\hline $\begin{array}{ll}\text { Okuyahagi Pumped Storage Power Station, Aichi and Gifu } \\
\text { - } & \text { Okuyahagi } 1 \\
\text { - } & \text { Okuyahagi } 2 \\
\text { - } & \text { Yahagi } 1 \\
\text { - } & \text { Yahagi } 2 \\
\end{array}$ & Japan & 1,160 & $\begin{array}{r}\text { All Francis } \\
3 \text { reversible pump turbine x } 116 \\
3 \text { reversible pump turbine x } 260 \\
2 \times 31 \\
1 \times 32\end{array}$ & 11 \\
\hline Tamahara Pumped Storage Power Station, Gunma & Japan & 1,200 & $\begin{array}{r}4 \times 300 \\
\text { reversible pump turbine Francis }\end{array}$ & 12 \\
\hline $\begin{array}{cl}\text { Omarugawa Pumped Storage Power Station, Miyazaki } \\
\bullet & \text { Oseuchi } \\
\bullet & \text { Kanasumi }\end{array}$ & Japan & 1,200 & $\begin{array}{r}4 \times 300 \text { reversible pump turbine } \\
\text { Francis }\end{array}$ & 13 \\
\hline Kazunogawa Pumped Storage Power Station, Yamanashi & Japan & 1,200 & $\begin{array}{r}4 \times 412 \text { Vertical axis pump turbine - } \\
\text { Francis }\end{array}$ & 14 \\
\hline Imaichi Pumped Storage Plant, Tochigi & Japan & 1,050 & $3 \times 350$ Francis & 15 \\
\hline Siah Bishe Pumped Storage Power Plant, Mazandaran & Iran & $\begin{array}{r}260 \text { (Current) } \\
1040 \text { (Planned) }\end{array}$ & $\begin{array}{r}4 \times 260 \text { Vertical axis pump turbine - } \\
\text { Francis }\end{array}$ & 16 \\
\hline Roncovalgrande Hydroelectric Plant, Maccagno & Italy & 1,016 & $\begin{array}{r}4 \times 126.8 \\
4 \text { x 127.32 All 4-stage Pelton-type }\end{array}$ & 17 \\
\hline Presenzano Hydroelectric Plant, Precenzano & Italy & 1,000 & $4 \times 250$ Francis & 18 \\
\hline $\begin{array}{cl}\text { Entracque Power Plant, Entracque } \\
\text { - } \quad \text { Chiotas } \\
\text { - } \quad \text { Rovina }\end{array}$ & Italy & 1,318 & $\begin{array}{r}\text { Francis-pump turbines: } \\
8 \times 148 \\
1 \times 133.67\end{array}$ & 19 \\
\hline $\begin{array}{ll}\text { Edolo Pumped Storage Plant, Edolo } \\
\text { - } & \text { Avio } \\
\text { - } & \text { Benedetto }\end{array}$ & Italy & 1,000 & $8 \times 125$ Francis & 20 \\
\hline Ming-hu Pumped Storage Hydro Power Station, Shuili & Taiwan & 1,008 & $4 \times 250$ Francis & 21 \\
\hline Mingtan Pumped Storage Hydro Power Plant, Shuili & Taiwan & 1,600 & $6 \times 267$ Francis & 22 \\
\hline Tai'an Pumped Storage Power Station, Shandong & China & 1,000 & $4 \times 250$ Francis & 23 \\
\hline Hongping Pumped Storage Power Station, Jiangxi & China & 1,200 & $4 \times 300$ Francis & 24 \\
\hline Qingyuan Pumped Storage Power Station, Guangdong & China & 1,280 & 4 x 320 Francis & 25 \\
\hline Sir Adam Beck Pump Generating Station, Ontario & Canada & 174 & $6 \times 29$ Francis & 26 \\
\hline \multicolumn{5}{|l|}{ (b) Under Construction Projects } \\
\hline Marmora Pumped Hydro Energy Storage & Canada & 400 & & 27 \\
\hline \multicolumn{5}{|l|}{ (c) $\quad$ Proposed Projects } \\
\hline Annie's Mountain PHES Facility, New Burnswick & Canada & 20 & $1 \times 20$ reversible pump turbine & 28 \\
\hline
\end{tabular}

Source 1: (Consumers Energy 2017)

Source 2: (Canary Systems 2017; International Water Power \& Dam Construction 2011)

Source 3: (PG\&E 2017) 
Source 4: (Columbia Grid 2013; International Water Power \& Dam Construction 2011)

Source 5: (Wong et al. 2009)

Source 6: (Dominion 2017; International Water Power \& Dam Construction 2011)

Source 7: (Tennessee Valley Authority (TVA) 2017)

Source 8: (Pérez-Díaz et al. 2014)

Source 9: (Suiryoku.com 2011)

Source 10: (Suiryoku.com 2012)

Source 11: (Chubu Electric Power Company 2017; Suiryoku.com 2014)

Source 12: (Suiryoku.com 2013)

Source 13: (Kyushu Electric Power Co. Ltd. 2017)

Source 14: (Tokyo Electric Power Company (TEPCO) 2014)

Source 15: (Suiryoku.com 2015)

Source 16: (Colenco Power Engineering AG 2017)

Source 17: (Istituto Comprensivo di Scuola Materna 2017)

Source 18: (Enel Spa 2014)

Source 19: (Franke 2016)

Source 20: (National Agency for Electricity ENEL 1980)

Source 21: (Chen 2009)

Source 22: (Charlwood et al. 2000; Hoek 2007)

Source 23: (Industcards 2011; JRJ.com 2008; Zhang et al. 2015)

Source 24: (Huadong Engineering Corporation Ltd. 2007)

Source 25: (Chongqing Gongmin Power Supply Equipment Co. Ltd. 2012; Xuenuo and Jing 2012)

Source 26: (Email communication with Steve Repergel, Corporate Relations Officer, Ontario Power Generation, May 31, 2016)

Source 27: (Northland Power 2016)

Source 28: (Namgyel 2004) 


\section{Appendix B - Rationales of Assumed Model Parameters}

The rationales have been defined to appropriately assume the model parameters for case study of Ontario, which are based on various factors including Ontario's policy on energy and energy storage, existing regulations of IESO electricity market, existing topology of Ontario, and the data available in relevant past studies. The explanation for individual parameters is given below:

\section{Maximum Efficiency of PHES System ( $\eta$ )}

In general, energy storage technologies include two main sections: (i) power conversion system (PCS) and (ii) energy storage section. The PCS is used to adjust the voltage, current, and other power characteristics of the storage based on load requirement. The energy storage section is the water reservoir.

According to the study by Zakeri and Syri (2015), the overall efficiency of the energy storage system $\left(\eta_{s y s}\right)$ for AC-to-AC conversion is defined as the AC electric energy output divided by the $\mathrm{AC}$ electric energy input as given in Equation (B.1)

$$
\begin{aligned}
& \eta_{\text {sys }}=\frac{E_{\text {out }}(k W h)}{E_{\text {in }}(k W h)} \\
& \text { Where, } \quad \mathrm{E}_{\text {out }} \quad=\text { Electric energy output } \\
& \mathrm{E}_{\mathrm{in}} \quad=\text { Electric energy input }
\end{aligned}
$$

The literature review reveals that the energy efficiency of PHES projects varies from $70 \%$ to $85 \%$ (IEC 2011) with some claiming up to $87 \%$ (Rehman et al. 2015). Therefore, in this research, the average pump-turbine unit efficiency of a PHES plant was assumed as $80 \%$ being living within the highest available figure.

\section{Minimum Volume of PHES Reservoir $\left(\mathrm{V}_{\mathrm{S}}\right)$}

Considering the Ontario's policy on pumped hydro energy storage and the available data provided in Table B-1 from past studies, the surface area for PHES reservoir was considered as $50,000 \mathrm{~m}^{2}$ with $10 \mathrm{~m}$ draw-down depth. This gives 500,000 $\mathrm{m}^{3}$ volume of PHES reservoir. 
Table B-1 PHES data used in previous studies

\begin{tabular}{|l|l|l|l|l|}
\hline Model Parameters & Study 1 & Study 2 & Study 3 & Study 4 \\
\hline Minimum volume of the primary reservoir & $1 \mathrm{M} \mathrm{m}^{3}$ & $3.6 \mathrm{M} \mathrm{m}^{3}$ & $0.1 \mathrm{M} \mathrm{m}^{3}$ & $0.1 \mathrm{M} \mathrm{m}^{3}$ \\
\hline $\begin{array}{l}\text { Maximum distance between the primary } \\
\text { reservoir and PHES site (buffer zone) }\end{array}$ & $5 \mathrm{~km}$ & $1 \mathrm{~km}$ & - & $20 \mathrm{~km}$ \\
\hline $\begin{array}{l}\text { Minimum differential head between primary } \\
\text { and PHES reservoirs }\end{array}$ & $150 \mathrm{~m}$ & $200 \mathrm{~m}$ & $150 \mathrm{~m}$ & $200 \mathrm{~m}$ \\
\hline Minimum surface area of PHES site & $70,000 \mathrm{~m}^{2}$ & $120,000 \mathrm{~m}^{2}$ & - & $700 \mathrm{~m}^{2}$ \\
\hline Average depth of PHES site fistes to & $500 \mathrm{~m}$ & - & $20 \mathrm{~m}$ & $10 \mathrm{~m}$ \\
\hline $\begin{array}{l}\text { Minimum distance from PHES } \\
\text { inhabited sites }\end{array}$ & & - & $200 \mathrm{~m}$ \\
\hline $\begin{array}{l}\text { Minimum distance from PHES site to the } \\
\text { existing nearest road }\end{array}$ & $200 \mathrm{~m}$ & - & $20 \mathrm{~km}$ & $100 \mathrm{~m}$ \\
\hline $\begin{array}{l}\text { Maximum distance from motor/ turbine to } \\
\text { nearest electricity transmission line }\end{array}$ & - & & & $10 \mathrm{~km}$ \\
\hline
\end{tabular}

Study 1: (Fitzgerald et al. 2012)

Study 2: (Connolly et al. 2010) - (First analysis)

Study 3: (Gutiérrez and Arántegui 2013)

Study 4: (Arántegui et al. 2012)

The study by Fitzgerald et al. (2012) suggested that approximately $28.57 \%$ of the total area is required for construction of the boundary walls and other structures at PHES site. Therefore, the total required minimum surface area for the PHES site is $70,000 \mathrm{~m}^{2}$.

\section{Calculation for Net Area of PHES Reservoir Site}

- Assumed minimum PHES reservoir volume $=500,000 \mathrm{~m}^{3}$

- Assumed draw-down depth $=10 \mathrm{~m}$

- PHES reservoir net area $=500,000 \mathrm{~m}^{3} / 10 \mathrm{~m}=50,000 \mathrm{~m}^{2}$

- Assumed minimum area for necessary structures including reservoir wall $=20,000 \mathrm{~m}^{2}$

- Therefore, minimum gross area of PHES reservoir site $(\mathrm{As})=50,000 \mathrm{~m}^{2}+20,000 \mathrm{~m}^{2}=$ $70,000 \mathrm{~m}^{2}$

\section{Minimum Elevation Difference (ED) between Primary and PHES Reservoirs (H)}

For the selection of PHES sites, the head parameter is used to define the minimum elevation difference between the primary reservoir and PHES site. The surface areas which are greater than the minimum required model parameter area are selected to find the average elevations. The difference of average elevations in between primary reservoir and qualified surface areas of PHES site are used to calculate the respective differential head between primary reservoirs and PHES site. 
The available energy potential (E) for a reservoir can be computed using Equation (3.1) of the methodology chapter as given below:

$$
\mathrm{E}=\mathrm{V} \rho \mathrm{gH} \eta
$$

Where,

$$
\begin{aligned}
& \mathrm{V}=\text { Volume of water stored in the upper reservoir }\left(500,000 \mathrm{~m}^{3}\right) \\
& \rho=\text { Density of water at } 4^{\circ} \mathrm{C}\left(1000 \mathrm{~kg} / \mathrm{m}^{3}\right) \\
& \mathrm{g}=\text { Acceleration due to gravity }\left(9.81 \mathrm{~m} / \mathrm{s}^{2}\right) \\
& \mathrm{H}=\text { Elevation difference between upper and lower reservoirs } \\
& \eta=\text { Generation efficiency }(80 \%)
\end{aligned}
$$

Therefore, considering the minimum rated power potential of $7 \mathrm{MW}$ with the minimum operating hours as 5 hours, the value of ' $\mathrm{H}$ ' is $32.11 \mathrm{~m}$.

The Lewiston Pump Generating Plant near Niagara Falls has 106 feet $(32.30 \mathrm{~m})$ differential head with a drawdown depth of 35 feet $(10.67 \mathrm{~m})$ and 60,000 acre-feet $\left(74 \mathrm{Mm}^{3}\right)$ reservoir volume (Thorgerson and Basilesco 1961). The study of Arantegui (2012) recommended the minimum head range from $15 \mathrm{~m}$ to $50 \mathrm{~m}$ depending on the selected study area regions for the PHES schemes. Therefore, considering the above data from past studies, the minimum ED between the primary reservoir and PHES site was considered as $33 \mathrm{~m}$.

\section{Maximum Slope of Surface Region (Degree)}

There are no set rules of assuming the surface slope. It is decided on a case to case basis depending upon the existing topology of the area. The main concern is that the large slope results in a large volume of excavation. The literature review reveals that different studies have adopted from 0 to 5 degrees as the maximum slope for PHES reservoir areas depending upon the topology of their case study (Fitzgerald et al. 2012; Gutiérrez and Arántegui 2013). Therefore, considering Ontario's topology, this research assumed 3 degrees as an average surface slope of PHES reservoir.

\section{Minimum Distance From Primary and PHES Reservoirs to Nearest $\operatorname{Road}\left(D_{R}\right)$}

This parameter is directly concerned with the construction cost of the access road. Small value estimates less cost whereas high value estimates high cost. Considering the data from past 
studies presented in Table B-1, the minimum distance from the primary reservoir and PHES site to existing nearest road was considered as $200 \mathrm{~m}$.

\section{Maximum Distance from Pump-Turbine Station to Nearest Transmission Line $\left(\mathrm{D}_{\mathrm{T}}\right)$}

This data has the same concern as explained in the case of the access road. The data available in past studies suggests that the maximum distance from the pump-turbine unit to the nearest transmission line can be assumed as $10 \mathrm{~km}$.

\section{Minimum Distance from Primary and PHES Reservoirs to Nearest Environmental Constraint Layers $\left(D_{E}\right)$}

The environmental constraints are concerned with public safety and to protect the government properties such as parks, residential areas, national heritage lands, etc. The data provided in past studies and suggests that the minimum distance from primary reservoirs and PHES site to the nearest environmental constraint can be considered as $500 \mathrm{~m}$.

\section{Minimum Volume of Primary Reservoir $\left(V_{P}\right)$}

This is important to carefully examine and finalize the minimum required volume for a new PHES site. The main purpose of developing a PHES plant is to store water up to a certain maximum storage capacity of its reservoir that will be used throughout the plant life. The water availability of primary reservoir must be greater than the required maximum volume of PHES reservoir. The water taking from natural water bodies is governed by the regulations set by the regional authorities and the relevant Ministries like Ministry of Natural Resources or the Ministry of Environment of the concerned province in the country. In some cases, the federal government policies are also applied such as at the cross-border areas of the two provinces or the water rights related to international boundaries are exercised by the federal governments.

The water allocation depends on the accuracy of the information regarding the source of waterbodies, water users, intended purpose for water takings, and existing institutional arrangements to govern the applicable rules and regulations for particular uses of water. In this regard, the study by Loe (2005) provided the basic information for water takings from the primary reservoir as given in Table B-2. 
With regard to the province of Ontario, Canada, it is blessed with abundant supplies of fresh water. Approximately $17 \%$ of Ontario is covered by water and $20 \%$ of the world's freshwater surface supply is stored in the great lakes. Moreover, only $1 \%$ of the Great Lakes water is actually renewable, the remainder being a gift from the last age of ice. However, despite appearances of water abundance, Ontario is a drought-susceptible province (Dolan et al. 2000). The problem of water availability and allocation is persisting and would likely to be intensified due to increasing pressure of urban expansion and various other uses, as well as from the seasonal variability and projected climatic changes. The resource managers have challenges to deal with the water allocations and the water use problems. The necessary provisions for withdrawal of water from the primary waterbodies can be viewed in the relevant documents of existing Laws and Acts in Ontario.

\section{Table B-2 Basic information for water taking from primary waterbodies}

\begin{tabular}{|c|c|c|}
\hline Parameter & Basic Data & Explanation Considering PHES Needs \\
\hline Source & $\begin{array}{ll}\text { - } & \text { Type of waterbody } \\
\text { - } & \text { Source reliability } \\
\text { - } & \text { Volume of water } \\
\text { - } & \text { Storage role }\end{array}$ & $\begin{array}{l}\text { Dams, lakes, rivers } \\
\text { Available seasonally, intermittently, or available year-round } \\
\text { Volumes of water available at different times of the year } \\
\text { Storage is used for pumping into another reservoir and } \\
\text { discharging of the same water to the parent waterbody. This } \\
\text { process will continue throughout the year to generate electricity. }\end{array}$ \\
\hline Users & $\begin{array}{l}\text { - User identity } \\
\text { - Types of use }\end{array}$ & $\begin{array}{l}\text { Particular association or individual owner of a PHES plant will } \\
\text { apply for the permit of water withdrawal. } \\
\text { Power generation }\end{array}$ \\
\hline User Pattern & $\begin{array}{ll}\text { - } & \text { Volume of water } \\
\text { - } & \text { Recirculation } \\
\text { - } & \text { Water quality } \\
\text { - } & \text { Withdrawal timings } \\
\text { - } & \text { Withdrawal variations } \\
\text { - } & \text { User sites (in case of } \\
\text { different withdrawal } \\
\text { sites) }\end{array}$ & $\begin{array}{l}\text { Volume of water withdrawn and consumed } \\
\text { Importance of recirculation } \\
\text { Quality of return flows } \\
\text { Seasonal or year-round, etc. } \\
\text { Inter-annual variations } \\
\text { Spatial distribution of water use among the users at different sites. }\end{array}$ \\
\hline $\begin{array}{l}\text { Allocation } \\
\text { Mechanism }\end{array}$ & $\begin{array}{l}\text { - Water rights } \\
\text { - Statutory mechanism } \\
\text { - Rules/regulation } \\
\text { - Pricing } \\
\text { - Conflicts }\end{array}$ & $\begin{array}{l}\text { Common law, riparian rights, prior appropriation, the rule of } \\
\text { capture } \\
\text { licenses, permits } \\
\text { Policies, procedures and guidelines } \\
\text { Pricing mechanism } \\
\text { Conflict resolution mechanism }\end{array}$ \\
\hline
\end{tabular}


Additionally, the assessment of water withdrawal from a river channel, lake or dam is also based on the following factors:

\section{(i) Downstream Water Quality of a River Channel}

Anderson (1991) stated two characteristics of water quality: (i) Chemical and physical characteristics; and (ii) biological characteristics. In order to the withdrawal of any water from the river, the effect on downstream water for these characteristics is needed to be examined. For example, the invertebrates' aquatic biological community that lives in the bottom of the river, need to be given more importance to test than any other community. The invertebrates which live in the bottom of the river include Zoobenthos and benthic invertebrates. Hence the water withdrawal application should not affect the invertebrates' aquatic biological community.

\section{(ii) River Flow Across the Provinces}

The Provinces and Territories have to respect the water rights agreement among them. Water quality and flow from one province to the other should be maintained to the agreed level (Shaw and Anderson 1994).

\section{(iii) River Flow Across Inter-Nation Borders}

The countries have to respect water rights agreements between them. The water quality and flows should be maintained to a level upon which the nations have agreed to.

\section{(iv) Downstream Drainage Areas}

The river flows are the function of the drainage area, physical characteristics of the channel, and precipitation in the drainage area. Therefore, these factors are needed to be considered while designing the water withdrawal from the rivers.

\section{(v) Downstream Ground Water Condition and Sea Water Intrusion}

This factor is also important in designing of water withdrawal from the rivers. Studies should be conducted to examine the effect of water withdrawal on downstream groundwater condition as well as the seawater intrusion before and after the water withdrawal from the river section. 


\section{(vi) Water Losses (Evaporation, Seepage and Conveyance Losses)}

Water losses including evaporation, seepage and conveyance losses are important for water withdrawal from the rivers, lakes or dams. The conveyance losses are the amount of water that is lost due to leakage of evaporation between the point of diversion and the point of use.

\section{(vii) Downstream Land Use (Farming, Mining, Oil Industry and Forestry)}

This is important to address the effect on quality and quantity of water being utilized downstream of the river. In case of the withdrawal for PHES reservoirs in pumped hydro, the measure of quantity and the withdrawal timings are very important to study before implementing the withdrawal scheme.

Loucks et al. (2005) reported that $80 \%$ to $90 \%$ of water withdrawn is returned to the river systems. The operation of hydropower project is environmentally friendly but it has bad impacts on changed flow regimes at downstream fish mortality due to entertainment and impingement at intake screens, blockage of fish migration due to continual withdrawal, and flooding of the terrestrial ecosystem by impoundments.

\section{(viii) Downstream Precipitation and Weather Effects (Drought and Floods)}

Minimum in-stream flows are to be maintained to sustain the downstream quality and quantity in both draught and floods periods.

\section{(ix) River Flow Hydrograph (Fluctuation in River Channel Flows)}

River hydrograph using flow measuring gauge with stage flow curve should be established at the withdrawal section of the river. There should be fluctuation in water withdrawal based on mean daily flows recorded at that section of the river.

Therefore, based on the above discussion, an average of $100 \%$ additional allowance has been considered for PHES reservoir being living within the permissible limits of acquiring the water taking permit from the provincial authorities as well as to maintain the assured water availability in the primary reservoir on regular basis throughout the plant life.

Therefore, minimum $1,000,000 \mathrm{~m}^{3}$ volume of water was considered for the primary reservoirs. However, at the time of initializing the actual project at a particular site, the 
actual water taking regulations are to be considered for finalizing the availability of water in the primary reservoir.

\section{Maximum Distance between Primary and PHES Reservoirs (Buffer Zone Distance)}

The buffer zone distance has a direct effect on penstock length which is based on the elevation head ' $\mathrm{H}$ ' and the horizontal distance ' $\mathrm{L}$ ' between upper and lower reservoirs. It is clear that the most effective layout is the comparison of $\mathrm{L} / \mathrm{H}$ with possible short distance ' $\mathrm{L}$ ' and big value of elevation head ' $H$ '. Rehman et al. (Rehman et al. 2015) provided the preferred $\mathrm{L} / \mathrm{H}$ ratio value as less than 10 . However, it is very difficult to get this ratio at the sites having low head locations. The length and diameter of the penstock have a direct effect on the overall efficiency of the plant and output of the pump/motor and the turbine/generator units.

The literature review provided different penstock lengths at different PHES projects which mainly depend on the topology of the concerned PHES site areas. In Canada, the longest penstock is $5.8 \mathrm{~km}$ at new hydroelectric development project at Blue River, British Colombia (Canadian Projects Limited 2016). Fitzgerald et al. (2012) assumed $5 \mathrm{~km}$ as the maximum distance between existing primary reservoir and potential PHES reservoir site. Therefore, this research has considered a maximum $5 \mathrm{~km}$ buffer distance for economic costs of both penstock and the pump-turbine units.

\section{Minimum Water Flow in River as Primary Reservoir $\left(Q_{R}\right)$}

The minimum water flow in a river has been calculated using the following data:

- Assumed minimum volume of PHES reservoir $\quad=500,000 \mathrm{~m}^{3}$

- Assumed average operating hours to fill PHES reservoir $=10$ hours

- Therefore, the discharge rate to fill the PHES reservoir $=14 \mathrm{~m}^{3} / \mathrm{sec}$

Considering the regional permit rules and other necessary regulations applicable to protect the downstream flow or to maintain the minimum required flow during water takings, the minimum required water flow in a river has been considered as $28 \mathrm{~m}^{3} / \mathrm{s}$. This flow covers the average consumptive uses at downstream area and conveyance losses during water takings.

On the basis of rationales explained above, the assumed criteria for model parameters have been summarized in Table B-3. 


\section{Table B-3 Assumed criteria for model parameters}

\begin{tabular}{|c|l|c|}
\hline No. & Model Parameters & $\begin{array}{c}\text { Assumed } \\
\text { Criteria }\end{array}$ \\
\hline 1 & Max. efficiency of PHES system $(\eta)$ & $80 \%$ \\
\hline 2 & Min. volume of PHES reservoir $\left(\mathrm{V}_{\mathrm{S}}\right)$ & $0.5 \mathrm{Mm}^{3}$ \\
\hline 3 & Min. elevation difference between primary and PHES reservoirs $(\mathrm{H})$ & $33 \mathrm{~m}$ \\
\hline 4 & Max. slope of surface region (degree) & $3 \mathrm{degree}$ \\
\hline 5 & Min. distance from primary and PHES reservoirs to nearest road $\left(\mathrm{D}_{\mathrm{R}}\right)$ & $200 \mathrm{~m}$ \\
\hline 6 & Max. distance from pump-turbine unit to nearest electricity transmission line $\left(\mathrm{D}_{\mathrm{T}}\right)$ & $10 \mathrm{~km}$ \\
\hline 7 & $\begin{array}{l}\text { Min. distance from primary and PHES reservoirs to nearest environmental } \\
\text { constraint layers }\left(\mathrm{D}_{\mathrm{E}}\right)\end{array}$ & $500 \mathrm{~m}$ \\
\hline 8 & Min. volume of primary reservoir $\left(\mathrm{V}_{\mathrm{P}}\right)$ & $1 \mathrm{Mm}^{3}$ \\
\hline 9 & Max. distance between primary and PHES reservoirs (buffer zone distance) & $5 \mathrm{~km}^{3}$ \\
\hline 10 & Min. water flow in the river as primary reservoir $\left(\mathrm{Q}_{\mathrm{R}}\right)$ & $28 \mathrm{~m}^{3} / \mathrm{s}$ \\
\hline
\end{tabular}




\section{Appendix C - Estimated River Flows using HYDAT and OFAT III Tool}

The river flows have been estimated using HYDAT database and OFAT III tool developed by the Ministry of Natural Resources Ontario. In order to get the HYDAT flow data on a particular river, HYDAT database is used which is maintained for a particular fixed HYDAT station located nearest to that particular river. Each station has its unique ID number such as the HYDAT station ID for the Nipigon River is 02AD012.

In Ontario, the OFAT III tool can provide a required flow data at any point in the river that is called a pour point. In the case study of this research, the feasible PHES sites have been selected on a river which is connected to its particular cross-sections. The mean annual flow and 7Q20 flow have been estimated by defining a pour point at the selected cross-sections of the river.

Table C-1 provides the estimated flows using HYDAT database and OFAT III tool at the selected rivers for their respective feasible PHES sites.

Table C-1 Estimated river flows using HYDAT database and OFATIII tool

\begin{tabular}{|c|c|c|c|c|c|c|c|}
\hline \multirow[t]{3}{*}{ No. } & \multirow[t]{3}{*}{$\begin{array}{c}\text { Official Name of } \\
\text { River }\end{array}$} & \multirow[t]{2}{*}{$\begin{array}{c}\text { HYDAT } \\
\text { Station ID }\end{array}$} & \multicolumn{2}{|c|}{$\begin{array}{c}\text { HYDAT Recorded } \\
\text { Data }\end{array}$} & \multicolumn{2}{|c|}{$\begin{array}{c}\text { OFATIII } \\
\text { Computation }\end{array}$} & \multirow{2}{*}{$\begin{array}{c}\text { Minimum } \\
\text { Flow } \\
\text { Condition } \\
\text { (Mean } \\
\text { Annual Flow } \\
-0.95 * 7 Q 20) \\
>=28 \\
\end{array}$} \\
\hline & & & $\begin{array}{c}\text { Mean Flow } \\
\text { years }\end{array}$ & $\begin{array}{c}\text { Mean } \\
\text { Annual } \\
\text { Flow }\end{array}$ & $\begin{array}{l}\text { Mean } \\
\text { Annual } \\
\text { Flow }\end{array}$ & $\begin{array}{l}\text { 7Q20 } \\
\text { Flow }\end{array}$ & \\
\hline & & (No.) & (years) & $\left(\mathrm{m}^{3} / \mathbf{s}\right)$ & $\left(\mathrm{m}^{3} / \mathrm{s}\right)$ & $\left(\mathrm{m}^{3} / \mathrm{s}\right)$ & $\left(\mathbf{m}^{3} / \mathbf{s}\right)$ \\
\hline 1 & Nipigon River & 02AD012 & $2008-2014$ & 394.00 & 409.42 & 61.41 & 351.08 \\
\hline 2 & Paddy Creek & $02 \mathrm{DB} 005$ & $1953-2014$ & 36.36 & 45.75 & 4.12 & 41.84 \\
\hline 3 & Kaministiquia River I & $02 \mathrm{~EB} 006$ & $1938-2014$ & 78.22 & 62.34 & 6.86 & 55.82 \\
\hline 4 & Kaministiquia River II & $02 \mathrm{AB} 025$ & $2008-2010$ & 58.58 & 74.68 & 8.96 & 66.17 \\
\hline 5 & White River & 02BC004 & $1960-2014$ & 50.01 & 66.75 & 6.18 & 60.88 \\
\hline 6 & Michipicoten River & 02BD002 & $1924-2014$ & 69.15 & 88.34 & 10.73 & 78.15 \\
\hline 7 & Montreal River & 02BE002 & $1936-2014$ & 40.45 & 48.61 & 4.37 & 44.46 \\
\hline 8 & Seine River & 05РB009 & $1964-2014$ & 45.73 & 50.42 & 4.73 & 45.93 \\
\hline
\end{tabular}




\section{References}

Agrawal, P., Nourai, A., Markel, L., Fioravanti, R., Gordon, P., Tong, N., and Huff, G. (2011). "Characterization and assessment of novel bulk storage technologies: a study for the DOE Energy Storage Systems program.” (May), 92.

Aihara, R., Yokoyama, A., Nomiyama, F., and Kosugi, N. (2012). “Optimal Operation Scheduling of Pumped Storage Hydro Power Plant and Thermal Power Plants in Power System with a Large Penetration of Photovoltaic Generations." Journal of International Council on Electrical Engineering, 2(3), 283-289.

American Water Works Association. (2014). Manual of Water Supply Practices M45: Fiberglass Pipe Design. (American Water Works Association, ed.).

Anderson, A. M. (1991). An overview of long-term zoobenthic monitoring in Alberta rivers (1983-1987). Edmonton.

Arántegui, R. L., Tzimas, E., and Bocin-Dumitriu, Andrei Zubaryeva, A. (2012). SETIS expert workshop on the assessment of the potential of pumped hydropower storage.

Azabi, T. M., Ansary, A. M. El, and Damatty, A. A. El. (2016). "COST ANALYSIS OF CONICAL TANKS ; COMPARISON BETWEEN REINFORCED CONCRETE AND STEEL." (1987), 1-10.

Bakos, G. C. (2002). "Feasibility study of a hybrid wind/hydro power-system for low-cost electricity production.” Applied Energy, 72(3-4), 599-608.

Bank of Canada. (2018). "Annual Average Rates."

<https://www.bankofcanada.ca/valet/observations/group/LEGACY_ANNUAL_RATES/csv $>$ (Jan. 5, 2018).

Bose, S., Gayme, D. F., Topcu, U., and Chandy, K. M. (2012). “Optimal placement of energy storage in the grid." Proceedings of the IEEE Conference on Decision and Control, 56055612 .

Bradbury, K., Pratson, L., and Patiño-Echeverri, D. (2014). "Economic viability of energy storage systems based on price arbitrage potential in real-time U.S. electricity markets." Applied Energy, Elsevier, 114, 512-519.

Brook, B. (2010). "Pumped-hydro energy storage - cost estimates for a feasible system." Brave New Climate, <http://bravenewclimate.com/2010/04/05/pumped-hydro-system-cost/>.

Canadian Manufacturing. (2015). "Toronto firm launches project that uses giant underwater 'balloons' to store energy." Toronto.

Canadian Projects Limited. (2016). "Bone Hydro Project." 
<http://www.canprojects.com/projects/hydro/bone/> (Mar. 15, 2016).

Canary Systems. (2017). "Rocky Mountain Pumped Storage Hydroelectric Plant."

<http://canarysystems.com/portfolio-item/rocky-mountain-pumped-storage-hydroelectricplant/> (Feb. 20, 2017).

Charlwood, R. G., Little, T. E., and Lou, J. K. (2000). A review of the performance of two large sub-stations and eight large dams during the Chi Chi Taiwan earthquake. 6, Toronto, Ontario, Canada.

Chen, P.-H. (2008). "Pumped-Storage Scheduling Using Evolutionary Particle Swarm Optimization." IEEE Transactions on Energy Conversion, 23(1), 294-301.

Chen, P. H. (2009). "Particle Swarm Optimization for Power Dispatch with Pumped Hydro.” A. Lazinica, ed., InTech.

Chongqing Gongmin Power Supply Equipment Co. Ltd. (2012). "The national key project of Qingyuan pumped storage power station started at the end of storage." <http://www.cqgmgd.com/en/ReadNews.asp?rid=822> (Feb. 17, 2017).

Chubu Electric Power Company. (2017). "Oku Yahagi Dai 1 / 2 Power Plant." <http://www.chuden.co.jp/energy/ene_energy/water/wat_chuden/okuyahagi/index.html> (Feb. 17, 2017).

City of London Ontario. (2017). Design Specifications \& Requirements Manual. London, ON, Canada.

Colenco Power Engineering AG. (2017). "Siah Bishe Pumped Storage Project." <http://www.muetzenberg.ch/iran/default.htm>.

Columbia Grid. (2013). "Historic PS Operation in WSCC.” 14.

Conejo, A. J., Caramanis, M. C., and Bloom, J. A. (1990). "Efficient algorithm for optimal reservoir utilization in probabilistic production costing." IEEE Transactions on Power Systems, 5(2), 439-447.

Connolly, D., Lund, H., Finn, P., Mathiesen, B. V., and Leahy, M. (2011). "Practical operation strategies for pumped hydroelectric energy storage (PHES) utilising electricity price arbitrage." Energy Policy, Elsevier, 39(7), 4189-4196.

Connolly, D., Lund, H., Mathiesen, B. V., Pican, E., and Leahy, M. (2012). “The technical and economic implications of integrating fluctuating renewable energy using energy storage." Renewable Energy, Elsevier Ltd, 43, 47-60.

Connolly, D., MacLaughlin, S., and Leahy, M. (2010). "Development of a computer program to locate potential sites for pumped hydroelectric energy storage." Energy, Elsevier Ltd, 35(1), 
$375-381$.

Consumers Energy. (2017). "Ludington Pumped Storage." <http://www.consumersenergy.com/content.aspx ?id=6985>.

Cortines, C., Hydropower, G., Supervisor, D., and Killingtveit, Å. (2013). "Testing a GIS-based methodology for optimal location of Pumped Storage power plants in Norway." (June).

Crosetto, M., and Tarantola, S. (2001). "Uncertainty and sensitivity analysis: tools for GIS-based model implementation." International Journal of Geographical Information Science, Taylor \& Francis, 15(5), 415-437.

Deane, J. P., Ó Gallachóir, B. P., and McKeogh, E. J. (2010). "Techno-economic review of existing and new pumped hydro energy storage plant." Renewable and Sustainable Energy Reviews, 14(4), 1293-1302.

Díaz-González, F., Sumper, A., Gomis-Bellmunt, O., and Villafáfila-Robles, R. (2012). “A review of energy storage technologies for wind power applications." Renewable and Sustainable Energy Reviews, Elsevier Ltd, 16(4), 2154-2171.

DMTI Spatial Inc. (2014). "Populated Placenames." <http://geo.scholarsportal.info.ezproxy.lib.ryerson.ca/\#r/details/_uri@=1690133422>.

DMTI Spatial Inc. (2015). “Transmission Lines.” <http://geo.scholarsportal.info.ezproxy.lib.ryerson.ca/\#r/details/_uri@=2731396105>.

Dolan, A. H., Kreutzwiser, R., and De Loë, R. (2000). "Rural water use and conservation in southwestern Ontario." Journal of Soil and Water Conservation, 55(2), 161-171.

Dominion. (2017). "Bath County Pumped Storage Station." $<$ https://www.dom.com/aboutus/making-energy/renewables/water/bath-county-pumped-storage-station>.

Droege, P. (2008). “Urban energy transition: from fossil fuels to renewable power ." Elsevier .

Drolc, A., and Končan, J. Z. (1996). "Water quality modelling of the river Sava, Slovenia." Water Research, 30(11), 2587-2592.

Dunn, B., Kamath, H., and Tarascon, J.-M. (2011). "Electrical Energy Storage for the Grid: A Battery of Choices.” Science, 334(6058), 928-935.

Einarsson, C., Norwood, D., Davidson, E., Lindberg, G., Cocchiola, J., Wallsten, M., Inge, M., Viberg, T., and Linder, U. (2012). Blasthole Drilling in Open Pit Mining. Garland, Texas, USA.

Enel Spa. (2014). “A Presenzano produces efficiency.” <https://www.enel.it/it/media/news/d201412-a-presenzano-si-produce-efficienza.html> (Feb. 17, 2017). 
Environmental Commissioner of Ontario. (2017). Developing the 2017 Long-Term Energy Plan. EPRI-DOE. (2003). Handbook of Energy Storage for Transmission \& Distribution Applications. Power.

ESA. (2009). "Energy Storage Technologies."

ESRI. (2014). “ArcGIS 10.2.” <http://resources.arcgis.com/en/help/main/10.2/index.html> (Jul. 20, 2017).

Eyer, J., and Corey, G. (2010). "Energy Storage for the Electricity Grid : Benefits and Market Potential Assessment Guide." Contract, 321(February), 232.

Farhan, B., and Murray, A. T. (2008). "Siting park-and-ride facilities using a multi-objective spatial optimization model." Computers \& Operations Research, 35, 445-456.

Fen, Q., Zhang, K., and Smith, B. (2012). Small Hydropower Cost Reference Model.

Fitzgerald, N., Lacal Arántegui, R., McKeogh, E., and Leahy, P. (2012). “A GIS-based model to calculate the potential for transforming conventional hydropower schemes and non-hydro reservoirs to pumped hydropower schemes." Energy, Elsevier Ltd, 41(1), 483-490.

Foley, A. M., Leahy, P. G., Li, K., McKeogh, E. J., and Morrison, A. P. (2015). "A long-term analysis of pumped hydro storage to firm wind power." Applied Energy, 137, 638-648.

Franke, U. (2016). “Entracque Power Plant.”

Galloway, C. D. (1966). “Storage.” (5), 459-465.

Galvan-Lopez, O. (2014). "The Cost of Pumped Hydroelectric Storage." <http://large.stanford.edu/courses/2014/ph240/galvan-lopez2/> (May 1, 2016).

Gayme, D., and Topcu, U. (2013). "Optimal power flow with large-scale storage integration." IEEE Transactions on Power Systems, 28(2), 709-717.

Gimeno-Gutiérrez, M., and Lacal-Arántegui, R. (2015). "Assessment of the European potential for pumped hydropower energy storage based on two existing reservoirs." Renewable Energy, 75, 856-868.

Gravity Power. (2014). "GPM Construction Plan. Shaft Construction Technology." $<$ http://www.gravitypower.net/technology-gravity-power-energy-storage/gpm-constructionplan/> (Apr. 5, 2014).

Grieco, C., and Brierley, G. (2012). Deep shaft sinking for grid-scale energy storage.

Gutiérrez, M. G., and Arántegui, R. L. (2013). Assessment of the European potential for pumped hydropower energy storage : A GIS-based assessment of pumped hydropower storage potential. 
Guzman, H. A. R. (2010). "Value of Pumped-Storage Hydro for Wind Power Integration in the British Columbia Hydroelectric System.” (June).

Hatch. (2010). "Pumped Storage at Mica Generating Station: Preliminary Cost Estimate." (December).

He, W. (1997). “TECHNICAL NOTE A simulation model for evaluating Tianhuangping pumped storage hydro-plant." Renewable Energy, 11(2), 263-266.

Heuvelink, G. B. M. (1998). "Uncertainty analysis in environmental modelling under a change of spatial scale." Nutrient Cycling in Agroecosystems, 50(1), 255-264.

Hino, T., and Lejeune, A. (2012). “6.15 - Pumped Storage Hydropower Developments.” Comprehensive Renewable Energy, 405-434.

Hoek, E. (2007). Design of large underground caverns - a case history based on the Mingtan Pumped Storage Project in Taiwan. Practical Rock Engineering, Toronto, Ontario, Canada.

Hoffman, M., Kintner-Meyer, M., Sadovsky, A., and DeSteese, J. (2010). “Analysis Tools for Sizing and Placement of Energy Storage in Grid Applications: A Literature Review." Review, (September), 1-56.

Huadong Engineering Corporation Ltd. (2007). Environmental Impact of Hongping Pumped Storage Power Station in Jiangxi Province. Hangzhou, China.

IEA. (1991). Guidelines for the economic analysis of renewable energy technology applications.

IEC. (2011). Electrical Energy Storage White Paper. Electrical Energy Storage White Paper.

IESO. (2016a). “Ontario Planning Outlook. A technical report on the electricity system prepared by the IESO." 74.

IESO. (2016b). "18-Month output. An Assessment of the Reliability and Operability of the Ontario Electricity System."

IESO. (2017a). Generator Output by Fuel Type Monthly Report.

IESO. (2017b). “Ontario Reserve Margin Requirements 2018-2022.” <http://www.ieso.ca//media/files/ieso/document-library/planning-forecasts/18-month-outlook/ontario-reservemargin-requirements-2018-2020.pdf>.

Iliadis, N. A., and Gnansounou, E. (2016). "Development of the methodology for the evaluation of a hydro-pumped storage power plant: Swiss case study." Energy Strategy Reviews, 9, 817.

Industcards. (2011). "Pumped-Storage Hydroelectric Plants in China." <http://www.industcards.com/ps-china.htm> (Feb. 20, 2017). 
International Energy Agency. (2010). “Annual Energy Outlook 2010: With Projections to 2035.” US Energy Information Administration, 1-231.

International Water Power \& Dam Construction. (2011). "Spotlight on pumped storage." $<$ http://www.waterpowermagazine.com/features/featurespotlight-on-pumped-storage/> (Feb. 20, 2017).

Istituto Comprensivo di Scuola Materna, E. e M. "Don M. di B. (2017). "The hydroelectric Power Plant Roncovalgrande Maccagno (Varese)." 〈http://www.icbisuschio.it/med_bisuschio/Maccagno/Home_centrale.htm〉.

Jiménez Capilla, J. A., Carrión, J. A., and Alameda-Hernandez, E. (2016). “Optimal site selection for upper reservoirs in pump-back systems, using geographical information systems and multicriteria analysis." Renewable Energy, Pergamon, 86, 429-440.

Joseph, a, and Shahidehpour, M. (2006). "Battery storage systems in electric power systems." Power Engineering Society General Meeting, 1-8.

JRJ.com. (2008). "Brief Introduction of Taishan Pumped Storage Power Station." <http://jyll.ifund.jrj.com.cn/forumjyll/topic43765.html> (Feb. 20, 2017).

Kapila, S., Oni, A. O., and Kumar, A. (2017). "The development of techno-economic models for large-scale energy storage systems.” Energy, 140, 656-672.

Ko, C.-D., Wicks, F. E., Becker, M., and Rutz, W. L. (1982). "Development and Application of Linear Programming Planning Methods for Pumped Storage Hydro." (8).

Kobler, U. G. (2018). "Effects of Lake - Reservoir Pumped-Storage Operations on Temperature and Water Quality." Sustainability, 10(6), 1-15.

Konrad, J., Carriveau, R., Davison, M., and Ting, D. S. (2012). "Geological compressed air energy storage as an enabling technology for renewable energy in Ontario , Canada." International Journal of Environmental, (September), 37-41.

Krajacic, G., Loncar, D., Duic, N., Zeljko, M., Lacal Arantegui, R., Loisel, R., and Raguzin, I. (2013). "Analysis of financial mechanisms in support to new pumped hydropower storage projects in Croatia." Applied Energy, 101, 161-171.

Kyushu Electric Power Co. Ltd. (2017). "Outline of the Omaru River Power Station." <http://www.kyuden.co.jp/effort_water_omarugawa_index> (Feb. 16, 2017).

Land Information Ontario. (2015). "Ontario Hydrology Network (OHN) User guide." <https://www.sse.gov.on.ca/sites/MNR-PublicDocs/EN/CMID/OHN - User Guide.pdf>.

Larentis, D. G., Collischonn, W., Olivera, F., and Tucci, C. E. M. (2010). "Gis-based procedures for hydropower potential spotting." Energy, Elsevier Ltd, 35(10), 4237-4243. 
Levine, J. G. (2007). "Pumped Hydroelectric Energy Storage and Spatial Diversity of Wind Resources as Methods of Improving Utilization of Renewable Energy Sources." University of Colorado.

Loe, R. C. de. (2005). "Agricultural water Use: A Methodolgy and Estimates for Ontario." Canadian Water Resources, 30(2), 111-128.

Loucks, D. P., van Beek, E., Stedinger, J. R., Dijkman, J. P. M., and Villars, M. T. (2005). Water Resources Systems Planning and Management and Applications: An Introduction to Methods, Models and Applications. Water.

Ma, T., Yang, H., and Lu, L. (2014). "Feasibility study and economic analysis of pumped hydro storage and battery storage for a renewable energy powered island." Energy Conversion and Management, 79, 387-397.

Makansi, J., and Abboud, J. (2002). Energy Storage. The Missing Link in the Electricity Value Chain. An ESC White Paper.

McLean, E., and Kearney, D. (2014). "An Evaluation of Seawater Pumped Hydro Storage for Regulating the Export of Renewable Energy to the National Grid." Energy Procedia, 46, 152-160.

Ming, Z., Kun, Z., and Liang, W. (2014). "Study on unit commitment problem considering wind power and pumped hydro energy storage." International Journal of Electrical Power \& Energy Systems, 63, 91-96.

Ministry of Energy. (2017). 2017 Long-Term Energy Plan: Delivering fairness and choice.

Ministry of Finance Information Centre. (2016). "Ontario Population Projections Update, 20162041." <https://www.fin.gov.on.ca/en/economy/demographics/projections/>.

Ministry of Northern Development and Mines. (2010). "Bedrock Geology." <http://www.geologyontario.mndmf.gov.on.ca/mndmaccess/mndm_dir.asp?type=pub\&id= MRD126-REV1>.

Mitteregger, A., and Penninger, G. (2008). "Austrian pumped storage power stations supply peak demands.” World Pumps, 2008(500), 16-21.

Murage, M. W., and Anderson, C. L. (2014). "Contribution of pumped hydro storage to integration of wind power in Kenya: An optimal control approach." Renewable Energy, Elsevier Ltd, 63(2014), 698-707.

Namgyel, D. (2004). "Wind Following with Pumped Hydroelectric Energy Storage in New Brunswick." THE UNIVERSITY OF NEW BRUNSWICK.

National Agency for Electricity ENEL. (1980). “GENERATION SYSTEM AND PUMPING 
LAKE AVIO - EDOLO." Pancreas, <http://francorino.altervista.org/1cedolo.htm> (Feb. 17, 2017).

Nazari, M. E., Ardehali, M. M., and Jafari, S. (2010). "Pumped-storage unit commitment with considerations for energy demand, economics, and environmental constraints." Energy, Elsevier Ltd, 35(10), 4092-4101.

NHA. (2012). "Challenges and Opportunities For New Pumped Storage Development."

Northland Power. (2016). "Marmora Pumped Storage Hydro." <http://www.northlandpower.ca/cmsAssets/docs/pdfs/Northlandpower_PDFs/Mamora_Pu mped_Storage/Marmora_Pumped_Storage_spread.pdf> (Dec. 2, 2016).

Ontario's Ministry of Northern Development and Mines. (2014). "Abandoned Mines." $<$ http://www.mndm.gov.on.ca/en/mines-and-minerals/applications/ogsearth/abandonedmines $>$.

Ontario Ministry of Energy. (2010). Ontario's Long-Term Energy Plan 2010.

Ontario Ministry of Energy. (2013). Making Choices.

Ontario Ministry of Natural Resources. (1991). "Floodplain Hazard Land Mapping." <http://geo.scholarsportal.info.ezproxy.lib.ryerson.ca/\#r/details/_uri@=3965627646>.

Ontario Ministry of Natural Resources. (2003). "Built-Up Areas." <http://geo.scholarsportal.info.ezproxy.lib.ryerson.ca/\#r/details/_uri@=2071421746>.

Ontario Ministry of Natural Resources. (2005). "National Wildlife Area." <http://geo.scholarsportal.info.ezproxy.lib.ryerson.ca/\#r/details/_uri@=3376792859>.

Ontario Ministry of Natural Resources. (2008a). "Provincial Parks." <http://geo.scholarsportal.info.ezproxy.lib.ryerson.ca/\#r/details/_uri@=180702964>.

Ontario Ministry of Natural Resources. (2008b). "Federal Protected Area." <http://geo.scholarsportal.info.ezproxy.lib.ryerson.ca/\#r/details/_uri@=982758561>.

Ontario Ministry of Natural Resources. (2009). "NGO Nature Reserve." <http://geo.scholarsportal.info.ezproxy.lib.ryerson.ca/\#r/details/_uri@=2219611138>.

Ontario Ministry of Natural Resources. (2012). "Ontario Road Network Segment With Address (ORN)." <http://geo.scholarsportal.info.ezproxy.lib.ryerson.ca/\#r/details/_uri@=3872254028>.

Ontario Ministry of Natural Resources. (2015). "Provincial Digital Elevation Model - Version 3.0." <http://geo.scholarsportal.info.ezproxy.lib.ryerson.ca/\#r/details/_uri@ $=4215761220>$. Ontario Ministry of Natural Resources and Forestry. (2013). "Wetland." 
<https://www.javacoeapp.lrc.gov.on.ca/geonetwork/srv/en/main.home?uuid=66db745f7199-4a7d-9a2e-5ad76a813e66>.

Ontario Ministry of Natural Resources and Forestry. (2015). "Ontario Dam Inventory." <https://www.javacoeapp.lrc.gov.on.ca/geonetwork/srv/en/file.disclaimer?id=13939\&fnam e=ODI.zip\&access=private $>$ (Nov. 27, 2015).

Opathella, C., and Venkatesh, B. (2013). "Managing Uncertainty of Wind Energy With Wind Generators Cooperative." 28(3), 2918-2928.

Otuagoma, S. O. (2016). "Turbine Selection Criteria for Small Hydropower Development - The River Ethiope Experience . S O Otuagoma.” 02(05), 34-40.

Palla, A., Gnecco, I., La Barbera, P., Ivaldi, M., and Caviglia, D. (2016). "An Integrated GIS Approach to Assess the Mini Hydropower Potential." Water Resources Management, 30(9), 2979-2996.

Patocka, F. (2014). "Environmental Impacts of Pumped Storage Hydro Power Plants." Norwegian University of Science and Technology.

Pejovic, S. (2011). "White Paper Hydro Energy Storage.”

Peltier, R. (2013). "Let Gravity Store the Energy." (August).

Pérez-Díaz, J. I., Cavazzini, G., Blázquez, F., Platero, C., Fraile-Ardanuy, J., Sánchez, J. A., and Chazarra, M. (2014). Technological developments for pumped-hydro energy storage, Technical Report, Mechanical Storage Subprogramme, Joint Programme on Energy Storage, European Energy Research Alliance.

PG\&E. (2017). "By the Numbers : Helms Pumped Storage Facility." <http://www.pgecurrents.com/2011/10/17/by-the-numbers-helms-pumped-storagefacility/>.

Pianosi, F., Beven, K., Freer, J., Hall, J. W., Rougier, J., Stephenson, D. B., and Wagener, T. (2016). "Sensitivity analysis of environmental models: A systematic review with practical workflow.” Environmental Modelling \& Software, 79, 214-232.

Poullikkas, A. (2013). "Optimization analysis for pumped energy storage systems in small isolated power systems.” Open Access Journal Journal of Power Technologies, 93(2), 7889.

Rehman, S., Al-Hadhrami, L. M., and Alam, M. M. (2015). "Pumped hydro energy storage system: A technological review." Renewable and Sustainable Energy Reviews, 44, 586598.

ROAM Consulting. (2012). "ROAM report on Pumped Storage modelling for AEMO 100 \% 
Renewables project.” (September), 197.

Rogeau, A., Girard, R., and Kariniotakis, G. (2017). “A generic GIS-based method for small Pumped Hydro Energy Storage (PHES) potential evaluation at large scale." Applied Energy, Elsevier Ltd, 197, 241-253.

Rus, G. de. (2010). "Introduction to cost-benefit analysis: looking for reasonable shortcuts ." Edward Elgar .

Schoenung, S. (2011). "Economic Analysis of Large-Scale Hydrogen Storage for Renewable Utility Applications.” Sandia Report, (August), 1196-1199.

Schoenung, S. M., and Hassenzahl, W. V. (2003). "Long- vs . Short-Term Energy Storage Technologies Analysis A Life-Cycle Cost Study A Study for the DOE Energy Storage Systems Program.” Power Quality, SAND2011-2(August), 84.

Shaw, R. D., and Anderson, A.-M. (1994). "The Effect of Dickson Dam on Water Quality and Zoobenthos of the Red Deer River." Environment Alberta.

Slocum, A. H., Fennell, G. E., Dündar, G., Hodder, B. G., Meredith, J. D. C., and Sager, M. A. (2013). "Ocean renewable energy storage (ORES) system: Analysis of an undersea energy storage concept." Proceedings of the IEEE, 101(4), 906-924.

SNC Lavalin. (2011). Unit cost estimates for transmission lines and facilities in Northern Ontario and the Far North. Toronto, Ontario, Canada.

Soha, T., Munkácsy, B., Harmat, Á., Csontos, C., Horváth, G., Tamás, L., Csüllög, G., Daróczi, H., Sáfián, F., and Szabó, M. (2017). "GIS-based assessment of the opportunities for smallscale pumped hydro energy storage in middle-mountain areas focusing on artificial landscape features." Energy, Pergamon, 141, 1363-1373.

Sousa, J. A. M., Teixeira, F., and Faias, S. (2014). "Impact of a price-maker pumped storage hydro unit on the integration of wind energy in power systems.” Energy, 69, 3-11.

Stantec. (2009). Assessment and Analysis of the State-Of-the-Art Electric Transmission Systems with Specific Focus on High-Voltage Direct Current (HVDC), Underground or Other New or Developing Technologies.

Statistics Canada. (2018). "Consumer Price Index, by province (Ontario)." <http://www.statcan.gc.ca/tables-tableaux/sum-som/101/cst01/econ09g-eng.htm> (Jan. 5, 2018).

Steffen, B., and Weber, C. (2016). "Optimal operation of pumped-hydro storage plants with continuous time-varying power prices." European Journal of Operational Research, 252(1), $308-321$. 
Suiryoku.com. (2011). "Power Development Shimogo Power Station."

<http://www.suiryoku.com/gallery/fukusima/simogou/simogou.html> (Feb. 20, 2017).

Suiryoku.com. (2012). "Power Supply Development Shin Toyon Power Station."

Suiryoku.com. (2013). “TEPCO Tamahara Power Station.”

<http://www.suiryoku.com/gallery/gunma/tanbara/tanbara.html> (Feb. 16, 2017).

Suiryoku.com. (2014). "Chubu Electric Power Yahagi and Yagaku Daiichi Power Station.” <http://www.suiryoku.com/gallery/gifu/yahagi1/yahagi1.html> (Feb. 17, 2017).

Suiryoku.com. (2015). "Tokyo Electric Power Imaichi Power Station.”

<http://www.suiryoku.com/gallery/tochigi/imaichi/imaichi.html> (Feb. 16, 2017).

Tennessee Valley Authority (TVA). (2017). "Raccoon Mountain." $<$ https://www.tva.com/Energy/Our-Power-System/Hydroelectric/Raccoon-Mountain>.

Thapar, O. D. (2002). "Modern hydroelectric engineering practice in India. Electromechanical works." $<$ http://ahec.org.in/publ/Modern_Hydroelectric_practice_OD_thapar.html > (Aug. 10, 2016).

The ECOReport. (2014). “Transmission Grid Loss.” <https://theecoreport.com/transmissiongrid-loss/>.

Thorgerson, T. E., and Basilesco, J. (1961). "Electrical features of the Niagara Power Project." Electrical Engineering, 739-744.

Tokyo Electric Power Company (TEPCO). (2014). Commercial Operation Commencement of Unit 4, Kazunogawa Hydroelectric Power Station.

Torres, O. (2011). "Life cycle assessment of a pumped storage power plant." Norwegian University of Science and Technology - Master thesis, (July).

US Energy Information Administration. (2010). Updated Capital Cost Estimates for Electricity Generation Plants. US Energy Information Administration.

Vojvodic, G., Jarrah, A. I., and Morton, D. P. (2016). "Forward thresholds for operation of pumped-storage stations in the real-time energy market." European Journal of Operational Research, Elsevier B.V., 254(1), 253-268.

Wang, X., Yu, S., and Huang, G. H. (2004). "Land allocation based on integrated GISoptimization modeling at a watershed level." Landscape and Urban Planning, 66(2), 61-74.

Whitman, D. L., and Terry, R. E. (2012). "Fundamentals of engineering economics and decision analysis ."Morgan \& Claypool .

Wong, B., Sumner, A., and Ludewig, P. (2009). "Pumped storage powers up for New York 
summer." International Water Power and Dam Construction, 61(8), 24-26.

Xuenuo, L., and Jing, W. (2012). "Guangdong Qingyuan Pumped Storage Power Station six people were killed." Caixin Global, Qingyuan.

Yang, B., Makarov, Y., Desteese, J., Viswanathan, V., Nyeng, P., McManus, B., and Pease, J. (2008). "On the use of energy storage technologies for regulation services in electric power systems with significant penetration of wind energy BT - 2008 5th International

Conference on the European Electricity Market, EEM, May 28, 2008 - May 30, 2008."

Zakeri, B., and Syri, S. (2015). "Electrical energy storage systems: A comparative life cycle cost analysis." Renewable and Sustainable Energy Reviews, Elsevier, 42, 569-596.

Zeng, M., Zhang, K., and Liu, D. (2013). "Overall review of pumped-hydro energy storage in China: Status quo, operation mechanism and policy barriers." Renewable and Sustainable Energy Reviews, Elsevier, 17, 35-43.

Zhang, S., Andrews-speed, P., and Perera, P. (2015). "Institutional and pricing reforms for pumped storage hydroelectricity in China : supporting the energy transition." Applied Energy, 9.

Zubi, G. R. L. A. (2012). "Presentation on: ' 'Introducing costs in the assessment of potential PHS sites." Joint Research Centre, European Commission, $\langle$ https://setis.ec.europa.eu/system/files/6-Integrating_costs_in_GIS_Lacal-Zubi.pdf〉. 